Portland State University

PDXScholar

Fall 10-27-2014

\title{
Bicyclists' Uptake of Traffic-Related Air Pollution: Effects of the Urban Transportation System
}

Alexander Y. Bigazzi

Portland State University

Follow this and additional works at: https://pdxscholar.library.pdx.edu/open_access_etds

Part of the Environmental Health and Protection Commons, Environmental Studies Commons, and the Sports Studies Commons

Let us know how access to this document benefits you.

\section{Recommended Citation}

Bigazzi, Alexander Y., "Bicyclists' Uptake of Traffic-Related Air Pollution: Effects of the Urban Transportation System" (2014). Dissertations and Theses. Paper 2064.

https://doi.org/10.15760/etd.2063

This Dissertation is brought to you for free and open access. It has been accepted for inclusion in Dissertations and Theses by an authorized administrator of PDXScholar. Please contact us if we can make this document more accessible: pdxscholar@pdx.edu. 
Bicyclists' Uptake of Traffic-Related Air Pollution:

Effects of the Urban Transportation System

by

Alexander York Bigazzi

A dissertation submitted in partial fulfillment of the requirements for the degree of

Doctor of Philosophy

in

Civil and Environmental Engineering

Dissertation Committee:

Miguel Figliozzi, Chair

Robert Bertini

James Pankow

Jennifer Dill

Portland State University

2014 
(C) 2014 Alexander York Bigazzi 


\begin{abstract}
While bicyclists and other active travelers obtain health benefits from increased physical activity, they also risk uptake of traffic-related air pollution. But pollution uptake by urban bicyclists is not well understood due to a lack of direct measurements and insufficient analysis of the determinants of exposure and ventilation (breathing). This knowledge gap impedes pollution-conscious transportation planning, design, and health impact assessment.

The research presented in this dissertation generates new connections between transportation system characteristics and pollution uptake by bicyclists. The primary research questions are: 1) how do urban bicyclists' intake and uptake of air pollution vary with roadway and travel characteristics and 2) to what extent can transportation-related strategies reduce uptake.

Breath biomarkers are used to measure absorbed doses of volatile organic compounds (VOCs). This research is the first application of breath biomarkers to travelers and the first uptake measurements of any pollutant to include roadway-level covariates. Novel methods to collect and integrate bicycle, rider, traffic, and environmental data are also introduced.

Bicyclist exposure concentrations, exhaled breath concentrations, respiratory physiology, and travel characteristics were collected on a wide range of facilities in Portland, Oregon. High-resolution trajectory and pollution data were then integrated with roadway and traffic data. Models of exposure, ventilation, and uptake of VOCs were estimated from the on-road data. Important new quantifications in the models include the
\end{abstract}


effects of average daily traffic (ADT) on multi-pollutant exposure, the lagged effect of on-road workload on ventilation, and the effects of exposure and ventilation on absorbed VOCs.

Estimated models are applied to situations of interest to travelers and transportation professionals. Sample applications include the inhalation dose effects of road grade, cruising speed choice, stops, and detouring to parallel low-traffic facilities. In addition, dose-minimizing routing behavior is compared with revealed routing preferences in the literature. Finally, findings from this research and the literature are distilled so that they can be incorporated into bicycle network design guidelines. 


\section{Acknowledgments}

The research described in this dissertation was supported by the National Institute for Transportation and Communities (NITC), Portland Metro, and the City of Portland (through a research grant with principal investigator Jim Pankow and co-investigator Miguel Figliozzi). In addition, my doctoral research was supported by fellowships from the U.S. National Science Foundation (Grant No. DGE-1057604) and NITC. The gas sample collection and analysis were masterminded by Jim Pankow and his team of Wentai Luo and the late Lorne Isabelle. I performed gas analysis tasks under their direction, but the VOC measurements were dependent on their knowledge and expertise. It was also Jim's expertise that led to the idea of using breath analysis as a biomarker of exposure - something I had never considered before undertaking this dissertation topic.

Completion of this dissertation was absolutely reliant on the support of many people in both my professional and private lives. Miguel Figliozzi advised me for five years, through both my master's and doctoral degrees. He was supportive and patient with me as I explored new topics such as respiratory physiology, and helped me to always bring my investigations back to the transportation engineering context. Robert Bertini, my previous advisor, launched my career in transportation research. He taught me about the science and profession of transportation engineering, in addition to broader skills about how to be a scholar and professional. Jim Pankow had the unenviable task of mentoring a transportation engineering student with little background in chemistry or exposure science through a research project full of chemistry and exposure science (a task which was, frankly, beneath his stature - and yet he never complained more than the 
occasional eye roll). Jim also tried to teach me how to write concisely, accurately, and intelligibly - though I never seemed to achieve more than two of those three objectives. Jennifer Dill graciously agreed to bring her expertise in bicycle transportation and planning to my committee and provided crucial context for the analysis work. Dr. Dill also provided me with valuable and insightful career advice as I prepared to leave school. In my time at PSU I also had the good fortune to work with Kelly Clifton and Chris Monsere, and I greatly appreciate all I learned from them. I would also like to thank the late Wendelin Mueller, my first research advisor (as an undergraduate in the structural engineering research lab). Dr. Mueller planted the idea of a Ph.D. in my head something which seemed preposterous at the time.

I have also had the support of a vibrant and collaborative peer group of graduate students at PSU. Christine Kendrick and Adam Moore helped me work through many roadblocks in the air quality arena, and the students in the ITS Lab have always been a stimulating lot. I'd like to especially thank the $\mathrm{PhT}$ group, which was a fantastic forum for exchange of ideas, insights, gripes, and pitchers. Kristi Currans also did her part to help organize a seemingly endless string of happy hours with which to rehydrate between chapters. Lastly but not leastly, the real hero of the story is Jade Koide, who always encouraged me to work less and go do something fun - providing a balance without which the whole thing would feel almost pointless. Jade is an inspiration and treasure. She had some help in her work from my wonderful family and my fantastic group of friends in Portland, to whom I owe much. In fact, without the broader bicycling community in Portland, I believe none of this would have happened - so keep on riding! 


\section{TABLE OF CONTENTS}

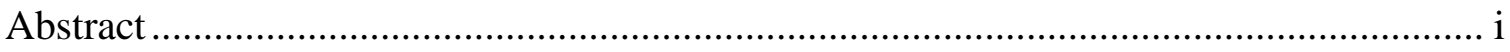

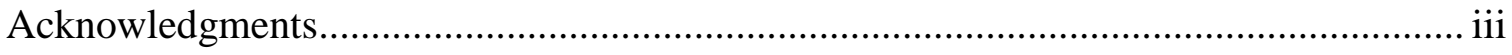

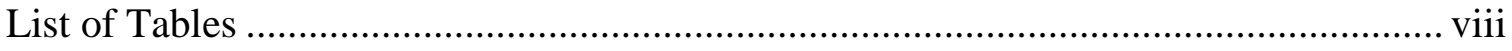

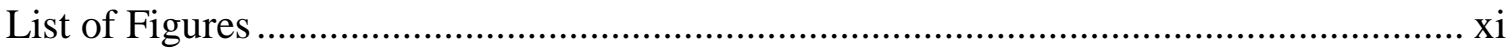

Chapter 1: Introduction ........................................................................................

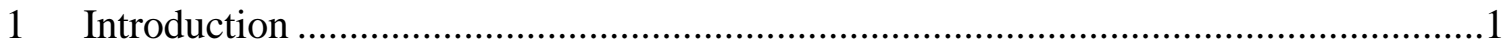

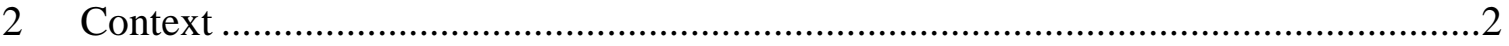

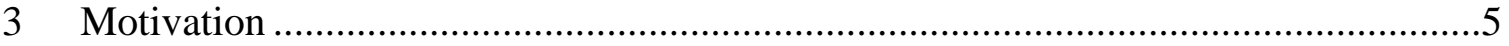

4 Objective \& Research Questions .........................................................................

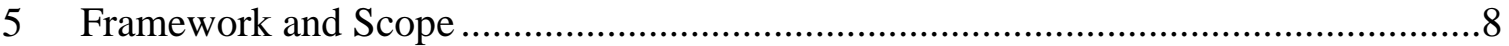

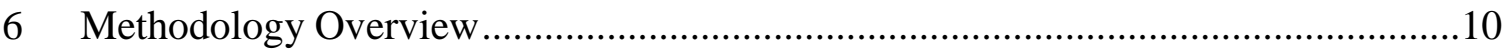

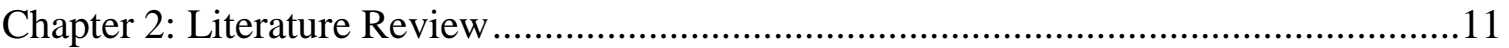

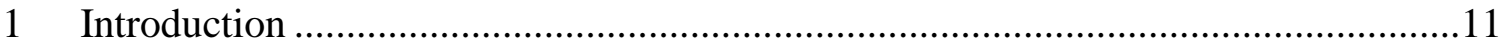

2 Literature Search Methodology …………………............................................12

3 Bicyclists' Air Pollution Exposure Concentrations.......................................................14

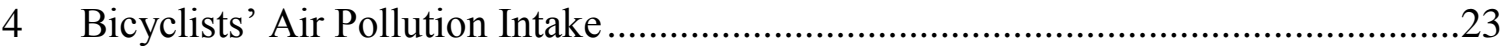

5 Bicyclists' Air Pollution Uptake ………………..................................................

6 Health Effects of Bicyclists' Air Pollution Uptake ......................................................38

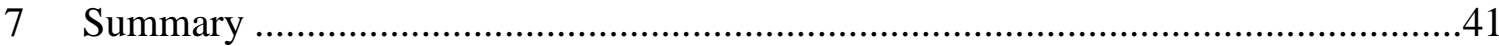

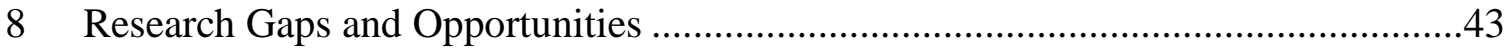

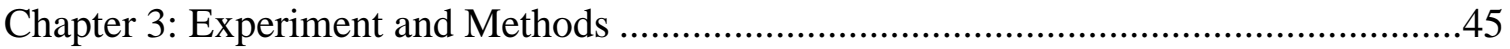

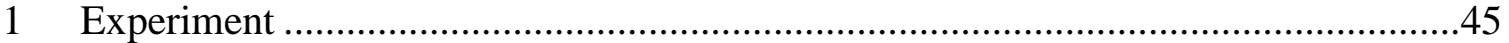

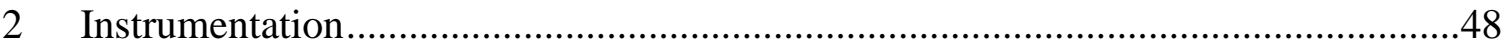

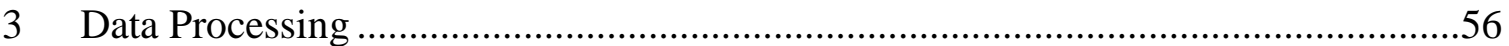

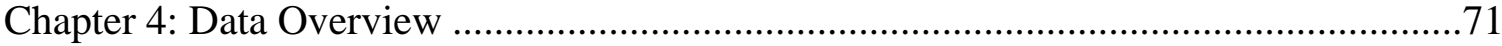

1 Sample size ..............................................................................................

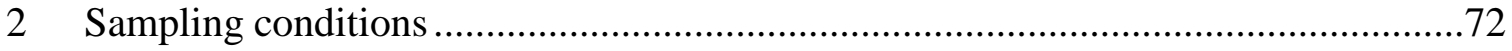

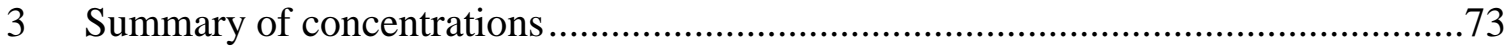

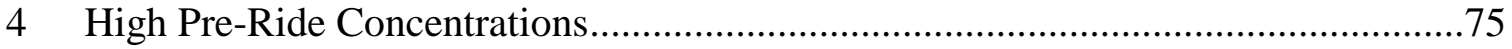

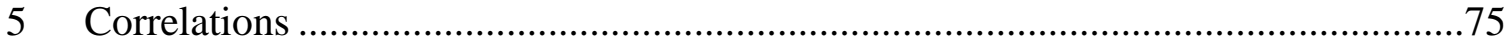

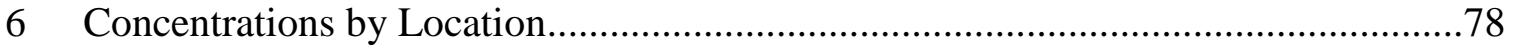

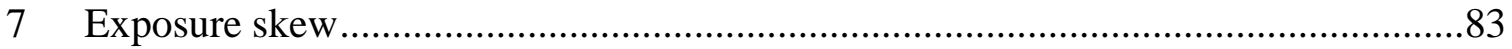




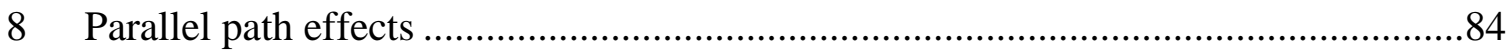

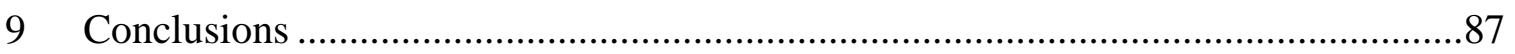

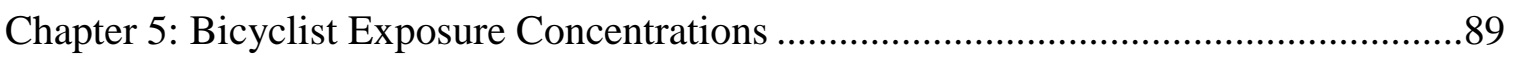

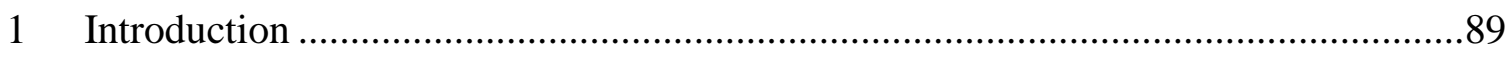

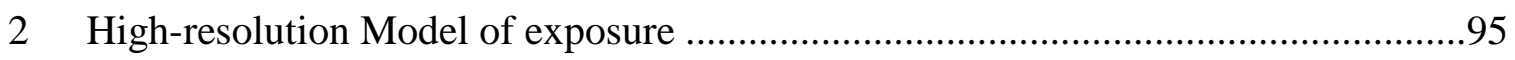

3 Segment-level Model of exposure ...................................................................112

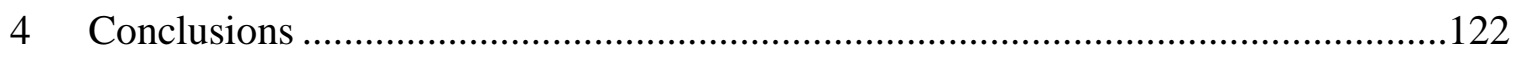

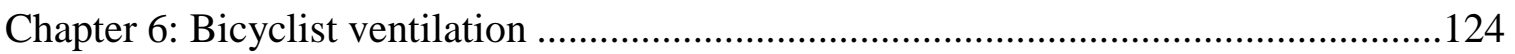

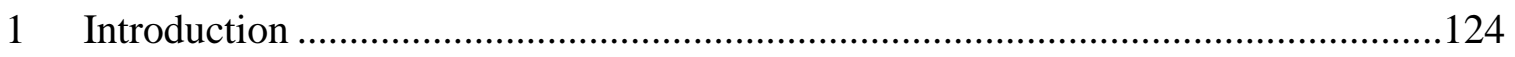

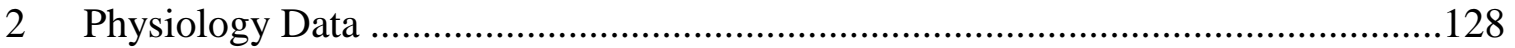

3 Physical Model of Bicyclist WorkLoad ...........................................................130

4 On-road Ventilation and Workload Results ........................................................136

5 Pollutant Inhalation rate Estimates ....................................................................

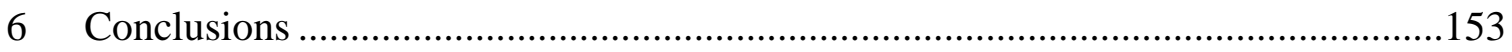

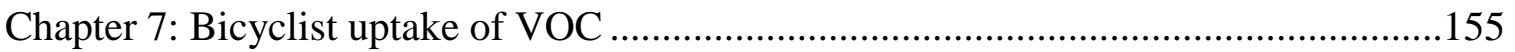

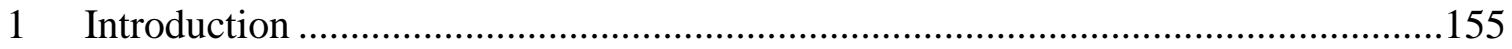

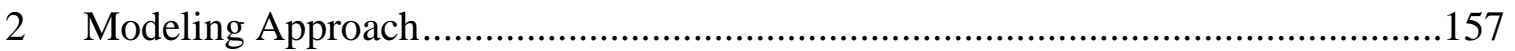

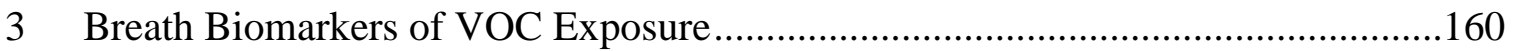

4 Breath concentrations as a function of exposure .....................................................168

5 Breath concentrations as a function of travel condition ..........................................175

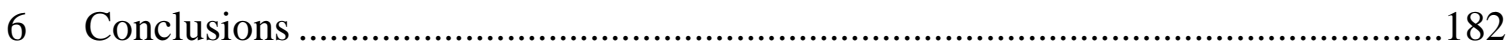

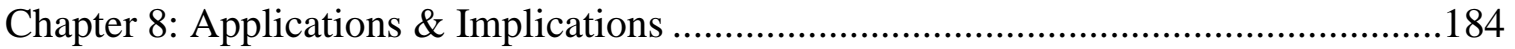

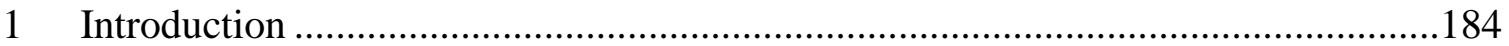

2 Inhalation dose effects of travel and roadway variables .........................................184

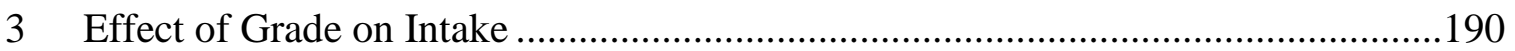

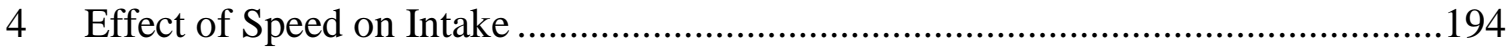

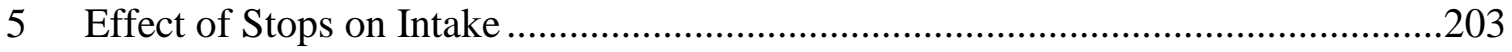

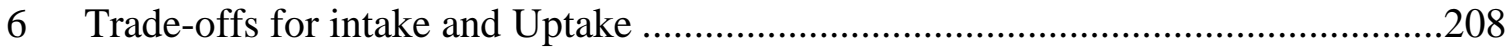

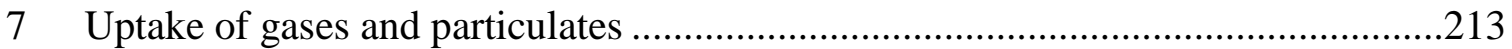

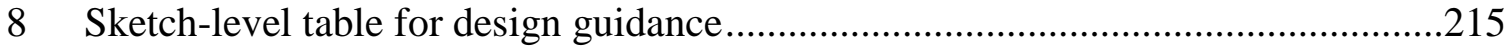

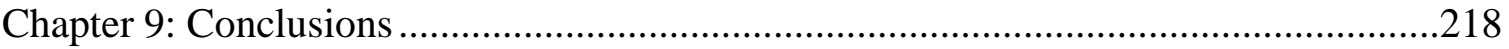

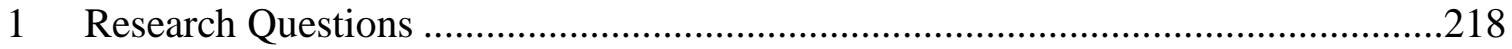

2 Summary of Findings and Unique Contributions...............................................220 


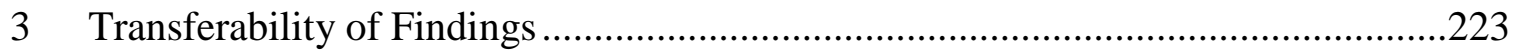

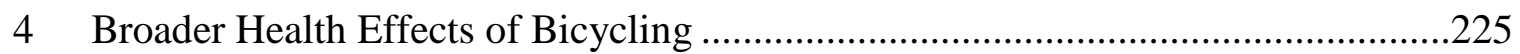

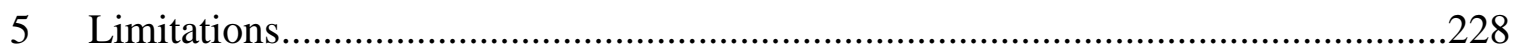

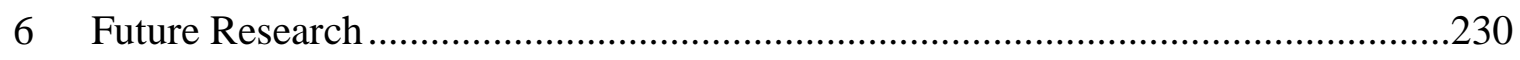

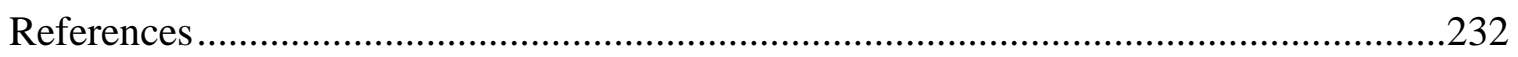

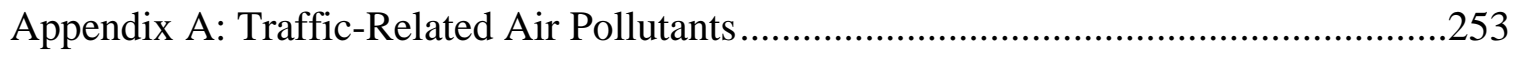

Appendix B: Reported Bicyclist Exposure Concentrations............................................257

Appendix C: Reported Bicyclist Respiration Measurements ........................................221

Appendix D: Zero-adjustment function code (R script) ..................................................273

Appendix E: Supplemental Concentration Data .......................................................274

Appendix F: Distributed Lag Model of Ventilation ...................................................278 


\section{LIST OF TABLES}

Table 1. Summary of the 42 studies directly measuring on-road bicyclists' exposure

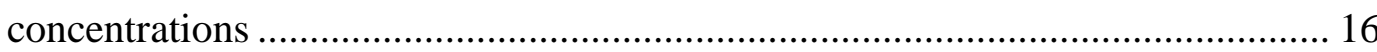

Table 2. Respiration-related parameters measured for bicyclists ..................................... 25

Table 3. Categorization of Bicyclists' Air Pollution Exposure, Intake, Uptake, and

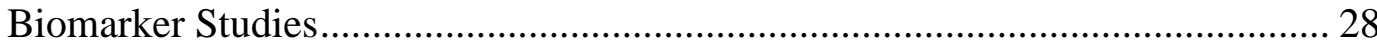

Table 4. Ratios of intake or uptake doses for bicyclists versus other modes..................... 32

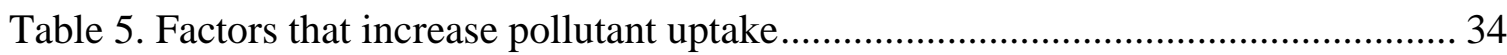

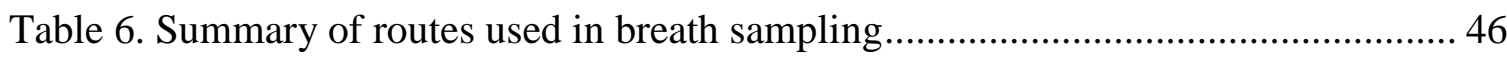

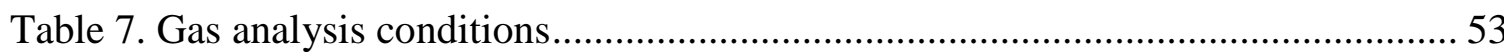

Table 8. Validation results comparing 2005 ADT map data with more recent (2008-2012)

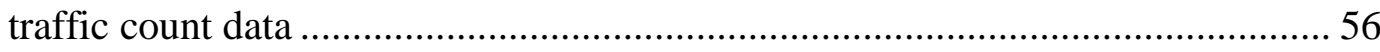

Table 9. Results of initial point-link matching based on proximity .....................................6

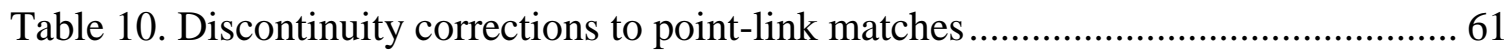

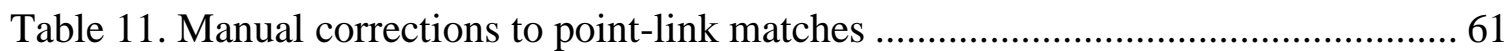

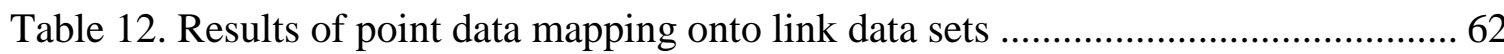

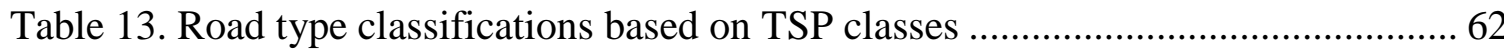

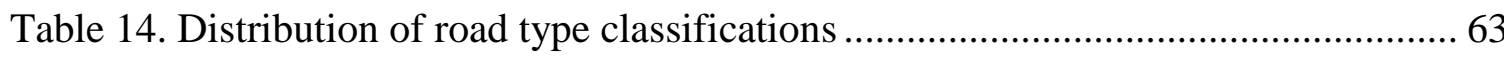

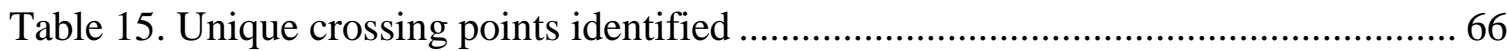

Table 16. Number of VOC samples by location/facility .................................................. 71

Table 17. Sampling conditions for 53 on-road segments by 3 subjects over 9 days ........ 72

Table 18. Characterization of breath and ambient concentrations $\left(\mathrm{ng}^{-1}\right)$ for on-road

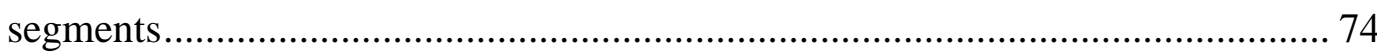

Table 19. Characterization of air quality monitoring concentrations ............................... 75

Table 20. Spearman correlation coefficients between 1-second air quality monitoring data

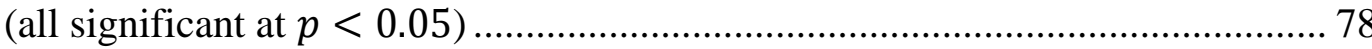

Table 21. Mean on-road concentrations, normalized to concentrations measured at the

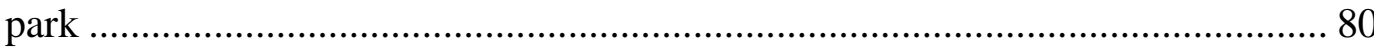

Table 22. Gini index of inequality and the minimum portion of the observations representing half of the cumulative exposure, by location ...................................... 84

Table 23. Potential explanatory variables for modeling exposure .................................... 91

Table 24. Measured explanatory variables .................................................................. 92

Table 25. Variable definitions in high-resolution BTEX exposure model; $i$ is the

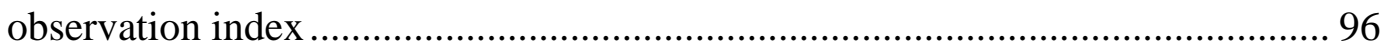

Table 26 . High-resolution BTEX exposure model estimated coefficients ...................... 97

Table 27. Characterization of pollutant concentrations and explanatory variables .......... 98

Table 28. Change in SSR with single-term deletion of explanatory variables ............... 102

Table 29. Comparison of alternative specifications of ADT variable ............................ 104 
Table 30. Comparison of high-resolution concentration model coefficients among pollutants with uniform specifications (log-transformed dependent variables) . 108

Table 31. Comparison of restricted high-resolution concentration model coefficients among pollutants (log-transformed dependent variables)............................... 109

Table 32. Model of TVOC concentrations with individual roadway names .................. 112

Table 33. Fit characteristics for the SUR system of 10 equations ................................ 114

Table 34. Estimated segment-level SUR model coefficients........................................ 115

Table 35. Expected effect of path dummy variables on exposure from semi-log SUR

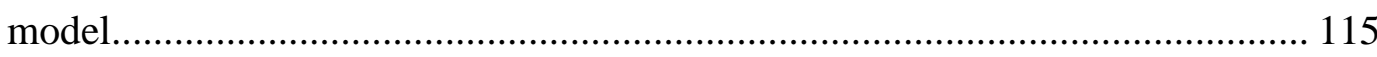

Table 36. Changes in SUR model system SSR with individual removal of explanatory variables $(\triangle D F=10$ for each) ............................................................... 116

Table 37. Alternative specifications for ADT in the SUR model ................................ 120

Table 38. Expected effects of facility types on exposure from semi-log SUR model... 121

Table 39. Segment-level SUR model coefficients with a differenced (exposure background) dependent variable ............................................................... 122

Table 40. Potential explanatory variables for modeling bicyclist workload ................. 131

Table 41. Parameters used in calculating bicyclist power ......................................... 135

Table 42. Summary statistics for physiology and workload data (five-second aggregation)

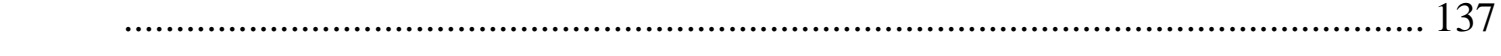

Table 43. Model parameters relating ventilation to heart rate ....................................... 139

Table 44 . Distributed lag models of on-road ventilation as a function of workload ..... 142

Table 45 . Mean and median lags for the effect of workload on ventilation ................. 143

Table 46. Summary of modeled $V E \sim W M$ relationship using different aggregation

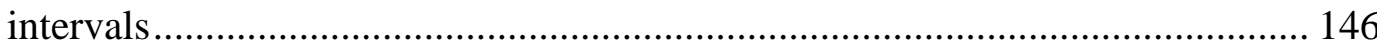

Table 47. Model parameters relating ventilation to workload from ergometer testing .. 148 Table 48 . Distributed lag models of on-road ventilation as a linear function of workload

Table 49. Summary of inhalation rates using 5-second concentration and ventilation data

Table 50. Potential explanatory variables for modeling uptake ................................. 159

Table 51. On-road breath/ambient concentration ratios ............................................ 161

Table 52. Relationship between changes in breath concentrations and changes in ambient

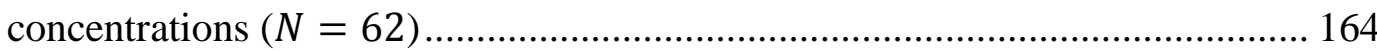

Table 53. Measured explanatory variables tested in uptake models............................ 168

Table 54. Variable definitions for VOC uptake model; $i$ is the observation index ........ 170

Table 55. Fit characteristics for the SUR system of 10 equations ................................ 171

Table 56. Estimated uptake model coefficients ...................................................... 172

Table 57. Changes in SUR model system SSR with individual removal of explanatory

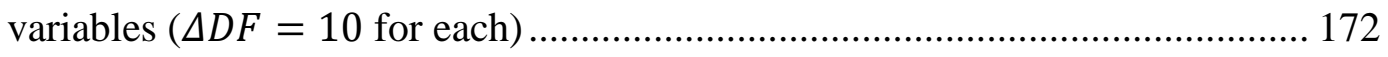


Table 58. Segment-level summary data for uptake model explanatory variables .......... 176

Table 59. Multi-stage least squares model of breath concentration.............................. 178

Table 60. Reference model of breath concentrations............................................... 179

Table 61. Summary of model parameter impacts on exposure and ventilation.............. 187

Table 62. Principles about bicyclist pollution risks for transportation professionals ..... 216

Table 63. Bikeway Design Considerations for Air Pollution Risks ............................. 217 


\section{LIST OF FIGURES}

Figure 1. Conceptual Diagram of Exposure Pathway for Traffic-Related Air Pollution ... 9

Figure 2. Literature Search Summary .................................................................. 14

Figure 3. Reported Increases in Bicyclists' Exposure Concentrations in "High Traffic" versus "Low Traffic" Routes and Locations* ..................................................... 21

Figure 4. Example sampling route with 4 segments (map imagery courtesy Google Maps)

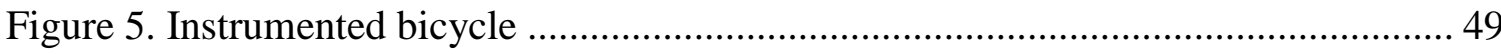

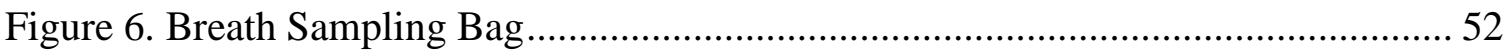

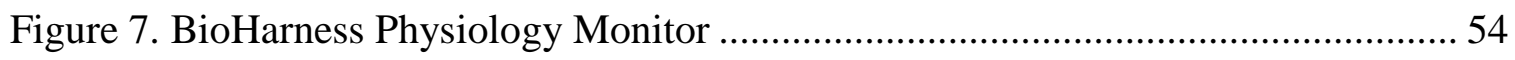

Figure 8. Associated road type classification (a) and ADT (b) for all location data points

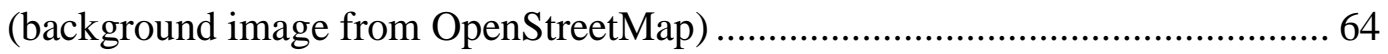

Figure 9. Comparison of ADT and road type for matched-link location data................. 65

Figure 10. Identified crossings on local roads and paths (background image from

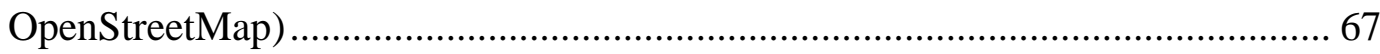

Figure 11. Elevation data from DEM (background image from OpenStreetMap) .......... 69

Figure 12. Estimated travel grades (background image from OpenStreetMap) ............... 70

Figure 13. Estimated grade versus travel speed (1-second data) ................................... 70

Figure 14. Correlation coefficients for ambient concentrations among 26 compounds (*

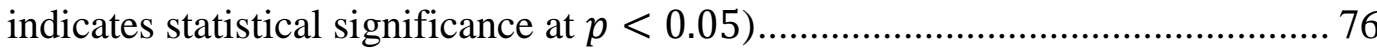

Figure 15. Correlation coefficients for breath concentrations among 26 compounds (*

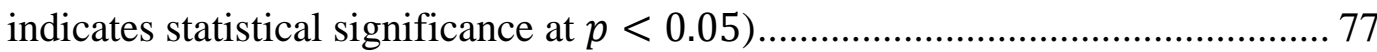

Figure 16. Ambient and breath concentrations by location ....................................... 79

Figure 17. Average ambient concentrations by location, normalized to park location .... 81

Figure 18. On-road measured TVOC concentration as pin height (travel speed as color, where from black/slow to green/fast); 2013-09-11 data collection ..................... 82

Figure 19. Lorenz curves showing exposure skew by location .................................... 83

Figure 20. Parallel facility comparisons (images from on-bicycle video data) ................ 86

Figure 21 . Correlations among 5-second aggregated explanatory variables and BTEX

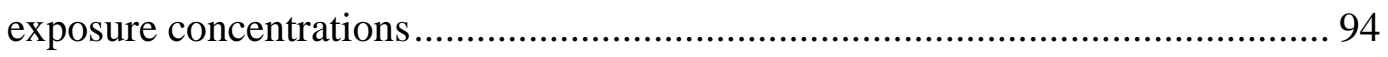

Figure 22. Industrial area along the Springwater Path............................................. 95

Figure 23. Modeled effects of ADT on BTEX exposure concentrations for mixed-traffic

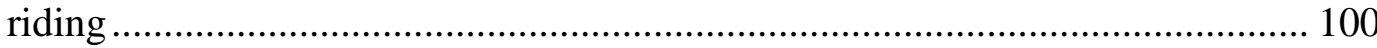

Figure 24. Modeled effects of ADT on BTEX exposure concentrations ...................... 101

Figure 25. Comparison of ADT effects on exposure for different specifications .......... 104 Figure 26. Comparison of Marginal ADT effects on exposure for different specifications

Figure 27. Correlation coefficients of residuals among 10 SUR model equations......... 116

Figure 28 . Residuals from 10 SUR model equations.............................................. 117 
Figure 29. Conceptual diagram of the connection between bicyclist ventilation and travel conditions 126

Figure 30. Simplified conceptual diagram connecting bicyclist ventilation to travel attributes

Figure 31. Incentive spirometer (image from medline.com) ..................................... 129

Figure 32. Lagged covariance between ventilation and heart rate................................ 138

Figure 33. Lagged covariance between and heart rate and workload (left) and between ventilation and workload (right) ............................................................. 141

Figure 34 . Marginal and cumulative impacts of workload on ventilation ..................... 143

Figure 35. Sensitivity of modeled $\beta T$ to power equation parameters $C D^{\prime}$ and $C R \ldots \ldots . .144$

Figure 36 . Marginal and cumulative impacts of workload on ventilation in the linear

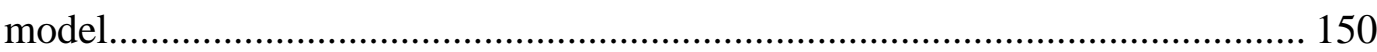

Figure 37. Comparison of steady-state predictions from log-linear and linear specifications of the ventilation-workload relationship

Figure 38. Coefficients of variability for 5-second concentration and ventilation data by location 152

Figure 39. Conceptual diagram of the influence of travel conditions on pollution uptake 158

Figure 40. Correlations among segment-aggregated exposure and uptake variables ..... 169

Figure 41. Time graph illustrating segment variable notation .................................. 170

Figure 42. Correlation coefficients of residuals among 10 SUR model equations......... 173

Figure 43. Path model of breath concentrations ....................................................... 181

Figure 44. Components of steady-state workload...................................................... 190

Figure 45. Effect of extended grades on ventilation per unit time at different speeds ... 192 Figure 46. Effect of extended grades on ventilation per unit distance at different speeds

Figure 47. Effect of steady speed on ventilation per unit time at different grades ........ 197

Figure 48. Effect of steady speed on ventilation per unit distance at different grades ... 198

Figure 49. Speed for minimum total ventilation per unit distance at increasing grades. 200

Figure 50. Ventilation envelope: ventilation at the minimum-ventilation speeds shown in

Figure 49

Figure 51. Acceleration curves for start-up workloads at factors of $k=2,4$, and 6 of cruising-speed workload 205

Figure 52. Cruise-equivalent excess ventilation associated with the deceleration and acceleration of a stop event at cruising speeds of 2-8 mps (7-29 kph). 207 


\section{Chapter 1: Introduction}

\section{INTRODUCTION}

Urban transportation systems can affect traveler health in many ways. Bicyclists and other physically active travelers enjoy the health benefits of increased physical activity, but with the major potential drawback of increased uptake of traffic-related air pollutants (de Hartog et al. 2010). It is clear from past research that exposure to trafficrelated air pollution has negative health impacts for urban populations (Health Effects Institute 2010), and exposure during travel can be especially dangerous because of proximity to sources of pollution. However, the details of exposure concentrations within individual transportation microenvironments are not well established because of the great diversity of environmental, meteorological, and traffic factors (Kaur et al. 2007, Knibbs et al. 2011).

The health risks of pollution exposure during bicycling are particularly uncertain because of varying physical activity levels. Not only are bicyclists' exposure concentrations highly variable, but different levels of physical exertion and individual physiology affect the intake of pollutants because of varying volumes and depths of respiration (Nadeau et al. 2006, Zuurbier et al. 2009). The current state of uncertainty about bicyclists' intake of traffic-related air pollution leaves unsatisfying gaps in health impact assessments and impedes health-conscious transportation planning and management. 


\section{CONTEXT}

Bicycling is currently a small share of total trips taken in most of North America, but many urban areas are actively promoting increased bicycling as a mode of transportation (Pucher et al. 2011). Promotional programs and policies often take the forms of new or improved bicycle infrastructure (on-road or at trip-ends), bike-sharing programs, pro-bicycle marketing and education, or restrictions on private automobile usage (City of Portland 2010, Pucher et al. 2010, Department for Transport 2013). The promotion of bicycling is justified by expected environmental benefits (reduced emissions \& fuel consumption), public health benefits (increased physical activity leading to positive health outcomes), and social/livability benefits (more active public spaces, reduced road \& parking land uses, and increased community connectivity) (Gotschi 2011, Pucher and Buehler 2012). The city of Portland, Oregon is one of the cities with the most bicycling in the U.S., where bicycling is actively supported with comprehensive public policy (City of Portland 2010, Pucher et al. 2011). The Portland Bicycle Plan for 2030 (City of Portland 2010) aims to achieve a 25\% bicycle mode share in the city, based on recommendations in the city's Climate Action Plan 2009 (City of Portland and Multnomah County 2009).

\subsection{Bicycling and Health}

Public health benefits are expected from an increase in bicycling, due to increased physical activity and decreased stress. Active commuting (walking and biking) has been associated with an $11 \%$ reduction in cardiovascular risk (Hamer and Chida 2008), while longer driving commutes are associated with higher obesity and blood pressure - likely 
due to less physical activity and other aspects of suburban life (Hoehner et al. 2012). But there are potential safety risks associated with crashes during bicycling, too, which are often cited as a caveat to public health benefits (Reynolds et al. 2010).

The other potential mitigation of health benefits from bicycling is an increased absorption of traffic-related air pollution in the body. The intake of air pollution by bicyclists can be increased because of longer exposure duration and higher respiration rates than other modes (Int Panis et al. 2010, Zuurbier et al. 2010), though there is also the potential of lower exposure concentrations for bicyclists (Kaur et al. 2007, Boogaard et al. 2009, Knibbs et al. 2011). The issue of bicyclists' health effects from air pollution is still under debate; as stated by Reynolds et al. (2010) "it is unclear whether active transportation is associated with ... a reduction or increase in air pollution exposure at both the individual and societal level."

The question of the net health effects of bicycling, including physical activity, crashes, and air pollution, has been asked frequently in recent years (de Hartog et al. 2010, Reynolds et al. 2010, Int Panis 2011, Rojas-Rueda et al. 2011, Teschke, Reynolds, et al. 2012). Generally, physical activity benefits are expected to dominate, resulting in a net positive health benefit. When looking at society as a whole a net benefit is likely, but there is more uncertainty on the net health effects for the individual travelers making a transition to bicycling. Part of the continued uncertainty is due to the lack of sound information on bicyclists' intake of pollution under varying circumstances. 


\subsection{Planning \& Managing Bicycle Transportation for Health}

While the net health effects of bicycling are important to consider, transportation planners and managers benefit more from information about how to reduce pollution exposure and intake for travelers, rather than a comparison of the risks between modes. An urban transportation system influences bicyclists through its infrastructure, management, and policies. The bicycling environment affects travel decisions (Dill and Carr 2003, Dill 2009, Broach et al. 2012), crash risks (Ragland et al. 2013, Winters et al. 2013), and likely pollution intake, too - though that is not well quantified (Hertel et al. 2008, Kendrick et al. 2011, Cole-Hunter et al. 2012).

In the "Survey of Best Practices" for "Bikeway Facility Design" used in the development of the Portland 2030 Bicycle Master Plan (Appendix D) ${ }^{1}$, bicyclists' exposure to air pollution does not explicitly appear as a design criterion. The Dutch Design Manual for Bicycle Traffic (CROW 2007) recognizes the pollution benefits of separating bicycles from motor vehicles, stating that "when designing a cycle network, longitudinal or lateral combinations of cycle connections with busy flows of motorized traffic should be avoided where possible." The CROW manual further cites a benefit of separated cycle tracks and bike boxes as "less nuisance from exhaust fumes" but does not provide any quantitative guidance.

Much previous research on travelers' exposure to air pollution is based on modal comparisons - i.e. travel along the same routes or between the same origins and destinations is compared for different travel modes (O’Donoghue et al. 2007, McNabola

\footnotetext{
${ }^{1}$ http://www.portlandoregon.gov/transportation/article/334689
} 
et al. 2008, Boogaard et al. 2009). These studies are useful for comparing mode choice effects on pollution exposure because they control for many factors, but they provide little information on which parameters most influence bicyclists' intake of pollution, or how best to mitigate exposure. Some recent research has shown that bicycle facility design and route characteristics can affect bicyclists' pollution exposure concentrations (Hertel et al. 2008, Kendrick et al. 2011, Cole-Hunter et al. 2013, MacNaughton et al. 2014). But apart from a handful of studies, there is little quantitative information on ways to reduce pollution exposure for bicyclists.

Furthermore, while the more robust traveler exposure studies apply different respiration rates for travelers of different modes (van Wijnen et al. 1995, Zuurbier et al. 2010), respiration is almost never considered as a function of travel or roadway characteristics other than mode (i.e. intra-modal respiration variability is ignored). Two exceptions are McNabola et. al. (2008), who found speed-varying respiration rates for a bicyclist based on laboratory tests (though the respiration model is not related to a transportation network), and Int Panis et. al. (2010), who directly measured on-road respiration (though respiration covariates were not analyzed). The ability of transportation system planners and managers to mitigate pollution uptake for travelers is impeded by a lack of quantitative information on how both exposure concentrations and respiration vary during active travel.

\section{MOTIVATION}

Human exposure to traffic-related air pollution is a serious public health problem, with a variety of negative health impacts from long-term exposure (Health Effects 
Institute 2010, Nawrot, Vos, et al. 2011, Shah et al. 2012, Forastiere and Agabiti 2013). Commuting represents a disproportionately high portion of daily pollution dose and risk because of high concentrations around roadways (Fruin et al. 2008, Hill and Gooch 2010, Nawrot, Perez, et al. 2011, Dons et al. 2012). A study in Southern California estimated that human mortality due to excessive fine particulate matter $\left(\mathrm{PM}_{2.5}\right)$ exposure was on par with traffic crash-related deaths (Hall et al. 2008). Still, as described above there is continued uncertainty about the magnitude of health effects from air pollution exposure for bicyclists (de Hartog et al. 2010, de Nazelle et al. 2011, Int Panis 2011). No quantitative guidance is available on bicycle transportation planning and management to lower pollution uptake, and yet the public is interested in knowing the health risk of pollution exposure while bicycling ${ }^{2}$.

Bicyclist exposure research is particularly relevant in Portland, which is strongly associated with bicycling in the U.S. Portland has a $6 \%$ bicycle commute mode share, compared with $0.5 \%$ nationally - the highest percent of any large American city - and experienced a $238 \%$ increase in the number of people commuting by bicycle over the years 2000 to $2010^{3}$. Portland is the only large American city to be labeled "Platinum" by the League of American Bicyclists, and continues to actively promote bicycling in the city ${ }^{4}$

\footnotetext{
${ }^{2}$ For example, for proposed bicycle facility projects: http://bikeportland.org/2011/04/28/224000-forsullivans-gulch-plan-now-in-city-coffers-52243

${ }^{3}$ Portland Bureau of Transportation fact sheet: http://www.portlandoregon.gov/transportation/article/407660

${ }^{4}$ See the Portland Bicycle Plan for 2030: http://www.portlandoregon.gov/transportation/44597
} 
Unfortunately, Portland also has elevated concentrations of several hazardous air pollutants, as demonstrated by the Portland Air Toxics Assessment (PATA) (Rosenbaum et al. 2004, Oregon Department of Environmental Quality 2012). With benchmarks set at a health risk increase of 1 mortality in 1 million population, 8 studied air toxics are more than 10 times over the benchmark, and 6 more are 1 to 10 times over the benchmark. Cars and truck emissions are "the largest sources of air toxics," with on-road engines emitting 1,3-butadiene, benzene, diesel particulate, arsenic and chromium 6 with regional and neighborhood effects. Portland's benzene levels are predicted to be up to 30 times over benchmarks in 2017, due to the high benzene content of gasoline in the Pacific Northwest (Oregon Department of Environmental Quality 2011). Because of elevated respiration and a close proximity between bicyclists and motor vehicles, these hazardous pollutants are particularly a concern for bicyclists in the city. Lastly, few bicyclist exposure studies have been conducted in the U.S., which has a unique population of bicyclists and different motor vehicle fleet, fuels, and transportation systems from Europe (where most other studies were conducted).

\section{OBJECTIVE \& RESEARCH QUESTIONS}

The main objective of this dissertation is to determine how uptake of air pollution by bicyclists is affected by transportation system characteristics, in order to provide tools for transportation system planners and managers to more explicitly consider the health risks of air pollution in decision-making, and for active travelers to make more informed choices about their own travel.

The primary research questions that this dissertation aims to address are: 
1 How do urban bicyclists' intake and uptake of traffic-related air pollution vary with roadway and travel characteristics, considering both respiration and concentration changes? For example, how is pollution uptake impacted by facility type (e.g. arterials, bike boulevards) and road grade?

2 To what extent can transportation-related strategies reduce bicyclists' pollution intake and uptake? For example, how can bicycle facilities or routing guidance reduce uptake?

From these research questions, the anticipated results of the dissertation are 1) better models of bicyclists' pollution uptake based on roadway characteristics and 2) new information for roadway and network design that considers pollution exposure for bicyclists. These results can lead to better tools for traveler health impact assessments and health-conscious transportation system planning and management.

\section{FRAMEWORK AND SCOPE}

A conceptual diagram linking traffic-related pollution emissions and health effects is illustrated in Figure 1, adapted from Ott, Steinemann, \& Wallace (2007). Motor vehicle emissions (a) degrade urban air quality (b) in accordance with atmospheric dispersive, chemical, and physical processes. Travelers' exposure concentrations (c) then depend on their travel trajectory. The inhalation of traffic-related air pollution (d) depends on travelers' breathing volume while exposed to a pollutant concentration. Uptake of the inhaled pollutants into the body (f) depends on processes in the respiratory tract and other body systems. Finally, the health effects $(\mathrm{g})$ of air pollution uptake doses are a function of the toxicity of the pollutants and physiology of the individual. The 
processes between inhalation and uptake can be further demarcated as $\left(\mathrm{e}_{1}\right)$ intake dose (the amount of pollutant that crosses the body boundary at the mouth and nose), $\left(\mathrm{e}_{2}\right)$ absorbed dose (the amount of pollutant that is not exhaled but deposited or absorbed), $\left(\mathrm{e}_{3}\right)$ effective dose (the bioavailable amount of pollutant that reaches body tissue instead of being expelled from the respiratory tract lining by coughing, sneezing, etc.), and $\left(\mathrm{e}_{4}\right)$ uptake dose (the amount of pollutant that is incorporated into the body).

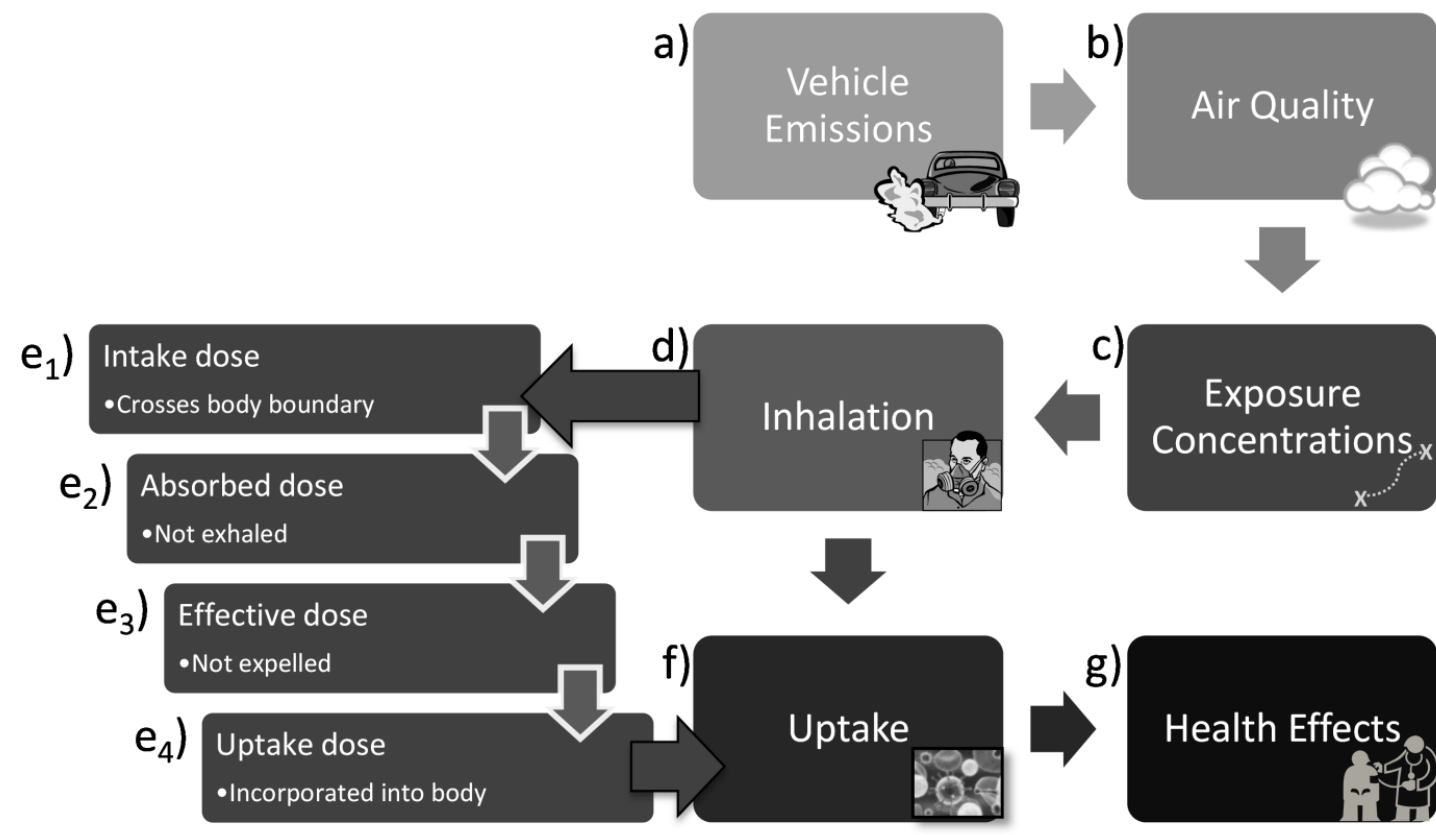

\section{Figure 1. Conceptual Diagram of Exposure Pathway for Traffic-Related Air Pollution}

This research only addresses the steps from exposure concentrations (Figure 1-c) to uptake dose (Figure 1-f). This research will not explicitly model emissions or atmospheric dispersion and chemical transformations, which lead to ambient concentrations, nor does it include detailed analysis of health outcomes from pollution uptake. 


\section{METHODOLOGY OVERVIEW}

1 Literature review: an exhaustive literature review was performed to catalogue and synthesize existing literature on bicyclist exposure to and uptake of air pollution. The literature review is presented in Chapter 2.

2 Data collection: collect on-road data on bicyclists' exposure concentrations, breath concentrations, physiology, and travel characteristics. The experimental methodology is described in Chapter 3, and an overview of the collected on-road data is presented in Chapter 4.

3 Model development: use the empirical data to estimate models of bicyclist exposure to traffic-related air pollution, ventilation during riding, and uptake of VOC using transportation system and travel characteristics among the explanatory variables. Exposure, ventilation, and uptake models are described in Chapters 5, 6 , and 7 , respectively.

4 Model application: analyze uptake mitigation strategies using the models developed in part 3. Model applications are described in Chapter 8. Conclusions are presented in Chapter 9. 


\section{Chapter 2: Literature Review}

\section{INTRODUCTION}

Bicycling as a mode of transportation is enjoying a boost in urban areas around the world through new bike-sharing systems, bicycle-specific roadway facilities, public outreach and incentive programs (Pucher and Buehler 2012). The push toward promoting bicycling is motivated by a range of environmental, economic, health, and social benefits. Although there are clear health benefits of increased physical activity, bicyclists may experience increased inhalation of traffic-related air pollutants (de Hartog et al. 2010).

Human exposure to traffic-related air pollution has well-established negative health impacts for urban populations (Brook et al. 2010, Health Effects Institute 2010, Nawrot, Vos, et al. 2011, Forastiere and Agabiti 2013). Air pollution exposure is particularly high for travelers because of proximity to mobile sources of pollution (Kaur et al. 2007), and air quality is a source of concern for urban bicyclists (Badland and Duncan 2009). However, the health risks of air pollution exposure during travel are not easily characterized because of the numerous individual, environmental, and traffic factors involved.

Past reviews of travelers' pollution exposure have been oriented by pollutant (Kaur et al. 2007, Knibbs et al. 2011) and/or focused on in-vehicle exposures (El-Fadel and Abi-Esber 2009). These reviews focused on exposure concentrations and provide little or no discussion of respiration or its effects on intake and uptake doses. The focus of this review is on bicyclists' exposure to, inhalation of, and uptake of traffic-related air 
pollution - i.e. steps (c) through (f) in Figure 1 in the Introduction (Chapter 1). This review is unique in focusing exclusively on bicyclists. ${ }^{5}$

\section{LITERATURE SEARCH METHODOLOGY}

A systematic literature search for bicyclist exposure and dose measurements was performed through January 2014 using all 20 possible keyword combinations $\{A+B+$ $C$ \} utilizing the keyword sets $A=\{$ bicycle, bicyclist, cyclist, bike $\}, B=\{$ pollution $\}$ and $C=\{$ exposure, intake, inhalation, uptake, dose $\}$. An exhaustive search was performed using the WorldCat ${ }^{\mathrm{TM}}$ catalogue. The number of hits returned for each search phrase ranged from 0 ("bicyclist pollution intake") to 131 ("bicycle pollution exposure"); 231 unique hits were returned. The same 20 search phrases were used with the Google Scholar ${ }^{\mathrm{TM}}$ search engine. Because of the volume of Google Scholar ${ }^{\mathrm{TM}}$ hits returned (28,100 for "bicycle pollution exposure" alone), only the first 50 hits per search phrase were processed (sorted by relevance).

Of the 231 unique hits returned from the WorldCat ${ }^{\mathrm{TM}}$ database search, a first screening was performed with exclusion based on title review or reference format (theses, conference papers, and textbooks were excluded). This screening removed 119 hits, leaving 112 potential papers. A matching exercise was then performed to remove further duplicate papers - resulting in 47 duplicates removed. Another 11 papers were excluded based on abstract review, leaving 54 papers for full-text extraction. The title and abstract review process required that papers describe original studies about on-road bicyclists and

\footnotetext{
${ }^{5}$ Note: this chapter has been published in Transport Reviews as: Bigazzi, A.Y. and Figliozzi, M.A., 2014. Review of Urban Bicyclists' Intake and Uptake of Traffic-Related Air Pollution. Transport Reviews, 34 (2), 221-245. doi:10.1080/01441647.2014.897772
} 
environmental air pollution exposures. Reviews, chamber studies using bicycle ergometers, and traveler exposure studies not including bicyclists were excluded. The citation lists of these 54 papers and the Google Scholar ${ }^{\mathrm{TM}}$ search returns were searched for additional papers that passed the same format, title review, and abstract review criteria. The result was 14 additional papers manually added to the full-text body of references, now composed of 68 papers.

The full-text body of 68 references was reviewed for two nested inclusion criteria. The first criterion was the use of spatially-explicit concentration data, either measured or modeled. Studies that assumed a generic concentration value (de Hartog et al. 2010) were excluded. 57 papers met this criterion. The second criterion was the presentation of original exposure concentration data, measured on-road by bicyclists. Studies using modeled concentration data, roadside monitor data, conducting analysis using previouslypublished exposure concentration data, or not reporting central value statistics were excluded. 42 papers met this criterion. If multiple papers reported on the same data set, a single reference was included in this subset. Two studies measured bicyclists' exposures but were focused on instrument development and did not report central value statistics (Piechocki-Minguy et al. 2006, Elen et al. 2013). The literature search method is summarized in Figure 2. 


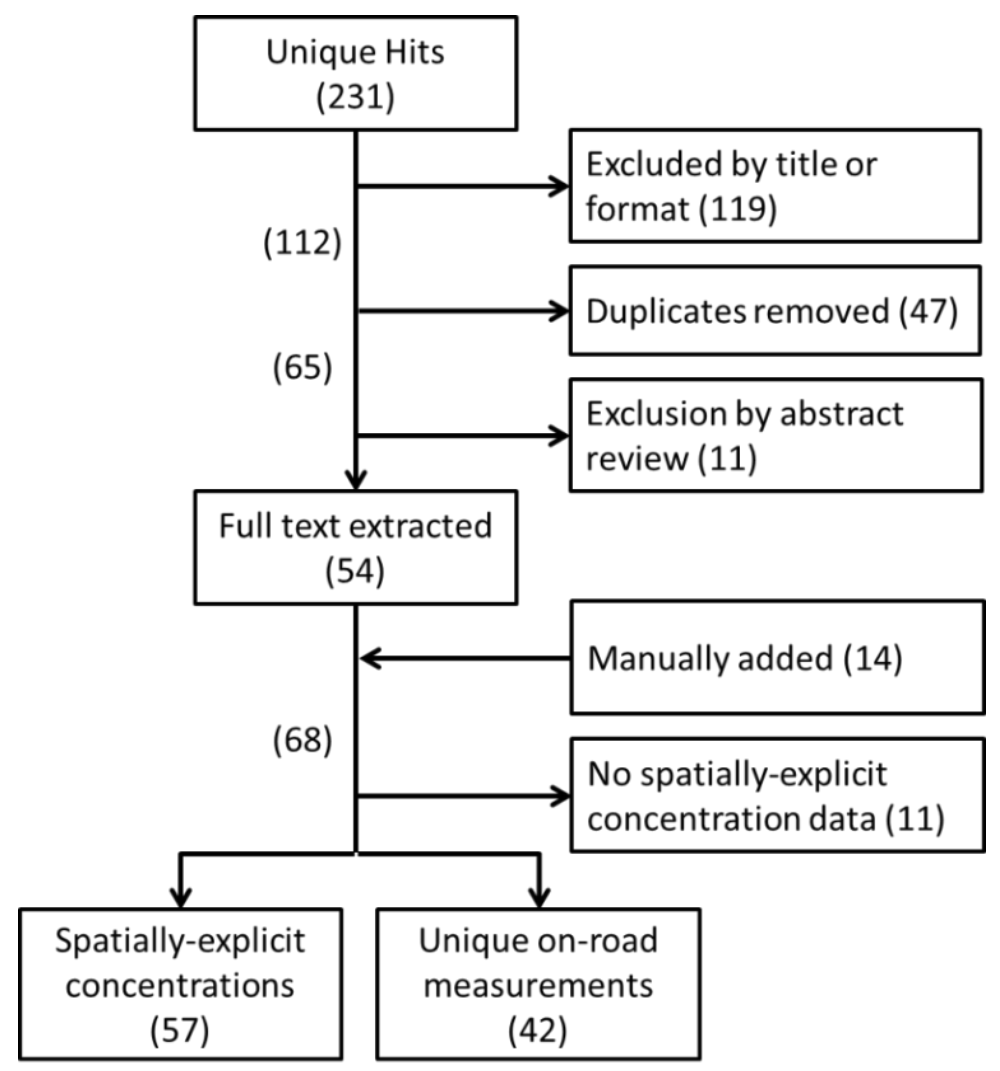

Figure 2. Literature Search Summary

\section{BICYCLISTS'AIR POLLUTION EXPOSURE CONCENTRATIONS}

The main traffic-related air pollutants linked to health risks for road travelers and measured for bicyclists are carbon monoxide $(\mathrm{CO})$, nitrogen oxides $\left(\mathrm{NO}_{\mathrm{x}}\right)$ - including nitric oxide (NO) and nitrogen dioxide $\left(\mathrm{NO}_{2}\right)$, volatile organic compounds (VOC), and particulate matter (PM) of various sizes and composition: ultrafine particles (UFP), PM2.5, $\mathrm{PM}_{10}$, and elemental carbon (EC) / black carbon (BC). These pollutants are described in Appendix A.

A traveler's exposure concentration is the concentration of pollutants in their breathing zone. Concentrations of traffic-related primary pollutants are particularly high near roadways - especially for shorter-lived pollutants such as UFP and reactive VOC 
(Karner et al. 2010, Gordon et al. 2012). Steep concentration gradients can be seen even on the scale of a few meters (Clifford et al. 1997, McNabola et al. 2009a, Tiwary et al. 2011). Exposure concentrations are sampled using a variety of pollutant-specific devices, each requiring specialized knowledge and careful sampling procedures (Vallero 2008). Roadside studies of air pollution concentrations are more common than on-road data collections because on-road measurements are more difficult to execute (particularly for pedestrians and bicyclists). But the body of research on active travelers' pollution exposure concentrations has grown notably in recent years. On-road air quality sampling has become more precise and more portable because of improvements in measurement technology, power storage, and position tracking systems (Gulliver and Briggs 2004, Steinle et al. 2013).

A literature search revealed 42 published studies reporting unique exposure concentration data collected with on-bicycle sampling devices. Summary information on all 42 studies is included in Appendix B, allowing comparisons of methodologies and settings. Table 1 summarizes reported concentrations in all 42 studies, excluding results for "rural" settings). Ranges of reported central value statistics and disaggregate (samplelevel) values are presented, including the country where the low and high measurements were taken. 


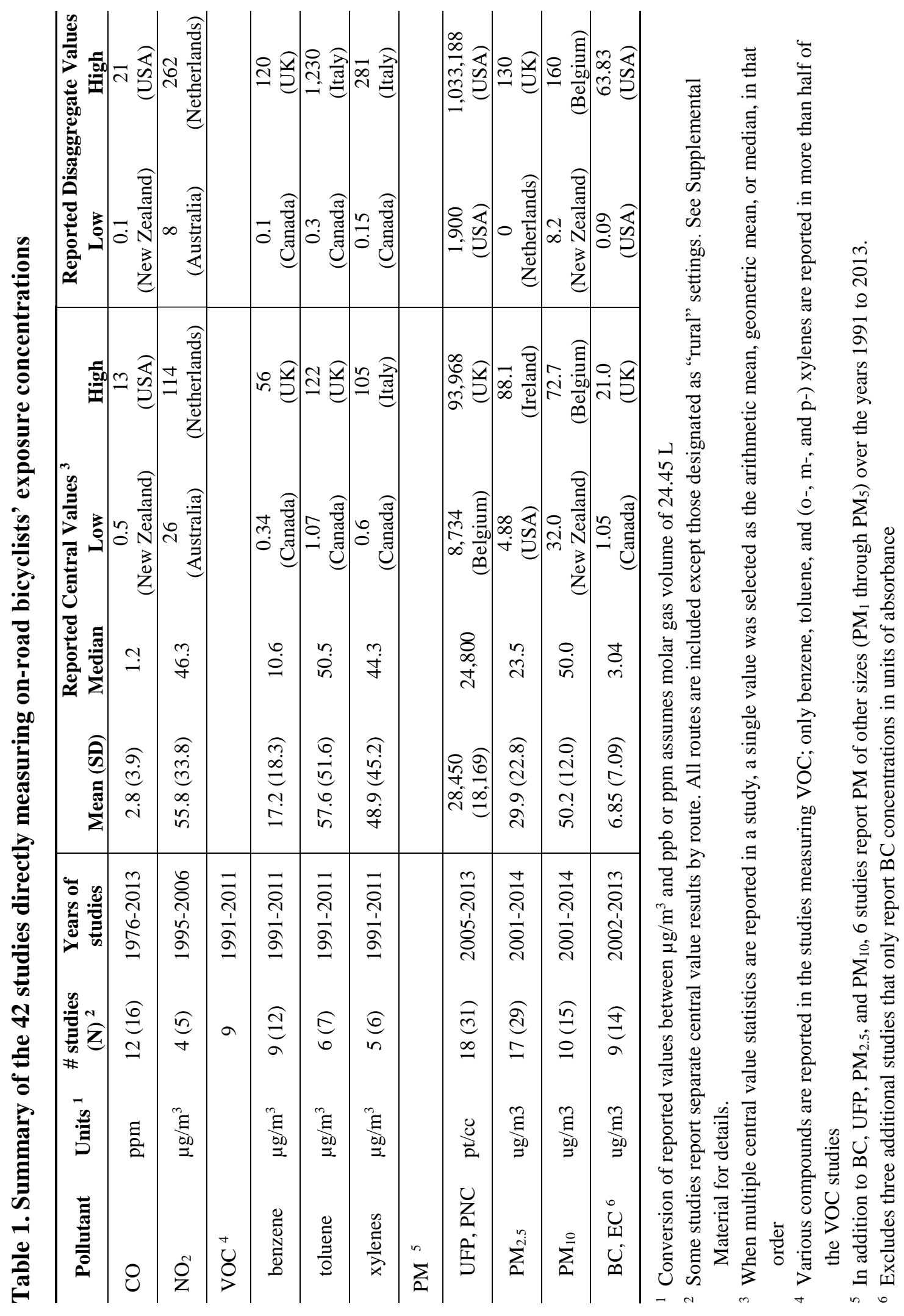


The mean on-road measurements in Table 1 are all well above typical urban background concentrations (see Appendix B). Table 1 shows that measured bicyclist exposure concentrations for most pollutants exhibit high variability among studies, with a standard deviation (SD) greater than $50 \%$ of the mean value for all pollutants except $\mathrm{PM}_{10}$, and a SD greater than the mean for $\mathrm{CO}$, benzene, and $\mathrm{BC} / \mathrm{EC}$. Bicyclists' average $\mathrm{CO}$ exposure concentrations have been measured in the range of 0.5 to $13 \mathrm{ppm}$, though all studies after 1995 report central value concentrations below 3 ppm.

\subsection{Modal Comparisons of Exposure Concentration}

A popular study design for traveler exposure studies is modal comparisons, in which exposure concentrations are compared for travelers using different transportation modes between the same origin and destination or along identical or parallel routes. Results from modal comparisons of exposure are inconsistent. Bicyclists sometimes have lower exposure concentrations than motorized modes, especially when they use facilities that are separated from traffic (van Wijnen et al. 1995, Kingham et al. 1998, 2013, Adams, Nieuwenhuijsen, and Colvile 2001, Adams et al. 2002, Chertok et al. 2004, Kaur et al. 2007, McNabola et al. 2008, Boogaard et al. 2009, Knibbs et al. 2011, de Nazelle et al. 2012, Dons et al. 2012). But modal comparison studies have also found insignificant differences in concentrations by mode, significantly higher bicyclist exposure concentrations than other modes, or inconsistent results by pollutant, location, or time of day (Waldman et al. 1977, Chertok et al. 2004, Boogaard et al. 2009, Kaur and Nieuwenhuijsen 2009, Int Panis et al. 2010, de Nazelle et al. 2012, Nwokoro et al. 2012, Yu et al. 2012, Kingham et al. 2013, Quiros et al. 2013, Ragettli et al. 2013). Likely 
causes of inconsistent results across studies include differences in the proximity and intensity of motor vehicle traffic, varying availability and use of bicycle facilities, and instrumentation/sampling differences (see Appendix B for information on study methods).

Modal comparison exposure studies typically use the same routes or origins and destinations across modes and fix other travel characteristics (e.g. departure time). While potentially informative, these comparisons are not always realistic because pollution exposure is also affected by intrinsic modal travel differences. The more realistic modal comparisons allow self-selected routes or direct active travelers to use representative routes for their mode - but local transportation network characteristics may affect the results. Bicycle travel patterns are different from motorized ones because of distinct traveler characteristics, trip distances, and route preferences (Plaut 2005, Broach et al. 2012). Real-world bicycle trips tend to be shorter and in higher-density parts of a city than trips using motorized modes. Bicycle trips are also highly seasonal (Nankervis 1999), so a different distribution of meteorological conditions could be expected by mode, with a systematic influence on exposure concentrations. Most bicycle exposure studies occur during warmer months when a greater proportion of bicycling occurs (see Appendix B), but the joint seasonality of mode splits and pollution levels should be considered when comparing travelers' exposures - especially for year-round bicyclists.

Although modal comparisons can be informative, they rarely provide practical insights into how to reduce exposure concentrations, other than mode shifts. Modal comparison studies rarely vary within-mode factors (such as route choice), which can be 
the most important determinants of exposure concentrations during travel (Knibbs et al. 2011).

\subsection{Factors Affecting Bicyclists' Exposure Concentrations}

Multivariate analyses of travelers' exposure concentrations have shown that important factors include wind and weather, traffic and route, and the built environment around the roadway (Adams, Nieuwenhuijsen, and Colvile 2001, Kaur et al. 2007, Berghmans et al. 2009, Boogaard et al. 2009, Kaur and Nieuwenhuijsen 2009, McNabola et al. 2009b, Knibbs et al. 2011, Hatzopoulou, Weichenthal, Dugum, et al. 2013, Quiros et al. 2013). But few studies have looked at bicyclist-specific factors that could influence exposure, such as lateral position in the road, proximity to exhaust pipes, breathing height, and the ability to "dodge between" vehicles (Kaur et al. 2007).

Wind is consistently a significant factor for exposure, decreasing concentrations through dispersion (Kingham et al. 1998, Adams, Nieuwenhuijsen, and Colvile 2001, Kaur et al. 2007, Kaur and Nieuwenhuijsen 2009, McNabola et al. 2009b, Knibbs et al. 2011, Hong and Bae 2012, Hatzopoulou, Weichenthal, Dugum, et al. 2013, Jarjour et al. 2013). Temperature is less consistently a significant factor, and effects can be difficult to distinguish from humidity because of a strong negative correlation (Kingham et al. 1998, Adams, Nieuwenhuijsen, and Colvile 2001, Kaur et al. 2007, Kaur and Nieuwenhuijsen 2009, Knibbs et al. 2011, Hatzopoulou, Weichenthal, Dugum, et al. 2013). Time-of-day is a factor that incorporates influencing effects of local weather and diurnal traffic patterns - particularly relevant for urban areas with diurnal temperature inversions that significantly affect pollutant levels. 
After weather, the next most important factors for bicyclists' exposure concentrations can be combined into a single category: separation from motor vehicle traffic. These factors include the concentration-reducing effects of traveling on lowtraffic routes (Hertel et al. 2008, Hatzopoulou, Weichenthal, Dugum, et al. 2013), on separated bicycle facilities (Kingham et al. 1998, 2013, Kendrick et al. 2011, Hong and Bae 2012, Hatzopoulou, Weichenthal, Dugum, et al. 2013, MacNaughton et al. 2014), and during off-peak periods or weekends (Kleiner and Spengler 1976, Huang et al. 2012, Dons et al. 2013). Lacking more specific data, the influence of motor vehicle traffic on exposure concentrations is sometimes estimated using a proxy of facility type, time-ofday, or average daily traffic (ADT) estimates (Boogaard et al. 2009, Weichenthal et al. 2011, Cole-Hunter et al. 2012, Hong and Bae 2012, Jarjour et al. 2013, Ragettli et al. 2013).

The influence of motor vehicle traffic was measured in 14 different studies by comparing bicyclists' exposure concentrations on "high traffic" and "low traffic" routes or using a related dichotomy (inner-city/suburban, on-road/off-road, near-road/cycle path). The combined results are shown in Figure 3, with the median and range of reported percent increases on "high traffic" versus "low traffic" routes (see Appendix B for sources). As expected, pollutants that are more dominated by motor vehicle sources in roadway environments (hydrocarbon VOC, UFP) show larger increases on high-traffic routes. 


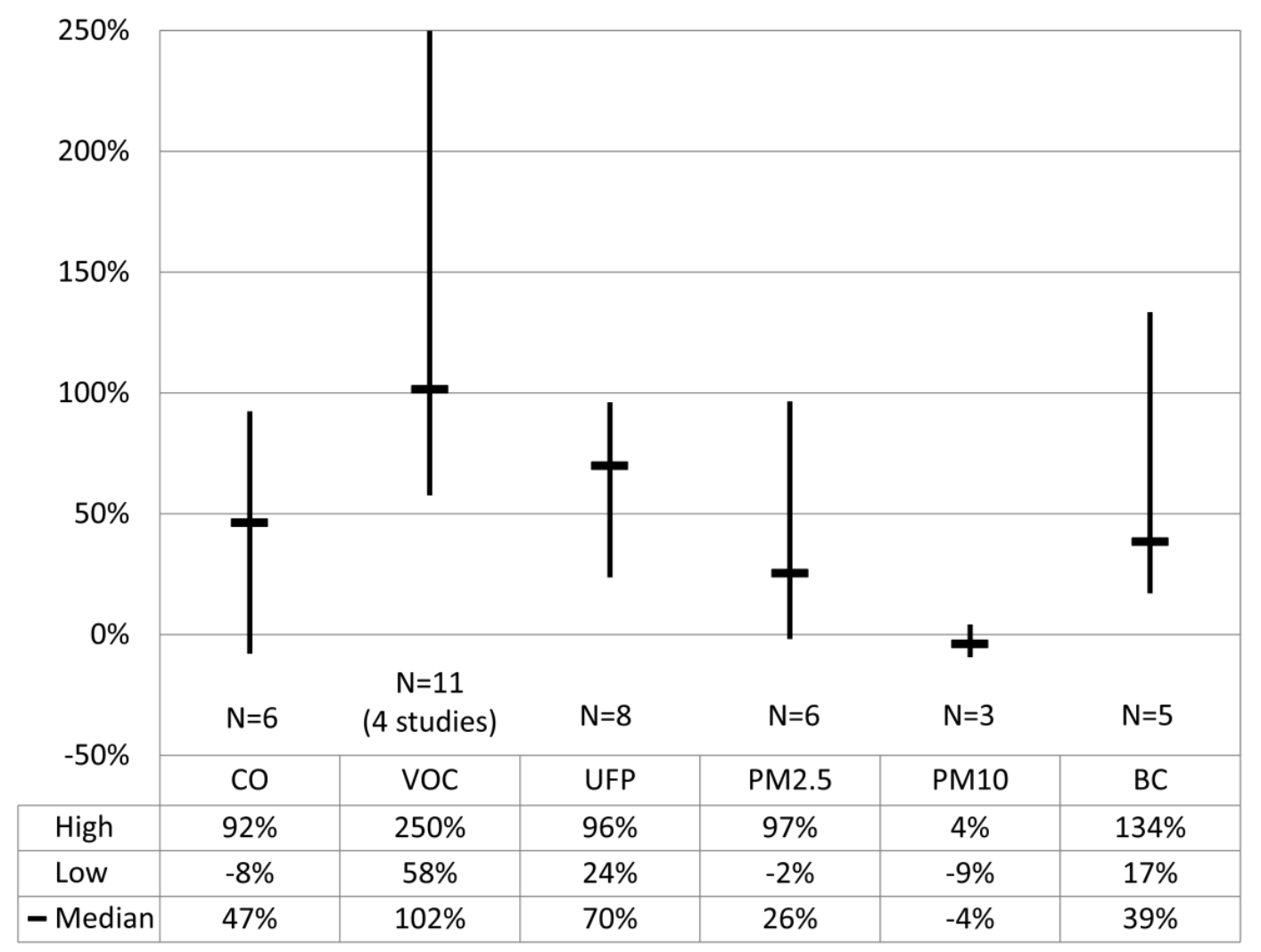

\section{Figure 3. Reported Increases in Bicyclists' Exposure Concentrations in "High Traffic" versus "Low Traffic" Routes and Locations"}

${ }^{*}$ Urban/rural comparisons are excluded. Where multiple observations are reported per study (e.g. by city or time period), a weighted average by number of samples was used. For VOC, reported BTEX compounds (benzene, toluene, ethylbenzene, and xylenes) are included (11 comparisons for these compounds in 4 different studies). Sources: CO (Kleiner and Spengler 1976, Waldman et al. 1977, Bevan et al. 1991, Weichenthal et al. 2011, Jarjour et al. 2013, Kingham et al. 2013), VOC: (Bevan et al. 1991, Kingham et al. 1998, McNabola et al. 2008, Weichenthal et al. 2011), UFP: (Strak et al. 2010, Zuurbier et al. 2010, Weichenthal et al. 2011, Cole-Hunter et al. 2012, 2013, Jarjour et al. 2013, Kingham et al. 2013, Ragettli et al. 2013), $\mathrm{PM}_{2.5}$ : (Adams, Nieuwenhuijsen, Colvile, et al. 2001, McNabola et al. 2008, Zuurbier et al. 2010, Weichenthal et al. 2011, Jarjour et al. 2013, Kingham et al. 2013), $\mathrm{PM}_{10}$ : (Strak et al. 2010, Zuurbier et al. 2010, Kingham et al. 2013), BC: (Kingham et al. 1998, Strak et al. 2010, Zuurbier et al. 2010, Weichenthal et al. 2011, Jarjour et al. 2013)

Explicit traffic variables such as motor vehicle volume or speed are often not included in bicyclist pollution exposure analysis because of a lack of concomitant data. When assessed, vehicle volumes, particularly truck or diesel vehicles, generally have a 
positive influence on pollutant exposure concentrations, though they are not always significant variables (Boogaard et al. 2009, Kaur and Nieuwenhuijsen 2009, McNabola et al. 2009b, Knibbs et al. 2011, Dons et al. 2013, Hatzopoulou, Weichenthal, Dugum, et al. 2013, Quiros et al. 2013). Aggregate traffic variables such as ADT cannot reveal the potentially important influences of varying traffic volumes, speeds, queuing, and fleet composition over the data collection periods. Furthermore, highly aggregate traffic variables are often correlated with geometric roadway characteristics such as the number of lanes, which also influence pollutant concentrations through dispersion.

Traffic data used in bicycle exposure studies to date have been non-specific to the study period, limited in spatial and temporal coverage, and/or highly aggregated (in time and vehicle type). Of the 42 studies included in Table 1, only 4 report traffic data collected at the locations and time periods of air quality measurements. Kaur et al. $(2005)^{6}$ and McNabola et al. (2008) ${ }^{7}$ retrieved unclassified hourly vehicle volumes from traffic signal data at major intersections on the study routes. Hatzopoulou et al. (2013) collected intermittent manual vehicle counts using 5 vehicle classes for 10-20 minute periods sequentially at dozens of locations around the on-road measurement area. Quiros et al. (2013) performed intermittent manual vehicle counts for 5-minute periods using 9 vehicle classes (including bicycles and pedestrians) at a single location on the study corridor.

The next major factors for exposure concentrations, after weather and motor vehicle traffic, are the study setting and methodology. Comparing measured exposure

\footnotetext{
${ }^{6}$ Traffic data are reported in a companion paper, Kaur and Nieuwenhuijsen (2009).

${ }^{7}$ Traffic data are only used in a companion paper, McNabola et al. (2009a).
} 
concentrations across studies reveals wide ranges (Table 1), indicative of different study settings (time frame, city, locational characteristics) and different experimental methods (instruments, sampling strategy, aggregation, etc.). Potentially important differences among study settings include traffic patterns, weather conditions, vehicle fleets and fuels, urban form, and topography. Boogaard et al. (2009) compare bicyclists' on-road exposure concentrations in 11 Dutch cities over a 3-month period (using a consistent methodology) and report coefficients of variability for UFP and $\mathrm{PM}_{2.5}$ of 0.22 and 0.86 among cities. For comparison, the coefficients of variability for UFP and $\mathrm{PM}_{2.5}$ among studies in Table 1 are 0.64 and 0.76 .

\section{BICYCLISTS' AIR POLLUTION INTAKE}

The mass of air pollutants that cross the body boundary through the mouth and nose is the intake dose (Ott et al. 2007). Estimates of intake dose rates per unit time combine exposure concentrations with a respiration rate; intake dose rates per unit distance also take travel duration into account (as does total intake dose over a journey). Some studies consider only duration (not respiration) by estimating cumulative exposure, such as (Nwokoro et al. 2012, Ragettli et al. 2013). Measurement and analysis of bicyclists' pollutant intake facilitates a transition toward a dose-oriented estimation of health effects.

\subsection{Respiration}

Respiration rate is commonly expressed as the minute respiratory volume (or minute ventilation, $\dot{V}_{E}$ ) - which is the volume of air displaced per minute. Minute respiratory volume is the product of the tidal volume $V_{T}$ and the breathing frequency $f_{r}$ 
(breaths per minute). Tidal volume $V_{T}$ is the volume of air displaced in a single breath; typical ranges are 1.4 to 2.2 liters $(\mathrm{L})$ for bicyclists and 0.6 to $0.8 \mathrm{~L}$ for persons at rest or in a car (Int Panis et al. 2010). Multiplying $V_{E}$ by the average exposure concentration yields the average pollutant inhalation rate in mass per unit time.

Table 2 summarizes published traveling bicyclists' respiration parameters (see Appendix $\mathrm{C}$ for a description of the measurement methods). Minute ventilation has been reported as 22 to $59 \mathrm{~L} / \mathrm{min}$ for bicyclists: 2 to 5 times higher than for travelers in automobiles or at rest. Bernmark et al. (2006) found $V_{E}$ peaks for bicycle messengers of up to $97 \mathrm{~L} / \mathrm{min}$. The ranges of minute ventilations in Table 2 are related to the different average travel speeds and heart rates among the studies (included in Table 2), as well as potentially other experimental differences such as terrain, bicycle weight and condition, weather, and subject fitness. Greater exertion increases $\dot{V}_{E}$ primarily by an increase in $V_{T}$ at lower levels of exercise and by an increase in $f_{r}$ at higher levels of exercise; $f_{r}$ is the dominant factor at 70-80\% of peak exercise level (Weisman 2003). Trained professional bicyclists can achieve a greater increase in $V_{E}$ through increases in $V_{T}$ than recreational bicyclists (Faria et al. 2005a).

For active travelers such as bicyclists, $\dot{V}_{E}$ will be a function of travel characteristics that determine power requirements. The major determinants of power output during bicycling are energy losses (resistance) and changes in kinetic and potential energy (acceleration and grades, respectively). The largest energy losses are typically aerodynamic drag followed by rolling resistance. Rolling resistance becomes a more important factor at lower speeds and in still air, when drag is less severe (Whitt 1971, di 
Prampero et al. 1979, Martin et al. 1998, Olds 2001, Wilson 2004, Faria et al. 2005b).

Nadeau et al. (2006) measured $\dot{V}_{E}$ of around 12, 23, and $35 \mathrm{~L} / \mathrm{min}$ for bicycle ergometer workloads of 0,50 , and $100 \mathrm{~W}$, respectively - suggesting that the subjects in the studies in Table 2 experienced workloads ranging from around $50 \mathrm{~W}$ to well over $100 \mathrm{~W}$ of power.

Table 2. Respiration-related parameters measured for bicyclists

\begin{tabular}{|c|c|c|c|c|c|c|c|}
\hline Group & $\begin{array}{c}\text { Minute } \\
\text { ventilation, } \\
\dot{V}_{E}(\mathrm{~L} / \mathrm{min})\end{array}$ & $\begin{array}{c}\text { Tidal } \\
\text { volume } \\
(\mathrm{L})\end{array}$ & $\begin{array}{c}\text { Breathing } \\
\text { frequency } \\
\left(\mathrm{min}^{-1}\right)\end{array}$ & $\begin{array}{l}\text { Heart } \\
\text { rate } \\
(\mathrm{bpm})\end{array}$ & $\begin{array}{l}\text { Speed } \\
(\mathrm{kph})\end{array}$ & $\begin{array}{c}\text { Ratio of } \\
\text { bicycle/car } \dot{V}_{E}{ }^{1}\end{array}$ & $\begin{array}{c}\text { Reference \& } \\
\text { Method }^{2}\end{array}$ \\
\hline \multirow{2}{*}{ All } & 23.5 & & & 100 & 12 & 2.0 & 1, estimated \\
\hline & 28.7 & & & & 13.5 & 2.5 & 2 , on-road \\
\hline \multirow{10}{*}{ Male } & 22 & & & 94 & 12 & 1.8 & 1, estimated \\
\hline & 22.7 & & & & 14 & 1.9 & 3, on-road \\
\hline & 25 & 1.25 & 20 & & 8 & 2.1 & 4, lab \\
\hline & 28 & & & & & 2.3 & $5, \mathrm{lab}$ \\
\hline & 31 & & & 107 & & 2.6 & 6 , estimated \\
\hline & 31.4 & & & & 19.5 & 2.6 & 3 , on-road \\
\hline & 44.2 & & & 138 & 20 & 3.7 & 7, estimated \\
\hline & 50 & 1.92 & 26 & & 19 & 4.2 & $4, \mathrm{lab}$ \\
\hline & 51.2 & & & & 24 & 4.3 & 3 , on-road \\
\hline & 59.1 & 2.2 & 27.9 & 129.6 & 20.5 & 4.9 & 8 , on-road \\
\hline \multirow{5}{*}{ Female } & 22.6 & & & & 14 & 2.1 & 3 , on-road \\
\hline & 27.6 & & & 116 & 12 & 2.5 & 1, estimated \\
\hline & 32.8 & & & & 19.5 & 3.0 & 3 , on-road \\
\hline & 46.2 & 1.4 & 32.7 & 140 & 19.5 & 4.2 & 8 , on-road \\
\hline & 51.8 & & & & 24 & 4.7 & 3 , on-road \\
\hline
\end{tabular}

Blank cells are not reported

${ }^{1}$ Reference minute ventilation for car drivers of $12 \mathrm{~L} / \mathrm{min}$ for Males, $11 \mathrm{~L} / \mathrm{min}$ for Females, and $11.5 \mathrm{~L} / \mathrm{min}$ for All, based on (Adams 1993, van Wijnen et al. 1995, O'Donoghue et al. 2007, Zuurbier et al. 2009, Int Panis et al. 2010)

${ }^{2}$ References: 1 (Zuurbier et al. 2009), 2 (van Wijnen et al. 1995), 3 (Adams 1993), 4 (McNabola et al. 2007), 5 (O’Donoghue et al. 2007), 6 (Bernmark et al. 2006), 7 (Cole-Hunter et al. 2012), 8 (Int Panis et al. 2010)

Methodologies are categorized as: "on-road" (direct on-road measurement of respiration using masks), "lab" (laboratory ergometer-based respiration measurements), and "estimated" (on-road measurement of heart rate and estimation of respiration using laboratory ergometer-based heart rate/ventilation relationships) 
Compilations of physical activity data often use MET units to compare energy expenditure with a standardized unit; a MET is defined as MET $=\frac{\dot{e}}{\mathrm{RMR}}$ where $\dot{e}$ is the rate of metabolic energy production and RMR is the resting metabolic rate (U.S.

Environmental Protection Agency 2009, Ainsworth et al. 2011a, 2011b). RMR is an individual-specific value (varying across individuals), often assumed to be $3.5 \mathrm{ml}-\mathrm{O}_{2} / \mathrm{min}$ per $\mathrm{kg}$ body mass - i.e. MET $=\frac{\dot{e}}{K \cdot m}$, where $K$ is a constant and $m$ is body mass. Thus, MET values are directly proportional to energy expenditure for an individual and inversely proportional to an individual's body mass for a given energy expenditure ${ }^{8}$.

Resting activities are at a MET of 1, while "general" bicycling is at a MET of 7.5 and bicycling "to/from work, self selected pace" is at MET 6.8 in the "Compendium of Physical Activities" (Ainsworth et al. 2011a, 2011b). The Compendium lists 16 different types of bicycling as activities with energy expenditures ranging from 3.5 MET for "leisure" bicycling at $5.5 \mathrm{mph}$ to $16 \mathrm{MET}$ for competitive mountain bicycle racing. Nonsport bicycling has been estimated to require 3.5 to 9 MET of energy expenditure, with power output of roughly 50 to $150 \mathrm{~W}$, depending on the speed (Whitt 1971, Bernmark et al. 2006, de Geus et al. 2007). MET values have been employed to estimate bicyclists' respiration for pollution dose assessments using both reference MET values and MET values estimated from accelerometer measurements; average accelerometer-based MET

\footnotetext{
${ }^{8}$ It should be noted that metabolic energy expenditure during bicycling is the sum of energy expenditure for baseline functions and the rate of external work (Olds 2001). Assuming that the baseline energy expenditure is roughly equal to the RMR, the MET can be expressed as a function of external power output $p$ as MET $=1+\frac{p}{R M R}$. Thus, MET values increase linearly (but not proportionally) with the external power demands of bicycling.
} 
for bicycling was estimated at 6.58 with a corresponding ventilation rate of $41 \mathrm{~L} / \mathrm{min}$ (de Nazelle et al. 2012). Respiration was estimated from MET values using stochastic relationships between oxygen uptake rates and ventilation rates along with the individuals' body mass (Johnson 2002, de Nazelle et al. 2009).

\subsection{Studies of Bicyclists' Pollution Intake}

Table 3 characterizes published studies of bicyclists' air pollution exposure, intake, uptake, or biomarkers that use spatially-explicit exposure concentration data (modeled or measured). Studies are categorized according to how (and whether) they account for 1) respiration (i.e. intake), 2) uptake of gases or deposition of particles, and 3) health biomarkers. The last two dimensions are discussed in Sections 5 and 6, respectively. "Constant" respiration refers to studies that apply fixed respiration rates by mode or individual; "variable" respiration refers to studies that use varying respiration rates by trip or at a greater level of detail. The categorization in Table 3 proceeds roughly from least to most comprehensive (A to $\mathrm{M}$ ) in terms of targeting farther along the exposure-health pathway, assessing linkages more directly (e.g. measuring versus assuming), and/or examining more intermediate steps between exposure and uptake or biomarkers. 


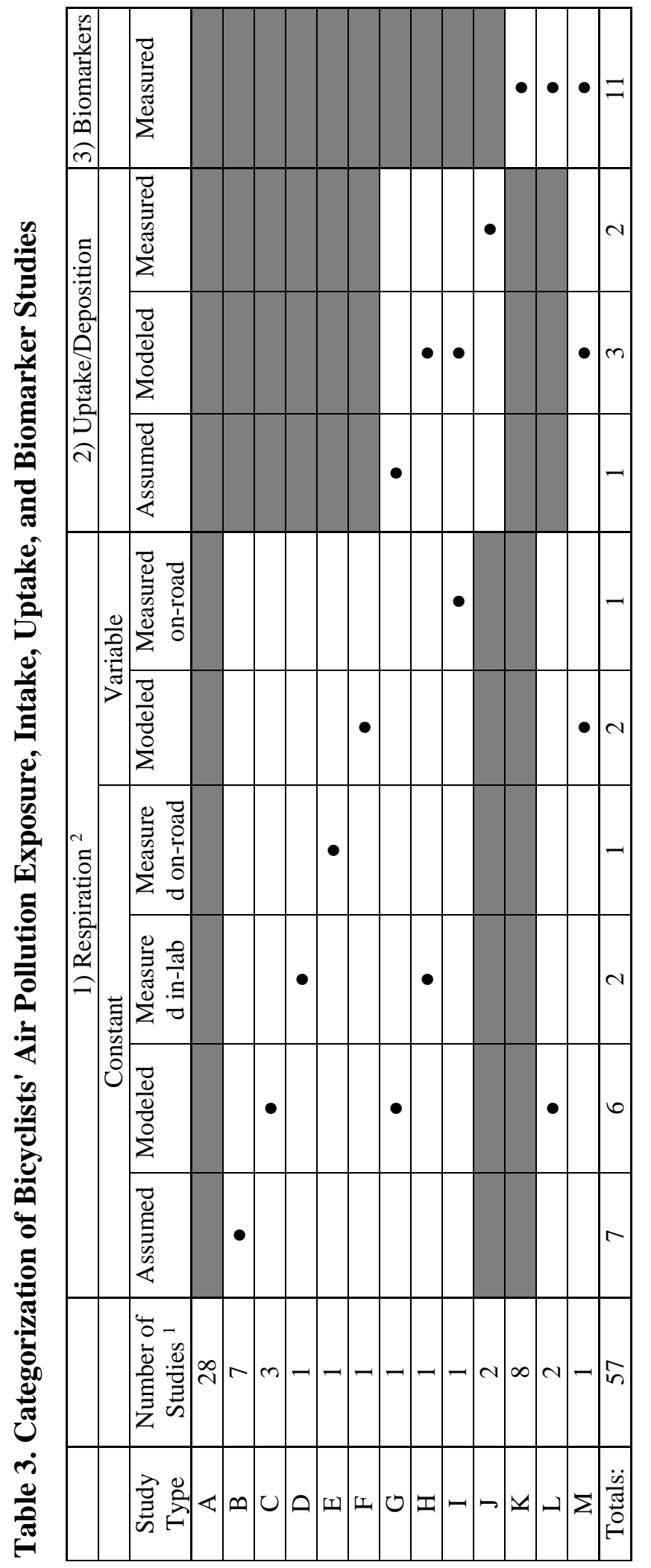

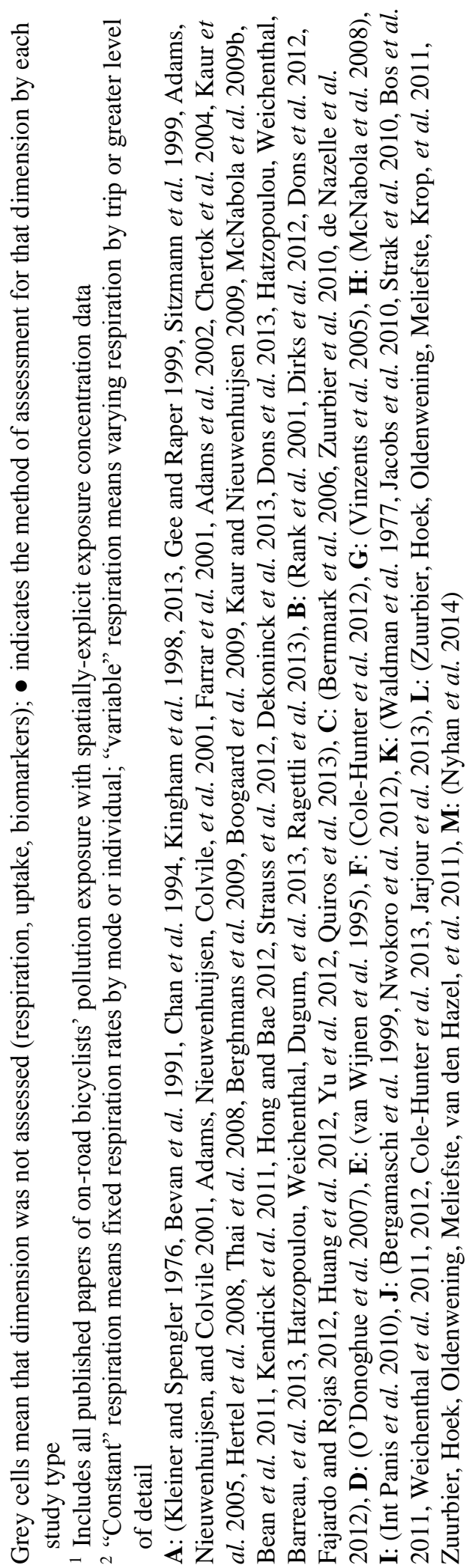


Many studies consider only exposure concentrations and neglect the question of intake dose and the issue of varying respiration and energy expenditure by travel mode and condition (Type A). Similarly, some studies measure exposure concentrations and uptake doses or health biomarkers directly, but do not address the intermediate step of intake or respiration (Types $\mathrm{J}$ and $\mathrm{K}$ ). Of the 19 studies in Table 3 that explicitly consider respiration, 16 use fixed values of $V_{E}$ for each travel mode or individual (Types B-E, G, $\mathrm{H}$, and L). Type B studies (7 of the 19) apply an assumed $V_{E}$ for bicyclists based on other published research. Two studies (Types D and $\mathrm{H}$ ) use bicycle ergometers in a laboratory to determine representative respiration values by mode. Of the 8 studies that model respiration (Types C, F, G, L, and M), 6 use ergometers to develop individual subject functions to estimate on-road $V_{E}$ from field-measured $\mathrm{HR}, 1$ uses previously-developed $V_{E}$-HR functions with field-measured $\mathrm{HR}, 1$ estimates respiration from accelerometerbased MET values - see Section 4.1. Only 2 of these 8 studies (Types F and M) estimate intake using variable ventilation rates by trip (Cole-Hunter et al. 2012) or at 2-minute aggregations (Nyhan et al. 2014).

Two studies in Table 3 directly measure on-road bicyclists' minute ventilation in order to estimate intake dose (Types E and I). Van Wijnen et al. (1995) use fixed modespecific respiration rates that are the averages of measured on-road minute ventilation for a set of test subjects traveling on the same test routes as the concentration measurements, but at different times. Int Panis et al. (2010) use simultaneously monitored on-road respiration and concentration data to estimate intake dose. Combining tidal volume and pollutant concentration measurements, Int Panis et al. calculate breath-by-breath mass 
intake and sum over trips, thus including both respiration and duration effects on total intake.

Table 3 shows that there has been little assessment of the variability of bicyclists' respiration as they travel in an urban environment. If the variability in respiration is independent of exposure concentrations, then representative averages for each will suffice (assuming linearity). But there is likely to be spatial correlation between pollutant concentrations and bicyclist energy expenditure at locations such as intersections and hills, where both motor vehicles and bicyclists are required to generate more energy. There is also a potential correlation between exposure duration and exposure concentration at congested bottlenecks or busy intersections. At the route level, ColeHunter et al. (2013) found no significant differences in measured HR for routes with low and high proximity to traffic; they conclude that variability in UFP intake dose for bicyclists would be predominantly determined by exposure concentrations, not ventilation characteristics. But a wide range of bicyclists' respiration values have been reported (Section 4.1), and the lack of bicyclist intake dose studies considering variable respiration rates leaves the question open.

\subsection{Modal Comparisons of Pollution Intake}

Int Panis (2010) argues that comparisons of exposure concentrations by travel mode (as in Section 0) are "not entirely relevant" because of the dominating effect of breathing differences among modes. Modal comparisons of pollution intake dose go beyond exposure concentrations by including respiration to compare intake dose rates per unit time. More detailed comparisons also consider the intake effects of travel duration 
differences, assessing intake doses per trip or unit travel distance. For faster trips, the time spent in an alternative environment is typically neglected; this aspect may be important when the air quality at the trip destination is poor. Inherent speed differences by mode are problematic for modal comparisons of intake rates by either normalization.

Table 4 summarizes the 12 published modal comparisons that include respiration, showing the median and range for ratios of bicycle to alternative mode intake or uptake doses. Dose ratios are presented separately for the 8 studies that compare doses per unit distance and the 5 studies that compare doses per unit time (1 assesses both). For most pollutants, studies that compare doses per unit distance find greater bicycle/car dose ratios than comparisons per unit time, as expected from bicyclists' lower travel speeds. This body of literature is still much smaller than modal comparisons of exposure, but for the most part 2 to 5 times higher ventilation rates and slower travel speeds for bicyclists compared to motor vehicle passengers outweigh any beneficial exposure concentration differences. Bicyclists' doses are less consistent when compared to pedestrians, which is not surprising because walking is another active travel mode with elevated respiration. Pedestrians typically have lower respiration rates (McNabola et al. 2007) but also lower speeds, with counteracting effects on intake rates per unit distance. 
Table 4. Ratios of intake or uptake doses for bicyclists versus other modes

\begin{tabular}{|c|c|c|c|c|c|}
\hline & \multirow[b]{2}{*}{$\begin{array}{l}\text { Alternative } \\
\text { Mode }\end{array}$} & \multicolumn{2}{|c|}{ Per unit distance ${ }^{1}$} & \multicolumn{2}{|c|}{ Per unit time } \\
\hline & & $\mathrm{N}^{2}$ & Median (Range) & $\mathrm{N}$ & Median (Range) \\
\hline \multirow{4}{*}{$\mathrm{CO}$} & Pedestrian & 1 & 0.80 & 0 & \\
\hline & Car/Taxi & 3 & $\begin{array}{l}1.09(0.36-4.67) \\
\end{array}$ & 1 & 0.87 \\
\hline & Bus & 3 & $1.63(1.07-4.67)$ & 0 & \\
\hline & Rail & 1 & 7.00 & 0 & \\
\hline \multirow{3}{*}{ VOC $^{3}$} & Pedestrian & 1 & 1.11 & 0 & \\
\hline & Car & 1 & 0.81 & 4 (2 studies) & $0.71(0.50-0.72)$ \\
\hline & Bus & 2 & $1.60(1.25-1.96)$ & 0 & \\
\hline $\mathrm{NO}_{2}$ & Car & 0 & & 1 & 3.08 \\
\hline \multirow{3}{*}{ UFP } & Pedestrian & 2 & $0.68(0.51-0.84)$ & 0 & \\
\hline & Car & 3 & $5.42(1.00-10.42)$ & 1 & 2.09 \\
\hline & Bus & 1 & 1.90 & 1 & 1.87 \\
\hline \multirow{4}{*}{$\mathrm{PM}_{2.5}$} & Pedestrian & 4 & $1.13(0.47-1.97)$ & 1 & 2.09 \\
\hline & Car/Taxi & 5 & $3.36(1.38-10.88)$ & 1 & 1.70 \\
\hline & Bus & 4 & $1.77(1.06-4.78)$ & 2 & $3.14(1.91-4.36)$ \\
\hline & Rail & 1 & 2.56 & 1 & 2.29 \\
\hline \multirow{4}{*}{$\mathrm{PM}_{10}$} & Pedestrian & 1 & 1.62 & 1 & 1.82 \\
\hline & Car & 1 & 6.75 & 1 & 1.66 \\
\hline & Bus & 1 & 3.21 & 2 & $2.13(1.15-3.10)$ \\
\hline & Rail & 1 & 3.06 & 1 & 2.21 \\
\hline \multirow{3}{*}{$\mathrm{BC}$} & Pedestrian & 1 & 0.81 & 0 & \\
\hline & Car & 1 & 0.84 & 2 & $1.90(1.36-2.44)$ \\
\hline & Bus & 1 & 1.64 & 1 & 1.51 \\
\hline
\end{tabular}

1 Values are ratios of bicycle to alternative mode doses in mass, particles, or ppb per unit distance (i.e. per $\mathrm{km}$ or per trip) or per unit time (i.e. per hour of travel); the table includes all studies that directly compare pollutant intake or uptake between travelers by bicycle and other modes for similar trips.

2 A single mean value (weighted by number of samples) was computed for studies reporting separate results by routes or times of day. VOC doses per unit time are from 2 studies, with one reporting 3 different compounds.

${ }^{3}$ Only reported values for BTEX compounds are included.

Sources, per unit distance: CO: (de Nazelle et al. 2012, Dirks et al. 2012, Huang et al. 2012), VOC: (O’Donoghue et al. 2007, McNabola et al. 2008), UFP: (Int Panis et al. 2010, de Nazelle et al. 2012, Quiros et al. 2013), PM2.5: (McNabola et al. 2008, Int Panis et al. 2010, de Nazelle et al. 2012, Huang et al. 2012, Quiros et al. 2013, Nyhan et al. 2014), PM10: (Int Panis et al. 2010, Nyhan et al. 2014), BC: (de Nazelle et al. 2012)

Sources, per unit time: CO: (van Wijnen et al. 1995), VOC: (van Wijnen et al. 1995, Rank et al. 2001), NO2: (van Wijnen et al. 1995), UFP: (Zuurbier et al. 2010), PM2.5: (Zuurbier et al. 2010, Nyhan et al. 2014), PM10: (Zuurbier et al. 2010, Nyhan et al. 2014), BC: (Zuurbier et al. 2010, Dons et al. 2012)

Few of the modal comparisons of dose directly measure on-road respiration or model respiration as a function of travel characteristics beyond mode. This is important 
because travel attributes such as road grade and speed affect respiration and inhalation rates for bicyclists but not motorized modes. Intake doses per trip will be further affected by duration changes with route and destination choices, which are normally not varied in modal comparisons (as discussed in Section 0). Furthermore, active travelers tend to have unique demographics (Plaut 2005), which could systematically impact respiration through physiological attributes such as sex and health condition (Adams 1993).

\section{BICYCLISTS' AIR POLLUTION UPTAKE}

A portion of inhaled pollutants are either absorbed (gases) or deposited (particles) onto the lining of the respiratory tract or into the bloodstream. Absorbed/deposited pollutants are then either expelled (through mucociliary clearance or desorption) or transported to body tissues. The air pollution uptake dose is the amount of pollutant that is not exhaled or expelled, but rather incorporated into the body (Figure 1 in the Introduction, Chapter 1).

Table 5 summarizes the factors that are expected to increase pollutant uptake for bicyclists. The first two factors reflect the exposure in terms of concentration and duration. The next set of factors in Table 5 is attributes of the pollutants that determine uptake dose (independent of travel characteristics). Particle size is important for PM uptake because deposition and clearance rates vary with particle size. UFP deposition is also influenced by the particles' growth characteristics in high humidity conditions such as in lung airways (hygroscopicity). Gas reactivity and solubility in blood and lipids are similarly important because they affect absorption and diffusion rates (International 
Commission on Radiological Protection [ICRP], 1994, Daigle et al. 2003, Löndahl et al. 2007, Ott et al. 2007, McNabola et al. 2008, West 2012).

Table 5. Factors that increase pollutant uptake

\begin{tabular}{ll}
\hline Factor & Increased uptake with: \\
\hline $\begin{array}{l}\text { Exposure } \\
\text { Concentration } \\
\text { Duration }\end{array}$ & $\begin{array}{l}\text { Higher concentrations } \\
\text { Longer duration }\end{array}$ \\
\hline $\begin{array}{l}\text { Pollutant } \\
\text { Particle size }\end{array}$ & $\begin{array}{l}\text { Smaller particles } \\
\text { Particle hygroscopicity }\end{array}$ \\
Gas solubility & More hydrophobic particles \\
Respiration/physiology & More blood- and lipid-soluble compounds \\
Breath volume flow rate $\left(V_{E}\right)$ & Greater ventilation \\
Depth of breathing $\left(V_{T}\right)$ & Greater tidal volume \\
Path of breathing & Oral breathing \\
Cardiac output (lung perfusion) & Greater perfusion \\
Metabolic rate & Higher metabolic rate \\
\hline
\end{tabular}

Table 5 also summarizes the physiology and respiration factors that influence uptake. Intake dose is determined by $\dot{V}_{E}$ and the exposure concentration; uptake dose is further influenced by the depth of respiration $\left(V_{T}\right)$ and the amount of oral breathing. Greater uptake fractions of inhaled PM occur during deeper and more oral breathing (ICRP, 1994), which are associated with higher levels of exertion (Samet et al. 1993, Weisman 2003). Daigle et al. (2003) found that when subjects' $\dot{V}_{E}$ increased from 11.5 to 38.1 L/min the deposition fraction (DF), the portion of particles that are not exhaled after inhalation, increased from 0.66 to 0.83 by number of particles and from 0.58 to 0.76 by mass of particles. Thus, a $\dot{V}_{E}$ increase by a factor of 3.3 led to a total deposition increase by a factor of 4.5 due to a higher DF. Löndahl et al. (2007) found only small changes in DF for UFP (by less than 0.03) during exercise when compared to rest $\left(\dot{V}_{E}\right.$ of 33.9 versus 
7.8 $\mathrm{L} / \mathrm{min}$ ), but both of these studies found that established models under-predicted deposition of UFP - especially during exercise.

Uptake rates for gaseous pollutants are also affected by the characteristics of the gas and the level of physical exertion. VOC and $\mathrm{CO}$ uptake rates are several times greater during exercise than at rest for a given exposure concentration. But the uptake fraction of inhaled gases tends to decrease with exertion level because gas uptake rates increase more slowly than intake rates with exercise. (Filley et al. 1954, Astrand et al. 1978, Astrand 1985, Pezzagno et al. 1988, Nadeau et al. 2006). Diffusion-limited gases such as $\mathrm{CO}$ are primarily impacted by the diffusing capacity of the lungs, which can increase by a factor of three during exercise (West 2012). Uptake rates for perfusion-limited gases such as low-solubility $\mathrm{VOC}$ and $\mathrm{NO}_{2}$ increase with ventilation and perfusion of the lungs, gas partial pressure differences between blood and air, and gas solubility in blood (Farhi 1967, Astrand 1985, Csanády and Filser 2001, West 2012). As blood concentrations approach equilibrium with inspired air, the uptake rate will fall to the steady-state rate of metabolic clearance (Wallace et al. 1993, Csanády and Filser 2001). Although exercise increases ventilation and perfusion, it also can decrease the rate at which pollutants are metabolized by reducing blood flow to the liver - reducing the steady-state uptake rate while simultaneously increasing blood concentrations (Astrand 1985, Kumagai and Matsunaga 2000, Csanády and Filser 2001, Nadeau et al. 2006).

Detailed uptake models allow estimation of different locations/tissues of pollutant uptake, which is relevant because of varying susceptibility to negative health effects from air pollution uptake by different tissues. Common uptake models include body 
compartment and physiologically based pharmacokinetic (PBPK) models for gases and human respiratory tract models for both gases and PM (Wallace et al. 1993, 1997, ICRP, 1994, Heinrich-Ramm et al. 2000, Ott et al. 2007, Hofmann 2011, King et al. 2011). Uptake models are generally validated using much steadier air concentrations than have been observed in on-road environments, so it is not clear how applicable they are for onroad uptake analysis with highly transient exposure concentrations.

Uptake of air pollutants by bicyclists has been studied less than exposure concentrations or intake doses ( 6 of the 57 studies in Table 3 explicitly consider uptake). Vinzents et al. (2005) conservatively estimate deposition as linearly proportional to workload (on average 43\% higher deposition of PM while bicycling than at rest). Int Panis et al. (2010) use DF that vary with $\dot{V}_{E}, V_{T}$, and particle size, based on two previous studies of particle deposition (Daigle et al. 2003, Chalupa et al. 2004). Although other factors in Table 5 were not explicitly modeled, these reference studies used physically active subjects and traffic exhaust particles. Intake doses of UFP were 4.2 to 6.6 times higher for bicyclists than car passengers, while uptake doses were 5.1 to 8.3 times higher - despite lower or roughly equivalent exposure concentrations for bicyclists. $\mathrm{PM}_{2.5}$ comparisons were similar, with intake doses 5.7 to 7.6 times higher for bicyclists than car passengers but uptake doses 8.0-12.0 times higher.

McNabola et al. (2008) modeled uptake of VOC and $\mathrm{PM}_{2.5}$ using the ICRP human respiratory tract model (ICRP, 1994) with on-road measured exposure concentrations and laboratory-measured respiration characteristics for bicycle, pedestrian, car, and bus modes. The ICRP model can include all relevant factors in Table 5 except lung perfusion, 
though the assumed fraction of oral breathing is not reported by McNabola et al.. Bicyclists had the highest total lung deposition of $\mathrm{PM}_{2.5}$ and the second-highest absorption of VOC over similar trips to other modes. Breathing characteristics (frequency, tidal volume) and VOC solubility affected the uptake dose and the location of absorption, with more benzene absorbed deep in the lungs for bicyclists and pedestrians. Breathing differences also affected benzene absorption more than 1,3-butadiene absorption because of benzene's lower solubility. McNabola et al. (2007) similarly model VOC uptake by bicyclists using different travel speeds, but with assumed (rather than measured) exposure concentrations. They found that higher bicycling speeds reduce VOC absorption over a fixed travel distance because the increase in respiration rate is smaller than the reduction in exposure duration.

The same ICRP model was also applied by Nyhan et al. (2014) to estimate $\mathrm{PM}_{2.5}$ and $\mathrm{PM}_{10}$ lung deposition for trips by bicycle, foot, bus, and train. Their estimates indicate that bicyclists' PM intake and uptake per trip is disproportionately higher than exposure concentrations compared to other modes. But the cross-mode ratios are equivalent for modeled intake and deposition, suggesting that only ventilation rate $V_{E}$ was varied by mode in the uptake model.

Bicyclists' uptake of traffic-related VOC was directly measured by sampling blood and urine concentrations of BTEX compounds (benzene, toluene, ethylbenzene, and xylenes) by Bergamaschi et al. (1999). They found significant increases of benzene and toluene in blood for bicyclists in urban areas, and significant increases of toluene and xylenes in urine. Although uptake was directly measured, respiration was not measured, 
and there was no discussion of pollutant intake or inhalation, which inhibits placement of their findings in the larger context of the emissions-health pathway (Figure 1 in the Introduction, Chapter 1). Nwokoro et al. (2012) directly measured uptake doses of BC by bicyclists and non-bicyclists (pedestrians and public transit riders) in London by sampling airway macrophages. They found significantly higher (63\%) doses of BC for bicyclists, correlated with higher commute exposure concentrations. Bicyclists also had almost twice as long commute durations, and experienced $41 \%$ of daily BC exposure during the commute (as compared to 19\% for non-bicyclists).

The few studies of bicyclists' pollution uptake suggest that PM uptake doses are disproportionally greater for bicyclists than intake doses or exposure concentrations when compared to other modes. Bicyclists' uptake doses of gaseous pollutants are also disproportionately higher than exposure concentrations when compared to other modes, but have yet to be directly compared to intake doses. Uptake dose is the closest measure of health risks for exposed travelers, but connections to health outcomes still require application of a dose-response function that reflects the toxicity of the pollutants, the susceptibility of the travelers and other factors (ICRP, 1994, Cho et al. 2009).

\section{HEALTH EFFECTS OF BICYCLISTS' AIR POLLUTION UPTAKE}

Linkages between long-term exposure to traffic-related air pollution and health impacts have been established, as described elsewhere (Pope and Dockery 2006, Brugge et al. 2007, Samet 2007, Brook et al. 2010, Health Effects Institute 2010, Nawrot, Vos, et al. 2011, Bell 2012). Long-term health effects studies show elevated risk for development of asthma, reduced lung function, increased blood pressure, and cardiac and pulmonary 
mortality. An important gap for traveler health studies, though, is a lack of data on the health effects of chronic high-intensity but short-duration doses (Zuurbier, Hoek, Oldenwening, Meliefste, Krop, et al. 2011, Gunatilaka et al. 2014). Some evidence exists of effects on mortality and cardiovascular/pulmonary hospital admissions for short-term exposure to traffic-related air pollution in general, and particularly PM and UFP (Michaels and Kleinman 2000, Peters et al. 2004, McCreanor et al. 2007, Knibbs et al. 2011). A recent study indicates increased risk of acute myocardial infarction onset after travel specifically for bicyclists - though the risk is not higher than for other modes (Peters et al. 2013).

Health effects studies of bicyclists' exposure to air pollution have focused on respiratory and cardiovascular effect biomarkers following acute (0.5-2 hour) exposures to traffic (11 studies of Types K-M in Table 3). Biomarkers are physiological indicators in the pathway of the morbidity and mortality outcomes studied in epidemiology; for example, blood cell counts can be indicators of systemic inflammation, and systemic inflammation is linked to cardiovascular disease (Brook et al. 2010). Unfortunately, even when acute health effects are recognized in the form of biomarkers, the broader health significance is often not known - especially in the context of chronic daily exposures.

Studies of bicyclists' biomarkers show inconsistent results, with 4 of 11 reporting insignificant acute effects and others reporting some cardiovascular or respiratory biomarker changes. No significant changes in bicyclists' respiratory or cardiovascular biomarkers were reported in four studies of acute on-road exposure (Waldman et al. 1977, Zuurbier, Hoek, Oldenwening, Meliefste, Krop, et al. 2011, Zuurbier, Hoek, 
Oldenwening, Meliefste, van den Hazel, et al. 2011, Jarjour et al. 2013). Jacobs et al. (2010) found a significant but small increase in a single indicator of blood inflammation for bicyclists, with "unclear" health implications. Cole-Hunter et al. (2013) found significant differences in nasal and throat irritation between bicyclists in high-exposure and low-exposure routes, but no significant differences for airway inflammation biomarkers. Strak et al. (2010) found mostly insignificant changes in respiratory function biomarkers for bicyclists, though UFP and soot exposure were weakly associated with a biomarker of airway inflammation (exhaled NO) and degraded lung function. Weichenthal et al. (2011) found significant associations between UFP, ozone $\left(\mathrm{O}_{3}\right)$, and $\mathrm{NO}_{2}$ exposures during travel and cardiovascular risk indicators (changes in heart rate variability), but no strong associations between in-traffic exposure and respiratory biomarkers. Further analysis of individual VOC in the data set found "evidence of possible associations ... for a small number of compounds" with biomarkers of lung inflammation, lung function, and heart rate variability (Weichenthal et al. 2012). Nyhan et al. (2014) found significant associations between decreased heart rate variability and $\mathrm{PM}_{2.5}$ and $\mathrm{PM}_{10}$ doses - stronger for bicyclists and pedestrians than other modes. Bos et al. (2011) took a different approach and found that PM exposure during bicycling can suppress a positive exercise-induced health biomarker associated with cognitive performance. Though again, the effects of chronic exposure are still unknown.

This review does not address the health impacts of bicycling-related crashes and physical activity, only air pollution uptake. However, a review of five recent health impact assessments for bicycling concludes that the physical activity benefits of bicycling 
far outweigh the crash safety and air pollution risks - by factors of 9 to 96 (Teschke, Reynolds, et al. 2012). The air pollution risks in these assessments are based on extrapolations of epidemiological evidence for long-term health outcomes, and limited by the continued uncertainty of health effects of chronic daily uptake of air pollution by physically active travelers.

\section{SUMMARY}

This is the first review to specifically address bicyclists' health risks from trafficrelated air pollution and to explicitly include intake and uptake doses in addition to exposure concentrations. Bicyclists' pollution exposure concentrations are highly variable, with median increases of up to $102 \%$ (for gaseous hydrocarbons) on high traffic versus low traffic routes. Bicyclists' relative exposure concentrations compared to other

modes are inconsistent, varying by pollutant, facility, route, and city. Bicyclists' exposure concentrations are most affected by wind and proximity to motor vehicle traffic, though few studies have incorporated detailed, concurrent traffic data.

Bicyclists' pollution intake doses tend to be higher than motorized modes due to their 2 to 5 times higher respiration rates. Bicyclists' respiration and intake dose increase with bicycle travel speed and exertion, but only 12 of the 57 studies with spatiallyexplicit bicyclist exposure concentration data include any measurement of respiration. Furthermore, only 3 of those studies consider variable bicyclist respiration rates, and there has been almost no assessment of the variability in respiration with trip characteristics (including correlation with exposure concentrations). 
Bicyclists' pollution uptake doses are affected by the intake dose, pollutant characteristics, breathing depth and pathway, and other individual and physiological factors. Uptake rates tend to increase with exertion level, affecting bicyclists more than motorized travelers. There are clear links between traffic-related air pollution exposure and negative health outcomes in urban populations. However, the health effects of chronic daily air pollution uptake by bicyclists are still unknown. More research is needed on health impacts of pollution exposure because some studies of bicyclists' biomarkers show significant acute respiratory effects while other studies show insignificant effects.

To reduce exposure concentrations, spatial and temporal separation of bicyclists from motor vehicle traffic can be achieved with separated bicycle facilities, low-volume routes, and off-peak travel. These are potential “win-win” strategies because bicyclists already prefer low-traffic routes and bicycle-specific facilities (Wardman et al. 2007, Dill 2009, Broach et al. 2012, Kang and Fricker 2013) and separated bicycle facilities could also improve safety (Reynolds et al. 2009, Lusk et al. 2011, Teschke, Harris, et al. 2012). Regarding intake doses, other likely mitigation strategies would be to prioritize separation from traffic in locations where bicyclists' respiration is expected to be high (steep grades, for example) or to reduce energy expenditure requirements (by reducing required stops, for example) in locations where pollutant concentrations are known to be high. 


\section{RESEARCH GAPS AND OPPORTUNITIES}

This literature review reveals steady progress towards a better understanding of air pollution uptake by bicyclists. However, several significant research gaps deserve attention. Although the literature suggests that traffic-related air pollution uptake is higher for bicyclists than for travelers using motorized modes, persistent uncertainty in the intensity and effects of pollution uptake means that transportation planners and decision makers are unable to consider bicyclists' air pollution risks in a precise way. More research is needed to provide better quantification and understanding of the relative health benefits of alternative bicycle facility designs, bicycle network designs, and route options. Some research topics that can bring us closer to achieving these goals include:

- Study of the on-road variability of respiration and air quality for traveling bicyclists, including a broader array of pollutants (e.g. ground-level ozone);

- The impact of bicycle trip attributes such as road grade, road surface, travel speed, and number of stops on respiration rates for bicyclists;

- The impacts of bicycle facility design features on exposure concentrations (distance from motor vehicle travel lanes, physical barriers, intersection treatments such as "bike boxes", etc.);

- The impacts of traffic flow characteristics on bicyclists' exposure concentrations, including traffic speeds, volumes, and queuing along arterials or at major intersections;

- Inter-modal pollution exposure comparisons that apply more comprehensive and representative modal travel characteristics (trip location and distance, traveler 
demographics, route preferences) and that consider variable respiration (especially for active travelers);

- Characterization of different bicyclist types (e.g. commuters, recreational riders) and demographic factors that can impact respiration or health effects; these factors include physiology (height, weight, respiratory health), riding style (speed, acceleration, response to grades), and equipment (weight, condition, baggage);

- Analysis of bicyclists' pollutant doses along different types of routes and facilities, to enable health impact assessments; and

- Development of dose-response functions for health effects of chronic shortduration high-intensity air pollution exposure episodes. 


\section{Chapter 3: Experiment and Methods}

\section{EXPERIMENT}

\subsection{Subjects}

Three subjects participated in the data collection; this was considered adequate because the primary focus of the study involved environmental covariates rather than inter-subject covariates. The subjects were recruited from the university student body. Approval for the research was obtained from Portland State University's Human Subjects Research Review Committee (HSRRC).

All subjects were nonsmokers who reported moderate regular physical activity and good respiratory health based on the American Thoracic Society respiratory disease questionnaire $^{1}$. The characteristics of subjects $\mathrm{A}, \mathrm{B}$, and $\mathrm{C}$ were (respectively): male, male, and female; age, 34, 28, and 45; bicycle weight (including all gear), 25, 22, and 23 $\mathrm{kg}$; and average post-ride body weight, 80, 70, and $75 \mathrm{~kg}$. Breathing zone heights in normal riding position for subjects $\mathrm{A}, \mathrm{B}$, and $\mathrm{C}$ were $1.6,1.5$, and $1.6 \mathrm{~m}$, respectively.

\subsection{On-road sampling}

On-road breath measurements were carried out in Portland, Oregon, USA on nine days in April through September, 2013. Subject A participated all nine days; subjects B and C participated two days each. All on-road data collection was performed near the morning peak travel period (7:00-10:00 hr). A pre-ride period of 30 minutes at a low-

\footnotetext{
${ }^{1}$ American Thoracic Society, 1979. "Recommended Respiratory Disease Questionnaires for Use with Adults and Children in Epidemiological Research."
} 
concentration starting location (a $0.8 \mathrm{~km}^{2}$ park) was used in an effort to pre-equilibrate blood concentrations with low background levels. A variety of roadway facilities were used, including off-street paths and mixed-use roadways ranging from local roads to major arterials. The subjects were instructed to adhere to safe riding practices, follow traffic laws, and ride at a pace and exertion level typical for utilitarian travel.

Prescribed riding sample segments were 7-9 km (20-40 min) and comprised homogenous facility types. Riding each day involved 2-5 segments, requiring 1.2-3.0 hours. Breath sampling routes are summarized in Table 6 . Routes were ridden by an individual (April through August routes) or by paired subjects (September routes). Uptake of VOCs was examined by collecting end-tidal breath samples before and after each segment. Time-averaged ambient VOC concentrations were measured for the full ride time of each segment.

Table 6. Summary of routes used in breath sampling

\begin{tabular}{|c|c|c|c|c|c|}
\hline Day & Segment 1 & Segment 2 & Segment 3 & Segment 4 & Segment 5 \\
\hline 2 April & $\begin{array}{l}\text { Mixed collectors } \\
\text { and arterials }\end{array}$ & $\begin{array}{l}\text { Mixed collectors } \\
\text { and arterials }\end{array}$ & NA & NA & NA \\
\hline 2 July & Local roads & $\begin{array}{l}\text { Major arterials } \\
\text { (primarily SE } \\
\text { Powell Blvd.) }\end{array}$ & $\begin{array}{l}\text { Major arterials } \\
\text { (Segment } 2 \text { in } \\
\text { reverse) }\end{array}$ & $\begin{array}{l}\text { Local roads } \\
\text { (Segment } 1 \text { in } \\
\text { reverse) }\end{array}$ & $\begin{array}{l}\text { Mixed local } \\
\text { roads and } \\
\text { collectors }\end{array}$ \\
\hline 9 July & \multicolumn{5}{|c|}{ Same as 2 July } \\
\hline 11 July & \multicolumn{5}{|c|}{ Same as 2 July } \\
\hline 22 Aug. & \multicolumn{5}{|c|}{ Same as 2 July, Segments 1-4 } \\
\hline 4 Sept. & $\begin{array}{l}\text { Local roads } \\
\text { (primarily SE } \\
\text { Ankeney St.) }\end{array}$ & $\begin{array}{l}\text { Minor arterial (E } \\
\text { Burnside St.) }\end{array}$ & $\begin{array}{l}\text { Minor arterial } \\
\text { (Segment } 2 \text { in } \\
\text { reverse) }\end{array}$ & $\begin{array}{l}\text { Local roads } \\
\text { (Segment } 1 \text { in } \\
\text { reverse) }\end{array}$ & $\begin{array}{l}\text { Mixed local } \\
\text { roads and } \\
\text { collectors }\end{array}$ \\
\hline 10 Sept. & \multicolumn{5}{|c|}{ Same as 4 September } \\
\hline 11 Sept. & $\begin{array}{l}\text { Mixed local } \\
\text { roads and } \\
\text { collectors }\end{array}$ & $\begin{array}{l}\text { Springwater off- } \\
\text { street path }\end{array}$ & $\begin{array}{l}\text { I-205 off-street } \\
\text { path (south } \\
\text { section) }\end{array}$ & Local roads & $\begin{array}{l}\text { Mixed local } \\
\text { roads and } \\
\text { collectors }\end{array}$ \\
\hline 12 Sept. & Local roads & $\begin{array}{l}\text { I-205 off-street } \\
\text { path (north } \\
\text { section) }\end{array}$ & $\begin{array}{l}\text { I-205 off-street } \\
\text { path (Segment } 2 \\
\text { in reverse) }\end{array}$ & $\begin{array}{l}\text { Local roads } \\
\text { (Segment } 1 \text { in } \\
\text { reverse) }\end{array}$ & $\begin{array}{l}\text { Mixed local } \\
\text { roads and } \\
\text { collectors }\end{array}$ \\
\hline
\end{tabular}


In the example route in Figure 4 (July routes in Table 6), the subject first spent 30 minutes at the relatively clean reference location (park). A breath sample was taken just before riding, and again at the end of segment 1 (low-volume local roads). The subject then rode segment 2 (high-volume arterials), and a breath sample was taken at the end. Segment 3 followed the reverse path of segment 2, and segment 4 followed the reverse path of segment 1; breath samples were collected at the end of each.

On-road location, physiology, and air quality data were collected on 4 additional days in Portland, Oregon, spanning October 2012 to September 2013. No samples of breath or ambient air were collected on these days for VOC analysis.

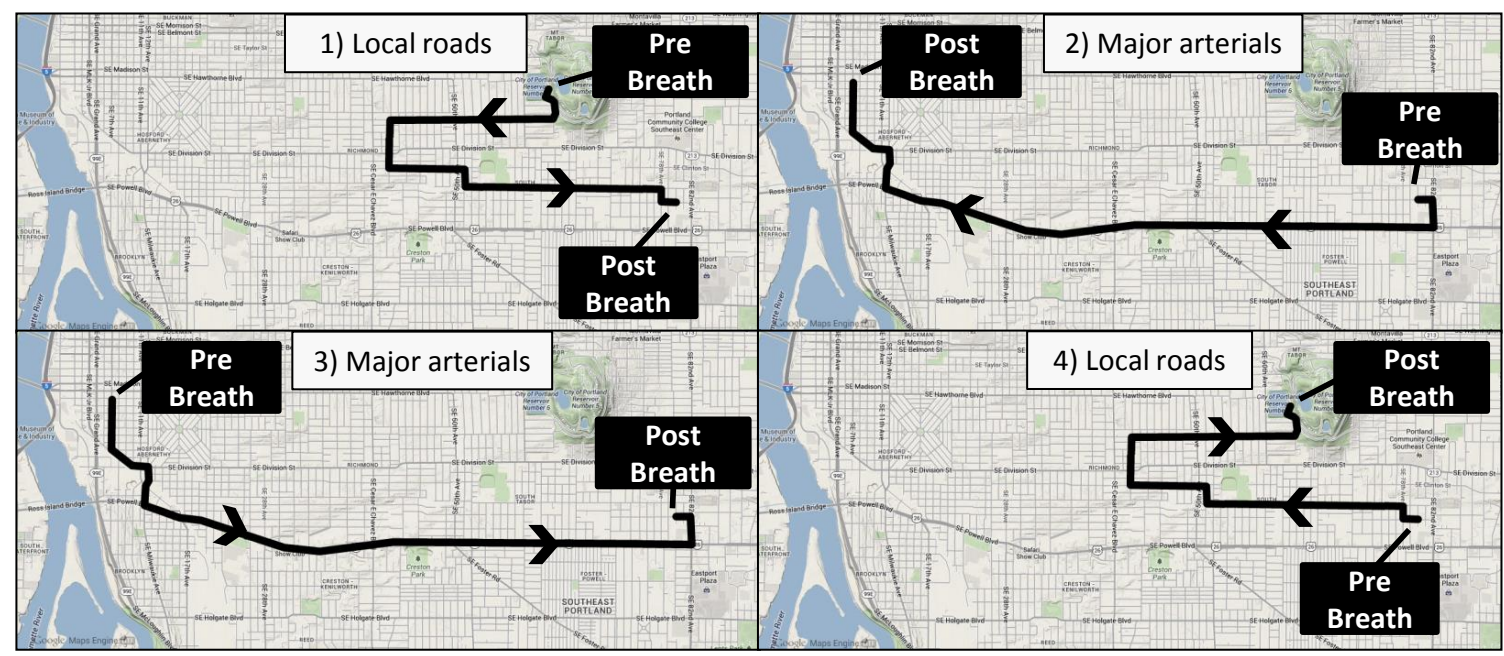

Figure 4. Example sampling route with 4 segments (map imagery courtesy Google Maps)

\subsection{Ergometer testing}

Physiological attributes of the subjects were assessed with a standard bicycle ergometer exercise test (Weisman 2003). Tests were conducted on bicycle ergometers (New Bike Exc 700, Technogym, Gambettola, Italy) on September 12, 2013. The protocol was 3-minute incremental workloads of $50 \mathrm{~W}$ from $0 \mathrm{~W}$ to volitional exhaustion 
- which was 350, 250, and $200 \mathrm{~W}$ for subjects A, B, and C, respectively. Self-selected cadences were around $70 \mathrm{rpm}$.

\section{INSTRUMENTATION}

\subsection{Location}

GPS receivers recorded $1 \mathrm{~Hz}$ location data. Redundant GPS devices and onbicycle video were used to cross-check the location data. The GPS devices included

- Droid RAZR M smartphone (Motorola, Chicago, Illinois), logged using the Google MyTracks application

- Citrus smartphone (Motorola, Chicago, Illinois), logged using the Google MyTracks application

- Joule GPS cycle computer (CycleOps, Madison, Wisconsin)

- Portland ACE custom multi-sensor device (Bigazzi 2013) with a GPS receiver (Fastrax UP501, u-blox, Thalwil, Switzerland)

\subsection{Meteorology}

Temperature and humidity were measured on-road with a HOBO U12 (Onset, Bourne, MA), logged at $1 \mathrm{~Hz}$. Wind data were retrieved from an Oregon Department of Environmental Quality monitoring station in the data collection area (Station SEL 10139). Wind data were scalar average wind speeds at five minute aggregation, measured by an anemometer at a height of $10 \mathrm{~m}$. 


\subsection{Air quality monitoring}

Several air quality instruments were mounted to the bicycles used in data collection (Figure 5). The air quality instruments were selected to be highly portable, precise, and provide near-continuous measurements.

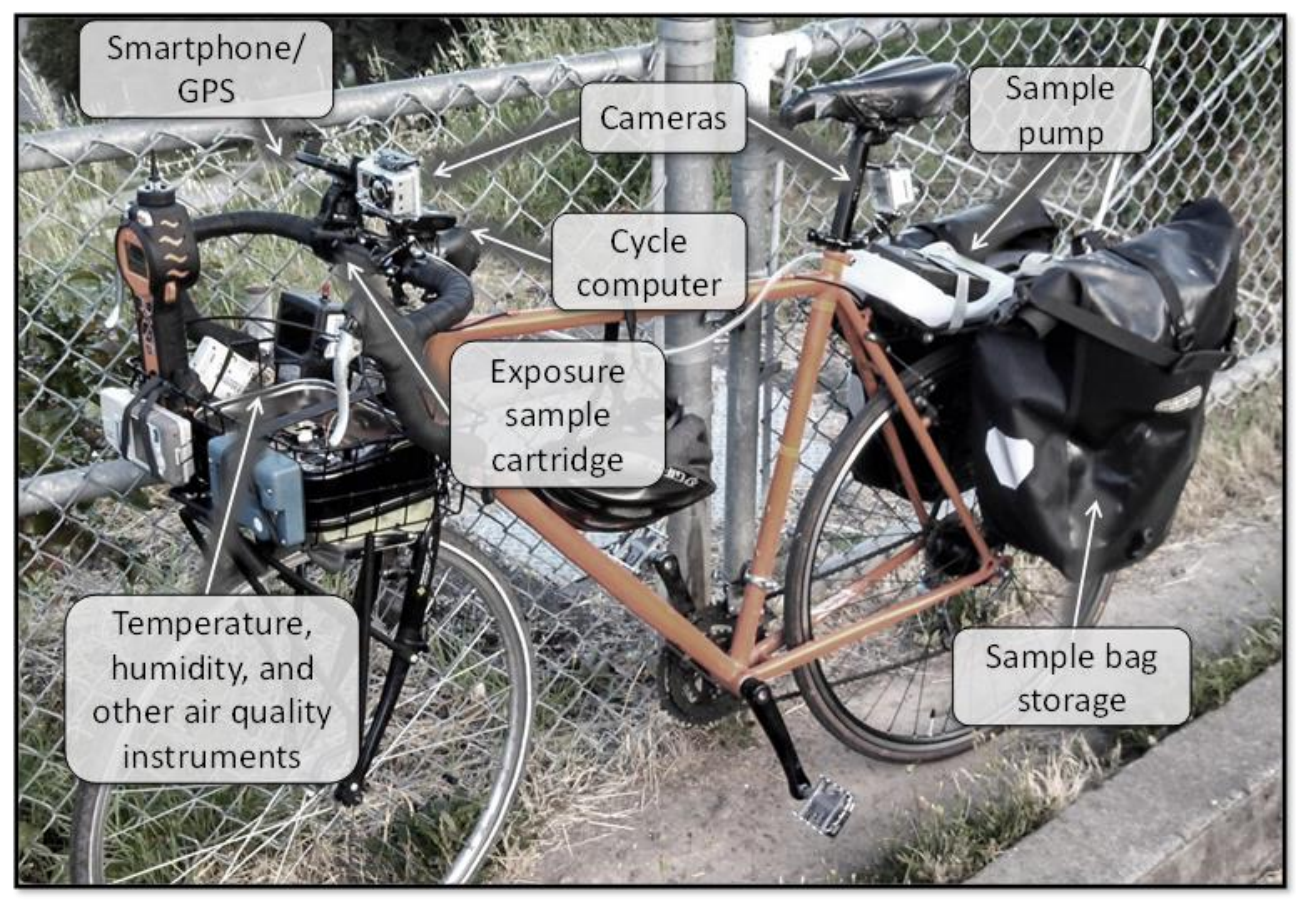

Figure 5. Instrumented bicycle

1 Carbon monoxide (CO): The T15n (Langan Products, San Francisco, California) uses an electrochemical sensor to measure $\mathrm{CO}$ concentrations at $1 \mathrm{~Hz}$, logged on an internal storage medium using the HOBO platform (OnSet). The Langan device has a range of 0 to $200 \mathrm{ppm}$, and a resolution of $0.05 \mathrm{ppm}$. It is commonly used for ambulatory CO measurements (Kaur et al. 2007). The Langan instrument used in data collection was calibrated on 2012-05-01; all data were collected within 24 months of calibration, in accordance with manufacturer instructions. 
2 Carbon dioxide $\left(\mathbf{C O}_{2}\right)$ : The Telaire 7001 (Telaire, Santa Barbara, California) uses an electrochemical sensor to measure $\mathrm{CO}_{2}$ concentrations at $1 \mathrm{~Hz}$, logged on an external HOBO data logger (Onset). The Telaire device has a range of 0 to $2500 \mathrm{ppm}$, and a resolution of $10 \mathrm{ppm}$. Although $\mathrm{CO}_{2}$ is not a pollutant of concern for human health, it can be a useful surrogate for traffic emissions because of the high $\mathrm{CO}_{2}$ content of exhaust streams (Bigazzi et al. 2010). The Telaire instrument used in data collection was calibrated on 2012-07-01; all data were collected within 5 years of calibration, in accordance with manufacturer instructions.

3 Particulate matter (PM): The P311 (Airy Technology, Orem, Utah) laser particle counter measures $\mathrm{PM}$ in 3 size categories: $\mathrm{PM}_{0.3}, \mathrm{PM}_{2.5}$, and $\mathrm{PM}_{5}$. The Airy has a range of up to 4 million particles per cubic foot and logs at 5 second intervals to an internal medium. The P311 instrument used in data collection was calibrated on 2012-05-28 and 2013-05-09; all data were collected within 12 months of calibration, in accordance with manufacturer instructions.

4 Total volatile organic compounds (TVOC): TVOC concentrations are measured using the PhoCheck Tiger (IonScience, Cambridge, UK). The Tiger measures TVOC using a photoionization detector (PID) with a $10.6 \mathrm{eV}$ lamp, which detects compounds with an ionization potential below $10.6 \mathrm{eV}$. Individual compounds within that range are not distinguished, and the reported concentrations are in isobutylene-equivalent units. The Tiger measures a TVOC concentration range of $1 \mathrm{ppb}$ to $20,000 \mathrm{ppm}$, with a resolution of $1 \mathrm{ppb}$. The Tiger is lightweight $(0.72$ $\mathrm{kg}$ ) and portable, capable of operating on battery power for over 4 hours while 
collecting $1 \mathrm{~Hz}$ measurements. Annual factory calibration and firmware updates keep the instrument accurate, in addition to re-calibration after every 100 hours of use. The instrument is zeroed with a carbon filter at the beginning of each collection. The Tiger is a new model of portable PID within the IonScience PhoCheck line, and so has not yet been used in published studies, to our knowledge. Earlier models of the PhoCheck were used for air quality studies in motor-vehicle environments (Li et al. 2006, Chien 2007, Atabi et al. 2013). The TVOC instrument used in data collection was calibrated on 2012-04-12 and 201305-15; all data were collected within 12 months and 100 operating hours of calibration, in accordance with manufacturer instructions.

\subsection{VOC/gas Sampling}

Ambient air was sampled through stainless steel adsorption/thermal desorption (ATD) cartridges (Tenax TA plus Carbotrap 1TD) as in Pankow et al. (2011). The pump used was from SKC (Eighty Four, PA), model PCXR8, set at 50 or $75 \mathrm{ml} \mathrm{min}^{-1}$ so as to collect a $\sim 2 \mathrm{~L}$ sample on each segment. The cartridges were attached to the handlebars (Figure 5) at a height of $1.02 \mathrm{~m}$. For paired riders, a single ambient sample was obtained for each segment. End-tidal breath samples were collected roadside using gas sample bags (3 L, FlexFilm ${ }^{\mathrm{TM}}$, SKC) with a mouthpiece (Figure 6). To avoid sampling "deadspace" respiratory air, only the second half of an exhaled breath was sampled (Boots $e t$ al. 2012). Breath sample volumes were 1.5 to $2.0 \mathrm{~L}$. 


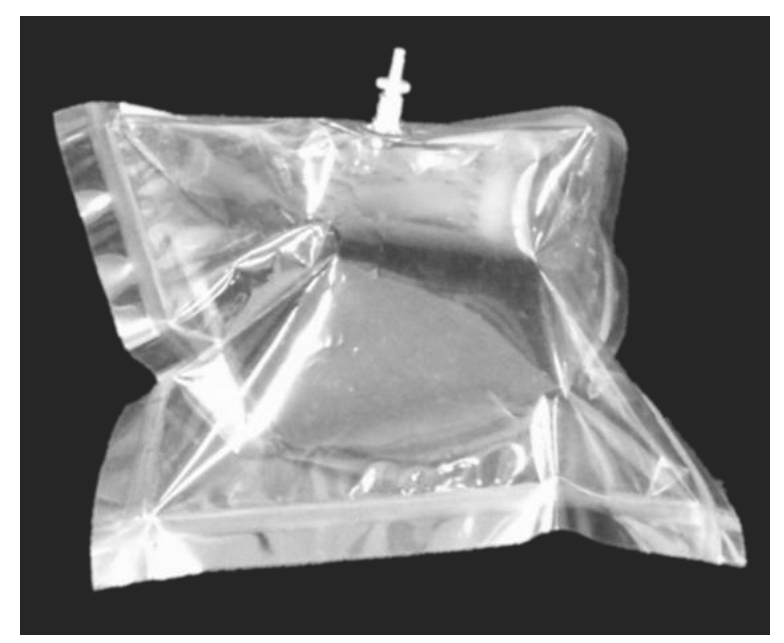

Figure 6. Breath Sampling Bag

At the end of each ride, the ATD cartridges used to sample ambient air and breath sample bags were immediately returned to the laboratory. The latter were processed using ATD cartridges. Each cartridge was thermally desorbed (TurboMatrix 650 ATD, Perkin Elmer, Waltham, MA) and analyzed for VOCs using an Agilent (Santa Clara, CA) 7890A gas chromatograph and 5975C mass spectrometer (see Pankow et al. (1998, 2003, 2004)). Every sample was analyzed on the day collected. Sample concentrations were determined for 75 target compounds, with corrections for travel and lab blanks. Other details are given in Table 7. 
Table 7. Gas analysis conditions

\begin{tabular}{l|l}
\hline Parameter & Value \\
\hline Cartridge desorption temperature & $280{ }^{\circ} \mathrm{C}$ \\
Cartridge desorption flow rate & $40 \mathrm{~mL} / \mathrm{min}$ \\
Cartridge desorption time & $10 \mathrm{~min}$ \\
Inlet split flow & $5 \mathrm{~mL} / \mathrm{min}$ \\
Secondary trap temperature & $-15^{\circ} \mathrm{C}$ \\
Secondary trap desorption & $295{ }^{\circ} \mathrm{C}$ \\
temperature & \\
Secondary trap desorption time & $3 \mathrm{~min}$ \\
Outlet split flow & $6 \mathrm{~mL} / \mathrm{min}$ \\
GC column & $\mathrm{DB}-\mathrm{VRX} 60 \mathrm{~m}, 0.25 \mathrm{~mm}$ id and $1.4 \mu \mathrm{m}$ film \\
& thickness \\
GC column flow & $\mathrm{Constant} \mathrm{head} \mathrm{pressure} \mathrm{of} 35 \mathrm{psi}$ \\
GC oven temperature program & $45^{\circ} \mathrm{C}$ for $10 \mathrm{~min}$, program to $190{ }^{\circ} \mathrm{C}$ at 12 \\
& ${ }^{\circ} \mathrm{C} / \mathrm{min}$, hold at $190^{\circ} \mathrm{C}$ for 2 min, then program to \\
GC transfer line temperature & $240{ }^{\circ} \mathrm{C}$ at $6{ }^{\circ} \mathrm{C} /$ min, hold at $240 \mathrm{~V}$ for $1 \mathrm{~min}$. \\
MS source temperature & $240{ }^{\circ} \mathrm{C}$ \\
MS quadrupole temperature & $250^{\circ} \mathrm{C}$ \\
Scam range & $150^{\circ} \mathrm{C}$ \\
EM voltage & $34-400$ amu \\
\hline
\end{tabular}

\subsection{Physiology}

Heart rate and breathing were measured by a physiology monitoring strap worn around the chest (BioHarness 3, Zephyr, Annapolis, MD) - see Figure 7. The Zephyr BioHarness $3^{2}$ is a relatively new commercial device for mobile physiological monitoring. Data are logged at $1 \mathrm{~Hz}$ and can also be streamed over Bluetooth to a paired device. A custom Android application was written to log the BioHarness data stream with simultaneous GPS data on a smartphone ${ }^{3}$.

\footnotetext{
${ }^{2}$ http://www.zephyranywhere.com/products/bioharness-3/

${ }^{3}$ See http://alexbigazzi.com/PortlandAce
} 


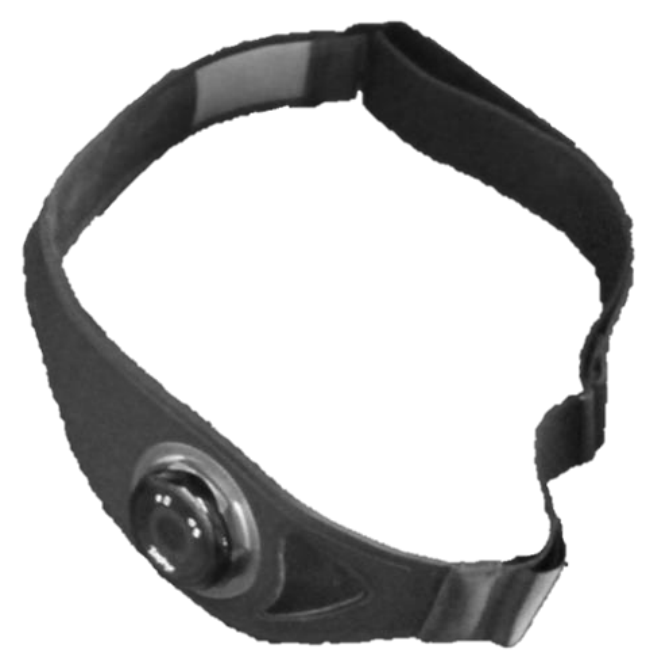

\section{Figure 7. BioHarness Physiology Monitor}

The BioHarness band stretches around the chest and contains a conductive elastic fabric. Expansion of the chest is monitored by measuring the resistance in the conductive fabric. The breathing rate $\left(f_{b}\right)$ is assessed by detecting inflections in the resistance waveform. The BioHarness also reports a raw breath amplitude $\left(B_{A}\right)$ value in volts which is "indicative". The BioHarness data fields used in this research were:

1. Heart rate, $H R$ (from ECG sensors)

2. Breathing rate, $f_{b}$ (from the waveform of the conductive elastic material in the strap)

3. Breathing amplitude (from the raw voltage of the conductive elastic material in the strap)

Since the resistance changes with the expansion of the chest, there should be a relationship between breath amplitude $B_{A}$ and the tidal volume $V_{T}$. One caveat is that respiration can produce expansion in various parts of the upper body, including the chest, 
abdomen, and lower back. A second caveat is that the relationship between $B_{A}$ and $V_{T}$ will depend on the location and tightness of the strap. Tidal volumes and breath amplitudes were measured before and after each data collection in order to develop session-specific $V_{T} \sim B_{A}$ relationships that could be used to estimate dynamic $V_{E}$ from onroad measured $f_{b}$ and $B_{A}$. The tidal volume calibration is described in Chapter 6 on ventilation.

\subsection{Traffic and roadway data}

Arterial traffic data for SE Powell Blvd. (one of the high-volume facilities used the study) were obtained from the Portland Bureau of Transportation (PBOT). Powell Blvd. is equipped with Digital Wave Radar (DWR) sensors measuring traffic volume and speed in each lane at mid-block locations near SE $24^{\text {th }}$ Ave. and SE $35^{\text {th }}$ Ave. Concurrent traffic data were retrieved at ten second aggregations for the data collection time periods. DWR data were compared with manual counts by other researchers at Portland State University $^{4}$. EB and WB vehicle counts were compared for 5 15-minute periods on May 1, $2013(\mathrm{~N}=10)$. The comparison produced a MPE of $6.1 \%$ and a MAPE of $9.1 \%$, with larger errors in the WB than EB directions (EB MPE of $2.6 \%$ and MAPE of 5.0\%; WB MPE of $9.6 \%$ and MAPE of $13.2 \%$ ).

Average daily traffic (ADT) estimates were available for street links in the City of Portland through a GIS layer obtained from PBOT. The ADT data set was created by the City of Portland in 2005 by interpolating Monday-Thursday count data from the previous

\footnotetext{
${ }^{4}$ Chawalit Tipagornwong and Adam Moore, Portland State University - unpublished correspondence, 2014-01-02
} 
5 years (prioritizing more recent counts and excluding counts with inconsistent volumes) $)^{5}$. The ADT data were validated with 51 arbitrary locations in SE Portland for which more recent counts were available (2008-2012). Table 8 presents the results of the validation exercise, showing a reasonable reliability of the ADT data.

Table 8. Validation results comparing 2005 ADT map data with more recent (20082012) traffic count data

\begin{tabular}{lc} 
Number of locations & 51 \\
Correlation coefficient & 0.987 \\
Average ADT & 6,955 \\
Mean error (ADT) & 200 \\
Mean absolute error (ADT) & 808 \\
Mean percent error & $1.1 \%$ \\
Mean absolute percent error & $16.4 \%$ \\
\hline
\end{tabular}

In addition to the ADT GIS layer, two other GIS data sets were obtained for analysis: link-based transportation system plan (TSP) and bicycle network data. Both data sets were obtained from Metro (the metropolitan planning organization for Portland, Oregon), through the Regional Land Information System (RLIS) ${ }^{6}$.

\section{DATA PROCESSING}

\subsection{Air quality data processing}

\subsubsection{Temperature and Humidity Adjustments to $\mathrm{CO}$ and $\mathrm{CO}_{2}$ Data}

The Langan $\mathrm{CO}$ data were adjusted for on-road measured temperature and humidity according to the manufacturer's documentation. The adjustment equation was

\footnotetext{
${ }^{5}$ Mary Edin, City of Portland - unpublished correspondence, 2014-02-10

${ }^{6} \mathrm{http} / / /$ rlisdiscovery.oregonmetro.gov/
} 


$$
C_{\text {adjusted }}=\frac{C_{\mathrm{raw}}-1.75^{0.1 C_{\mathrm{raw}}-2}}{1+a\left(C_{\mathrm{raw}}-20\right)}
$$

where the concentrations $C_{\text {raw }}$ and $C_{\text {adjusted }}$ are in ppm,

$$
a=\left\{\begin{array}{l}
0.0030 \text { when } T>20^{\circ} \mathrm{C} \\
0.0055 \text { when } T<20^{\circ} \mathrm{C}
\end{array}\right.
$$

and $T$ is the temperature in ${ }^{\circ} \mathrm{C}$.

The Telaire $\mathrm{CO}_{2}$ data were adjusted for on-road measured temperature according to the manufacturer's documentation. The adjustment equation was

$$
C_{\text {adjusted }}=C_{\text {raw }}-2(T-25)
$$

where concentrations are in ppm and temperature $T$ is in ${ }^{\circ} \mathrm{C}$.

\subsubsection{Zero Reference Curve for TVOC Instrument}

In early testing, the PID TVOC data showed inconsistent zero points at start-up and a slow decay in the zero reference value over the course of a data collection. The manufacturer's recommendation was to use a "zero at startup" function, which uses the lowest reading since startup as the (running) zero reference value ${ }^{7}$ While this approach avoids negative values, it creates an untraceable and inconsistent shift in the data values.

As an alternative, a function was written to construct a zero reference curve after data collection was complete. The zero reference curve is the maximum-value convex, monotonically decreasing, piecewise linear curve that can be fit to the data. Adjusted TVOC values were calculated as the raw TVOC readings minus the zero reference curve. Zero-readings were taken with a carbon filter at the beginning and end of each collection

\footnotetext{
${ }^{7}$ Justin Blackman, Ion Science - unpublished correspondence, 2012-09-11
} 
to serve as anchor points for the zero reference curve. The zero-reading points were removed for analysis, as were the first 15 min after the instrument was turned on (the warm-up period suggested by the manufacturer). The R script used to compute the zero reference curve is included in Appendix D.

\subsubsection{Disaggregation of VOC Sample Data}

High-resolution BTEX concentrations were estimated by disaggregating the segment-level VOC data using the TVOC measurements. The BTEX concentration at time $t$ on segment $s$ was calculated utilizing the formula:

$$
C_{t, s}=\frac{T_{V O C}}{\overline{T V O C}_{s}} \bar{C}_{s}
$$

where $\bar{C}_{s}$ and $\overline{T V O C}_{s}$ are the average BTEX and TVOC concentrations on segments, respecitvely. This approach uses the variability information in the TVOC data with the precision information in the GC/MS data. The main assumption is that on-road variation in TVOC is representative of BTEX variation. This disaggregation is likely conservative with respect to sub-segment-level BTEX variability due to the predominance of vehicular sources of BTEX compounds.

\subsection{GIS data processing}

All GIS/spatial data analysis was performed in R.

\subsubsection{Mapping location data points to roadway networks}

The GPS-based location data points were mapped onto GIS roadway network links based on proximity (out to $15 \mathrm{~m}$ ). Manual and scripted corrections to the initial 
mappings were applied at cross-streets and coincident roadways (e.g. parallel paths and overpasses). The link-based GIS roadway network data sets are described above (Section 2.6) and include

1. Roadway facility types from the transportation system plan (TSP),

2. Bicycle network facility designations, and

3. ADT estimates based on interpolated traffic counts.

The bicycle network dataset was restricted to "active" links (excluding "planned" and "recommended").

The method of initial proximity point-link matching is described in the following steps. The procedure was performed three times - once with each of the ling-based GIS layers above, using the same point location data.

1. Create a buffer around each point. The initial buffer size (radius) was $15 \mathrm{~m}$ to allow for GPS error and lateral distance between riding location and the roadway centerline (the approximate location of the link data). The average GPS accuracy recorded for the full data set was $3.6 \mathrm{~m}$ (range, 2-195 $\mathrm{m} ; 1^{\text {st }}$ and $3^{\text {rd }}$ quartiles, 3 $\mathrm{m})$. Riding on the edge of a four-lane road with $4 \mathrm{~m}$ lanes is an approximately $8 \mathrm{~m}$ offset from the centerline. Together, $12 \mathrm{~m}$ is a reasonable outer buffer, and $15 \mathrm{~m}$ is conservative.

2. Perform a spatial intersect between the buffered points and the link data set to find all the links which intersect the $15 \mathrm{~m}$ buffer of each point.

3. Refine points with multiple links intersecting the buffer. Step through the subset of points with multiple matches in step 2. For each point, iterate steps 1 and 2 
with a decremented buffer size. Use a factor of 0.95 to decrement the buffer size at each iteration. Stop the iteration when each point has zero or one associated link.

The total number of valid $1 \mathrm{~Hz}$ GPS location data points was 104,291 (longitude and latitude fields both present). The results of this point-link mapping process are shown in the following table. Some un-matched data points are due to locations off the network, while some are due to inaccuracy in the GPS data or failure of the matching algorithm.

Table 9. Results of initial point-link matching based on proximity

\begin{tabular}{l|rr}
\hline Dataset & \# points matched & \% points matched \\
\hline TSP & 94,919 & $91.0 \%$ \\
Bicycle network & 54,461 & $52.2 \%$ \\
ADT & 89,160 & $85.5 \%$ \\
\hline
\end{tabular}

The initial point-link matches were further processed to correct for street crossings (at which the cross-street centerline is closer than the travel street centerline) and other matching errors.

\section{Discontinuity correction}

Identify sequences of data for which the street name field of the matched link changes (or is missing) and then returns to the original street name within 12 observations (seconds). For these sequences, assign the departure link to all intervening data points, up to the point which returns to the street name. Results of the discontinuity correction are shown in Table 10. 
Table 10. Discontinuity corrections to point-link matches

\begin{tabular}{l|rrr}
\hline Dataset & $\begin{array}{r}\text { Discontinuities } \\
\text { identified }\end{array}$ & $\begin{array}{r}\text { \# points } \\
\text { corrected }\end{array}$ & $\begin{array}{r}\text { \% points } \\
\text { corrected }\end{array}$ \\
\hline TSP & 3,629 & 8,537 & $8.2 \%$ \\
Bicycle & 884 & 1,603 & $1.5 \%$ \\
network & & & \\
ADT & 3,450 & 8,037 & $7.7 \%$ \\
\hline
\end{tabular}

2. Manual correction

The true route of the data collection bicycles was known because of scripted routes, field logs, and on-bicycle video data. After the discontinuity correction, the data were displayed on a map and inspected visually. Points on the map were color-coded for un-matched data, facility type, and ADT value. Points identified as erroneously matched were manually re-matched with appropriate links in the relevant GIS data set (or with null values if the true facility was not present in the GIS network). The corrections included errors such as an off-street trail matched to the adjacent road or an overpass matched to the lower road. One of the offstreet trails was missing from the TSP data set and all were missing from the ADT data set; these points were corrected to null values. Results of the discontinuity correction are shown in Table 11.

Table 11. Manual corrections to point-link matches

\begin{tabular}{l|rrr}
\hline Dataset & \# corrections & $\begin{array}{r}\text { \# points } \\
\text { corrected }\end{array}$ & $\begin{array}{r}\text { \% points } \\
\text { corrected }\end{array}$ \\
\hline TSP & 63 & 9,453 & $9.1 \%$ \\
Bicycle network & 44 & 1,439 & $1.4 \%$ \\
ADT & 77 & 11,074 & $10.6 \%$ \\
\hline
\end{tabular}

The final results of the matching exercise are shown in Table 12. 
Table 12. Results of point data mapping onto link data sets

\begin{tabular}{l|rrr}
\hline Dataset & $\begin{array}{r}\text { \# location } \\
\text { data points }\end{array}$ & $\begin{array}{r}\text { \# points } \\
\text { matched }\end{array}$ & $\begin{array}{r}\text { \% points } \\
\text { matched }\end{array}$ \\
\hline TSP & 104,291 & 94,027 & $90.2 \%$ \\
Bicycle network & 104,291 & 56,986 & $54.6 \%$ \\
ADT & 104,291 & 87,691 & $84.1 \%$ \\
\hline
\end{tabular}

3.2.2 Assigning roadway types to location data

A "Road Type" field was created for the location data using information in the matched TSP and bicycle network data sets.

1. Initial road types were assigned using a mapping from the TSP data shown in

Table 13.

Table 13. Road type classifications based on TSP classes

\begin{tabular}{l|l}
\hline TSP Classification & Road Type Classification \\
\hline NA or Unknown & NA \\
Local St. & Local \\
Traffic Access & Minor Collector \\
Neighborhood Collector & Major Collector \\
District Collector & Minor Arterial \\
Major Traffic, Regional/Major & Major Arterial \\
Traffic, or Regional Traffic & \\
\hline
\end{tabular}

2. Data points identified as a "Multi-Use Trail" in the bicycle network data set or "Off-St. Path" in the TSP data set were classified as "Path" road type.

3. Data points with a "BR" abbreviation in the Segment Name field of the bicycle network data set were classified as "Bridge" road type - to distinguish them from the more separated trails.

The resulting distribution of road type classifications is shown in Table 14. 
Table 14. Distribution of road type classifications

\begin{tabular}{ccccccccc}
\hline & Path & Bridge & Local & $\begin{array}{c}\text { Minor } \\
\text { Collector }\end{array}$ & $\begin{array}{c}\text { Major } \\
\text { Collector }\end{array}$ & $\begin{array}{c}\text { Minor } \\
\text { Arterial }\end{array}$ & $\begin{array}{c}\text { Major } \\
\text { Arterial }\end{array}$ & NA \\
\hline $\begin{array}{c}N \\
\text { (1-sec data) }\end{array}$ & 10,701 & 2,009 & 49,560 & 7,724 & 5,539 & 8,922 & 16,866 & 2,970 \\
\hline$\%$ of total & $10.3 \%$ & $1.9 \%$ & $47.5 \%$ & $7.4 \%$ & $5.3,1 \%$ & $8.6 \%$ & $16.2 \%$ & $2.9 \%$ \\
\hline
\end{tabular}

Figure 8 shows road type and ADT estimates for all data plotted over an Open Street Map background. Combining the road type classifications with the ADT estimates produces Figure 9 (note that not all data points with a road type classification have an associated ADT link - especially the Path road type). Despite the fact that the road type and ADT come from different GIS data sets, the relationships are generally as expected.

A last classification step used the bicycle network link data to separate the two main off-street paths used in data collection:

1. the "I-205 Path" runs north-south parallel to the freeway, intermittently inside and outside of a soundwall, and

2. the "Springwater Path" runs east-west between the river and the I-205 Path, including sections in parkland and sections parallel to a roadway in an industrial area.

Data points at the park reference location (Mt. Tabor Park) were also identified based on the longitude/latitude boundaries. 


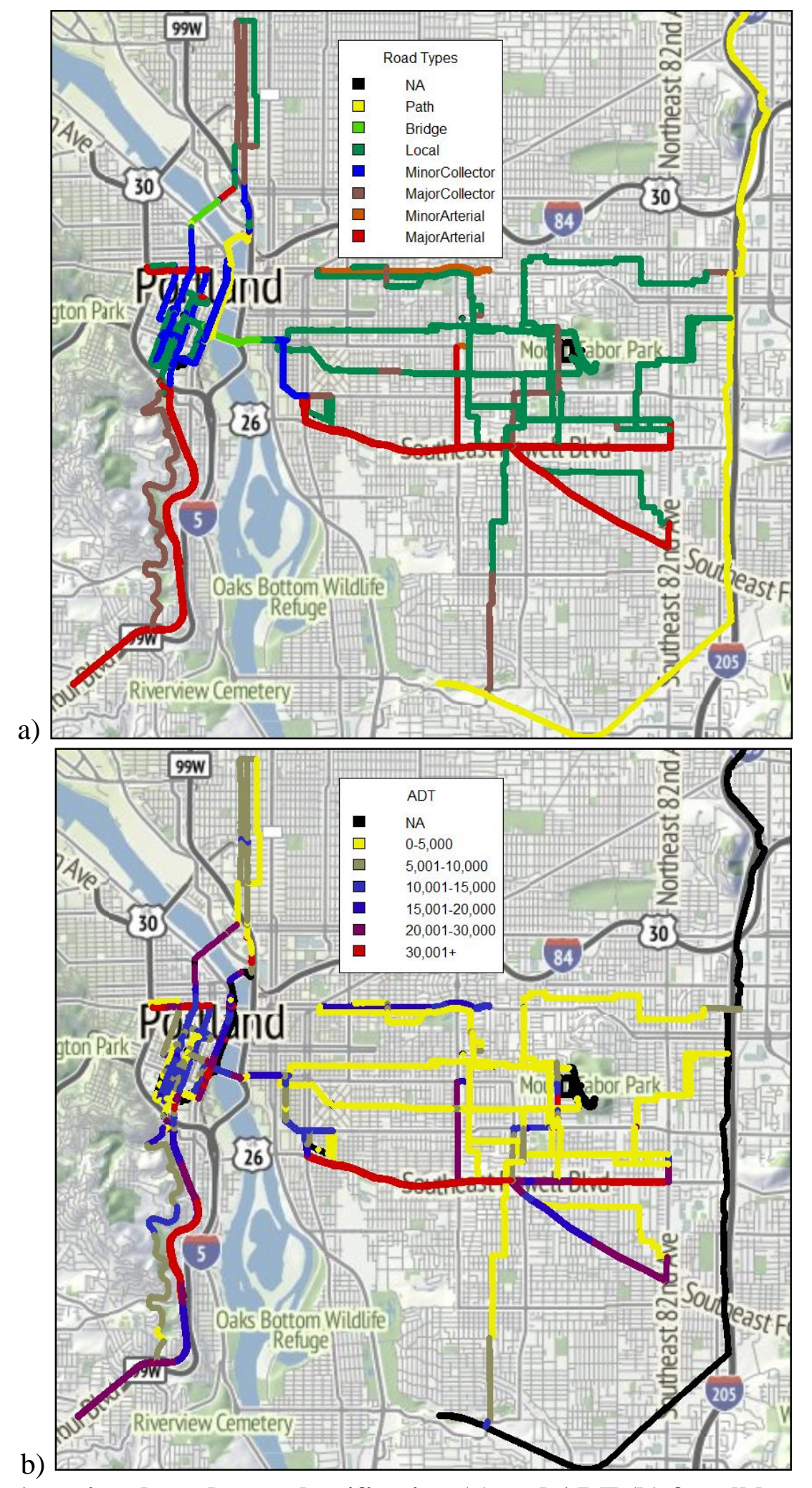

Figure 8. Associated road type classification (a) and ADT (b) for all location data points (background image from OpenStreetMap) 


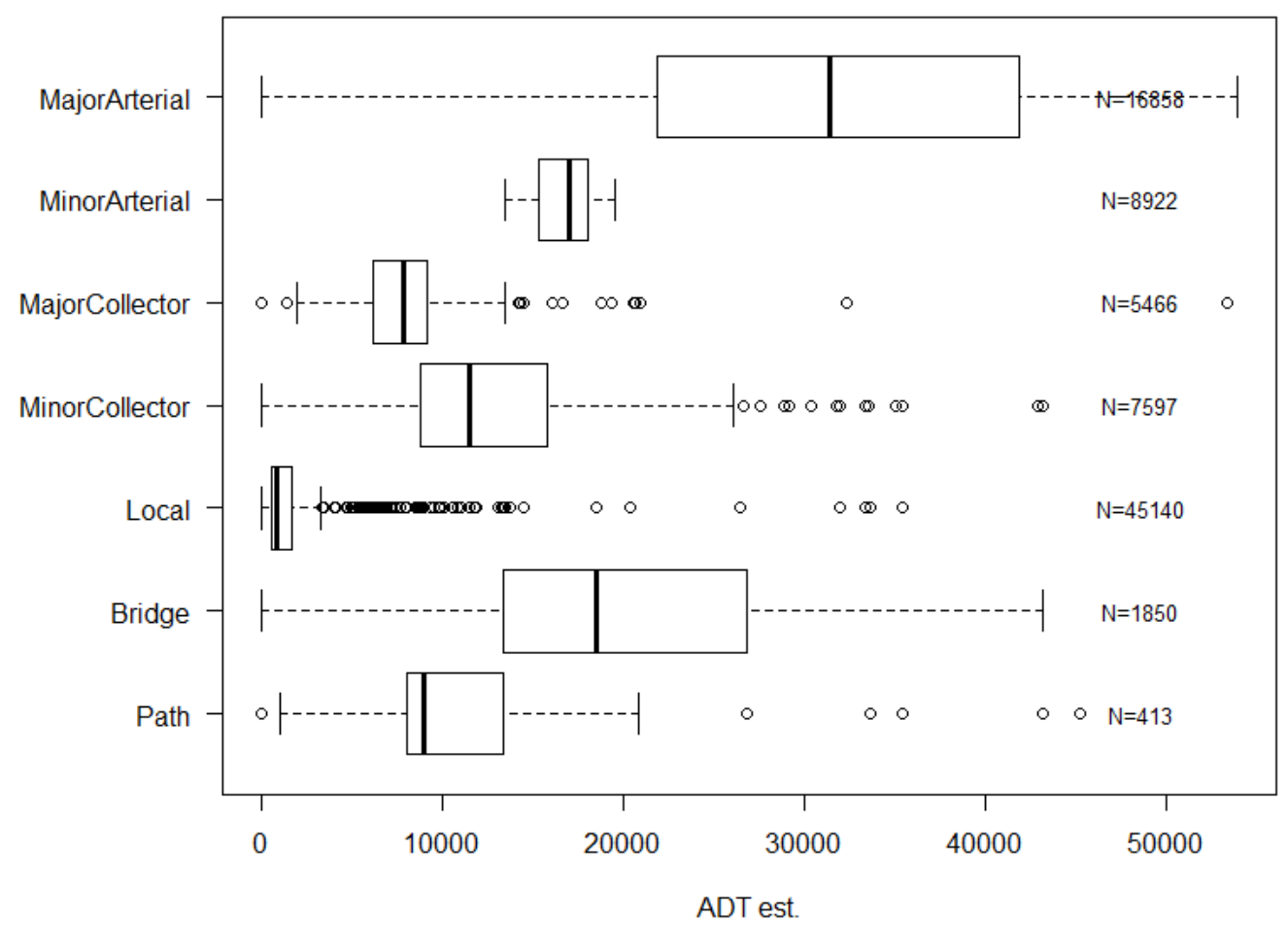

\section{Figure 9. Comparison of ADT and road type for matched-link location data}

\subsubsection{Identify major road crossings}

To identify crossings of larger roads during travel on paths and local streets, points were identified that 1) had a road type classification of "Local" or "Path" (by the process described in Section 3.2.2) and 2) had an initial proximity match (single-nearest link in Section 3.2.1, before the discontinuity and manual corrections) to a TSP facility type of "Neighborhood Collector", "District Collector" or "Major Traffic". This method identified crossings because, as described above, the data points were closer to the centerline of cross-streets during crossing than the centerline of the traveled roadway ${ }^{8}$.

\footnotetext{
${ }^{8}$ At $17 \mathrm{kph}$ bicycling speed there are $4.7 \mathrm{~m}$ between 1 -second observations. The closest observation to the cross-street centerline (assuming complete data), would then be 0 to $2.4 \mathrm{~m}$, averaging $1.2 \mathrm{~m}$ assuming a
} 
To capture missed crossings at repeated locations, a buffer of $5 \mathrm{~m}$ was created around each identified crossing point and a spatial intersect performed on the set of points with road type "Local" and "Path". The intersecting points were added to the pool of crossing points. Lastly, a single point per crossing was selected as the first point in a cluster of crossing points (a cluster being the same crossing link value within a range of 30 seconds). The results of the crossing identification procedure are shown in Table 15 and Figure 10.

Table 15. Unique crossing points identified

\begin{tabular}{|l|c|c|c|}
\hline & \multicolumn{3}{|c|}{ Crossing facility } \\
\hline Travel facility & Neighborhood Collector & District Collector & Major Traffic \\
\hline Local & 141 & 10 & 52 \\
\hline Path & 22 & 2 & 25 \\
\hline
\end{tabular}

uniform distribution. In most situations, $1.2 \mathrm{~m}$ is smaller than the lateral distance from a bicyclist to the centerline. Even a bicyclist riding in the center of the travel lane on a two-lane street with narrow $3 \mathrm{~m}$ lanes (i.e. "taking the lane") would be $1.5 \mathrm{~m}$ from the centerline. Still, the method is not guaranteed to capture every crossing. 


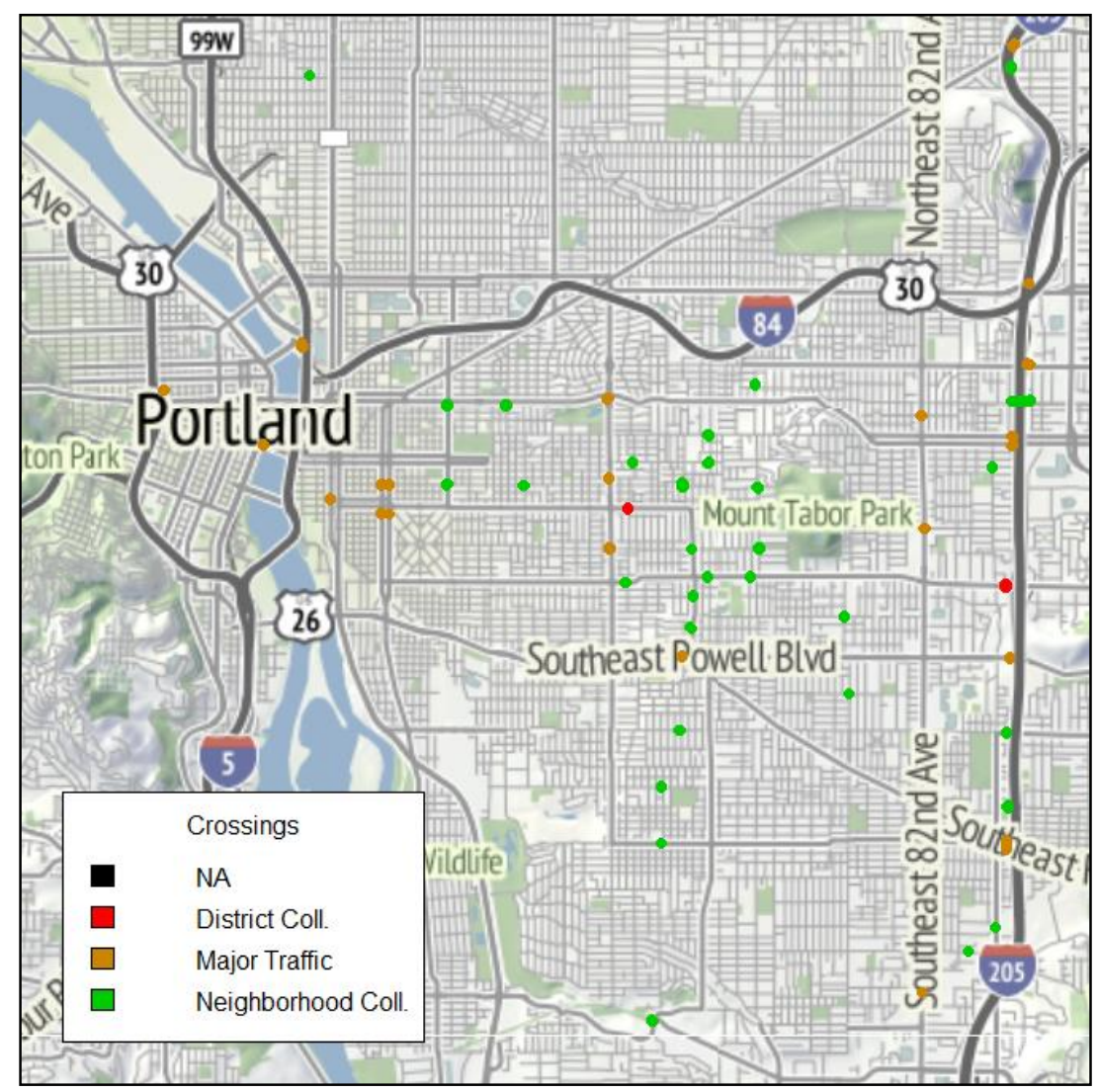

Figure 10. Identified crossings on local roads and paths (background image from OpenStreetMap)

\subsubsection{Integration of GIS data into main data set}

The full data set contained many observations without location/GPS data. Missing GPS data was due to the lack of a GPS device, GPS devices without a satellite fix, or stationary GPS devices (GPS data points were only recorded when new values were present). For example, when the bicyclist was stopped at a traffic signal, the $1 \mathrm{~Hz}$ observations would have missing GPS data, even though the device was tracking location. Additionally, there was imperfect syncing between the GPS satellite time stamps and the device time clock, resulting in occasional 1-second observations missing GPS data. 
The processed GIS data were combined with the full data set by first integrating the values with present GPS data. GIS fields for records with missing GPS data were then completed with the most recent GIS observation, up to 300 seconds in the past. This process added road type classifications and ADT data for 44,052 data points $(13.1 \%$ of the full data set) at 4,419 separate discontinuities.

\subsection{Elevation and grade data}

Unfortunately, no GIS data set was available with high-resolution roadway grade or data. In order to calculate grade, $1 \mathrm{~Hz}$ elevation data were extracted from archived data and differentiated in two dimensions. The Department of Geography at Portland State University maintains an online GIS data portal $^{9}$ which can be queried to retrieve elevation data. For the Portland metropolitan region, $1 \mathrm{~m}$ digital elevation maps (DEM) and digital surface maps (DSM) data are available based on LIDAR readings. An R script ${ }^{10}$ was written to construct URL queries that return DSM and DEM data from GPS data. Extracted DEM data for the data set is shown in Figure 11.

Grade of travel was calculated as $G=\frac{\Delta \text { elevation }}{\text { distance }} 100 \%$ using $1 \mathrm{~Hz}$ elevation and location data. Distance was calculated by a spatial distance function in GIS. Grade was calculated and compared based on elevation values from 1) DEM, 2) DSM, and 3) GPS. The GPS-based elevation data did not agree well with the DSM and DEM data sets and were not used. The DSM data were highly erratic because of features such as trees of the

\footnotetext{
${ }^{9}$ http://atlas.geog.pdx.edu/

${ }^{10}$ Available on GitHub: https://github.com/abigazzi/R/blob/master/getPdxElevation.r
} 
road, while the DEM data were smoother but followed the ground contours and missed elevated roadway structures.

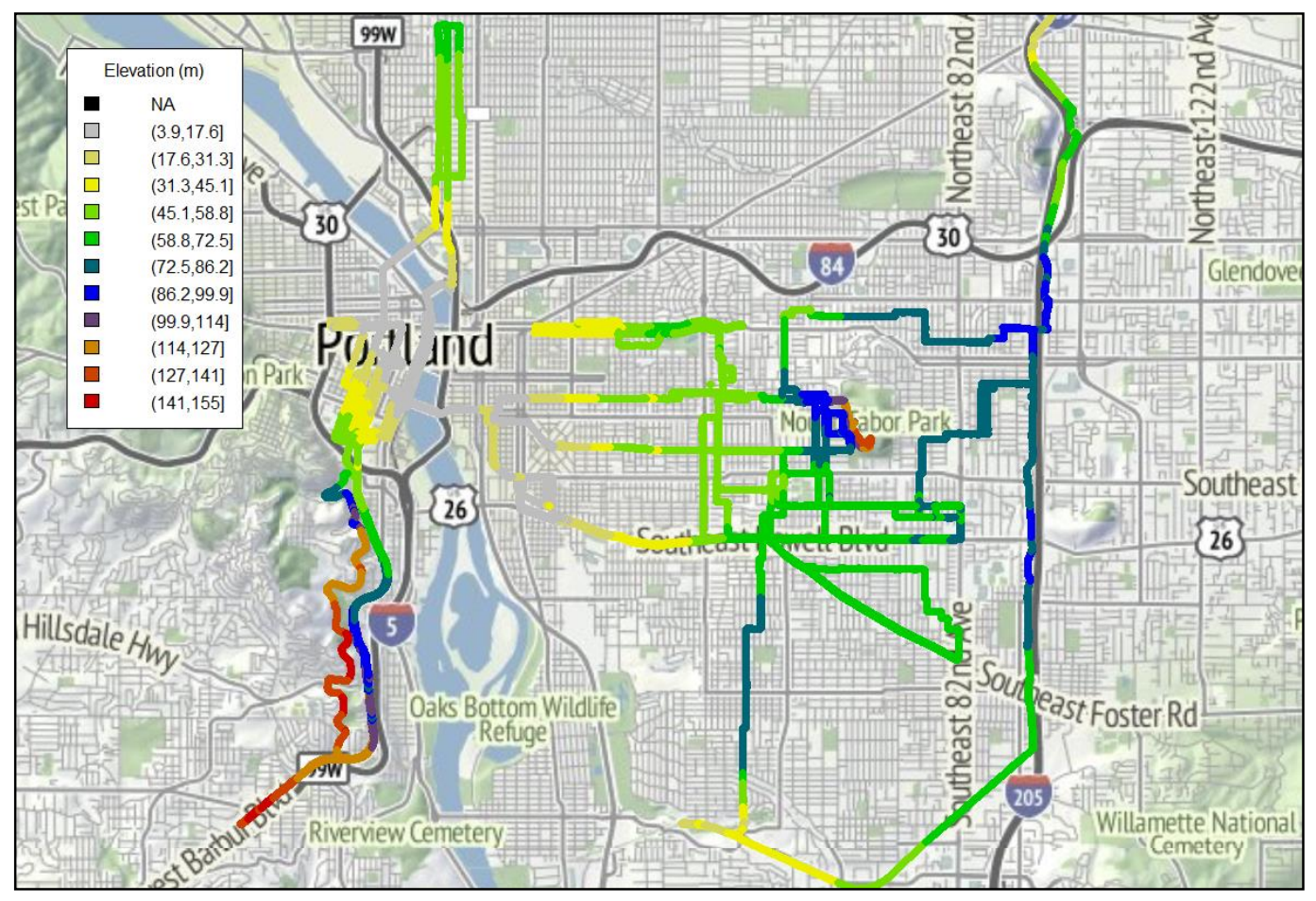

\section{Figure 11. Elevation data from DEM (background image from OpenStreetMap)}

The decision was made to use the DEM data and filter the grades for jumps which would indicate a roadway structure over a cut or a bridge transition. Grades over $25 \%$ or under $-25 \%$ were removed ( $0.3 \%$ of grade data). In addition, a smoothing algorithm was applied to the grade data (5-second moving average). Estimated grades are mapped in Figure 12. Figure 13 shows the estimated grade versus the travel speed for 1-second data. As expected, speed declines with grade; a trendline fits with $R^{2}=0.15, p<0.01$ $($ speed $=19.42-6,503 G$ with speed in $\mathrm{kph}$ and grade in \%). 


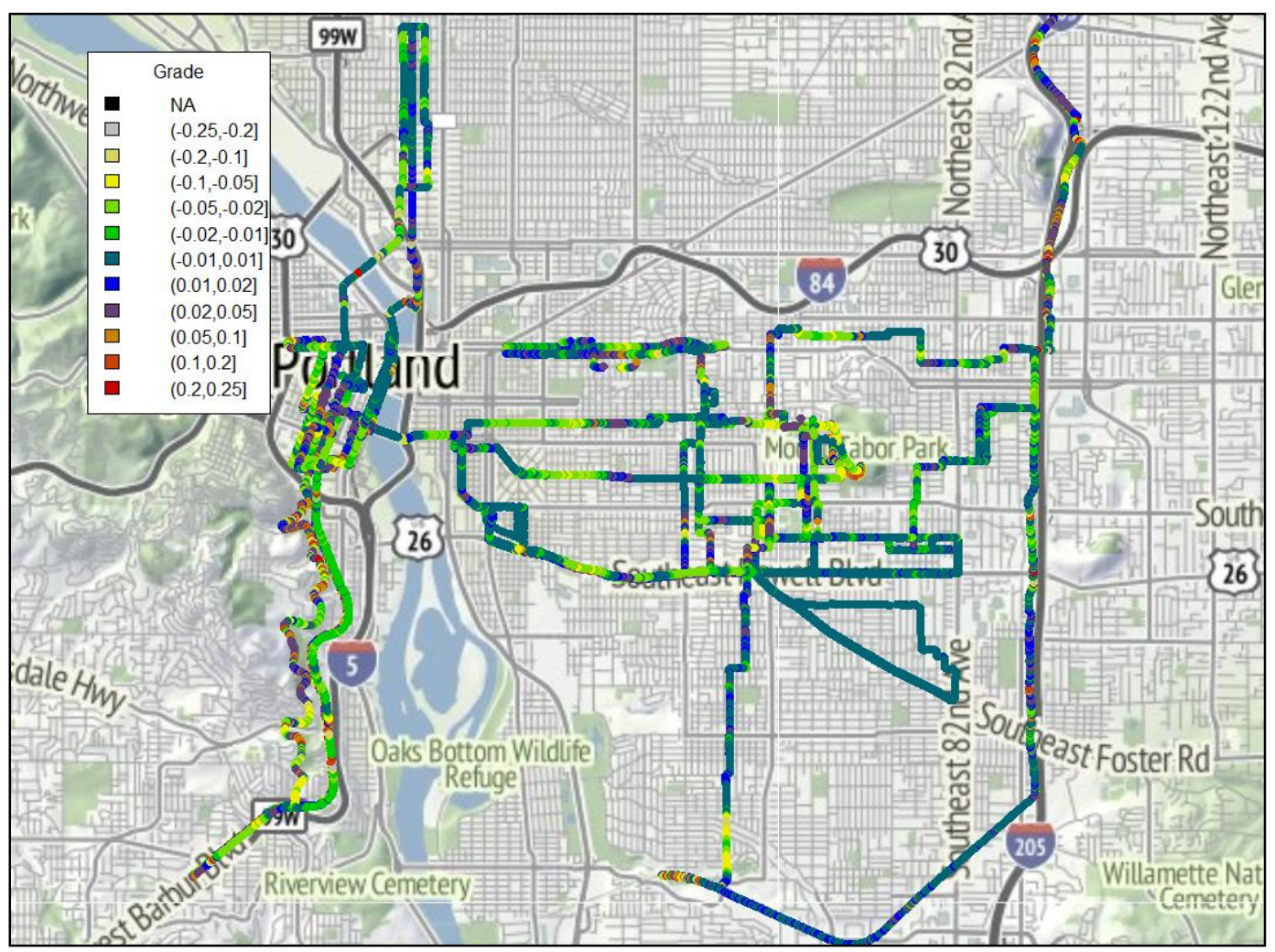

Figure 12. Estimated travel grades (background image from OpenStreetMap)

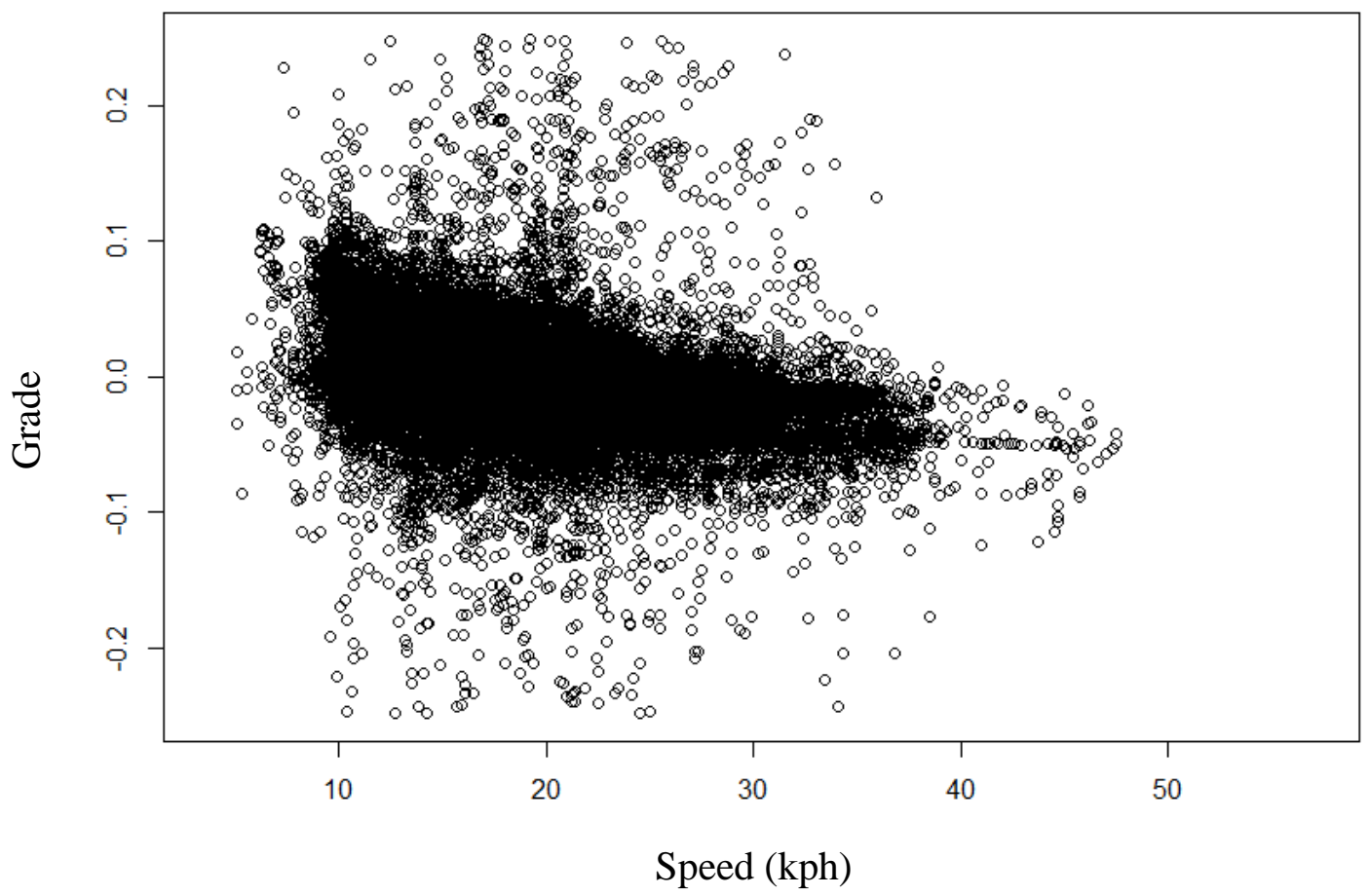

Figure 13. Estimated grade versus travel speed (1-second data) 


\section{Chapter 4: Data Overview}

\section{SAMPLE SIZE}

A total of 51 ambient samples and 74 breath samples (51, 12, and 11 from subjects A, B, and C, respectively) were obtained. Of these, 37 ambient and 53 breath samples were collected after riding; the other samples were collected after a stationary period to determine pre-segment or post-segment conditions. The 9 breath sampling days were 2013-04-02, 2013-07-02, 2013-07-09, 2013-07-11, 2013-08-22, 2013-09-04, 201309-10, 2013-09-11, and 2013-09-12. All samples were collected between 6:54 and 10:14. Additional continuous on-road data were collected on 4 other days (2012-10-26, 201211-15, 2013-09-26, and 2013-09-27), and ergometer tests were completed on 2013-09-12 and 2013-09-13.

Location designations for the VOC samples are based on the road type classifications. "Mixed" is used to designate a segment without at least $75 \%$ of the observations on a single road type ${ }^{1}$. The number of breath and ambient samples by road type are shown in Table 16.

Table 16. Number of VOC samples by location/facility

\begin{tabular}{l|ccccccc}
\hline & Park & $\begin{array}{c}\text { I-205 } \\
\text { Path }\end{array}$ & $\begin{array}{c}\text { Springwater } \\
\text { Path }\end{array}$ & Local & Mixed & $\begin{array}{c}\text { Minor } \\
\text { Arterials }\end{array}$ & $\begin{array}{c}\text { Major } \\
\text { Arterials }\end{array}$ \\
\hline Exposure samples & 14 & 3 & 1 & 17 & 4 & 4 & 8 \\
Breath samples & 21 & 6 & 2 & 25 & 4 & 8 & 8 \\
\hline
\end{tabular}

\footnotetext{
${ }^{1}$ Sensitivity analysis reveals little difference in results if the threshold for a "Mixed" segment varies from $60 \%$ to $80 \%$.
} 
During air sampling for VOC analysis, a total of $29.9 \mathrm{hr}$ of continuous data were collected (some of it simultaneous), $22.5 \mathrm{hr}$ from on-road segments. On-road segment durations ranged 22-38 min and distances ranged 5.6-8.9 $\mathrm{km}$. Including times without VOC samples, $51.3 \mathrm{hr}$ of continuous data were collected with location information, $75 \%$ of it during travel, yielding 135,295 1-second on-road observations and a total distance of approximately $500 \mathrm{~km}$. Much of the modeling is performed at 5-second aggregation, leading to 27,059 observations. In terms of individual fields, valid location-specific data were obtained for:

- $\quad 35.9 \mathrm{hr}$ of TVOC concentrations,

- $\quad 36.0 \mathrm{hr}$ of $\mathrm{CO}$ concentrations,

- $\quad 33.8 \mathrm{hr}$ of $\mathrm{PM}_{2.5}$ concentrations (at 5-second intervals), and

- $\quad 48.0 \mathrm{hr}$ of heart rate values.

\section{SAMPLING CONDITIONS}

The on-road conditions for the VOC sampling times are summarized in Table 17.

Table 17. Sampling conditions for 53 on-road segments by 3 subjects over 9 days

\begin{tabular}{l|llll}
\hline & Minimum & Median & Mean & Maximum \\
\hline Temperature (C) & 11.0 & 18.9 & 18.6 & 25.3 \\
Relative humidity (\%) & 56.9 & 74.9 & 74.9 & 90.5 \\
Wind speed $\left(\mathrm{m} \mathrm{s}^{-1}\right)$ & 0.6 & 1.6 & 1.8 & 3.6 \\
Segment duration (min) & 22.0 & 25.5 & 25.9 & 38.0 \\
Segment length (km) & 5.6 & 6.6 & 6.8 & 8.9 \\
Mean speed - with stops $\left(\mathrm{km} \mathrm{hr}^{-1}\right)$ & 13.1 & 15.9 & 15.7 & 19.9 \\
Mean speed - without stops $\left(\mathrm{km} \mathrm{hr}^{-1}\right)$ & 14.0 & 17.3 & 17.2 & 20.8 \\
Heart rate $\left(\mathrm{min}^{-1}\right)$ & 58.4 & 86.7 & 87.5 & 112.9 \\
Breath rate $\left(\mathrm{min}^{-1}\right)$ & 18.5 & 24.9 & 24.6 & 30.1 \\
\hline
\end{tabular}




\section{SUMMARY OF CONCENTRATIONS}

Of the 75 target analytes, 26 were above the detection limit of $0.05 \mathrm{ng} \mathrm{l}^{-1}$ in at least $50 \%$ of both on-road breath and on-road ambient samples (see Table 18; detection data are in Appendix E, Table S.9). For compounds not in the standard mixture, an additional 43 compounds were tentatively identified in breath air based on their mass spectra, but not quantified. These included dimethyl sulfide, aldehydes such as acetaldehyde and hexanal, alcohols such as ethanol and propanol, terpenes such as isoprene and pinene, and ethers such as dioxane (see Appendix E, Table S.10).

Previous measurements of bicyclist exposure to VOCs report benzene exposure concentrations ranging from 0.6 to $56 \mathrm{ng} \mathrm{l}^{-1}$ (Bigazzi and Figliozzi 2014). The mean on-

road concentrations in this study $\left(1.67 \mathrm{ng}^{-1}\right)$ is at the lower end of that range, and closest in value to the most similar study in space and time (Weichenthal et al. 2012). The onroad BTEX ambient concentrations from this study are similar to recent roadside measurements in London (von Schneidemesser et al. 2010), though much lower than concentrations reported for occupationally exposed workers (Egeghy et al. 2003) and travelers in heavier-polluted cities (Batterman et al. 2002, Wang et al. 2002, Zhao et al. 2004, Wang and Zhao 2008). The BTEX concentrations at the park reference location (see Appendix E,

Table S.11) are similar to previously measured ambient concentrations for urban areas in the U.S. (Pankow et al. 2003) and for a Canadian city (Miller et al. 2012). 
The on-road measured concentration from the continuous instruments are

summarized in Table 19.

Table 18. Characterization of breath and ambient concentrations $\left(n g \mathrm{l}^{-1}\right)$ for on-road segments

\begin{tabular}{|c|c|c|c|c|c|c|c|c|}
\hline & \multicolumn{4}{|c|}{ Breath } & \multicolumn{4}{|c|}{ Ambient } \\
\hline & Minimum & Median & Mean & Maximum & Minimum & Median & Mean & Maximum \\
\hline $\begin{array}{l}\text { trichlorofluoromethane } \\
\text { (CFC11) }\end{array}$ & 0.42 & 0.61 & 0.65 & 1.27 & 0.45 & 0.69 & 0.72 & 1.09 \\
\hline acetone & 220.1 & 388.5 & 412.7 & 814.2 & 1.46 & 4.52 & 4.82 & 13.40 \\
\hline methylene chloride & ND & 0.58 & 1.22 & 7.24 & 0.27 & 0.65 & 0.79 & 3.49 \\
\hline methyl acetate & 1.91 & 7.12 & 7.09 & 15.02 & ND & 0.12 & 0.13 & 0.40 \\
\hline $\begin{array}{l}\text { 1,1,2,-trichloro-1,2,2- } \\
\text { trifluoroethane }\end{array}$ & & & & & & & & \\
\hline (CFC113) & 0.45 & 0.53 & 0.53 & 0.70 & 0.50 & 0.60 & 0.61 & 0.75 \\
\hline carbon disulfide & 0.59 & 1.31 & 1.70 & 11.58 & ND & 0.05 & 0.08 & 0.53 \\
\hline 2-butanone & 1.24 & 2.34 & 2.43 & 4.30 & 0.53 & 0.80 & 1.05 & 3.33 \\
\hline chloroform & 0.08 & 0.16 & 0.17 & 0.36 & 0.07 & 0.13 & 0.14 & 0.48 \\
\hline carbon tetrachloride & 0.31 & 0.38 & 0.39 & 0.48 & 0.44 & 0.51 & 0.51 & 0.64 \\
\hline benzene & 0.16 & 0.67 & 0.87 & 3.97 & 0.19 & 1.35 & 1.67 & 7.43 \\
\hline methyl methacrylate & 0.30 & 0.78 & 0.93 & 5.34 & ND & 0.16 & 0.25 & 3.79 \\
\hline 4-methyl-2-pentanone & & & & & & & & \\
\hline (MIBK) & ND & 0.12 & 0.11 & 0.32 & ND & 0.10 & 0.11 & 0.39 \\
\hline toluene & 0.46 & 1.20 & 1.38 & 3.58 & 0.73 & 3.20 & 4.03 & 16.91 \\
\hline 2-hexanone (MBK) & ND & 0.08 & 0.07 & 0.20 & ND & 0.06 & 0.06 & 0.17 \\
\hline tetrachloroethene (PCE) & 0.10 & 0.29 & 0.36 & 1.79 & 0.07 & 0.32 & 0.37 & 1.24 \\
\hline ethylbenzene & 0.08 & 0.16 & 0.19 & 0.42 & 0.19 & 0.71 & 0.85 & 2.86 \\
\hline$m+p$-xylene & 0.28 & 0.53 & 0.62 & 1.46 & 0.71 & 2.61 & 3.16 & 10.35 \\
\hline ethenylbenzene & & & & & & & & \\
\hline (styrene) & 0.07 & 0.17 & 0.21 & 0.92 & ND & 0.21 & 1.44 & 32.30 \\
\hline$o$-xylene & 0.12 & 0.18 & 0.22 & 0.51 & 0.27 & 0.93 & 1.14 & 3.78 \\
\hline$n$-propylbenzene & 0.05 & 0.09 & 0.10 & 0.25 & 0.06 & 0.18 & 0.21 & 0.71 \\
\hline 1,3,5-trimethylbenzene & ND & 0.07 & 0.07 & 0.17 & 0.08 & 0.24 & 0.30 & 1.04 \\
\hline 2-ethyltoluene & ND & 0.05 & 0.06 & 0.12 & 0.07 & 0.21 & 0.26 & 0.94 \\
\hline 1,2,4-trimethylbenzene & 0.08 & 0.15 & 0.18 & 0.40 & 0.26 & 0.78 & 0.98 & 3.49 \\
\hline $\begin{array}{l}\text { 1-isopropyl-4- } \\
\text { methylbenzene }\end{array}$ & 0.15 & 0.38 & 0.49 & 1.78 & ND & 0.14 & 0.16 & 0.38 \\
\hline 1,2,3-trimethylbenzene & ND & 0.05 & 0.06 & 0.17 & 0.07 & 0.21 & 0.25 & 0.98 \\
\hline naphthalene & ND & 0.21 & 0.25 & 0.92 & 0.06 & 0.26 & 0.31 & 1.18 \\
\hline
\end{tabular}


Table 19. Characterization of air quality monitoring concentrations

\begin{tabular}{l|rrrr}
\hline & minimum & median & mean & maximum \\
\hline TVOC $(\mathrm{ppb}$ isobutylene) & 0.0 & 6.5 & 10.8 & $1,162.2$ \\
$\mathrm{CO}(\mathrm{ppm})$ & $-1.10^{*}$ & 0.48 & 0.53 & 20.46 \\
$\mathrm{CO}_{2}(\mathrm{ppm})$ & 373 & 485 & 490 & 730 \\
$\mathrm{PM}_{0.3}(\mathrm{pt} / \mathrm{cc})$ & 8.3 & 60.6 & 74.3 & 439.4 \\
$\mathrm{PM}_{2.5}(\mathrm{pt} / \mathrm{cc})$ & 0.00 & 0.14 & 0.20 & 46.45 \\
$\mathrm{PM}_{5.0}(\mathrm{pt} / \mathrm{cc})$ & 0.00 & 0.02 & 0.03 & 1.78 \\
\hline
\end{tabular}

${ }^{*}$ Electrochemical sensors can produce negative readings due to the linear concentration/voltage assumption

\section{HIGH PRE-RIDE CONCENTRATIONS}

The aromatic VOC in the pre-ride Subject A sample on 2013-04-02 all have breath/ambient concentration ratios that are more than five times the median values. This sample is likely the result of high exposures before the sampling period. One possible explanation is very high in-home exposures with insufficient equilibration time at the preride location. It is notable that the breath/ambient concentration ratios for aromatic compounds returned to a more normal range (0.8-3.2 times the median values) by the end of the first riding segment. Two other samples had all aromatic VOC breath/ambient ratios more than two times the median values: Subject B pre-ride sample on 2013-09-11 and Subject A Segment 4 sample on 2013-07-02. Although these data were noted for high concentrations, no data were excluded during the model development described in the following chapters.

\section{CORRELATIONS}

Correlation coefficients for the ambient concentrations of 26 compounds are plotted in Figure 14. An asterisk (*) denotes a significant correlation $(p<0.05)$. For 
every aromatic hydrocarbon except ethenylbenzene (styrene), ambient concentrations are highly correlated with the ambient concentrations of every other aromatic hydrocarbon. The ambient concentrations of some of the ketones are also highly correlated with the ambient concentrations of the aromatic hydrocarbons. The ambient concentrations of the esters and some of the halocarbons are largely uncorrelated with the ambient concentrations of any of the other compound. A recent multi-modal VOC exposure study in Belgium found similar correlations among concentrations of BTEX and related aromatic compounds (Do et al. 2014).

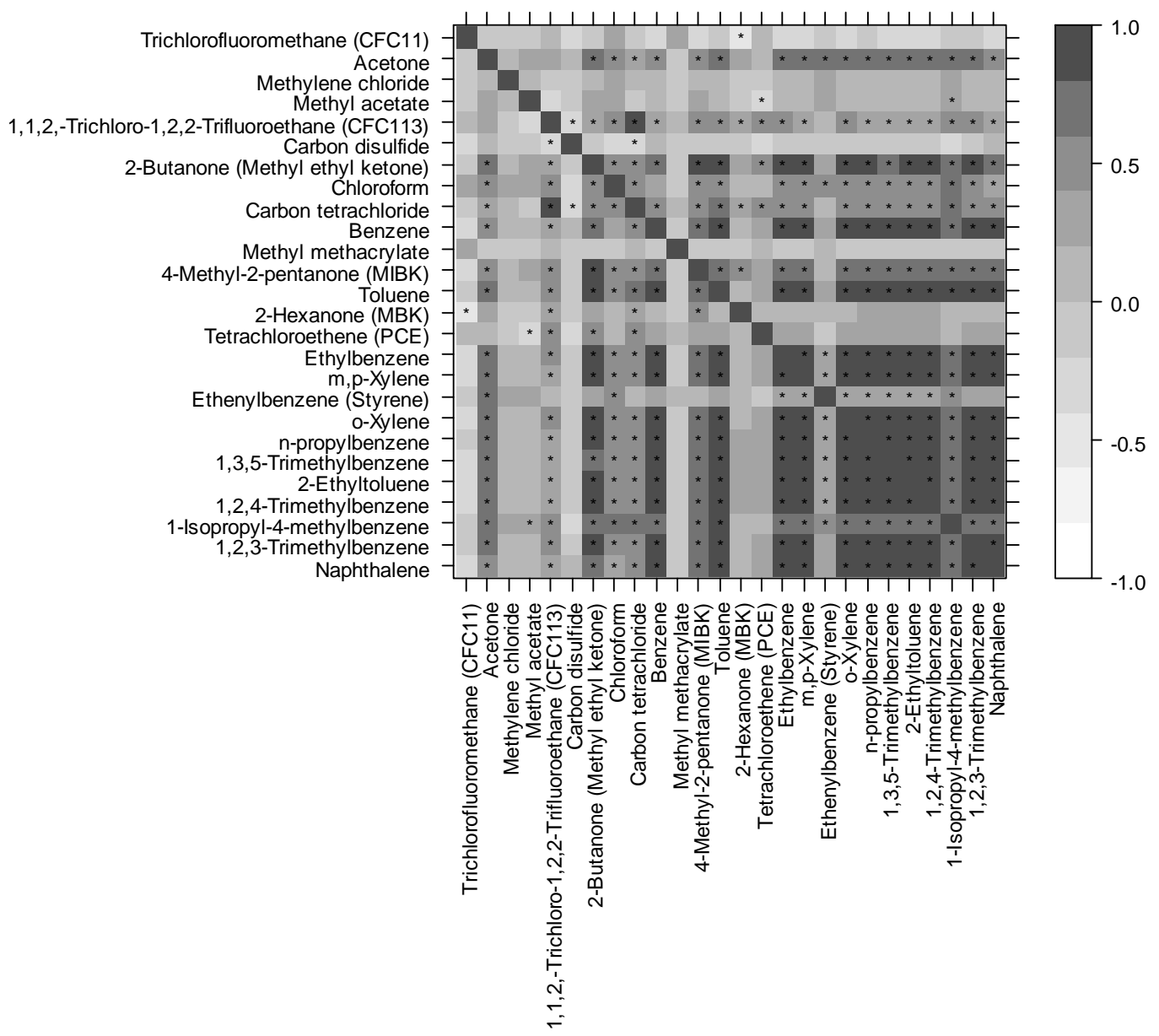

Figure 14. Correlation coefficients for ambient concentrations among 26 compounds (* indicates statistical significance at $\boldsymbol{p}<0.05$ ) 
The analogous figure for breath concentrations is presented in Figure 15.

Compared to Figure 14, in the breath data the concentrations of acetone and naphthalene are less correlated with the concentrations of aromatic hydrocarbons while the concentrations of methylene chloride are more correlated with the concentrations of aromatic hydrocarbons.

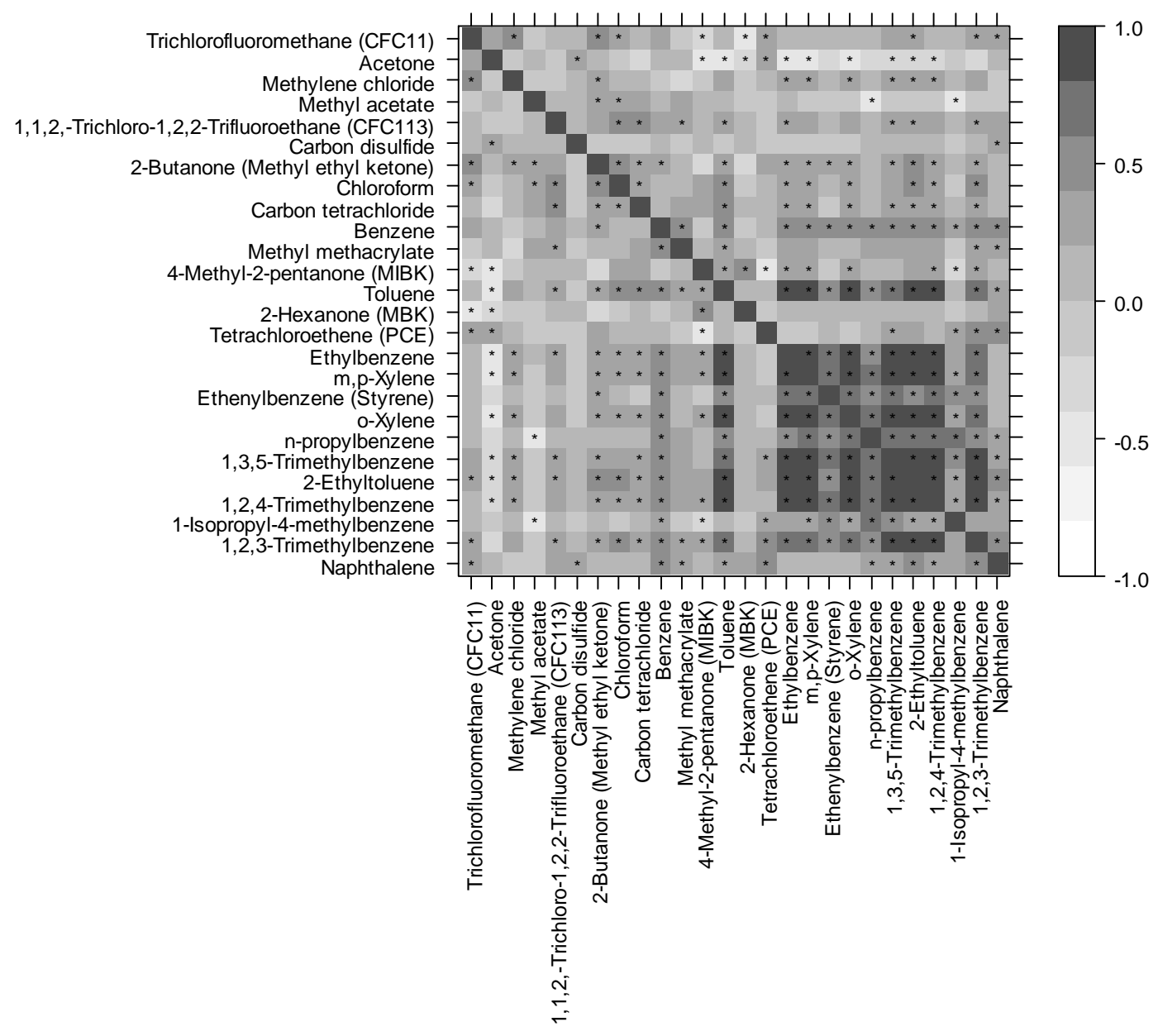

Figure 15. Correlation coefficients for breath concentrations among 26 compounds (* indicates statistical significance at $p<0.05$ )

Table 20 presents Spearman's rank correlation coefficients for the 1-second air monitoring data. The coarse particles are the least correlated with other pollutants. TVOC 
is positively correlated with $\mathrm{CO}$ and $\mathrm{CO}_{2}$, though the $\mathrm{PM}_{0.3}$ coefficient is negative. $\mathrm{CO}_{2}$ is positively correlated with all other pollutants (as the most general indicator of exhaust presence).

Table 20. Spearman correlation coefficients between 1-second air quality monitoring data (all significant at $\boldsymbol{p}<0.05$ )

\begin{tabular}{|l|l|l|l|l|l|l|}
\hline & $\mathrm{CO}$ & $\mathrm{CO}_{2}$ & TVOC & $\mathrm{PM}_{0.3}$ & $\mathrm{PM}_{2.5}$ & $\mathrm{PM}_{5.0}$ \\
\hline $\mathrm{CO}$ & & 0.09 & 0.16 & 0.26 & -0.01 & -0.10 \\
\hline $\mathrm{CO}_{2}$ & 0.09 & & 0.27 & 0.17 & 0.11 & 0.08 \\
\hline $\mathrm{TVOC}$ & 0.16 & 0.27 & & -0.03 & 0.09 & 0.05 \\
\hline $\mathrm{PM}_{0.3}$ & 0.26 & 0.17 & -0.03 & & 0.30 & 0.18 \\
\hline $\mathrm{PM}_{2.5}$ & -0.01 & 0.11 & 0.09 & 0.30 & & 0.66 \\
\hline $\mathrm{PM}_{5.0}$ & -0.10 & 0.08 & 0.05 & 0.18 & 0.66 & \\
\hline
\end{tabular}

\section{CONCENTRATIONS BY LOCATION}

Figure 16 presents breath and ambient concentrations for benzene and toluene from the park reference location and from bicycling on local roads and major arterials ( $N=21,25$, and 8, respectively; note the different vertical scales). The average ADT on the local road segments was 1,359 veh day ${ }^{-1}$ while the average ADT on the major arterial segments was 30,718 veh day ${ }^{-1}$. There is a clear trend of increasing ambient and breath concentrations from bicycling on higher-traffic roadways, though still much overlap among the observations - especially for measured breath concentrations. The larger variance in the breath concentrations may be due to numerous physiological factors.

Table 21 gives mean ambient and breath concentrations for riding segments on local roads and major arterials, normalized to mean ambient and breath concentrations measured at the park location. Only segments with both breath and ambient concentration data are included. Bicycling on higher-traffic roadways led to 
higher ambient and breath concentrations, though the increases in breath concentrations were smaller than the increases in ambient concentrations. Ethenylbenzene (styrene) and $n$-propylbenzene deviated most from this pattern. Wilcoxon rank-sum tests were used to determine whether the concentrations measured on each roadway type were significantly greater than at the park. Significance levels for accepting the alternative hypothesis that on-road concentrations were greater than at the park are indicated in each cell of Table 21.
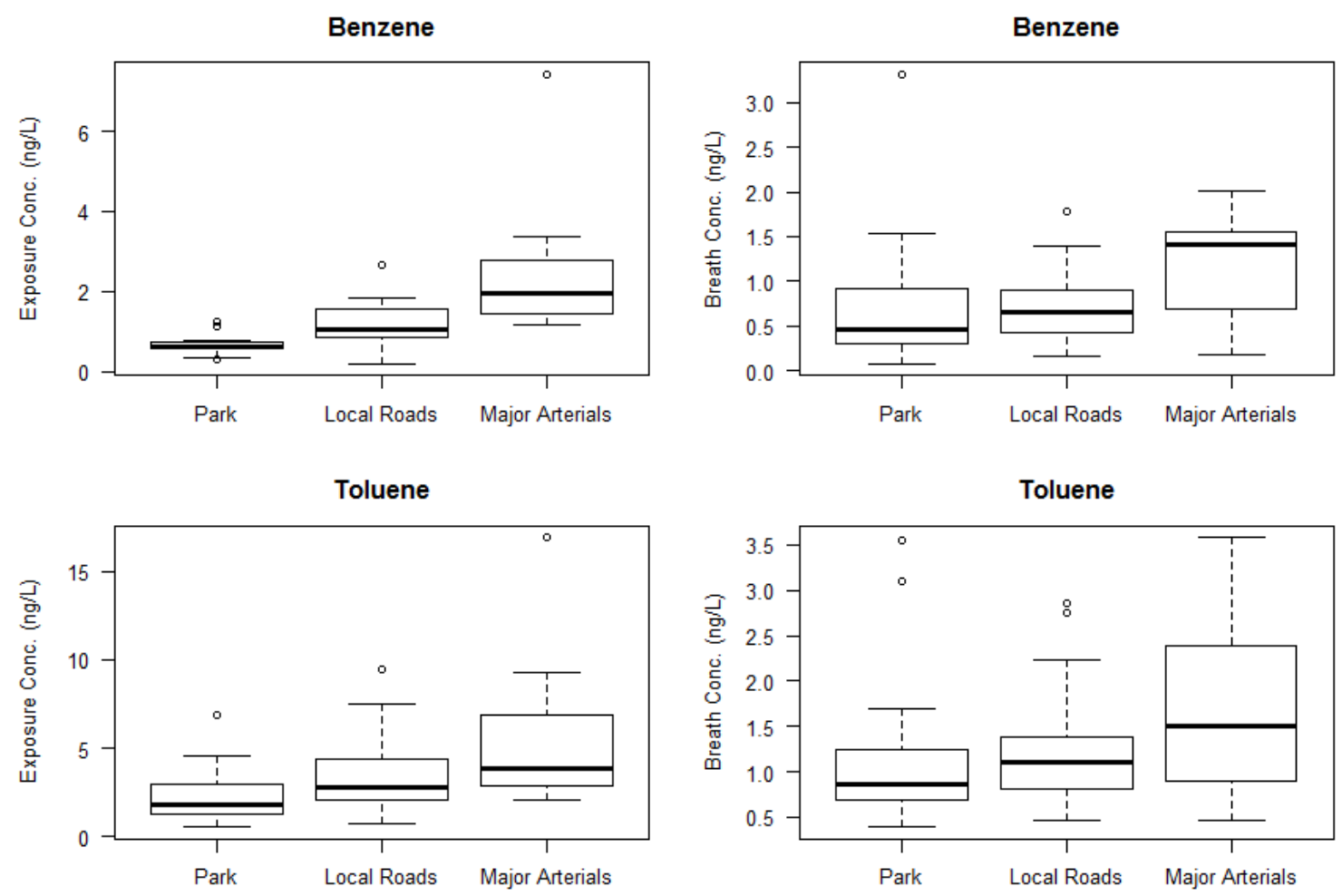

Figure 16. Ambient and breath concentrations by location

Ambient concentrations on major arterials were on average $97 \%$ to $317 \%$ greater than at the park location, while breath concentrations were $25 \%$ to $66 \%$ higher for the significantly different compounds (at $p<0.05$ ). Excepting styrene and $n$-propylbenzene, 
ambient concentrations on major arterials were $48 \%-119 \%$ higher than ambient concentrations on local roads, and breath concentrations were $12 \%-64 \%$ higher. In terms of fractional changes from the initial park location (i.e. subtracting 1 from the values in Table 21), increases in breath concentrations were 2.5-4.8 times greater after riding on major arterials than after riding on local roads for the seven compounds in Table 21 for which significant effects on breath were observed on both roadway types. Increases in ambient concentrations from the initial park location were 2.1-3.2 times greater during riding on major arterials than during riding on local roads for the same compounds.

Table 21. Mean on-road concentrations, normalized to concentrations measured at the park

\begin{tabular}{|c|c|c|c|c|}
\hline \multirow{2}{*}{ Compound } & \multicolumn{2}{|c|}{$\begin{array}{c}\text { Mean ambient concentration, } \\
\text { normalized to the park }\end{array}$} & \multicolumn{2}{|c|}{$\begin{array}{c}\text { Mean breath concentration, } \\
\text { normalized to the park }\end{array}$} \\
\hline & $\begin{array}{l}\text { Local } \\
\text { roads }\end{array}$ & $\begin{array}{c}\text { Major } \\
\text { arterials }\end{array}$ & $\begin{array}{l}\text { Local } \\
\text { roads }\end{array}$ & $\begin{array}{c}\text { Major } \\
\text { arterials }\end{array}$ \\
\hline benzene & $1.81^{* * * *}$ & $3.95^{* * *}$ & 1.01 & $1.66^{\text {** }}$ \\
\hline toluene & $1.51^{* * *}$ & $2.62^{* * * *}$ & $1.10^{*}$ & $1.50^{*}$ \\
\hline ethylbenzene & $1.79^{* * * *}$ & $2.77^{* * * *}$ & $1.10^{* *}$ & $1.33^{*}$ \\
\hline$m+p$-xylene & $1.79^{* * *}$ & $2.65^{* * *}$ & $1.08^{* *}$ & $1.28^{* *}$ \\
\hline $\begin{array}{l}\text { ethenylbenzene } \\
\text { (styrene) }\end{array}$ & $3.32^{* * *}$ & $1.97^{* * *}$ & 0.84 & 0.91 \\
\hline$o$-xylene & $1.80^{* * *}$ & $2.66^{* * * *}$ & $1.07^{* *}$ & $1.20^{*}$ \\
\hline n-propylbenzene & $1.86^{* * * *}$ & $3.07^{* * * *}$ & 0.96 & 0.96 \\
\hline 1,3,5-trimethylbenzene & $2.26^{* * * *}$ & $3.99^{* * *}$ & $1.10^{*}$ & $1.25^{* *}$ \\
\hline 2-ethyltoluene & $2.12^{* * *}$ & $3.77^{* * *}$ & $1.09^{*}$ & $1.21^{*}$ \\
\hline 1,2,4-trimethylbenzene & $2.33^{* * *}$ & $4.17^{* * *}$ & $1.06^{*}$ & $1.19^{*}$ \\
\hline 1,2,3-trimethylbenzene & $1.96^{* * *}$ & $3.68^{* * * *}$ & 1.02 & $1.33^{* *}$ \\
\hline naphthalene & $1.38^{* *}$ & $2.27^{* * *}$ & 0.97 & 1.29 \\
\hline
\end{tabular}

Significance level of Wilcoxon rank-sum test with the alternative hypothesis that concentrations were greater on-road than at the park:

$$
\begin{aligned}
& { }^{* * *} p<0.01 \\
& { }^{* *} p<0.05 \\
& { }^{*} p<0.10
\end{aligned}
$$


Ambient concentrations normalized to the park location are shown for various facility types in Figure 17. Ambient concentrations were lowest at the park and highest on the Springwater Path. The lowest concentrations were on the I-205 Path. The high concentrations on the Springwater Path were confirmed by the continuous on-road data. Inspection of the continuous TVOC data shows that VOC concentrations were extremely high along the Springwater Path coincident with light and medium industry in the same corridor (Figure 18). Likely VOC-emitting businesses in the corridor include metal casting and machining (Precision Castparts Corp., Metal Machinery, LLC), engine services, paint and power-coating, and other light manufacturing. This finding emphasizes the importance of near-road sources of traffic-related air pollutants.

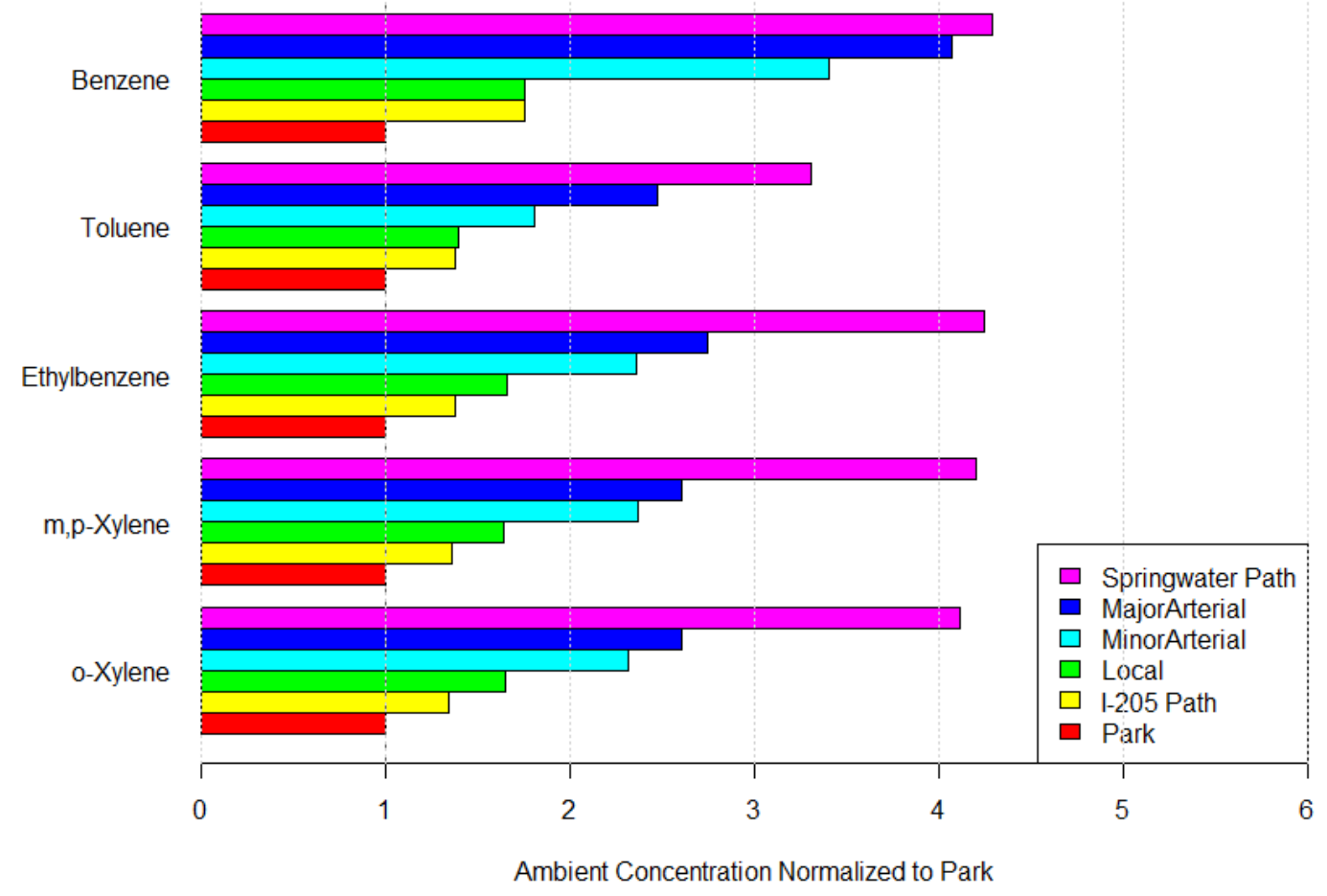

Figure 17. Average ambient concentrations by location, normalized to park location 


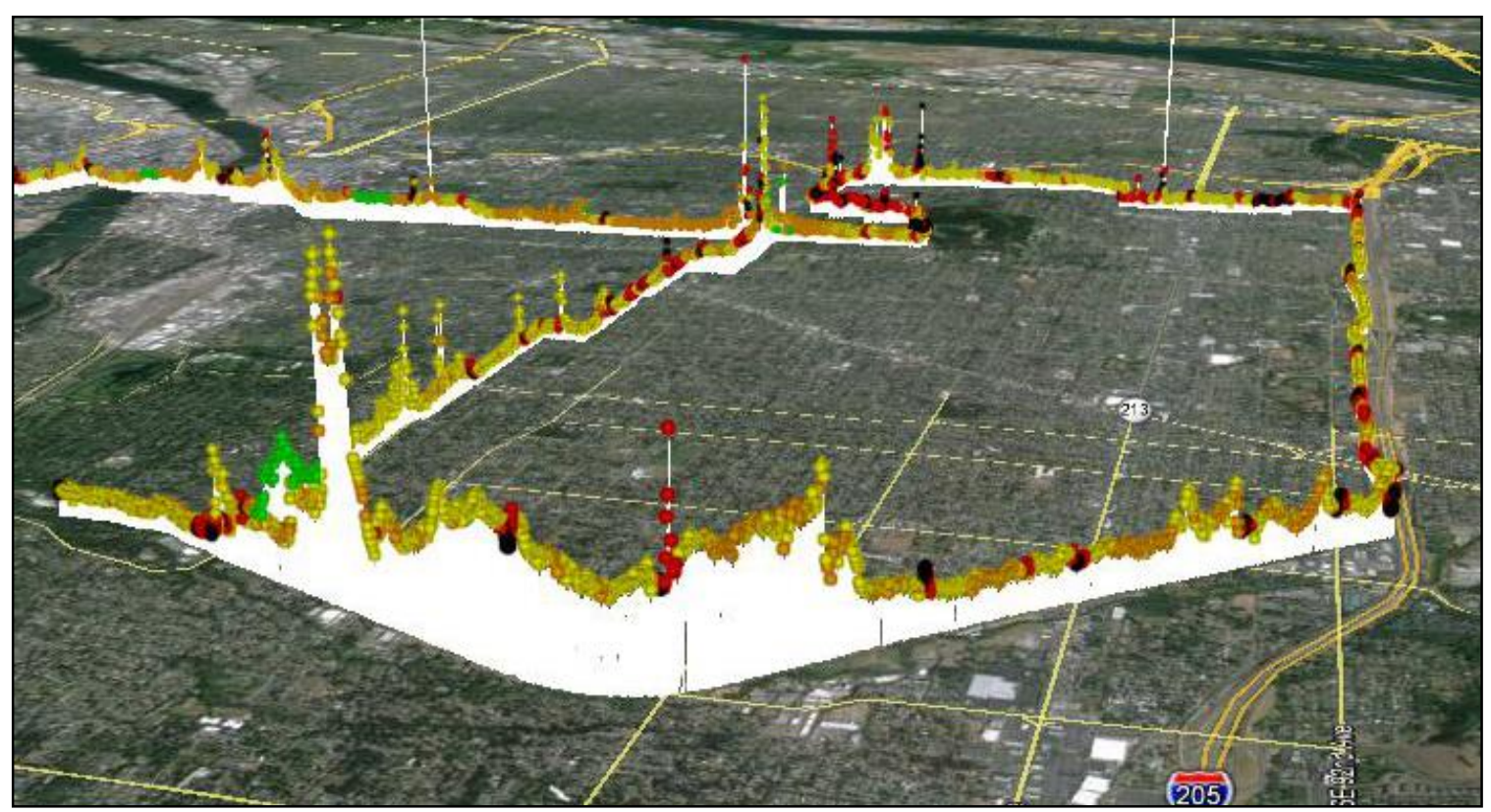

Figure 18. On-road measured TVOC concentration as pin height (travel speed as color, where from black/slow to green/fast); 2013-09-11 data collection

Average ambient concentrations of BTEX compounds in this study were $50 \%$ to $120 \%$ higher on major arterials than on local roads. This finding agrees well with past studies, which have reported bicyclist BTEX exposure differences of $58 \%$ to $250 \%$ in high-traffic versus low-traffic environments, including cities with an order of magnitude higher measured on-road concentrations (see Literature Review, Chapter 2 Figure 1). Similar relative effects of roadway type on exposure can be expected in urban areas with higher VOC concentrations, to the extent that motor vehicles emit a proportionate share of aromatic VOC. A higher fraction of industrial VOC sources would mitigate the influence of roadway facility type on exposure while increasing the influence of surrounding land use. 


\section{EXPOSURE SKEW}

Figure 19 shows Lorenz curves for exposure on the different roadways. The Lorenz curve is a measure of inequality in distributions, widely used in economic analysis of income distributions. Lorenz curves show the proportion of a measured item $(Y)$ occurring in the bottom $(X)$ proportion of a population; in Figure 19, $X=$ observations and $Y=$ cumulative exposure. The degree of inequality is also indicated by the Gini index, which takes a value between 0 (perfect equality) and 1 (perfect inequality). The Gini indices are shown in Table 22, along with the minimum portion of observations that comprise $50 \%$ of total exposure. .

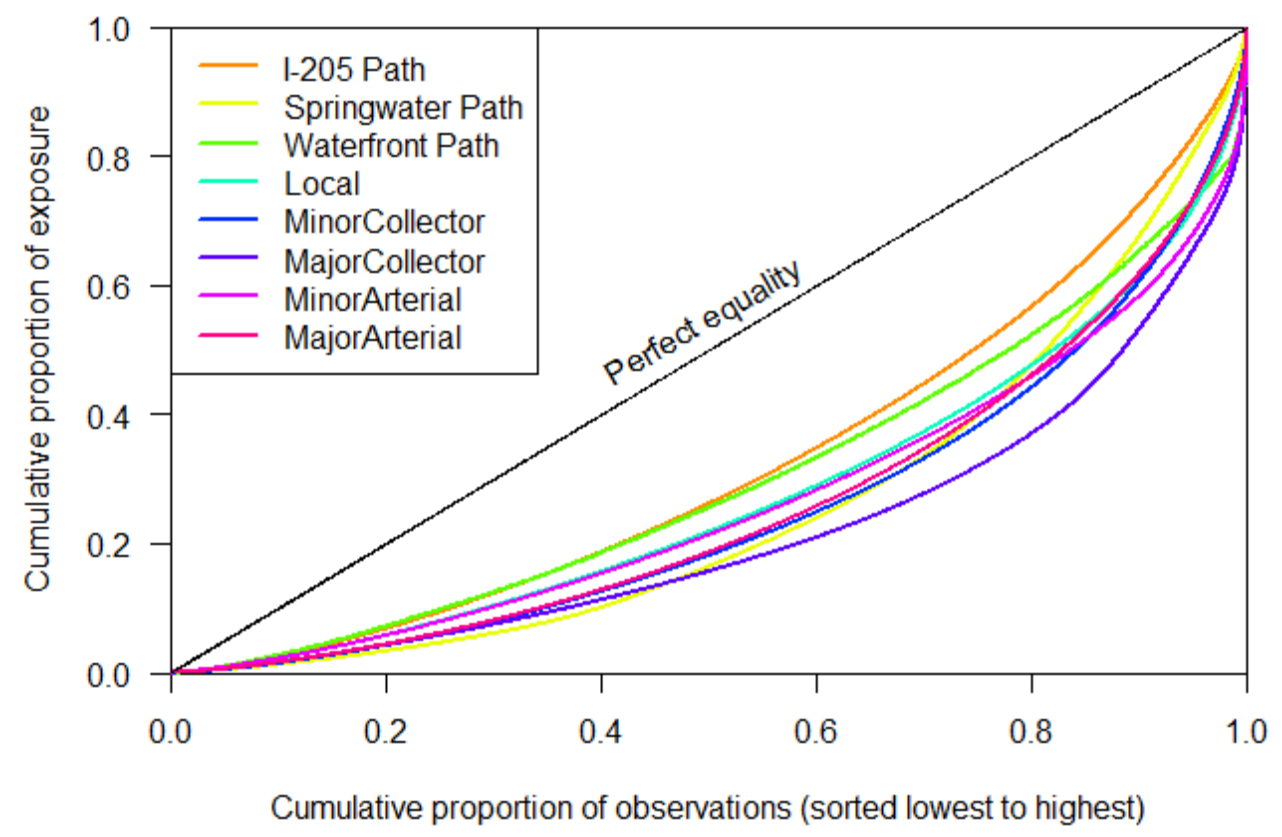

Figure 19. Lorenz curves showing exposure skew by location

Figure 19 and Table 22 show that a large portion of exposure occurred in short periods of time, especially on mixed-traffic roadways. Off-street paths had more consistent (equal) exposure, with the exception of the Springwater Path. Half of 
cumulative exposure occurred in the highest $12-18 \%$ of on-road observations, and 19$30 \%$ of off-road observations. The higher skew on mixed-traffic facilities is likely attributable to nearby vehicle activity: passing vehicles and intersecting roadways.

Table 22. Gini index of inequality and the minimum portion of the observations representing half of the cumulative exposure, by location

\begin{tabular}{l|rr}
\hline Location & Gini Index & $\begin{array}{c}\text { Minimum portion with } \\
\text { 50\% of exposure }\end{array}$ \\
\hline I205 Path & 0.36 & 0.25 \\
Springwater Path & 0.49 & 0.19 \\
Waterfront Path & 0.40 & 0.22 \\
Other Path & 0.40 & 0.23 \\
Local & 0.45 & 0.18 \\
Bridge & 0.29 & 0.30 \\
Minor Collector & 0.50 & 0.16 \\
Major Collector & 0.56 & 0.12 \\
Minor Arterial & 0.47 & 0.16 \\
Major Arterial & 0.49 & 0.17 \\
\hline
\end{tabular}

\section{PARALLEL PATH EFFECTS}

Some of the concentrations measurements were taken on parallel facilities with starkly different traffic volumes. In order to test the effect of minor detours on exposure, concentrations on the parallel facilities were directly compared. The 4 comparisons in this section show that even minor, 1-2 block detours to parallel low-volume streets can significantly reduce exposure concentrations. Representative images for all four pairs of facilities are shown in Figure 20 (screen shots from on-bicycle video data).

E Burnside St. and SE Ankeney St. are parallel facilities separated by one block (80 m) with average ADT on the sampled links of 16,518 and 722, respectively. Burnside is a minor arterial classified as a District Collector in the TSP. Ankeney is a local road 
classified as a Local Service Traffic Street in the TSP. The facilities were ridden four times each over a distance of $2.8 \mathrm{~km}$ on two different days during the morning peak period. Concentrations of BTEX compounds were on average 44-88\% higher on Burnside than Ankeney, 59\% higher for the total BTEX concentration. Other concentrations were 51\% (TVOC), 201\% (CO), and 9\% $\left(\mathrm{PM}_{2.5}\right)$ higher on Burnside than Ankeney. All differences were significant based on a Wilcoxon rank sum test $(p<0.01)$.

N Williams Ave. and NE Rodney Ave. are parallel facilities separated by two blocks with average ADT on the sampled links of 7,358 and 655, respectively ${ }^{2}$. Williams is major collector classified as a Neighborhood Collector in the TSP. Rodney is a local road classified as a Local Service Traffic Street in the TSP. The facilities were ridden three times. Concentrations were on average 329\% (TVOC) and 221\% (CO) higher on Williams than Rodney. The differences were significant based on a Wilcoxon rank sum test $(p<0.01)$. Video data from Williams reveal frequent interactions ("leapfrogging") with buses due to heavy traffic congestion during the data collection period.

Naito Pkwy is a minor collector classified as a Traffic Access Street in the TSP. Average ADT on the sampled links was 19,092. A riverside path in Tom McCall Waterfront park runs parallel to Naito Pkwy for $2 \mathrm{~km}$, separated by $\sim 70 \mathrm{~m}$. The segments were ridden four times. Concentrations were on average 112\% (TVOC), 30\% (CO), and $4 \%\left(\mathrm{PM}_{2.5}\right)$ higher on Naito than the riverside path. The differences were significant based on a Wilcoxon rank sum test $(p<0.01)$ for TVOC and CO, but not $\mathrm{PM}_{2.5}(p=$

\footnotetext{
${ }^{2} \mathrm{~N}$. Williams Ave. has undergone a recent surge in development and traffic volumes are likely higher than reported.
} 
0.06). Unlike the previous comparisons of facilities separated by buildings, the parallel path has only a few trees acting as a barrier to the traffic emissions on Naito. However, being immediately adjacent to the river, the dispersion characteristics are good.

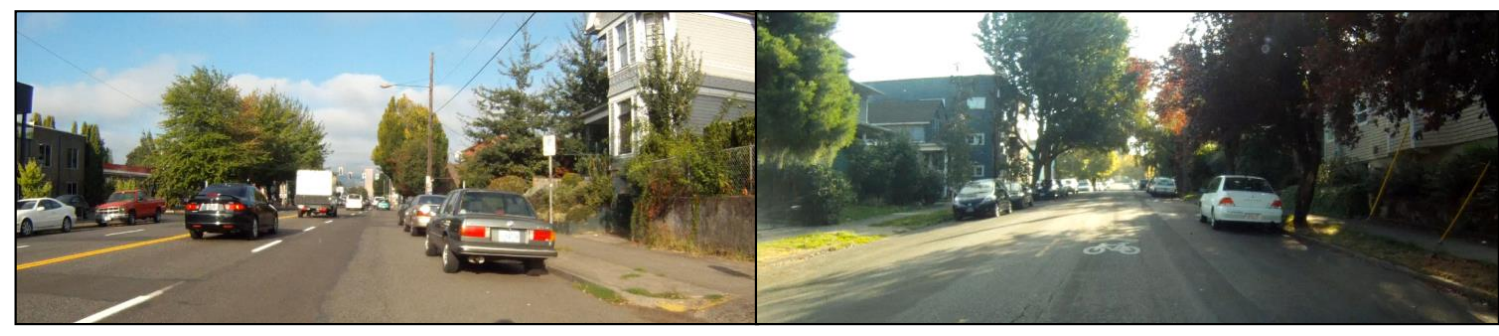

E Burnside St.

SE Ankeney St.

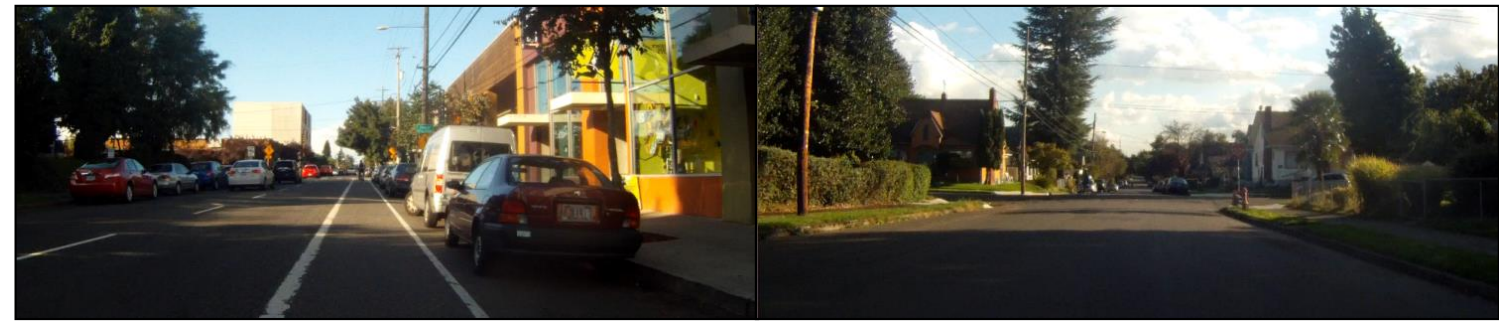

N Williams Ave.

NE Rodney Ave.

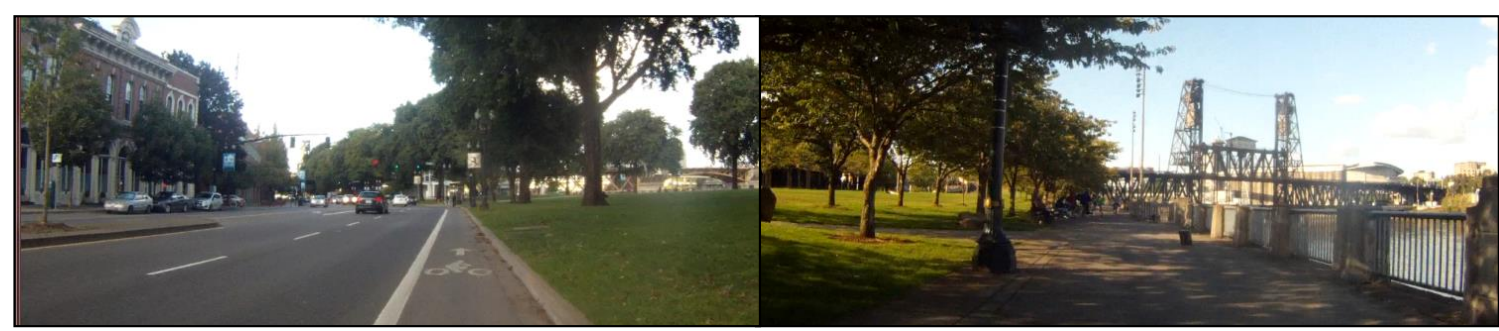

Naito Pkwy.

Riverside Path

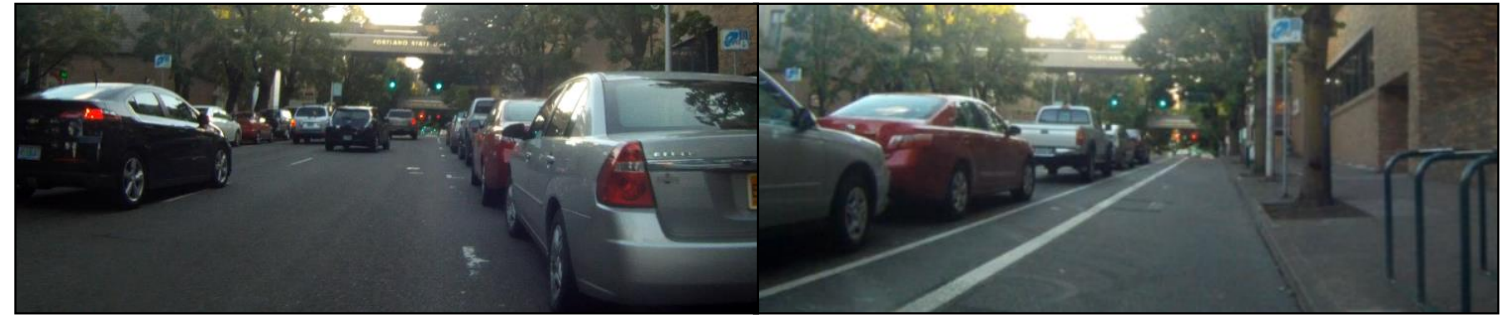

SW Broadway (on-road)

SW Broadway (cycle track)

Figure 20. Parallel facility comparisons (images from on-bicycle video data)

Measurements were taken along a cycle track on SW Broadway between SW Clay St. and SW Jackson St. The seven-block segment (560 m, 2 min) was ridden eight 
times total: two times each in the cycle track and in the far right traffic lane. Average TVOC concentrations were $9.2 \%$ higher on-road than in the cycle track, though the difference was not significant based on a Wilcoxon rank sum test $(p=0.16)^{3}$. Video data from Broadway showed that vehicle volumes were relatively light during the data collection periods. For comparison, a 2011 study of UFP on the same cycle track measured 8-38\% higher concentrations on-road than in the cycle track based on 6 sampling periods over 8 months of 2-7 hours each (Kendrick et al. 2011). The results suggest that cycle tracks are useful to reduce bicyclist exposure concentrations by increasing the separation between bicyclists and motorized traffic, but that cycle tracks are not as effective as parallel paths.

\section{CONCLUSIONS}

This chapter presents summary data on measured ambient and breath VOC concentrations. Assessment of ambient and breath differences by roadway facility type provides the first empirical evidence of the intuitive finding that on-road uptake of traffic-related air toxicants by bicyclists is greater on higher-volume facilities. Direct comparisons of exposure concentrations on parallel routes showed that minor detours to nearby low-traffic facilities can dramatically reduce exposure concentrations; hence provision and usage of low-traffic parallel paths in residential areas is an effective way to reduce bicyclists' exposure.

\footnotetext{
${ }^{3}$ The morning segments were $46.3 \%$ higher on-road, while the afternoon segments were $10.9 \%$ lower onroad.
} 
For other researchers intending to use breath sampling to measure environmental exposures, it is worthwhile to note that a critical pilot data collection period was undertaken to verify the instrumentation in our study. Initially FlexFoil air sampling bags were tested had high background levels of aromatic hydrocarbons and other compounds of interest. The FlexFilm bags used in this study had low background levels for the compounds of interest, but could only be filled and evacuated about ten times before incurring risks of cracking in the bag material and sample loss. This limitation meant that each bag could only be used for about four data collections, due to the need to purge the bags with helium several times between collections. In addition, the pilot period revealed the need to equilibrate blood concentrations of VOCs before starting data collection, as initial samples from uncontrolled start locations indicated continued clearance of previously-absorbed VOCs. Finally, the high water content in the breath samples makes measuring highly water-soluble compounds such as alcohols and acids challenging. 


\section{Chapter 5: Bicyclist Exposure Concentrations}

\section{INTRODUCTION}

While more than 40 studies have measured bicyclist pollutant exposure concentrations, studies including intra-modal covariates are still lacking (see Literature Review, Chapter 2). Several studies have tested the effects of specific facility types and found lower concentrations on more separated bicycle infrastructure (Kendrick et al. 2011, Hatzopoulou, Weichenthal, Dugum, et al. 2013, MacNaughton et al. 2014). A few studies have also tested high-traffic versus low-traffic bicycle routes, finding significant differences in exposure (Weichenthal et al. 2011, Cole-Hunter et al. 2012, Jarjour et al. 2013). High-traffic vs. low-traffic differences are typically larger for the more strongly traffic-related pollutants such as volatile organic compounds (VOC), ultrafine particles (UFP), carbon monoxide (CO), and black carbon particulate matter (BC) (see Literature Review, Chapter 2).

But bicyclist exposure research frequently fails to find significant associations between more specific traffic variables and exposure - especially if the traffic variables include all vehicle types and not specifically heavy vehicles (Adams, Nieuwenhuijsen, and Colvile 2001, Boogaard et al. 2009, Kaur and Nieuwenhuijsen 2009, Hatzopoulou, Weichenthal, Dugum, et al. 2013). Due to the lack of quantified traffic-exposure relationships, transportation professionals are unable to easily estimate expected exposure reductions when assessing bicyclist routes. The objective of this paper is to model bicyclist exposure concentrations on a wide range of facilities using roadway, traffic, and 
weather variables, with the primary intent of quantifying the impact of ADT on exposure to $\mathrm{VOC}, \mathrm{CO}$, and $\mathrm{PM}_{2.5}$ (fine particulate matter).

Bicyclists' exposure concentrations were modeled at two different levels: a highresolution model using 5-second data and a segment-level model. The advantage of the high-resolution model is that it can capture micro-scale variation in travel conditions (e.g. proximity to intersections), while the segment-level model illuminates trip-level impacts and informs the uptake models (which use segment-level breath data).

The literature on travelers' exposure to traffic-related air pollution suggests the potential explanatory variables in Table 23. Many of the variables in Table 23 are unavailable for the present analysis. Also, some available variables are correlated with other variables in the data set. For example, the number of lanes is related to facility type and ADT, and background concentrations are dependent to weather variables. 
Table 23. Potential explanatory variables for modeling exposure

\begin{tabular}{|c|c|c|c|c|c|}
\hline Category & Role & $\begin{array}{l}\text { Explanatory } \\
\text { element }\end{array}$ & Example variables & $\begin{array}{l}\text { Expected } \\
\text { size of } \\
\text { influence }\end{array}$ & $\begin{array}{l}\text { Availability } \\
\text { of data }\end{array}$ \\
\hline Traffic & Emissions & Vehicle volume & $\begin{array}{l}\text { Passing vehicles, } \\
\text { hourly traffic counts, } \\
\text { ADT, facility as proxy }\end{array}$ & High & $\begin{array}{l}\text { Low to } \\
\text { High }\end{array}$ \\
\hline Traffic & $\begin{array}{l}\text { Emissions \& } \\
\text { dispersion }\end{array}$ & Vehicle type & $\begin{array}{l}\text { Classification of } \\
\text { vehicle volume data }\end{array}$ & High & Low-Med \\
\hline Traffic & Emissions & Fuels & $\begin{array}{l}\text { Fuel composition and } \\
\text { characteristics }\end{array}$ & Low-Med & Low-Med \\
\hline Traffic & $\begin{array}{l}\text { Emissions \& } \\
\text { dispersion }\end{array}$ & Vehicle activity & $\begin{array}{l}\text { Speeds, queues, } \\
\text { accelerations, idling, } \\
\text { etc. }\end{array}$ & Low-Med & Med \\
\hline Weather & $\begin{array}{l}\text { Emissions \& } \\
\text { transformations }\end{array}$ & Temperature & Temperature & Med & High \\
\hline Weather & $\begin{array}{l}\text { Emissions \& } \\
\text { transformations }\end{array}$ & Humidity & Relative humidity & Low & High \\
\hline Weather & Dispersion & Wind & $\begin{array}{l}\text { Wind speed \& } \\
\text { variability }\end{array}$ & High & High \\
\hline Weather & Dispersion & $\begin{array}{l}\text { Atmospheric } \\
\text { mixing }\end{array}$ & Mixing layer height & Low-Med & Low-Med \\
\hline Land use & Emissions & $\begin{array}{l}\text { Near-road } \\
\text { industry, auto } \\
\text { services, } \\
\text { restaurants, } \\
\text { residential } \\
\text { combustion, etc. }\end{array}$ & $\begin{array}{l}\# \text { and types of } \\
\text { activities }\end{array}$ & Med-High & Low \\
\hline Land use & Dispersion & $\begin{array}{l}\text { Near-road } \\
\text { structure } \\
\text { geometry }\end{array}$ & $\begin{array}{l}\text { Building/wall height, } \\
\text { set-back }\end{array}$ & Med & Low \\
\hline Land use & Dispersion & $\begin{array}{l}\text { Near-road } \\
\text { vegetation }\end{array}$ & $\begin{array}{l}\text { Number of } \\
\text { trees/plants/shrubs, } \\
\text { size, location, foliage } \\
\text { density, type }\end{array}$ & Low & Low \\
\hline Land use & Dispersion & $\begin{array}{l}\text { Proximity to } \\
\text { other roadways }\end{array}$ & $\begin{array}{l}\text { Crossing or parallel } \\
\text { major road }\end{array}$ & Med & Med \\
\hline Geography & Dispersion & $\begin{array}{l}\text { Near-road } \\
\text { topography }\end{array}$ & $\begin{array}{l}\text { Roadway cuts, bridges, } \\
\text { land berms, hills, etc. }\end{array}$ & Med & Low \\
\hline Geography & Dispersion & $\begin{array}{l}\text { Roadway cross- } \\
\text { sectional } \\
\text { geometry }\end{array}$ & $\begin{array}{l}\text { \# of lanes, lanes } \\
\text { widths, location of } \\
\text { bicyclists }\end{array}$ & Low-Med & Med \\
\hline Geography & Emissions & Road grade & $\%$ grade & Med & Med \\
\hline Background & $\begin{array}{l}\text { Emissions, } \\
\text { transformations, } \\
\& \text { dispersion }\end{array}$ & $\begin{array}{l}\text { Combined } \\
\text { effects of other } \\
\text { region-scale } \\
\text { events and } \\
\text { processes }\end{array}$ & $\begin{array}{l}\text { Measured ambient } \\
\text { concentration }\end{array}$ & Med & Med \\
\hline
\end{tabular}


The measured explanatory variables tested in this analysis are shown in Table 24. As described in the Methods Chapter 3, the 5-second BTEX exposure concentrations are calculated by disaggregating the segment-level BTEX concentrations using the 1-Hz TVOC measurements, then aggregating up to 5 seconds. Aggregation was performed using the mode for dummy variables and mean for continuous variables. Traffic, ADT, and grade variables were set at 0 when sampling on an off-street path. |Grade| is the absolute value of the roadway grade in the direction of travel. LogAdt is the natural $\log$ transformed ADT. StopEnRoute is a dummy variable for when the data collection bicycle was stopped during the course of a ride because of traffic signals, stop signs, traffic congestion, etc. (for up to 120 seconds). StartupEnRoute is a dummy variable for the first ten seconds after a StopEnRoute event. LowSpeed is an indicator of sustained low-speed bicycling (0-12 kph, exclusive). NearCrossing is a dummy variable for when the data collection bicycle was on a local road and within $25 \mathrm{~m}$ of a major road crossing. Crossing Proximity is the distance to a major road crossing. Traffic Speed, Traffic Volume, and Traffic Density are real-time traffic variables from the DWR sensors. 
Table 24. Measured explanatory variables

\begin{tabular}{llll}
\hline Category & Explanatory element & Variable & Units \\
\hline Traffic & Vehicle volume & Coincident ADT, facility type & Vehicles/day, NA \\
\hline Traffic & $\begin{array}{l}\text { Vehicle activity } \\
\text { (congestion) }\end{array}$ & $\begin{array}{l}\text { Traffic volume, density, and minimum } \\
\text { speed at two reference locations on } \\
\text { Powell Blvd. }\end{array}$ & $\begin{array}{l}\text { vphpl, veh/ln-mi, } \\
\mathrm{kph}\end{array}$ \\
\hline Traffic & $\begin{array}{l}\text { Vehicle activity } \\
\text { (congestion) }\end{array}$ & $\begin{array}{l}\text { Bicyclist is traveling at a sustained low } \\
\text { speed (0-12 kph, exclusive, based on } \\
\text { modeling below) }\end{array}$ & $0 / 1$ \\
\hline Traffic & $\begin{array}{l}\text { Vehicle activity } \\
\text { (idle) }\end{array}$ & $\begin{array}{l}\text { Bicyclists is stopped en route - } \\
\text { presumably at a traffic signal (for up to } \\
\text { 120 seconds) }\end{array}$ & $0 / 1$ \\
\hline Traffic & $\begin{array}{l}\text { Vehicle activity } \\
\text { (acceleration) }\end{array}$ & $\begin{array}{l}\text { Bicyclist is in the first 10 seconds after a } \\
\text { stop en route }\end{array}$ & $0 / 1$ \\
\hline Weather & Temperature & On-road measured temperature & $\mathrm{C}$ \\
\hline Weather & Humidity & On-road measured temperature & $\%$ \\
\hline Weather & Wind speed & $\begin{array}{l}\text { Mean wind speed at a reference ODEQ } \\
\text { station }\end{array}$ & $\mathrm{mps}$ \\
\hline Land use & $\begin{array}{l}\text { Proximity to major } \\
\text { roadways }\end{array}$ & $\begin{array}{l}\text { Proximity to a major road crossing, when } \\
\text { riding on a Local Road }\end{array}$ & $\mathrm{m}$ \\
\hline Land use & $\begin{array}{l}\text { Proximity to major } \\
\text { roadways }\end{array}$ & $\begin{array}{l}\text { Bicyclist is near (within 25 m of) a major } \\
\text { road crossing, when riding on a Local } \\
\text { Road }\end{array}$ & $0 / 1$ \\
\hline Geography & Road grade & Grade, absolute grade & $\%$ \\
\hline Background & $\begin{array}{l}\text { Regional emissions, } \\
\text { transformations, and } \\
\text { dispersion }\end{array}$ & $\begin{array}{l}\text { Reference concentration at the park } \\
\text { location before each data collection } \\
\text { period }\end{array}$ & $\mathrm{ng} / \mathrm{L}$ \\
\hline
\end{tabular}

Correlations among the measured explanatory variables and exposure

concentrations are shown in Figure 21 using 5-second data. The real-time traffic variables are correlated amongst each other, as are weather variables. Background concentrations are positively correlated with temperature and negatively correlated with wind speed and humidity. 


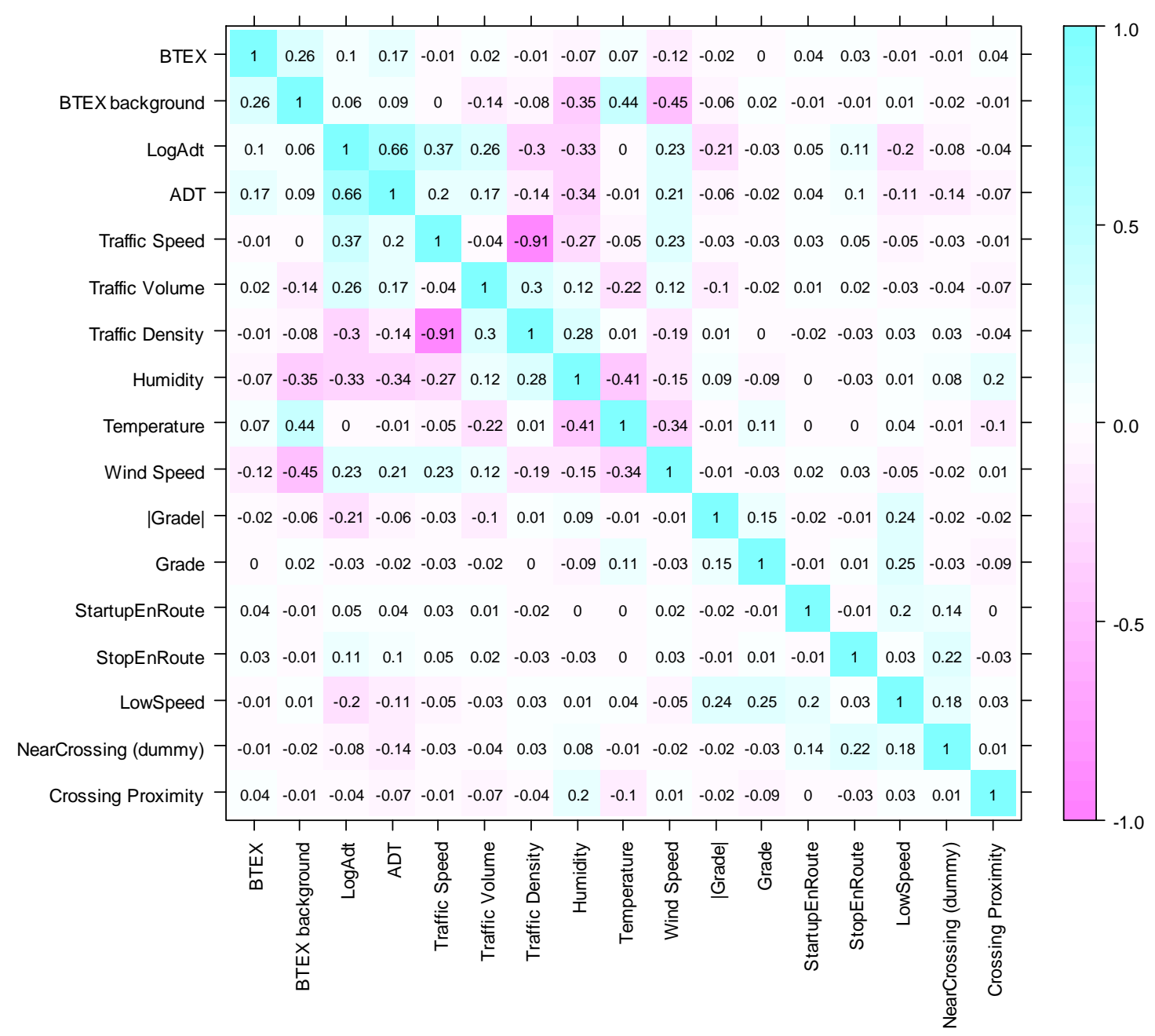

\section{Figure 21 . Correlations among 5-second aggregated explanatory variables and BTEX exposure concentrations}

As shown in the Data Overview Chapter 4, distinctly high concentrations were observed at a location on the Springwater Path coincident with polluting near-path industry. In order to separate the near-industry effects from the more general effects of the path in the model, observations within a geographic bound of the industrial area were identified as shown in Figure 22 (a distance of $2.5 \mathrm{~km}$ along the Springwater Path). The subset of observations comprises 995 -second data points $(0.74 \%$ of the dataset). 


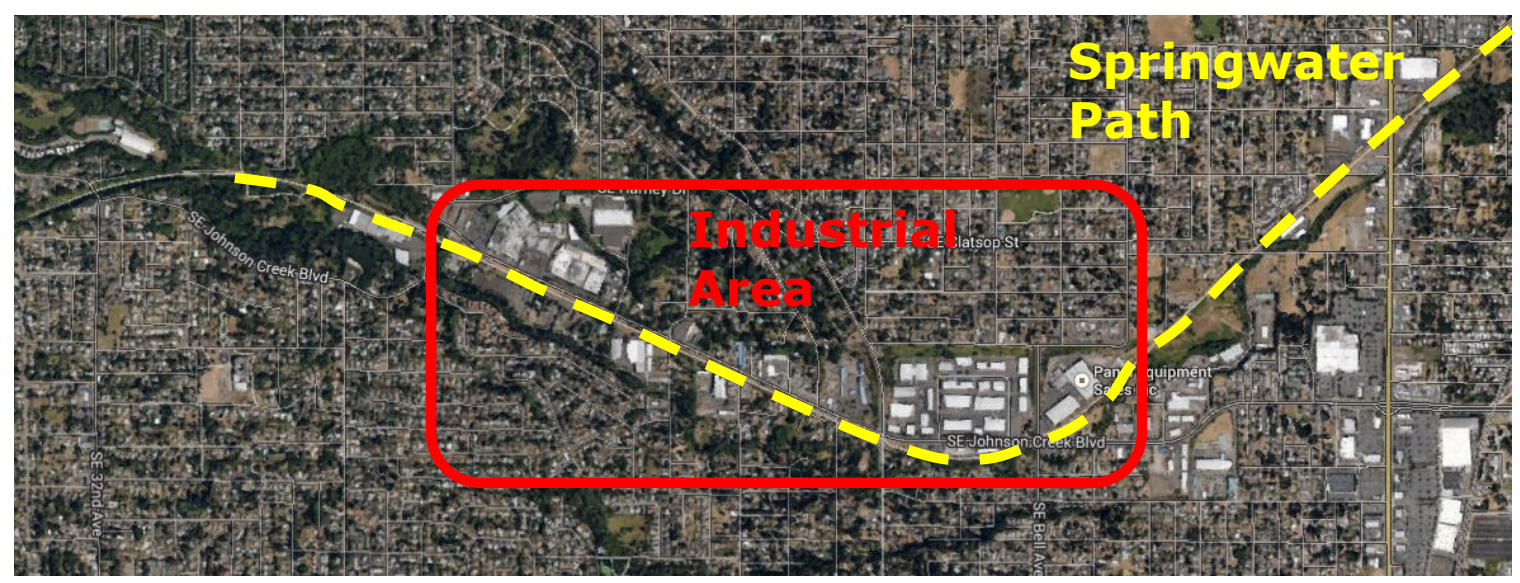

Figure 22. Industrial area along the Springwater Path

\section{HIGH-RESOLUTION MODEL OF EXPOSURE}

A model of 5-second BTEX exposure concentration was estimated using ordinary least squares with heteroscedasticity and autocorrelation consistent (HAC) standard errors $^{1}$. The measured explanatory variables in Table 24 and Figure 21 were tested by stepwise addition to the model. Interaction terms and transformations were explored, and a discussion of alternative specifications is presented below. The model specification is based on theoretical basis, statistical significance, model fit, and judgment. The full model is specified:

$$
\begin{aligned}
\ln \left(C_{i}^{\text {ex }}\right) & =\beta_{0}+\beta_{1} \ln \left(\mathrm{C}_{i}^{\text {bg }}\right)+\beta_{2} \text { WindSpeed }_{i}+\beta_{3} \text { MixedTraffic }_{i}+ \\
& \beta_{4} \text { OffStreetPath }_{i}+\beta_{5} \text { NearPathIndustry }_{i}+\beta_{6} \mathrm{ADT}_{i}+\beta_{7} \mathrm{ADT}_{i}^{2}+ \\
& \beta_{8} \text { StopEnRoute }_{i}+\beta_{9} \text { StartUpEnRoute }_{i}+\beta_{10} \text { LowSpeed }_{i}+\beta_{11} \mathrm{ADT}_{i} * \\
& \text { StopEnRoute }_{i}+\beta_{12} \mathrm{ADT}_{i} * \text { LowSpeed }_{i}+\varepsilon_{i}
\end{aligned}
$$

where $\varepsilon_{i}$ is an error term and the other variables are defined in Table 25 .

\footnotetext{
${ }^{1}$ Estimated using the 'vcovHAC' function from the 'sandwich' package in R, which implements the prewhitened covariance matrix from Andrews and Monahan(1991)(1991)(1991) (1992)
} 
Table 25. Variable definitions in high-resolution BTEX exposure model; $i$ is the observation index

\begin{tabular}{|c|c|c|}
\hline Variable & Units & Description \\
\hline$C_{i}^{e x}$ & $\mathrm{ng} / \mathrm{L}$ & Measured exposure concentration \\
\hline$C_{i}^{b g}$ & $\mathrm{ng} / \mathrm{L}$ & $\begin{array}{l}\text { Measured concentration at the reference park location } \\
\text { before the data collection which included observation } i\end{array}$ \\
\hline WindSpeed $_{i}$ & mps & $\begin{array}{l}\text { Scalar-average concurrent wind speed from the ODEQ } \\
\text { station }\end{array}$ \\
\hline MixedTraffic $_{i}$ & 0,1 & $\begin{array}{l}\text { Dummy variable }=1 \text { if observation } i \text { is on a mixed- } \\
\text { traffic (non-separated) travel way }\end{array}$ \\
\hline OffStreetPath $_{i}$ & 0,1 & $\begin{array}{l}\text { Dummy variable }=1 \text { if observation } i \text { is on an off-street } \\
\text { path }\end{array}$ \\
\hline NearPathIndustry $_{i}$ & 0,1 & $\begin{array}{l}\text { Dummy variable }=1 \text { if observation } i \text { is in the industrial } \\
\text { area of the Springwater off-street path }\end{array}$ \\
\hline $\mathrm{ADT}_{i}$ & $\begin{array}{l}1,000 \\
\text { veh/day }\end{array}$ & $\begin{array}{l}\text { Average ADT estimate for the links traveled during } \\
\text { observation interval } i \text { (if on a mixed-traffic facility, not } \\
\text { an off-street path) }\end{array}$ \\
\hline StopEnRoute $_{i}$ & 0,1 & $\begin{array}{l}\text { Dummy variable }=1 \text { if observation } i \text { is during a stop } \\
\text { while riding }\end{array}$ \\
\hline StartupEnRoute $_{i}$ & 0,1 & $\begin{array}{l}\text { Dummy variable }=1 \text { if observation } i \text { is within } 10 \\
\text { seconds of a start while riding }\end{array}$ \\
\hline LowSpeed $_{i}$ & 0,1 & $\begin{array}{l}\text { Dummy variable }=1 \text { if the bicycle travel speed is } \\
\text { between } 0 \text { and } 12 \mathrm{kph} \text { (exclusive) }\end{array}$ \\
\hline
\end{tabular}

The high-resolution exposure model was estimated using data from travel segments and the park location $(N=14,220)$. The estimated model coefficients with HAC robust standard error estimates are shown in Table 26 (adjusted $R^{2}=0.334$ ). Analysis of the model residuals shows both autocorrelation and heteroscedasticity, justifying the need for HAC standard error estimates. The first-order autocorrelation coefficient for the residuals is 0.848, and a Box-Ljung test is significant at $p<0.01$. 
Regression of the squared residuals on an eight-factor RoadType variable ${ }^{2}$ rejects homoscedasticity by facility type (adjusted $R^{2}=0.020$ and $p<0.01$ ). Summary data on measured concentrations and the explanatory variables in the 5-second BTEX model are shown in Table 27.

Table 26. High-resolution BTEX exposure model estimated coefficients

\begin{tabular}{|c|c|c|c|c|}
\hline & Value & $\begin{array}{l}\text { Standard } \\
\text { Error }\end{array}$ & t-statistic & p-value \\
\hline (Intercept) & 0.521 & 0.216 & 2.415 & 0.016 \\
\hline $\ln \left(C^{b g}\right)$ & 0.677 & 0.094 & 7.190 & $<0.001$ \\
\hline WindSpeed & -0.125 & 0.024 & -5.314 & $<0.001$ \\
\hline MixedTraffic & 0.341 & 0.061 & 5.618 & $<0.001$ \\
\hline OffStreetPath TRUE & 0.489 & 0.082 & 5.941 & $<0.001$ \\
\hline NearPathIndustry TRUE & 1.408 & 0.270 & 5.225 & $<0.001$ \\
\hline$A D T$ & 0.033 & 0.005 & 6.415 & $<0.001$ \\
\hline$A D T^{2}$ & -0.00040 & 0.00012 & -3.240 & 0.001 \\
\hline StopEnRoute TRUE & 0.285 & 0.051 & 5.631 & $<0.001$ \\
\hline StartupEnRoute TRUE & 0.204 & 0.042 & 4.809 & $<0.001$ \\
\hline LowSpeed TRUE & 0.177 & 0.030 & 5.945 & $<0.001$ \\
\hline ADT:StopEnRoute & -0.010 & 0.004 & -2.747 & 0.006 \\
\hline$A D T:$ LowSpeed & -0.008 & 0.002 & -3.243 & 0.001 \\
\hline
\end{tabular}

\footnotetext{
${ }^{2}$ Levels: Park, I-205 Path, Springwater Path, Local Road, Minor Collector, Major Collector, Minor Arterial, Major Arterial
} 
Table 27. Characterization of pollutant concentrations and explanatory variables

\begin{tabular}{|c|c|c|c|c|}
\hline & minimum & median & mean & maximum \\
\hline$C^{e x}(\mathrm{ng} / \mathrm{l})$ & 0.01 & 6.28 & 9.83 & $1,020.00$ \\
\hline$C^{b g}(\mathrm{ng} / \mathrm{l})$ & 1.82 & 4.62 & 5.47 & 11.18 \\
\hline Wind speed (mps) & 0.18 & 1.74 & 1.85 & 4.11 \\
\hline$A D T$ & 0 & 890 & 8,360 & 53,950 \\
\hline Mixed traffic & \multicolumn{4}{|c|}{$68 \%$ TRUE } \\
\hline OffStreetPath & \multicolumn{4}{|c|}{$8 \%$ TRUE } \\
\hline NearPathIndustry & \multicolumn{4}{|c|}{$1 \%$ TRUE } \\
\hline StopEnRoute & \multicolumn{4}{|c|}{ 9\% TRUE } \\
\hline StartupEnRoute & \multicolumn{4}{|c|}{ 4\% TRUE } \\
\hline LowSpeed & \multicolumn{4}{|c|}{$17 \%$ TRUE } \\
\hline
\end{tabular}

The high-resolution exposure model coefficients in Table 26 show that background concentrations, wind, and roadway variables are important determinants of on-road exposure. The elasticity of on-road to background concentrations was 0.68 .

Concentrations decreased by $12.5 \%$ with each $1 \mathrm{mps}$ increase in wind speed. The dummy variable coefficients can be interpreted ${ }^{3}$ as an expected BTEX concentration increase (compared to the reference park location) of:

- $40 \%$ on mixed-traffic roadways (in addition to ADT effects),

- $63 \%$ on off-street paths,

- $294 \%$ in the industrial area of the Springwater Path (in addition to the baseline off-street path level),

- $33 \%$ while stopped during a ride (decreasing effect with increasing ADT),

\footnotetext{
${ }^{3}$ An established estimator for the effects of dummy variables on the dependent variable in a semi-log model is $\left[\exp \left(\beta-\frac{1}{2} S E_{\beta}^{2}\right)-1\right] 100 \%$, where $\beta$ is the estimated dummy variable coefficient and $S E_{\beta}$ is its standard error (Jan van Garderen and Shah 2002).
} 
- $22 \%$ in the first 10 seconds of riding after a stop, and

- $19 \%$ during sustained low-speed riding (decreasing effect with increasing ADT).

The ADT interaction terms indicate that the effects of stops and load-speed riding are proportionally smaller on higher-volume facilities.

The total effect of ADT on BTEX exposure is the combination of linear, squared, and interaction terms in the model. The maximum ADT effect occurs at

$$
\mathrm{ADT}=-\frac{1}{2} \frac{\beta_{6}+\beta_{11} * \text { StopEnRoute }+\beta_{12} * \text { LowSpeed }}{\beta_{7}}
$$

which yields 41,250 ADT during normal riding, 28,750 when stopped en route, and 31,250 during low-speed riding. The largest facilities in the data collection, major arterials, had ADT of 30,000 to 40,000.

Figure 23 shows the modeled BTEX exposure concentrations as a function of facility ADT for four different mixed-traffic riding conditions: riding, stopped, low-speed riding, and startup after a stop (assumed to also be at low speed). Mean background concentration and wind speed are applied (Table 27). Exposure generally increases with ADT, although exposure during stop-and-go riding (characterized by the last three conditions) level out and even decrease slightly on very large facilities. One potential reason is that in congested traffic streams on large facilities the volume of vehicles passing the bicyclist will decrease because the vehicles queue upstream. On lowervolume facilities stop-and-go riding leads to higher exposure concentrations, likely because of co-occurrence with intersections. 


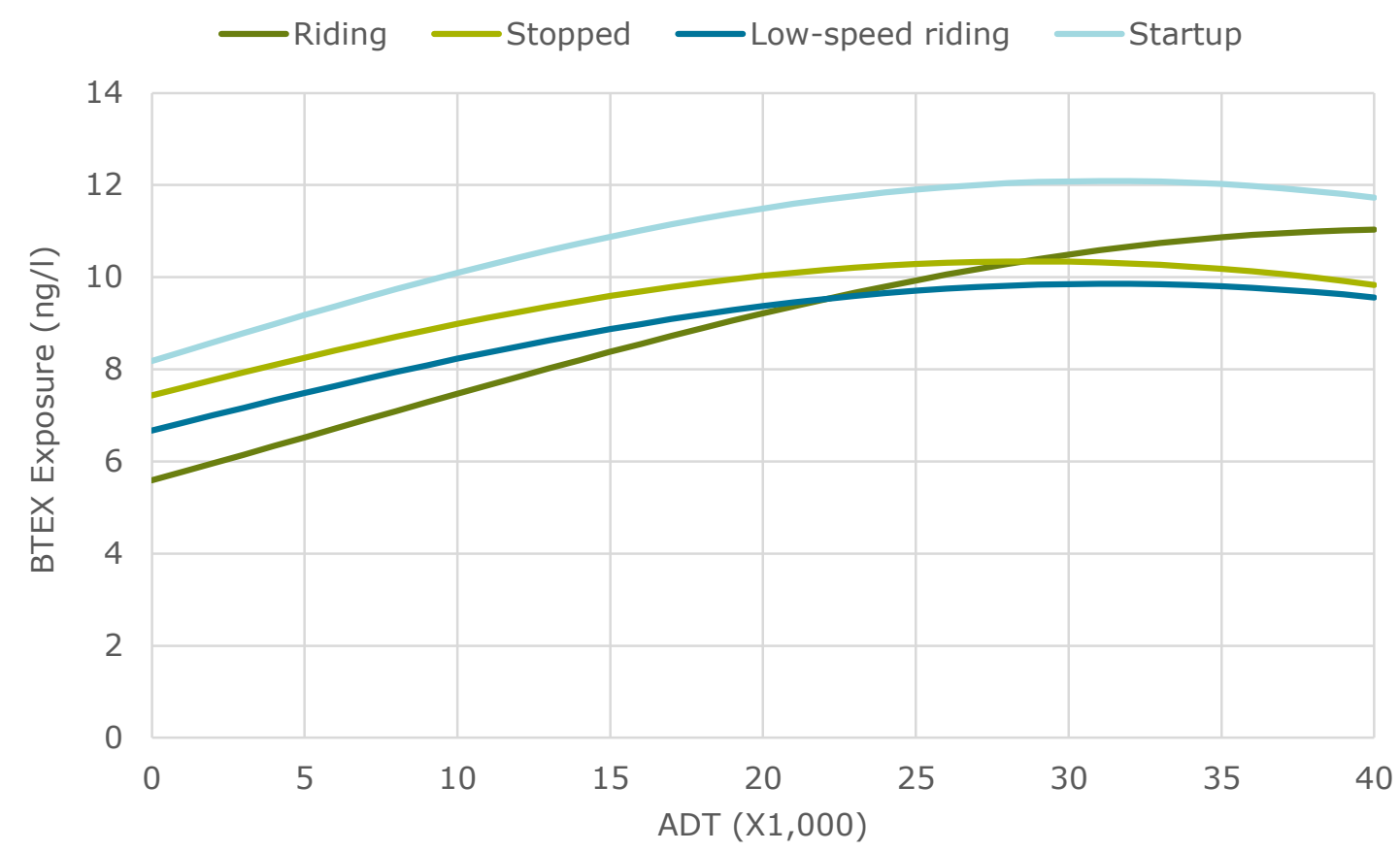

Figure 23. Modeled effects of ADT on BTEX exposure concentrations for mixedtraffic riding

Figure 24 shows the modeled concentrations for off-street facilities (dashed lines) in addition to the same four mixed-traffic riding conditions. Typical off-street paths are around expected concentrations for the lowest-volume mixed-traffic streets, while the path near industry has dramatically high exposure concentration. This finding emphasizes the important role of near-road, non-traffic sources of certain pollutants. 


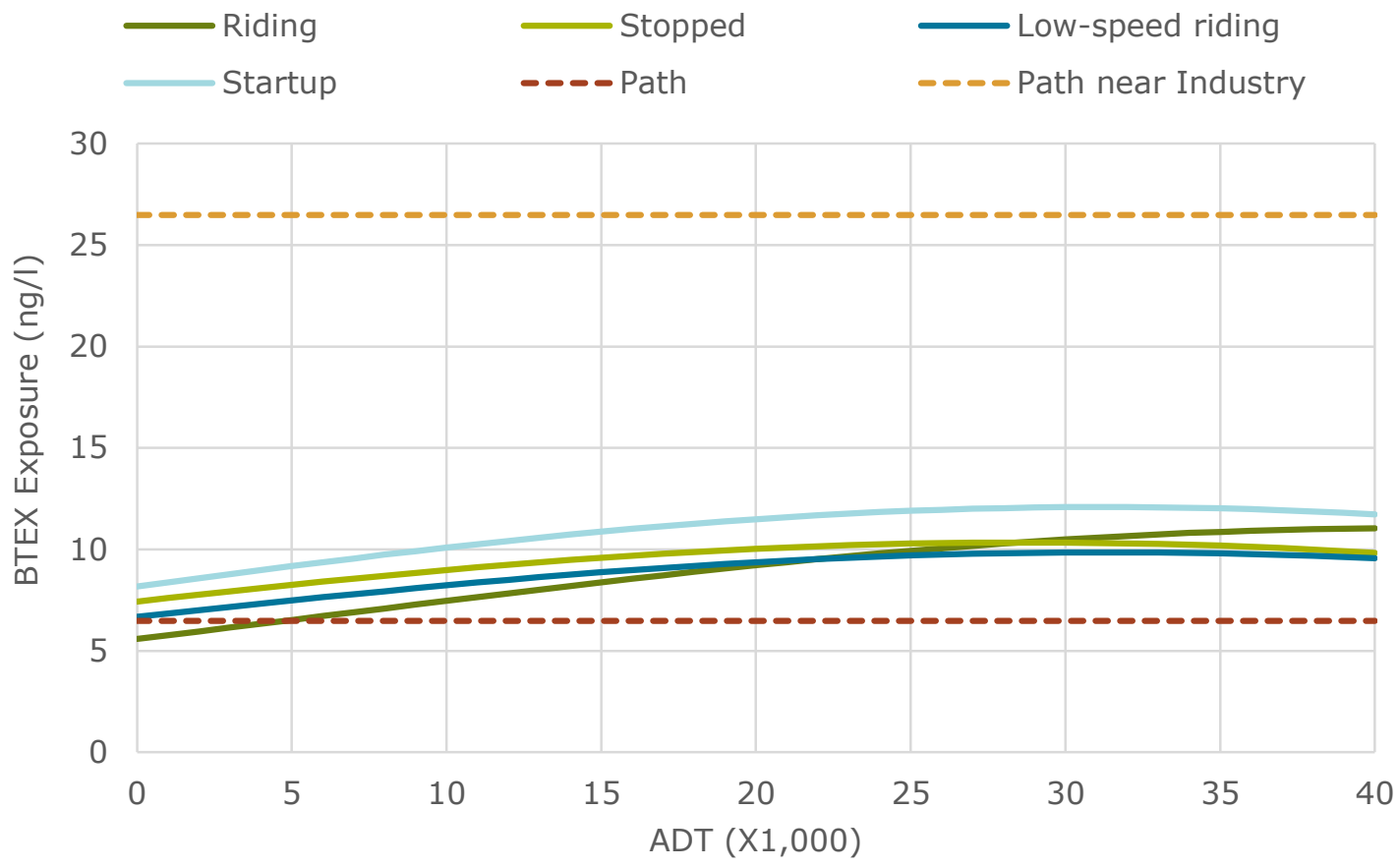

Figure 24. Modeled effects of ADT on BTEX exposure concentrations

Table 28 shows the changes in sum of squared residuals (SSR) with the singleterm deletion of model variables. Background concentrations are the strongest single explanatory variable in terms of explained variance, followed by facility classifications, ADT, and wind speed. Background concentrations and wind speed have similar combined SSR changes to the combined roadway/travel variables. 
Table 28. Change in SSR with single-term deletion of explanatory variables

\begin{tabular}{l|rr}
\hline Dropped Term $(s)$ & \multicolumn{1}{l}{ SSR } & SSR change \\
\hline- & 7047.2 & - \\
$\ln \left(C^{b g}\right)$ & 7912.4 & 865.2 \\
WindSpeed & 7170.1 & 122.9 \\
MixedTraffic & 7265.3 & 218.1 \\
OffStreetPath & 7232.9 & 185.7 \\
NearPathIndustry & 7224.8 & 177.6 \\
$A D T$ and interaction terms & 7247.3 & 200.1 \\
$A D T^{2}$ & 7101.6 & 54.4 \\
StopEnRoute and interaction term & 7103.6 & 56.4 \\
StartupEnRoute & 7067.4 & 20.2 \\
LowSpeed and interaction term & 7095.7 & 48.5 \\
\hline
\end{tabular}

\subsection{Alternative specifications}

The first alternative models consider specifications without the NearPathInsutry dummy variable. Removing that variable, the OffStreetPath coefficient increases to 0.615 and the overall model fit falls to adjusted $R^{2}=0.318$. The other model coefficients are relatively unchanged, and all are significant at $p<0.05$. The estimated OffStreetPath coefficient can be interpreted as an expected BTEX concentration increase (compared to the reference park location) of $84 \%$. If the two off-street paths are represented with separate dummy variables, the I-205 Path coefficient is 0.424 and the Springwater Path coefficient is 1.064 . These coefficients imply expected BTEX concentration increases (compared to the reference park location) of 52\% and $165 \%$ on the I-205 and Springwater Paths, respectively. The overall model fit is adjusted $R^{2}=0.329$. The other model coefficients are relatively unchanged, and all coefficients are significant at $p<0.05$. 
Without a separate variable, the NearPathInsutry effect is absorbed by the Springwater Path or OffStreetPath dummy variables.

The ADT variable is important as a strong predictor of exposure and a useful, accessible parameter to apply in practice. Several specifications of ADT in the model were explored to provide more insight into its relationship with BTEX exposure. Table 29 compares similar models with three different ADT specifications: linear, quadratic, and logarithmic. All three are similar to the full model described in the previous section with the interaction terms removed. Estimated coefficients are shown, in addition to model fit characteristics. All coefficients are significant at $p<0.05$ based on HAC robust standard error estimates. Figure 25 illustrates the effects of ADT on BTEX exposure for the same three model specifications in Table 29. A semi-elasticity of BTEX exposure of around $2 \%$ per 1,000 ADT appears to be a good central estimate for the relationship across model specifications. 
Table 29. Comparison of alternative specifications of ADT variable

\begin{tabular}{l|rrr}
\hline & Linear & Logarithmic & Quadratic \\
\hline (Intercept) & 0.554 & 0.517 & 0.534 \\
$\ln \left(C^{b g}\right)$ & 0.670 & 0.690 & 0.680 \\
WindSpeed & -0.127 & -0.122 & -0.124 \\
MixedTraffic & 0.388 & -0.502 & 0.332 \\
OffStreetPath & 0.485 & 0.487 & 0.487 \\
NearPathIndustry & 1.399 & 1.390 & 1.394 \\
StopEnRoute & 0.209 & 0.172 & 0.182 \\
StartupEnRoute & 0.210 & 0.186 & 0.196 \\
LowSpeed & 0.129 & 0.139 & 0.135 \\
\hline$A D T$ & 0.0139 & - & 0.0305 \\
$A D T^{2}$ & - & - & -0.000394 \\
ln $(A D T)$ & - & 0.128 & - \\
\hline Adjusted $R^{2}$ & 0.326 & 0.332 & 0.331 \\
Change in SSR from & 408.45 & 470.81 & 459.96 \\
dropping ADT term(s) & & & \\
AIC & 30579 & 30453 & 30478 \\
\hline
\end{tabular}

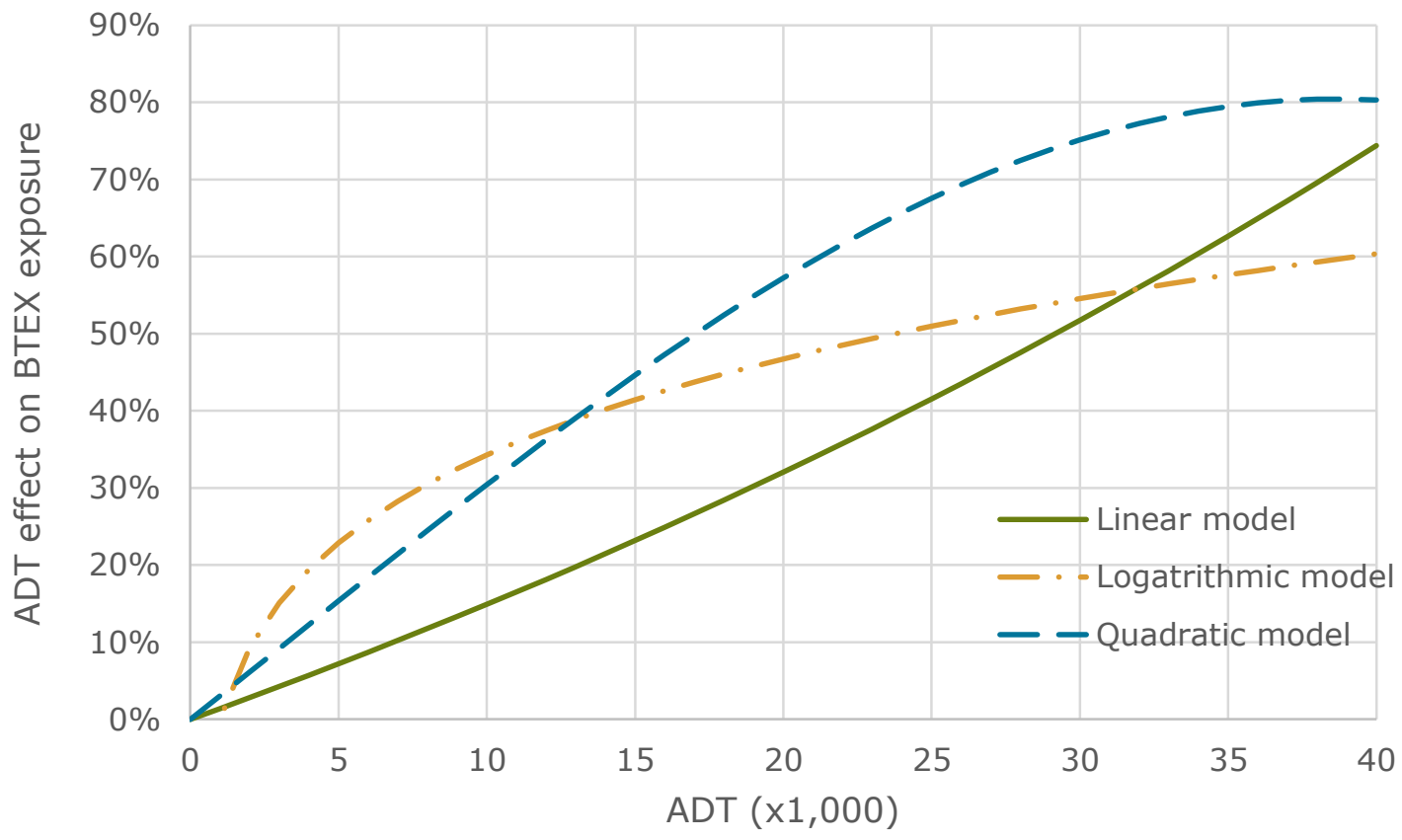

Figure 25. Comparison of ADT effects on exposure for different specifications 
Figure 26 illustrates the marginal impact of ADT on BTEX exposure concentrations for the 3 models in Table 29. Although the effects illustrated in Figure 25 are roughly consistent among the models, the marginal effects in Figure 26 vary dramatically. The semi-elasticity from the linear model is a 1.4\% increase in BTEX exposure per 1,000 additional ADT. The semi-elasticity from the quadratic model falls from $3.0 \%$ per 1,000 ADT at 1,000 ADT to $1.5 \%$ per $1,000 \mathrm{ADT}$ at $40,000 \mathrm{ADT}$, and is equal to the linear model semi-elasticity at $42,000 \mathrm{ADT}$. The estimated $\ln (A D T)$ coefficient indicates BTEX exposure elasticity to ADT of 0.128 , which aligns with the semi-elasticity in the linear model at an ADT of 9,000.

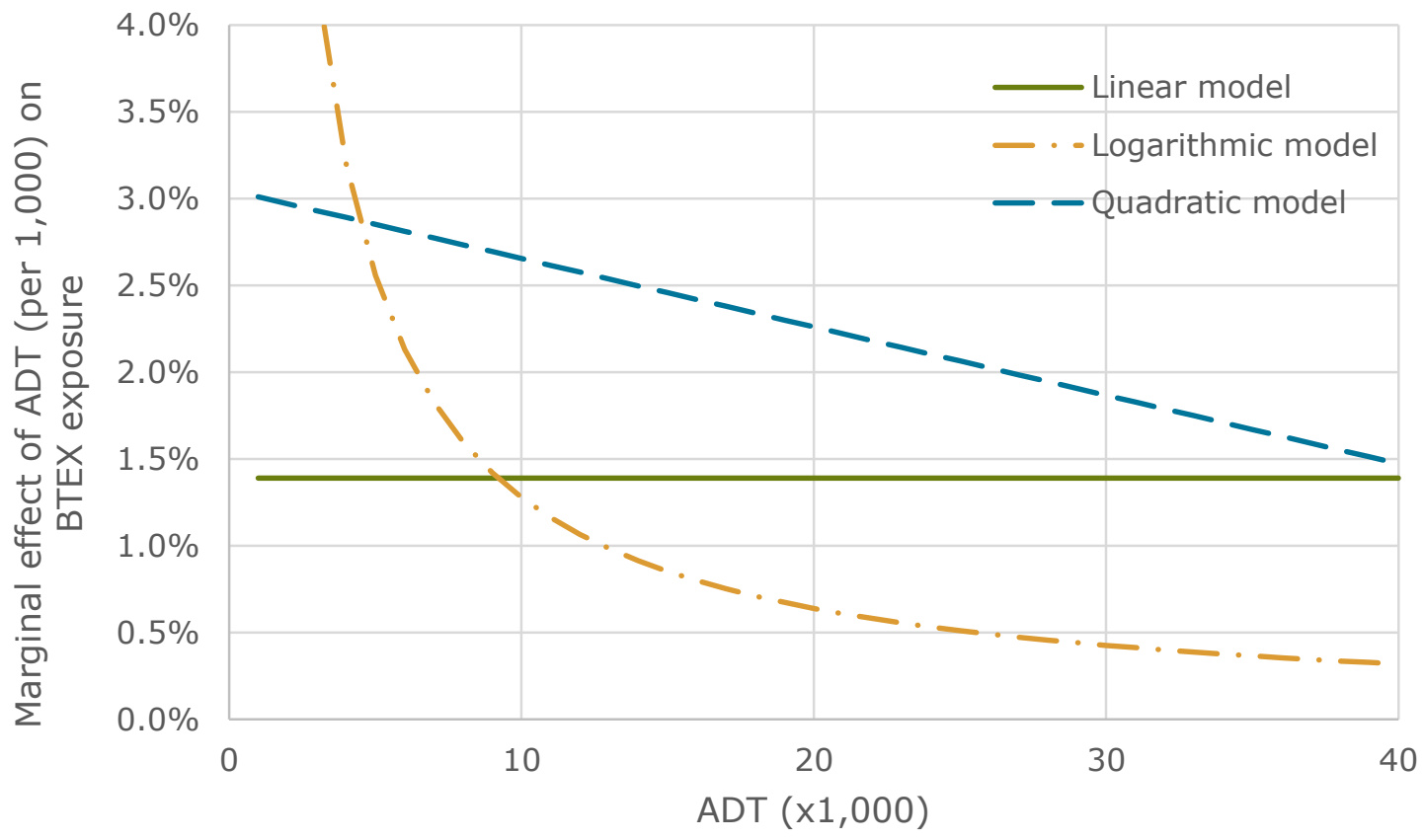

Figure 26. Comparison of Marginal ADT effects on exposure for different specifications

If background concentrations are not available then the weather factors become more important variables. Removing the $\ln \left(\mathrm{C}_{i}^{b g}\right)$ term, the model $R^{2}$ falls to 0.253 . 
Removing the $\ln \left(\mathrm{C}_{i}^{b g}\right)$ term but adding temperature and relative humidity terms brings the $R^{2}$ back up slightly to 0.278 . The estimated coefficient on the temperature term (in ${ }^{\circ} \mathrm{C}$ ) is $0.050(p<0.01)$ and on the relative humidity term (in \%) is -0.0001 (not significant, with $p=0.32$ ). The wind speed coefficient increases in magnitude to -0.236 and the other coefficients are largely unaffected. Both temperature and humidity were tested and found to be not significant at $p<0.05$ with background concentrations included in the model. An alternative specification was also tested with a differenced dependent variable of on-road minus background exposure concentrations: $\ln \left(C_{i}^{e x}\right)-$ $\ln \left(C_{i}^{b g}\right)$. All coefficients are still significant at $p<0.05$ (adjusted $R^{2}=0.166$ ). The Wind Speed coefficient in this model is -0.0446 , smaller than reported for the full model in Table 26, due to the correlation between wind speed and background concentrations. The traffic-related variables are relatively unchanged, lending confidence to the estimated traffic effects in the model.

The main two off-street facilities used in the data collection were 1) the I-205 Path running north-south parallel to a freeway with high ADT (100,000-150,000), intermittently inside and outside of an adjacent sound wall, and 2) the Springwater Path running east-west between the river and the I-205 Path, including sections in parkland and sections parallel to a roadway in an industrial area. Likely VOC-emitting businesses in the corridor include metal casting and machining, engine services, paint and powercoating, and other manufacturing. The difference in concentrations between the Springwater and I-205 paths is large, and models were estimated with separate dummy variables. Without the NearPathIndustry dummy variable the coefficients on the path 
dummy variables are significantly different (by an order of magnitude). With the NearPathIndustry dummy variable the coefficients on the path dummy variables $(0.425$ and 0.634 for the I-205 and Springwater paths, respectively) are not significantly different at $p<0.05$ based on a HAC-robust f-test (f-statistic of 0.835 with 1 degree of freedom).

Although static facility-related variables (ADT, facility dummy) were strong determinants of exposure, the dynamic traffic variables tested were not significant. This effect could be due to correlation between traffic conditions and meteorology/wind speed (Figure 21) or to the dominance of spatial over temporal traffic variables (especially for consistent times of the day). In other words, the variation in bicyclist exposure concentrations at one location is smaller than the variation over the course of a ride, as bicyclists traverse facilities of varying size and characteristics. Proximity to a major roadway crossing was not significant in the model when StopEnRoute and StartupEnRoute were included.

\subsection{Comparing pollutants}

A single model specification was estimated for all measured pollutants in order to compare the coefficients. The model was similar to the one specified in the previous section, but replacing background concentrations with temperature in ${ }^{\circ} \mathrm{C}$ (because background concentration data was not available for all pollutants). The model specification was 


$$
\begin{aligned}
& \ln \left(C_{i}^{\text {ex }}\right)=\beta_{0}+\beta_{1} \text { Temperature }_{i}+\beta_{2} \text { WindSpeed }_{i}+\beta_{3} \text { MixedTraffic }_{i}+ \\
& \beta_{4} \text { OffStreetPath }_{i}+\beta_{5} \text { NearPathIndustry }_{i}+\beta_{6} \mathrm{ADT}_{i}+\beta_{7} \mathrm{ADT}_{i}^{2}+ \\
& \beta_{8} \text { StopEnRoute }_{i}+\beta_{9} \text { StartUpEnRoute }_{i}+\beta_{10} \text { LowSpeed }_{i}+\beta_{11} \mathrm{ADT}_{i} * \\
& \text { StopEnRoute }_{i}+\beta_{12} \mathrm{ADT}_{i} * \text { LowSpeed }_{i}+\varepsilon_{i}
\end{aligned}
$$

The estimated model coefficients for natural log-transformed BTEX, TVOC, $\mathrm{CO}, \mathrm{CO}_{2}$, and $\mathrm{PM}_{2.5}$ concentrations are shown in Table 30, along with the number of non-missing observations used in estimation and the adjusted $R^{2}$ values. The data used for estimation were limited to the data collection periods with BTEX data. The model was estimated using OLS with five-second aggregated data and HAC robust standard error estimates.

\begin{tabular}{|c|c|c|c|c|c|c|c|c|c|c|}
\hline & BTEX & & TVOC & & $\mathrm{CO}$ & & $\mathrm{CO}_{2}$ & & $\mathrm{PM}_{2.5}$ & \\
\hline (Intercept) & 0.865 & $* * *$ & 2.683 & $* * *$ & 1.189 & $* * *$ & 6.089 & $* * *$ & -1.159 & $* * *$ \\
\hline Temperature & 0.051 & $* * *$ & -0.054 & $* * *$ & -0.135 & $* * *$ & 0.0038 & $*$ & -0.022 & $* * *$ \\
\hline WindSpeed & -0.235 & $* * *$ & -0.043 & $* *$ & -0.021 & & -0.013 & $* *$ & -0.137 & $* * *$ \\
\hline MixedTraffic & 0.350 & $* * *$ & 0.079 & & 0.216 & $* *$ & 0.024 & $* *$ & -0.270 & $* * *$ \\
\hline OffStreetPath & 0.404 & $* * *$ & 0.184 & $*$ & 0.604 & $* * *$ & 0.085 & $* * *$ & -0.263 & $* * *$ \\
\hline $\begin{array}{l}\text { NearPath } \\
\text { Industry }\end{array}$ & 1.647 & $* * *$ & 1.811 & $* * *$ & 0.221 & & 0.061 & $* * *$ & 0.616 & $* * *$ \\
\hline ADT & 0.030 & $* * *$ & 0.031 & $* * *$ & 0.010 & & 0.0030 & $* *$ & 0.00081 & \\
\hline $\mathrm{ADT}^{2} \times 10^{-3}$ & -0.31 & $* *$ & -0.33 & $* *$ & 0.14 & & -0.044 & & 0.035 & \\
\hline StopEnRoute & 0.271 & $* * *$ & 0.154 & $* * *$ & -0.120 & & 0.00069 & & 0.249 & $* * *$ \\
\hline StartupEnRoute & 0.196 & $* * *$ & 0.206 & $* * *$ & -0.0093 & & -0.0037 & & 0.023 & \\
\hline LowSpeed & 0.180 & $* * *$ & 0.076 & $* * *$ & 0.010 & & -0.0058 & & 0.051 & $* *$ \\
\hline $\begin{array}{l}\text { ADT: } \\
\text { StopEnRoute }\end{array}$ & -0.0090 & $* * *$ & -0.0043 & & 0.0058 & & -0.00053 & & 0.0055 & $* *$ \\
\hline ADT:LowSpeed & -0.0070 & $* * *$ & -0.0039 & & 0.00017 & & 0.00045 & & 0.0036 & $* *$ \\
\hline $\mathrm{N}$ & 14,220 & & 14,220 & & 10,925 & & 13,417 & & 13,869 & \\
\hline Adjusted $\mathrm{R}^{2}$ & 0.278 & & 0.166 & & 0.156 & & 0.221 & & 0.133 & \\
\hline
\end{tabular}

Table 31 shows model estimates of similar models with insignificant terms removed.

Table 30. Comparison of high-resolution concentration model coefficients among pollutants with uniform specifications (log-transformed dependent variables)

Significance level indicated by: ${ }^{* * *} p<0.01,{ }^{* *} p<0.05,{ }^{*} p<0.10$ 
Table 31. Comparison of restricted high-resolution concentration model coefficients among pollutants (log-transformed dependent variables)

\begin{tabular}{lrlrlrllllll}
\hline & \multicolumn{1}{c}{ BTEX } & \multicolumn{1}{c}{ TVOC } & \multicolumn{1}{c}{$\mathrm{CO}$} & & $\mathrm{CO}_{2}$ & \multicolumn{3}{c}{$\mathrm{PM}_{2.5}$} \\
\hline (Intercept) & 0.865 & $* * *$ & 2.736 & $* * *$ & 1.121 & $* * *$ & 6.136 & $* * *$ & -1.158 & $* * *$ \\
Temperature & 0.051 & $* * *$ & -0.052 & $* * *$ & -0.134 & $* * *$ & & & -0.023 & $* * *$ \\
WindSpeed & -0.235 & $* * *$ & -0.048 & $* *$ & & & & & -0.137 & $* * *$ \\
MixedTraffic & 0.350 & $* * *$ & & & 0.205 & $* *$ & 0.044 & $* * *$ & -0.269 & $* * *$ \\
OffStreetPath & 0.404 & $* * *$ & & & 0.635 & $* * *$ & 0.091 & $* * *$ & -0.261 & $* * *$ \\
NearPathIndustry & 1.647 & $* * *$ & 1.928 & $* * *$ & & & 0.056 & $* * *$ & 0.624 & $* * *$ \\
ADT & 0.030 & $* * *$ & 0.032 & $* * *$ & 0.016 & $* * *$ & & & 0.0031 & $* * *$ \\
ADT $^{2} \times 10^{-3}$ & -0.31 & $* *$ & -0.35 & $* * *$ & & & & & & \\
StopEnRoute & 0.271 & $* * *$ & 0.100 & $* *$ & & & & & 0.308 & $* * *$ \\
StartupEnRoute & 0.196 & $* * *$ & 0.211 & $* * *$ & & & & & & \\
LowSpeed & 0.180 & $* * *$ & 0.050 & $* *$ & & & & & 0.075 & $* * *$ \\
ADT:StopEnRoute & -0.0090 & $* * *$ & & & & & & & & \\
ADT:LowSpeed & -0.0070 & $* * *$ & & & & & & & & \\
\hline N & 14,220 & & 14,220 & & 10,925 & & 13,417 & & 13,869 & \\
Adjusted R & 0.278 & & 0.162 & & 0.155 & & 0.126 & & 0.131 & \\
\hline
\end{tabular}

Significance level indicated by: ${ }^{* * *} p<0.01,{ }^{* *} p<0.05,{ }^{*} p<0.10$

Comparison of roadway-related coefficients for the five pollutants in Table 30

and Table 31 supports the expectation that $\mathrm{CO}$ and VOC are more strongly traffic-related than $\mathrm{PM}_{2.5}$ and $\mathrm{CO}_{2}$. The ADT coefficients in Table 30 are similar for BTEX and TVOC, as expected. The linear ADT coefficient for CO in Table $31(0.016)$ agrees very well with the coefficient in the linear ADT specification for BTEX shown in Table 29 (0.014). The MixedTraffic and OffStreetPath coefficients are similar between BTEX and CO, although the more detailed location variables (StopEnRoute, StartupEnRoute, and LowSpeed) are not significant for CO. This difference could be due to the longer atmospheric lifetime of CO than aromatic VOC (Atkinson 2000, Seinfeld and Pandis 2012). The NearPathIndustry variable is not significant in the $\mathrm{CO}$ model, presumably because industrial sources generate proportionally less $\mathrm{CO}$ than motor vehicles, with 
respect to VOC. Near-road CO is generally higher than VOC, if each are normalized to background concentrations (Karner et al. 2010).

The ADT coefficient is positive and significant for $\mathrm{PM}_{2.5}$ in Table 31 but not significant for $\mathrm{CO}_{2}$, while NearPathIndustry is significant and positive for both. The MixedTraffic and OffStreetPath coefficients are significant and positive for $\mathrm{CO}_{2}$ but significant and negative for $\mathrm{PM}_{2.5}$. The negative MixedTraffic coefficient would be partially offset by the positive ADT coefficient for $\mathrm{PM}_{2.5}$ exposure on larger mixed-traffic facilities. Negative MixedTraffic and OffStreetPath coefficients suggest that the $\mathrm{PM}_{2.5}$ concentrations at the Park location were relatively high. Kaur and Nieuwenhuijsen (2009) also found more significant associations with traffic for $\mathrm{CO}$ than $\mathrm{PM}_{2.5}$.

\subsection{Identifying high-exposure roadways}

Regression was used to identify individual roadways with high exposure concentrations, after controlling for weather and traffic variables identified in the preceding sections. A model of five-second natural log-transformed TVOC concentrations was estimated by OLS with HAC robust standard errors, using the entire available data set (not limited to segments with GC/MS data). The specification was similar to the model shown in Table 31, adding dummy variables for roadway names. The road name dummy variables used roadway name attributes from the TSP GIS layer (see Methods Chapter 3).

An initial model was estimated using all road names with at least two minutes of data ( $N \geq 120$ for each dummy variable). Then road name dummy variables not significant at $p<0.05$ were removed sequentially, in the order of lowest associated 
change in SSR. The model was re-estimated and another dummy variable removed until all road name variables were significant. The resulting model is shown in Table 32, with average link ADT.

Compared to Table 31, the ADT coefficients in Table 32 suggest a more linear relationship (the squared term is no longer significant). The road names with negative coefficients in Table 32 are lower than expected from traffic and weather conditions, perhaps due to a less urban setting (e.g. SW Barbur Blvd.). The road names with positive coefficients in Table 32 are higher than expected from traffic and weather conditions. Note that a negative coefficient for SW Barbur Blvd. does not indicate low concentrations - only concentrations lower than expected from the 25,000 average ADT. Similarly, a positive coefficient for SE Harrison St. does not indicate high concentrations - only concentrations higher than expected for a 1,600 ADT roadway.

One possible explanation for significant roadways in Table 32 is incorrect or outdated ADT estimates (e.g. due to recent development on N. Williams Ave.). Another possibility is differences in sampling times (i.e. lower traffic during off-peak or shoulder periods). Temporal influences were tested by adding dynamic traffic variables (from the Powell Blvd. real-time sensors) to a restricted form of the model $^{4}$, but the traffic variables were found to be not significant at $p<0.05$. However, the magnitudes of the StopEnRoute and StartupEnRoute variable coefficients are smaller than in Table 31, suggesting that effects of congestion during sampling on certain roadways - previously

\footnotetext{
${ }^{4}$ Excluding the variables WindSpeed, ADT2, and StopEnRoute, which were not significant at $p<0.05$ in Table 10.
} 
captured with the Stop and Startup variables - could now be captured by the road name dummy variables.

Table 32. Model of TVOC concentrations with individual roadway names

\begin{tabular}{l|rrrrr}
\hline & Estimate & $\begin{array}{r}\text { HAC Std. } \\
\text { Error }\end{array}$ & statistic & p-value & $\begin{array}{r}\text { mean ADT } \\
\text { (vehicle/day) }\end{array}$ \\
\hline (Intercept) & 2.339 & 0.100 & 23.358 & $<0.001$ & \\
Temperature & -0.032 & 0.005 & -6.525 & $<0.001$ & \\
WindSpeed & 0.0065 & 0.018 & 0.364 & 0.716 & \\
NearPathIndustry & 1.877 & 0.261 & 7.184 & $<0.001$ & \\
ADT & 0.021 & 0.004 & 5.501 & $<0.001$ & \\
ADT $^{2}$ & -0.00015 & 0.00010 & -1.467 & 0.143 & \\
StopEnRoute & 0.056 & 0.034 & 1.651 & 0.099 & \\
StartupEnRoute & 0.141 & 0.032 & 4.383 & $<0.001$ & \\
LowSpeed & 0.044 & 0.020 & 2.156 & 0.031 & \\
Roadway Names: & & & & & 703 \\
$\quad$ SE Ankeny St & -0.146 & 0.056 & -2.631 & 0.009 & 1,059 \\
SE Woodward St & -0.255 & 0.040 & -6.422 & $<0.001$ & 1,286 \\
SE 42 $2^{\text {nd }}$ Ave & -0.346 & 0.083 & -4.166 & $<0.001$ & 1,571 \\
SE Harrison St & 0.460 & 0.112 & 4.125 & $<0.001$ & 7,378 \\
N Williams Ave & 0.664 & 0.132 & 5.035 & $<0.001$ & 12,120 \\
SE Division St & 0.468 & 0.149 & 3.143 & 0.002 & 16,270 \\
SE Madison St & 0.448 & 0.104 & 4.321 & $<0.001$ & 17,082 \\
SW 4 ${ }^{\text {th }}$ Ave & -0.643 & 0.090 & -7.143 & $<0.001$ & 25,074 \\
SW Barbur Blvd & -0.359 & 0.080 & -4.498 & $<0.001$ & \\
\hline
\end{tabular}

\section{SEGMENT-LEVEL MODEL OF EXPOSURE}

A segment-level VOC exposure model was estimated using seemingly unrelated regression (SUR) with a separate equation for each of 10 selected aromatic hydrocarbon compounds (see Data Overview Chapter 4 for a discussion of compound selection). The measured explanatory variables in Table 24 (aggregated at the segment level) were tested 
by stepwise addition to the model. The model specification is based on theoretical basis, statistical significance, model fit, and judgment. The preferred model was specified:

$$
\begin{gathered}
\ln C_{i}^{e x}=\beta_{0}+\beta_{1} \ln \left(C_{i}^{b g}\right)+\beta_{2} \text { WindSpeed }_{i}+\beta_{3} \text { TrafficDensity }_{i}+ \\
\beta_{4} \text { Springwater }_{i}+\beta_{5} \text { I205Path }_{i}+\beta_{6} \text { ADT }_{i}+\varepsilon_{i}
\end{gathered}
$$

where $\varepsilon_{i}$ is an error term that is i.i.d. within an equation, but correlates across equations

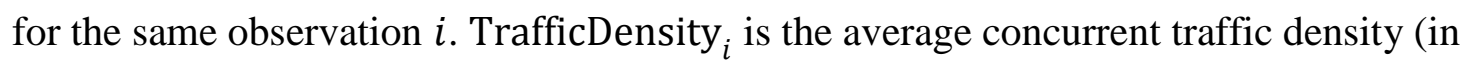
vehicles/lane-mile) at two reference locations on Powell Blvd (set to 0 if riding on an offstreet path), and the other variables are described in Table 25. The SUR model was estimated with $N=510$ and 440 degrees of freedom $(D F)$ for the entire system. The overall OLS R $\mathrm{R}^{2}$ was 0.726 and McElroy's SUR-specific $\mathrm{R}^{2}$ was 0.700 . Individual equation statistics are shown in Table 33.

The estimated segment-level SUR model coefficients are shown in Table 34. Coefficients significant at $p<0.05$ are highlighted by bold text. The ADT coefficients suggest a semi-elasticity of 1.9-3.5\% increases in exposure per 1,000 ADT. The effect on exposure of traffic density (at the reference location) is positive, while the effect of wind is negative - both as expected. Background concentrations are also significantly positive. The I-205 Path dummy variable is not significant at $p<0.05$ for 4 of the compounds due to the only slight increase from background concentrations and the small number of 
samples on that facility. The expected effect on exposure ${ }^{5}$ of the off-street path dummy variables is shown in Table 35 .

Table 33. Fit characteristics for the SUR system of 10 equations

\begin{tabular}{|c|c|c|c|c|c|c|c|c|}
\hline & & $N$ & $D F$ & $S S R$ & $M S E$ & $R M S E$ & $R^{2}$ & $\begin{array}{r}\text { Adjusted } \\
R^{2}\end{array}$ \\
\hline 1 & Benzene & 51 & 44 & 3.896 & 0.089 & 0.298 & 0.837 & 0.815 \\
\hline 2 & Toluene & 51 & 44 & 7.288 & 0.166 & 0.407 & 0.689 & 0.647 \\
\hline 3 & Ethylbenzene & 51 & 44 & 6.229 & 0.142 & 0.376 & 0.693 & 0.651 \\
\hline 4 & $m, p$-Xylene & 51 & 44 & 7.017 & 0.159 & 0.399 & 0.651 & 0.603 \\
\hline 5 & $o$-Xylene & 51 & 44 & 6.809 & 0.155 & 0.393 & 0.659 & 0.613 \\
\hline 6 & $n$-propylbenzene & 51 & 44 & 5.111 & 0.116 & 0.341 & 0.728 & 0.690 \\
\hline 7 & 1,3,5-Trimethylbenzene & 51 & 44 & 6.136 & 0.139 & 0.373 & 0.732 & 0.696 \\
\hline 8 & 2-Ethyltoluene & 51 & 44 & 5.383 & 0.122 & 0.350 & 0.774 & 0.743 \\
\hline 9 & 1,2,4-Trimethylbenzene & 51 & 44 & 6.150 & 0.140 & 0.374 & 0.761 & 0.729 \\
\hline 10 & 1,2,3-Trimethylbenzene & 51 & 44 & 6.547 & 0.149 & 0.386 & 0.707 & 0.667 \\
\hline
\end{tabular}

Comparing the BTEX compound coefficients in Table 34 to the 5-second BTEX exposure model in Table 26, the background and wind speed effects are roughly the same. The specification of the segment model is necessarily different from the specification of the high-resolution models because of different variable availability. The industrial area of the Springwater Path was averaged into the segment, so the OffStreetPath and NearPathIndustry variable effects are combined in the Springwater Path variable coefficient. The average value of the TrafficDensity variable is 13 , which, combined with the TrafficDensity coefficients for BTEX compounds in Table 34 (0.0180.028), roughly equals the MixedTraffic dummy variable coefficient in Table $26(0.34)$.

\footnotetext{
${ }^{5}$ As noted above, an established estimator for the effects of dummy variables on the dependent variable in a semi-log model is $\left[\exp \left(\beta-\frac{1}{2} S E_{\beta}^{2}\right)-1\right] 100 \%$, where $\beta$ is the estimated dummy variable coefficient and $S E_{\beta}$ is its standard error (Jan van Garderen and Shah 2002).
} 
The ADT coefficients for BTEX compounds (0.019-0.035) are slightly larger than the ADT coefficient for the linear-ADT model in Table 29 (0.014), but in line with the range of effects from the three specifications presented in Table 29.

Table 34. Estimated segment-level SUR model coefficients

\begin{tabular}{|c|c|c|c|c|c|c|c|}
\hline & Intercept & $\ln \left(C^{b g}\right)$ & $\begin{array}{c}\text { Wind } \\
\text { Speed }\end{array}$ & $\begin{array}{r}\text { Traffic } \\
\text { Density }\end{array}$ & $\begin{array}{r}\text { Springwater } \\
\text { Path }\end{array}$ & $\begin{array}{r}I-205 \\
\text { Path } \\
\end{array}$ & $\begin{array}{r}A D T \\
(x 1,000) \\
\end{array}$ \\
\hline Benzene & 0.194 & 0.849 & -0.175 & 0.028 & 1.171 & 0.625 & $\mathbf{0 . 0 3 5}$ \\
\hline Toluene & 0.652 & 0.593 & -0.244 & 0.018 & 1.250 & 0.579 & 0.019 \\
\hline Ethylbenzene & -0.117 & 0.577 & -0.183 & 0.023 & 1.395 & 0.248 & 0.022 \\
\hline$m, p$-Xylene & 0.495 & 0.521 & -0.200 & 0.023 & 1.435 & 0.237 & 0.020 \\
\hline$o$-Xylene & 0.013 & 0.549 & -0.194 & 0.023 & 1.409 & 0.247 & 0.019 \\
\hline$n$-propylbenzene & -0.796 & 0.560 & -0.176 & 0.027 & 1.357 & 0.430 & 0.023 \\
\hline $\begin{array}{l}1,3,5- \\
\text { Trimethylbenzene }\end{array}$ & -0.806 & 0.514 & -0.198 & 0.034 & 1.645 & 0.588 & $\mathbf{0 . 0 2 7}$ \\
\hline 2-Ethyltoluene & -0.719 & 0.590 & -0.181 & 0.034 & 1.497 & 0.642 & 0.027 \\
\hline $\begin{array}{l}1,2,4- \\
\text { Trimethylbenzene }\end{array}$ & -0.249 & 0.529 & -0.194 & 0.036 & 1.662 & 0.657 & 0.029 \\
\hline $\begin{array}{l}1,2,3- \\
\text { Trimethylbenzene }\end{array}$ & -0.866 & 0.495 & -0.200 & 0.028 & 1.486 & 0.522 & 0.025 \\
\hline
\end{tabular}

Table 35. Expected effect of path dummy variables on exposure from semi-log SUR model

\begin{tabular}{l|rr}
\hline & I-205 Path & $\begin{array}{r}\text { Springwater } \\
\text { Path }\end{array}$ \\
\hline Benzene & $83.5 \%$ & $208.0 \%$ \\
Toluene & $72.3 \%$ & $219.6 \%$ \\
Ethylbenzene & $24.4 \%$ & $274.0 \%$ \\
$m, p$-Xylene & $22.7 \%$ & $285.7 \%$ \\
$o$-Xylene & $24.0 \%$ & $276.8 \%$ \\
$n$-propylbenzene & $50.2 \%$ & $265.1 \%$ \\
1,3,5-Trimethylbenzene & $75.0 \%$ & $380.8 \%$ \\
2-Ethyltoluene & $85.3 \%$ & $318.9 \%$ \\
1,2,4-Trimethylbenzene & $87.4 \%$ & $389.4 \%$ \\
1,2,3-Trimethylbenzene & $63.5 \%$ & $308.3 \%$ \\
\hline
\end{tabular}

Table 36 shows the changes in SSR with the individual removal of explanatory variables form the mode. The strongest explanatory variables are ADT and 
TrafficDensity. Compared to similar analysis for the high-resolution model (Table 28), traffic and facility variables in the segment-level model contribute proportionally more explained variance (change in SSR) than the background and weather variables.

Table 36. Changes in SUR model system SSR with individual removal of explanatory variables $(\triangle D F=10$ for each)

\begin{tabular}{|c|c|c|c|}
\hline & $S S R$ & Change in SSR & $D F$ \\
\hline- & 60.56 & - & 440 \\
\hline $\ln C^{b g}$ & 85.53 & 24.97 & 450 \\
\hline WindSpeed & 70.92 & 10.36 & 450 \\
\hline TrafficDensity & 89.39 & 28.83 & 450 \\
\hline Springwater Path & 79.88 & 19.32 & 450 \\
\hline I-205 Path & 66.89 & 6.33 & 450 \\
\hline $\mathrm{ADT}$ & 92.37 & 31.81 & 450 \\
\hline
\end{tabular}

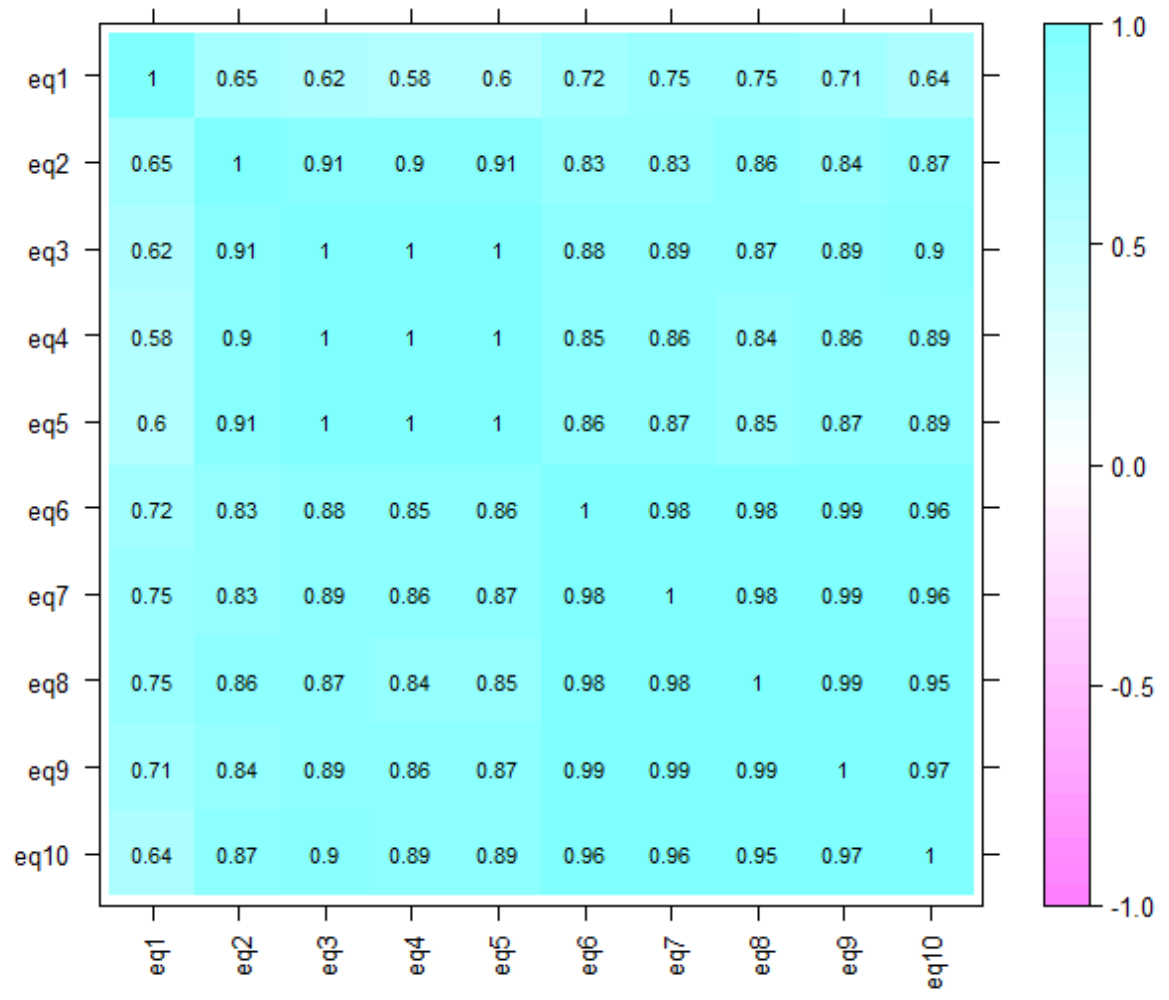

Figure 27. Correlation coefficients of residuals among 10 SUR model equations 
The correlation of residuals among equations is shown in Figure 27. The high correlations support the use of a SUR specification, which is more efficient than individual OLS under cross-correlated errors. Figure 28 shows model residuals from all 10 SUR equations.

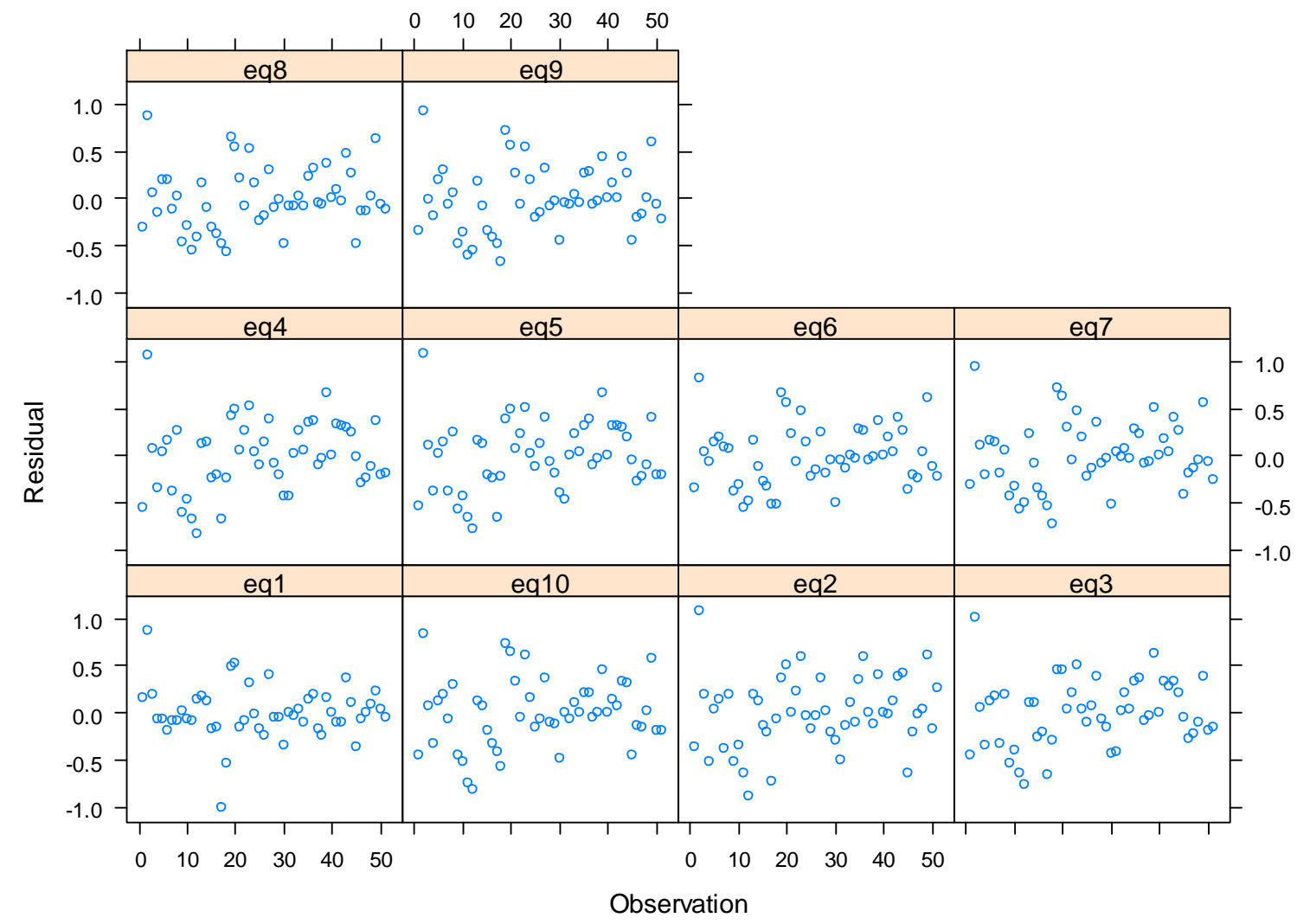

Figure 28 . Residuals from 10 SUR model equations

Serial correlation in the residuals was checked by regressing $\varepsilon_{i}$ on $\varepsilon_{i-1}$ for each equation using OLS. Significant serial correlation of the residuals was not found: $\mathrm{p}$ values for the lagged residual term were over 0.05 for all 10 equations $\left(R^{2}\right.$ ranged from 0.029 to 0.057$)$. 
Endogeneity in the background/reference concentration term $\left(\beta_{1}\right)$ was checked by regressing $\varepsilon_{i}$ on $\ln \left(C_{i}^{b g}\right)$ for each equation using OLS. Significant endogeneity was not found: $\mathrm{p}$-values for the background concentration term were over 0.05 for all 10 equations ( $R^{2}$ ranged from $<0.001$ to 0.035$)$.

Heteroscedasticity by facility type was checked by regressing $\varepsilon_{i}^{2}$ on RoadType ${ }_{i}$ for each equation. RoadType ${ }_{i}$ for the segment-level data is a seven-level factor variable describing the predominant facility type for segment $i$, with the levels Park, I-205 Path, Springwater Path, Local Roads, Minor Arterials, Major Arterials, and Mixed Roadway Types. Significant heteroscedasticity by facility was not found: p-values for F-tests on the RoadType factor variable (change in $D F=6$ ) were over 0.05 for all 10 equations $\left(R^{2}\right.$ ranged from 0.058 to 0.143 ).

\subsection{Alternative specifications}

An alternative specification that applies a natural log transformation to ADT has poorer statistical fit: OLS $R^{2}=0.685$, McElroy $R^{2}=0.625, \operatorname{SS} R=69.69$. The coefficients on the $\ln (A D T)$ term range from 0.0703 to 0.1055 (all $p<0.01$ ). The coefficient on the TrafficDensity dummy variable is no longer significant in any of the equations at $p<0.05$, while the other coefficients are essentially unchanged. The estimated $\ln (A D T)$ coefficients indicate BTEX exposure elasticity to ADT of 0.076 to 0.106, slightly smaller than the high-resolution BTEX model (0.128). The segment-level elasticities align with the semi-elasticities in the preferred model (1.9-3.5\% per 1,000 
ADT, from Table 34) at ADT of 3,000 to 4,000 - which would be expected on a smaller collector roadways ${ }^{6}$.

Another method to represent the non-linearity of the ADT effect is through a squared term. Adding a term for $A D T^{2}$ (again with $A D T$ in units of 1,000 vehicles per day) to the preferred SUR model described above leads to significant negative coefficients on the $A D T^{2}$ term for 4 of the 10 compounds at $p<0.05$. The negative coefficients indicate that the marginal effect of increasing ADT tends to diminish on larger roadways (with a maximum effect around 20,000-30,000 ADT). The non-ADT coefficients are largely unchanged. The $S S R$ falls to 55.54 and the OLS $R^{2}$ increases to 0.749, but a likelihood ratio test does not reject the restricted (preferred) model at $p<$ 0.05. Table 37 shows the estimated $A D T$-related coefficients for alternative specifications of the ADT terms in the SUR model (all other variables are specified as in the preferred model in Table 34). ADT interaction with TrafficDensity and WindSpeed variables was tested and found to be not significant at $p<0.05$.

\footnotetext{
${ }^{6}$ Elasticity/Semi-elasticity $($ per ADT $)=$ Equivalence ADT
} 
Table 37. Alternative specifications for ADT in the SUR model

\begin{tabular}{l|r|r|rr}
\hline & Linear & Logarithmic & \multicolumn{2}{r}{ Quadratic } \\
\hline & $A D T$ & $\ln (A D T)$ & $A D T$ & $A D T^{2}$ \\
& $(x l, 000)$ & & $(x l, 000)$ & $\left(x l, 000^{2}\right)$ \\
\hline Benzene & $\mathbf{0 . 0 3 5}$ & $\mathbf{0 . 1 0 6}$ & $\mathbf{0 . 0 6 0}$ & -0.001 \\
Toluene & $\mathbf{0 . 0 1 9}$ & $\mathbf{0 . 0 7 6}$ & $\mathbf{0 . 0 7 4}$ & $\mathbf{- 0 . 0 0 2}$ \\
Ethylbenzene & $\mathbf{0 . 0 2 2}$ & $\mathbf{0 . 0 8 5}$ & $\mathbf{0 . 0 8 0}$ & $\mathbf{- 0 . 0 0 2}$ \\
$m, p$-Xylene & $\mathbf{0 . 0 2 0}$ & $\mathbf{0 . 0 8 2}$ & $\mathbf{0 . 0 8 4}$ & $\mathbf{- 0 . 0 0 2}$ \\
-Xylene & $\mathbf{0 . 0 1 9}$ & $\mathbf{0 . 0 8 0}$ & $\mathbf{0 . 0 8 3}$ & $\mathbf{- 0 . 0 0 2}$ \\
n-propylbenzene & $\mathbf{0 . 0 2 3}$ & $\mathbf{0 . 0 7 0}$ & $\mathbf{0 . 0 5 1}$ & -0.001 \\
1,3,5-Trimethylbenzene & $\mathbf{0 . 0 2 7}$ & $\mathbf{0 . 0 9 3}$ & $\mathbf{0 . 0 6 6}$ & -0.001 \\
2-Ethyltoluene & $\mathbf{0 . 0 2 7}$ & $\mathbf{0 . 0 8 7}$ & $\mathbf{0 . 0 6 0}$ & -0.001 \\
1,2,4-Trimethylbenzene & $\mathbf{0 . 0 2 9}$ & $\mathbf{0 . 0 9 3}$ & $\mathbf{0 . 0 6 5}$ & -0.001 \\
1,2,3-Trimethylbenzene & $\mathbf{0 . 0 2 5}$ & $\mathbf{0 . 0 8 8}$ & $\mathbf{0 . 0 6 8}$ & -0.001 \\
\hline
\end{tabular}

An alternative specification that replaces the TrafficDensity variable with a MixedTraffic dummy variable (matching the high-resolution exposure model specification) has poorer statistical fit than the preferred specification (McElroy $R^{2}=$ 0.681). The estimated MixedTraffic coefficients are all significant $(p<0.01)$ and range from 0.356 to 0.716 , compared to 0.341 for the high-resolution model in Table 26 .

Another alternative specification was created by replacing the ADT variable and the two facility dummy variables with a seven-factor RoadType variable ${ }^{7}$. The McElroy $R^{2}$ of the model increases slightly to $0.714(S S R=60.29)$ and the RoadType factor is significant based on an F-test $(p<0.01)$. Table 38 shows the expected effects of each facility type on exposure (referenced to the Park location), calculated from the estimated coefficients and standard errors from the SUR model including the RoadType factor variable (and controlling for background, wind, and traffic density at the reference

\footnotetext{
${ }^{7}$ Levels: Park, I-205 Path, Springwater Path, Local Road, Minor Arterial, Major Arterial, and Mixed Roadway Types
} 
location). Significant coefficients at $p<0.05$ are indicated in bold text. The facility type effects are in line with expectations from averages described in the Data Overview, Chapter 4.

Table 38. Expected effects of facility types on exposure from semi-log SUR model

\begin{tabular}{l|rrrrrr}
\hline & $\begin{array}{r}\text { Springwater } \\
\text { Path }\end{array}$ & $\begin{array}{r}\text { I-205 } \\
\text { Path }\end{array}$ & $\begin{array}{r}\text { Local } \\
\text { Roads }\end{array}$ & $\begin{array}{r}\text { Mixed } \\
\text { Roadways }\end{array}$ & $\begin{array}{r}\text { Minor } \\
\text { Arterials }\end{array}$ & $\begin{array}{r}\text { Major } \\
\text { Arterials }\end{array}$ \\
\hline Benzene & $\mathbf{1 8 6 \%}$ & $30 \%$ & $\mathbf{6 3 \%}$ & $\mathbf{1 4 5 \%}$ & $\mathbf{1 8 8 \%}$ & $\mathbf{3 5 5 \%}$ \\
Toluene & $\mathbf{2 0 2 \%}$ & $39 \%$ & $27 \%$ & $\mathbf{1 4 2 \%}$ & $\mathbf{9 8 \%}$ & $\mathbf{1 2 2 \%}$ \\
Ethylbenzene & $\mathbf{2 4 8 \%}$ & $-5 \%$ & $\mathbf{4 3 \%}$ & $\mathbf{1 1 5 \%}$ & $\mathbf{1 4 4 \%}$ & $\mathbf{1 5 9 \%}$ \\
$m, p$-Xylene & $\mathbf{2 6 0 \%}$ & $-5 \%$ & $\mathbf{4 2 \%}$ & $\mathbf{1 1 6 \%}$ & $\mathbf{1 4 8 \%}$ & $\mathbf{1 4 3 \%}$ \\
-Xylene & $\mathbf{2 4 9 \%}$ & $-6 \%$ & $\mathbf{4 2 \%}$ & $\mathbf{1 1 4 \%}$ & $\mathbf{1 4 4 \%}$ & $\mathbf{1 3 7 \%}$ \\
$n$-propylbenzene & $\mathbf{2 3 3 \%}$ & $7 \%$ & $\mathbf{5 7 \%}$ & $\mathbf{1 2 6 \%}$ & $\mathbf{1 3 0 \%}$ & $\mathbf{2 1 3 \%}$ \\
1,3,5-Trimethylbenzene & $\mathbf{3 3 2 \%}$ & $16 \%$ & $\mathbf{7 9 \%}$ & $\mathbf{1 6 7 \%}$ & $\mathbf{1 9 2 \%}$ & $\mathbf{2 9 6 \%}$ \\
2-Ethyltoluene & $\mathbf{2 7 5 \%}$ & $21 \%$ & $\mathbf{7 6 \%}$ & $\mathbf{1 7 1 \%}$ & $\mathbf{1 7 4 \%}$ & $\mathbf{2 9 2 \%}$ \\
1,2,4-Trimethylbenzene & $\mathbf{3 4 2 \%}$ & $23 \%$ & $\mathbf{8 8 \%}$ & $\mathbf{1 8 3 \%}$ & $\mathbf{2 0 7 \%}$ & $\mathbf{3 3 4 \%}$ \\
1,2,3-Trimethylbenzene & $\mathbf{2 7 8 \%}$ & $22 \%$ & $\mathbf{6 2 \%}$ & $\mathbf{1 4 1 \%}$ & $\mathbf{1 6 9 \%}$ & $\mathbf{2 3 7 \%}$ \\
\hline
\end{tabular}

An alternative specification was also tested with a differenced dependent variable of on-road minus background exposure concentrations:

$$
\begin{gathered}
\ln \left(C_{i}^{\text {ex }}\right)-\ln \left(C_{i}^{b g}\right)=\beta_{0}+\beta_{1} \text { WindSpeed }_{i}+\beta_{2} \text { TrafficDensity }_{i}+ \\
\beta_{3} \text { Springwater }_{i}+\beta_{4} \text { I205Path }_{i}+\beta_{5} \mathrm{ADT}_{i}+\varepsilon_{i}
\end{gathered}
$$

The model results are shown in Table 39, again with significant coefficients at $p<0.05$ in bold text $\left(\mathrm{OLS} R^{2}=0.589\right.$, McElroy $\left.R^{2}=0.599, S S R=70.28\right)$. The Wind Speed coefficients are smaller and mostly not significant, due to the correlation between wind speed and background concentrations. The traffic-related variables are relatively unchanged, lending confidence to the estimated values in the preferred model. 
Table 39. Segment-level SUR model coefficients with a differenced (exposure background) dependent variable

\begin{tabular}{l|rrrrrr}
\hline & Intercept & Wind & Traffic & Springwater & I-205 & ADT \\
& & Speed & Density & Path & Path & $(x 1,000)$ \\
\hline Benzene & 0.232 & $\mathbf{- 0 . 1 5 8}$ & $\mathbf{0 . 0 2 9}$ & $\mathbf{1 . 1 1 5}$ & $\mathbf{0 . 6 5 8}$ & $\mathbf{0 . 0 3 6}$ \\
Toluene & 0.169 & -0.130 & $\mathbf{0 . 0 2 0}$ & $\mathbf{1 . 1 7 9}$ & $\mathbf{0 . 7 9 5}$ & $\mathbf{0 . 0 1 4}$ \\
Ethylbenzene & 0.044 & -0.042 & $\mathbf{0 . 0 2 2}$ & $\mathbf{1 . 2 9 1}$ & 0.291 & $\mathbf{0 . 0 1 9}$ \\
$m, p$-Xylene & 0.037 & -0.036 & $\mathbf{0 . 0 2 2}$ & $\mathbf{1 . 3 4 7}$ & 0.283 & $\mathbf{0 . 0 1 7}$ \\
$o$-Xylene & 0.053 & -0.049 & $\mathbf{0 . 0 2 3}$ & $\mathbf{1 . 3 2 2}$ & 0.298 & $\mathbf{0 . 0 1 6}$ \\
$n$-propylbenzene & 0.101 & -0.082 & $\mathbf{0 . 0 2 7}$ & $\mathbf{1 . 2 0 4}$ & $\mathbf{0 . 5 2 6}$ & $\mathbf{0 . 0 2 3}$ \\
1,3,5-Trimethylbenzene & 0.156 & -0.119 & $\mathbf{0 . 0 3 4}$ & $\mathbf{1 . 5 2 8}$ & $\mathbf{0 . 6 8 0}$ & $\mathbf{0 . 0 2 7}$ \\
2-Ethyltoluene & 0.103 & -0.091 & $\mathbf{0 . 0 3 4}$ & $\mathbf{1 . 3 3 7}$ & $\mathbf{0 . 7 5 7}$ & $\mathbf{0 . 0 2 6}$ \\
1,2,4-Trimethylbenzene & 0.099 & -0.085 & $\mathbf{0 . 0 3 6}$ & $\mathbf{1 . 5 0 3}$ & $\mathbf{0 . 7 6 1}$ & $\mathbf{0 . 0 2 8}$ \\
1,2,3-Trimethylbenzene & 0.073 & -0.066 & $\mathbf{0 . 0 2 9}$ & $\mathbf{1 . 3 7 9}$ & $\mathbf{0 . 7 0 0}$ & $\mathbf{0 . 0 2 2}$ \\
\hline
\end{tabular}

\section{CONCLUSIONS}

The chapter presented a high-resolution (five-second) model of BTEX exposure and a segment-level model of VOC exposure for 10 aromatic hydrocarbons, along with several variants of each. Background concentrations, weather, and traffic variables were all important determinants of exposure. BTEX exposure concentrations had an elasticity to background concentrations of 0.7 , increasing with temperature and decreasing with wind speed. BTEX exposure on off-street facilities was higher than the reference park location and varied widely, from similar concentrations to the lowest-traffic local streets to higher concentrations than the highest-traffic arterials. High exposure on off-street facilities was coincident with near-path industrial land use.

BTEX exposure during a ride increased by 19-33\% during a stop-and-go riding, although the effect diminished with facility ADT. These concentration effects are presumably due to the influences of intersections and traffic congestion. The significance of these variables shows that detailed travel attributes can be important determinants of 
exposure, in addition to link-level characteristics. Semi-elasticity of BTEX, TVOC, and CO exposure to ADT was around $1-3 \%$ per 1,000 ADT, robust to different model specifications. $\mathrm{PM}_{2.5}$ concentrations were much less impacted by traffic volumes than concentrations of $\mathrm{CO}$ and $\mathrm{VOC}$.

The results in this chapter have clear policy and design implications. Roadway characteristics have a strong impact on bicyclists' exposure concentrations, and ADT seems to be a parsimonious approach to characterize the impact of mixed-traffic facilities on bicyclists' exposure. The quantitative estimates of the impact of ADT on exposure concentrations provide a ready tool for analysts to calculate expected differences in exposure levels among routes. Route-level exposure differences can be used in both planning and routing applications (Hertel et al. 2008, Hatzopoulou, Weichenthal, Barreau, et al. 2013, Sharker and Karimi 2013). However, bicyclists traveling on offstreet paths near industrial areas can have VOC exposure concentrations higher than most mixed-traffic facilities. Distance to traffic is clearly a necessary but not sufficient condition to reduce exposure to BTEX compounds. 


\section{Chapter 6: Bicyclist ventilation}

\section{INTRODUCTION}

Active travelers experience conflicting health effects from physical activity on urban streets. Increased regular physical activity leads to well-established health benefits (Andersen L 2000). At the same time, greater physical exertion leads to increased ventilation $^{1}$ and in turn greater inhalation of traffic-related air pollution (Zuurbier et al. 2009). Although high ventilation rates for bicyclists are documented in the literature, existing studies of pollutant inhalation analyzed and reported ventilation rates by mode or trip (see Literature Review, Chapter 2). Little is known about how bicyclists' ventilation varies with travel conditions and over the course of a trip.

The pollutant inhalation rate $I$ is the product of the exposure concentration $(C)$ and ventilation rate $\left(V_{E}\right)$. Ventilation rate $V_{E}$ (also called "minute ventilation") is the product of the breathing frequency $f_{b}$ and tidal volume $V_{T}$. Hence, inhalation rate (in mass per unit time) is calculated

$$
I^{t}=C \cdot \dot{V}_{E}=C \cdot f_{b} \cdot V_{T}
$$

where $C$ is in mass per volume of air, $\dot{V}_{E}$ is in volume of air per unit time, $f_{b}$ is in breaths per unit time, and $V_{T}$ is in volume of air per breath. Beyond inhalation rate, particle deposition and location of gas absorption in the respiratory tract are affected by the

\footnotetext{
${ }^{1}$ This chapter uses physiological definitions whereby "ventilation" is the process of moving air into and out of the lungs while "respiration" is the exchange of gases (primarily oxygen and carbon dioxide) which takes place in the lungs, enabled by ventilation.
} 
relative values of $f_{b}$ and $V_{T}$, in addition to other factors such as fraction oral breathing (see Literature Review, Chapter 2).

Energy expenditure or workload is a key factor determining respiration and ventilation. Low to moderate levels of energy expenditure utilize aerobic respiration which requires inhalation of oxygen. Up to the anaerobic threshold, ventilation rate $\dot{V}_{E}$ is closely related to the volume rate of oxygen inhalation $\left(\dot{V}_{O_{2}}\right) \cdot \dot{V}_{E}$ increases primarily by an increase in $V_{T}$ at lower levels of exercise, then increasingly by $f_{b}$. At 70-80\% of peak exercise level $f_{b}$ becomes the dominant factor, although professional bicyclists can achieve a greater effect through $V_{T}$ (Weisman 2003, Faria et al. 2005a).

One previous study directly measured dynamic on-road ventilation rates while bicycling for the purpose of dose estimation, although analysis of ventilation was not provided (Int Panis et al. 2010). That study used a facemask system to measure ventilation - a method also used in other on-road (van Wijnen et al. 1995) and laboratory (Zuurbier et al. 2009) study settings. Another approach has been to estimate dynamic onroad ventilation rate $\left(\dot{V}_{E}\right)$ from measured heart rate $(H R)$, based on laboratory-derived $\dot{V}_{E} \sim H R$ relationships for individual subjects (Mermier et al. 1993, Cole-Hunter et al. 2012). Laboratory $\dot{V}_{E}$ measurements typically use a bicycle ergometer (stationary bicycle) and a facemask.

Figure 29 illustrates the connection between bicyclist ventilation and travel conditions. A rider's energy expenditure determines heart and ventilation rates, mediated by individual subject physiology (and to a lesser degree other variables such as air density). At the same time, the energy expenditure above baseline or resting metabolic 
rate leads to a commensurate energy transfer to the bicycle, mediated by bicycle attributes and the style of riding (pedaling cadence, upper body control, etc.). The energy transferred to the bicycle produces a certain travel speed, depending on bicycle, roadway, and travel attributes that determine energy state changes and losses.

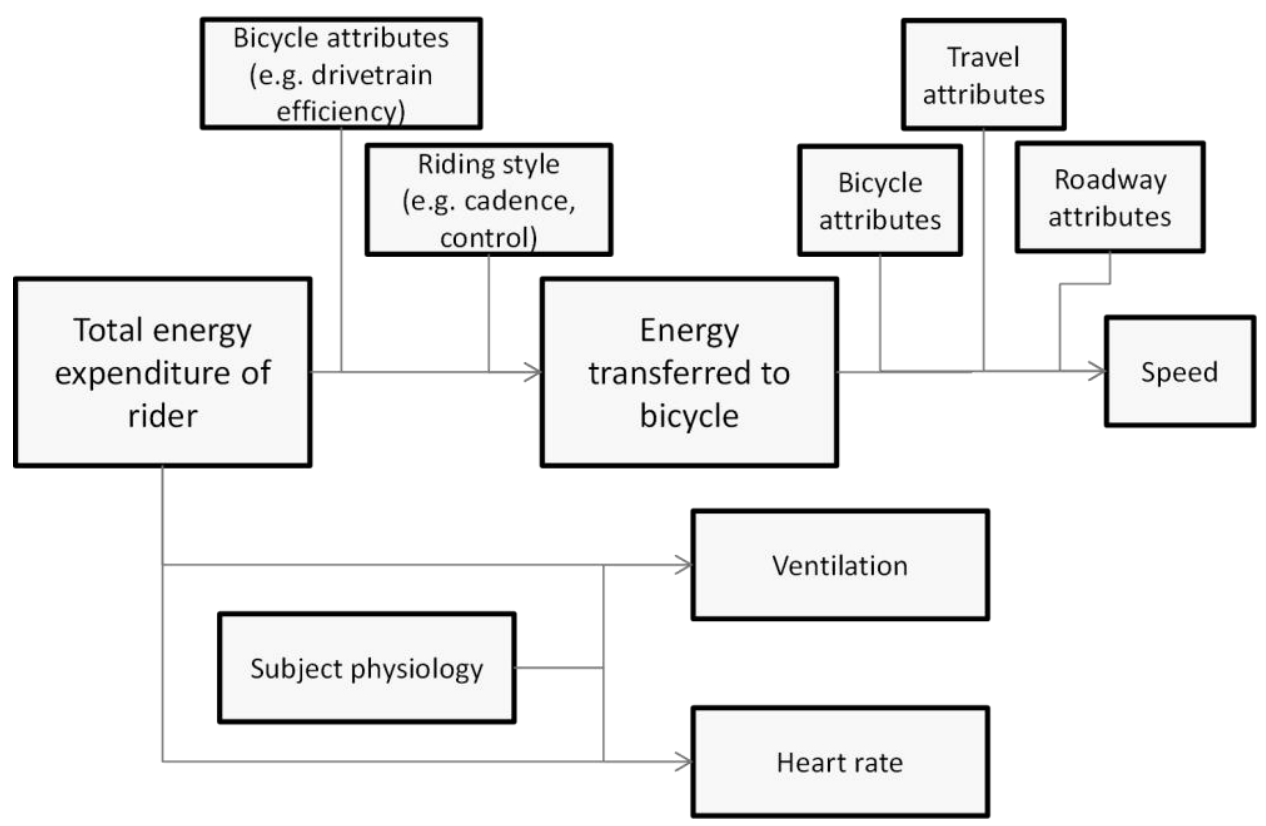

Figure 29. Conceptual diagram of the connection between bicyclist ventilation and travel conditions

The focus of this study is variation in bicyclist ventilation along a route. Figure 30 presents a simplified diagram connecting ventilation and travel characteristics in which subject-specific variables are assumed constant over the course of a ride and grouped into a "Subject" factor. Using Figure 30 , the connection between ventilation and travel conditions can be made in two steps:

1) Estimate energy transferred to the bicycle, based on travel outcomes, and 
2) Model ventilation as a function of energy transferred to the bicycle, mediated by the subject.

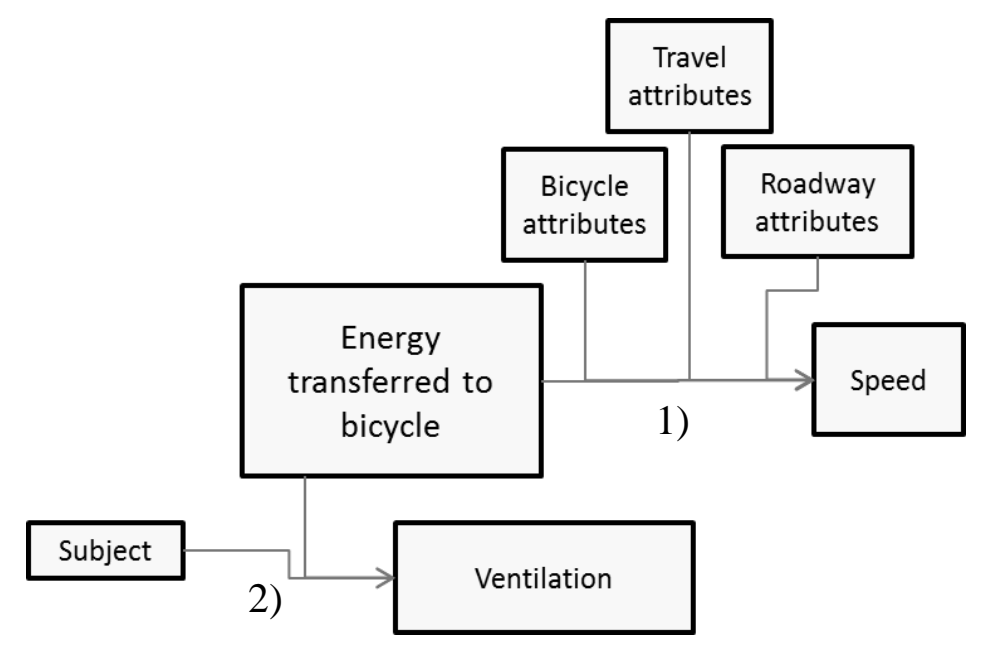

\section{Figure 30. Simplified conceptual diagram connecting bicyclist ventilation to travel attributes}

The objectives of this chapter are to:

1. Describe and validate a new approach to measure on-road ventilation rate using an unobtrusive chest strap, and

2. Analyze the ventilatory response to bicycling including

a. Dynamic analysis of on-road respiratory physiology (e.g. lags between heart rate and ventilation),

b. Application of a physical model of bicycle power to estimate workload while bicycling, and

c. Model the ventilatory response to on-road workload.

The goal of this research is to provide a clearer and more quantitative understanding of on-road ventilation and workload for urban bicyclists. The results will be useful for future 
studies of pollutant inhalation by bicyclists as well as studies of energy expenditure and physical activity.

\section{PHYSIOLOGY DATA}

The data collection and instrumentation are described in the Methods Chapter 3. The physiology monitoring strap (BioHarness 3, Zephyr, Annapolis, Maryland) provides heart rate $(H R)$, breathing rate $\left(f_{B}\right)$, and breath amplitude $\left(B_{A}\right)$ data at $1 \mathrm{~Hz}$. Previous research with on-road physiology measurements used heart rate monitors or facemasks. The BioHarness was selected because it provides more ventilation-specific data than heart rate alone. Facemasks would likely alter inhalation doses and so could not be used in a study of uptake. A portable facemask system such as the MetaMax (Cortex, Leipzig, Germany) can provide direct measurements of on-road ventilation rates, but is also more cumbersome for subjects to wear and more expensive (by roughly a factor of 50) than the BioHarness.

\subsection{Tidal volume calibration}

As stated in the Methods Chapter 3, the breath amplitude $\left(B_{A}\right)$ value reported by the BioHarness is raw information on expansion of the chest strap, reported in volts and provided as an "indicative" value. Because the measured resistance changes with the expansion of the chest, there should be a relationship between breath amplitude $B_{A}$ and the tidal volume $V_{T}$. However, the relationship between $B_{A}$ and $V_{T}$ will likely depend on the location and tightness of the strap. By calibrating $B_{A}$ to $V_{T}$ each time the BioHarness was used, session-specific $B_{A} \sim V_{T}$ relationships were estimated and used to calculate dynamic $V_{E}$ from on-road measured $f_{b}$ and $B_{A}$ 
A tidal volume calibration was conducted by each subject at the beginning and end of each data collection period. The tidal volume calibration consisted of 30-60 seconds of steady ventilation at prescribed tidal volumes of 500, 1000, 1500, and 2000 mL. An incentive spirometer was provided to the subjects to monitor tidal volume (DHD222500, Medline, Mundelein, Illinois - see Figure 31). The first ten seconds of $B_{A}$ readings at each tidal volume were discarded, and the remaining $B_{A}$ values averaged for each tidal volume. A curve was fit to each set of calibration data using the equation $V_{T}=$ $a+b \cdot B_{A}$. Calibration periods with missing data or a statistical fit of $R^{2}<0.75$ were discarded (4 calibration periods with poorly fitted straps or inconsistent tidal volumes). Median coefficients for the calibration curves were $a=-0.5702$ and $b=16.454\left(V_{T}\right.$ in $\mathrm{L}$ and $B_{A}$ in $\left.\mathrm{mV}\right)$.

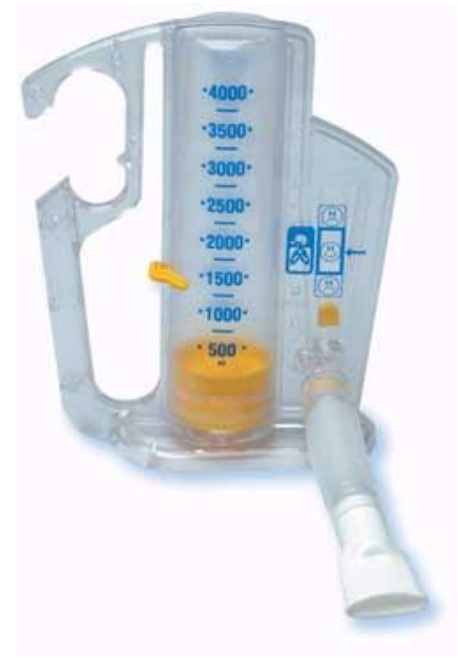

Figure 31. Incentive spirometer (image from medline.com)

\subsection{Estimating ventilation from BioHarness data}

On-road $V_{T}$ was estimated from $B_{A}$ measurements by applying the calibration curve $V_{T}=a+b \cdot B_{A}$ with calibration parameters $a$ and $b$ interpolated between the 
before and after calibration periods for each data collection. Data collections without calibration data at one end (before or after) used a single set of calibration parameters. Minute ventilation was then calculated $\dot{V}_{E}=V_{T} f_{b}$. Observations were filtered with the following constraints:

- BioHarness reported $H R$ confidence value of $\geq 80 \%$

- $B_{A}$ values within the range of calibration data

- $1<f_{B}<100$

- $20<H R<200$

50,241 observations (23\%) did not meet these constraints or were missing data. The processed physiological data set included 165,473 one-second data points (46 hours).

\subsection{Ergometer testing}

Physiological attributes of the subjects were assessed with a standard bicycle ergometer exercise test (Weisman 2003). Tests were conducted on bicycle ergometers (New Bike Exc 700, Technogym, Gambettola, Italy) on September 12, 2013. The protocol was 3-minute incremental workloads of $50 \mathrm{~W}$ from $0 \mathrm{~W}$ to volitional exhaustion - which was 350,250 , and $200 \mathrm{~W}$ for subjects A, B, and C, respectively. Self-selected cadences were around $70 \mathrm{rpm}$

\section{PHYSICAL MODEL OF BICYCLIST WORKLOAD}

A first-principles physical model was used to estimate bicyclist workload from measured roadway and travel characteristics. Table 40 summarizes the relevant variables that can be used in a model of bicyclists' energy expenditure. 
Olds (2001) provides a review of bicycle energy and power models. Beyond accounting for changes in energy state (due to speed/acceleration and elevation/grade), almost all power demand models include aerodynamic drag and rolling resistance terms. Some models include other factors in varying level of detail, such as angular momentum of the wheels and the rider's limbs, spoke drag, turbulence around the pedals, rolling resistance sensitivity to grade, humidity and altitude effects on air density, etc. (Whitt 1971, di Prampero et al. 1979, Olds et al. 1993, 1995, Martin et al. 1998, Candau et al. 1999, Wilson 2004, González-Haro et al. 2007). Although power demand models have been shown to perform well (Martin et al. 1998, González-Haro et al. 2007), validation experiments have been conducted with athletes and not utilitarian or commuter bicyclists. Similarly, models with empirical parameters such as di Prampero et al. (1979) and McCole, Claney, Conte, Anderson, \& Hagberg (1990) were estimated using racing bicyclist data sets.

\section{Table 40. Potential explanatory variables for modeling bicyclist workload}

\begin{tabular}{l|lll}
\hline Category & Example variables & $\begin{array}{l}\text { Expected size of } \\
\text { influence (Low- } \\
\text { Med-High) }\end{array}$ & $\begin{array}{l}\text { Ease of obtaining } \\
\text { data (Low-Med- } \\
\text { High) }\end{array}$ \\
\hline Bicycle attributes & Drivetrain efficiency & Low & Low \\
Bicycle attributes & Tire condition, size and pressure & Med & High \\
Bicycle attributes & Mass of bicycle and rider & High & High \\
Bicycle attributes & Frontal area and drag coefficient & High & Low \\
Travel attributes & Pedaling cadence & Low-Med & Low \\
Travel attributes & Upper body control & Low & Low \\
Travel attributes & Speed, acceleration & High & High \\
Travel attributes & Ground-level wind speed and direction & Med & Med \\
Travel attributes & Temperature, humidity & Low & High \\
Travel attributes & Braking activity & High & Low \\
Roadway attributes & Grade & High & Med-High \\
Roadway attributes & Pavement surface & Med & Low \\
\hline
\end{tabular}


The energy state of a bicycle/rider system at any point is the sum of the potential energy $(P E)$ and kinetic energy $(K E)$. The energy flux (power) balance for the bicycle/rider system is

$$
W_{M}-W_{L}-W_{B}=\Delta K E+\Delta P E
$$

where $W_{M}$ is the mechanical work input from the bicyclist ${ }^{2}, W_{B}$ is energy dissipated through braking (as heat), $W_{L}$ is other energy lost through drag, rolling resistance, friction, etc., and $\triangle K E$ and $\triangle P E$ are the changes in kinetic and potential energy. $W_{M}$ and $W_{B}$ are difficult to measure directly and unavailable in the study data set; $K E$ and $P E$ can be estimated from speed, weight, and elevation data, and $W_{L}$ can be estimated from the literature with the assumption of certain parameters.

We define the net work on the bicycle/rider system as $W_{N}=W_{M}-W_{B}$. The assumptions

1. $W_{B} \geq 0$ (i.e. brakes only remove energy from the system),

2. $W_{M} \geq 0$ (i.e. the bicyclist can only input energy to the system ${ }^{3}$ ), and

3. $W_{M} W_{B}=0$ (i.e. the bicyclist is never pedaling and braking at the same time) ${ }^{4}$ then lead to

\footnotetext{
${ }^{2} W_{M}$ is not the same as the total work generated by the bicyclist $W_{h}$, which can be related to $W_{M}$ by $W_{h}=$ $\frac{W_{M}}{\eta}$, where $\eta$ is the efficiency of power transfer from the muscles to the bicycle powertrain (including losses in the drivetrain and energy used for upper body control). In $\dot{V}_{E} \sim \dot{W}_{M}$ modelling below, the efficiency factor $\eta$ would be included in the subject-specific model coefficients.

${ }^{3}$ This might not be true for fixed-gear bicycles.

${ }^{4}$ This assumption could also be defined as $W_{M}=0 \mid W_{B}=0$.
} 


$$
W_{M}=\left\{\begin{array}{cc}
W_{N} & W_{N}>0 \\
0 & W_{N} \leq 0
\end{array}\right\}
$$

With work in units of energy (e.g. J), the rates of work and energy transfer are in units of power (e.g. W). The rate form of Equation 2 is simply:

$$
\dot{W}_{M}=\left\{\begin{array}{cc}
\dot{W}_{N} & \dot{W}_{N}>0 \\
0 & \dot{W}_{N} \leq 0
\end{array}\right\}
$$

where $\dot{W}_{N}=\frac{W_{N}}{\Delta t}$ is the net rate of work on the on the bicycle/rider system and $\dot{W}_{M}=\frac{W_{M}}{\Delta t}$ is the rate of mechanical work input from the bicyclist.

From the bicycle energy literature (Martin et al. 1998), neglecting spoke drag, rotational inertia of the wheels, and bearing losses, and assuming relatively low wind speeds and grades, energy transfer rates are:

$$
\begin{aligned}
& \frac{\Delta K E}{\Delta t}=\frac{m_{T}}{2} \frac{\Delta v_{b}^{2}}{\Delta t} \\
& \frac{\Delta P E}{\Delta t}=v_{b} m_{T} g G \\
& \frac{W_{L}}{\Delta t}=\frac{1}{2} \rho C_{D} A_{F} v_{b}^{3}+v_{b} C_{R} m_{T} g
\end{aligned}
$$

where the variables are defined:

- $m_{T}$, the total mass of the bicycle + rider system

- $v_{b}$, the ground speed of the bicyclist

- $g$, the acceleration due to gravity

- $G$, the grade of travel (in \%) 
- $\quad \rho$, the air density

- $C_{D}$, the drag coefficient

- $A_{F}$, the frontal area of the bicyclist (assuming 0 yaw angle)

- $C_{R}$, the coefficient of rolling resistance

Combining variables, a modified drag coefficient id defined: $C_{D}^{\prime}=\frac{1}{2} \rho C_{D} A_{F}$, leading to a rate of net work of

$$
\begin{gathered}
\dot{W}_{N}=\frac{\Delta K E+\Delta P E+W_{L}}{\Delta t} \\
\dot{W}_{N}=\frac{m_{T}}{2} \frac{\Delta v_{b}^{2}}{\Delta t}+v_{b} m_{T} g G+C_{D}^{\prime} v_{b}^{3}+v_{b} C_{R} m_{T} g
\end{gathered}
$$

All of the parameters needed to calculate $\dot{W}_{N}$ are measured in the study data set except $C_{D}^{\prime}$ and $C_{R}$, for which there is information in the literature. 
Table 41. Parameters used in calculating bicyclist power

\begin{tabular}{l|cccl}
\hline & $A$ & $B$ & $C$ & Source \\
\hline$m_{r}(\mathrm{~kg})$ & 80 & 70 & 75 & Measured; mass of the rider \\
$m_{T}(\mathrm{~kg})$ & 105 & 91 & 97 & Measured; includes rider and bicycle \\
Height, $H(\mathrm{~cm})$ & 189 & 175 & 163 & Measured; standing \\
Surface area of rider, $A_{S}\left(\mathrm{~m}^{2}\right)$ & 2.32 & 2.07 & 2.02 & Olds et al. (1995); $A_{S}=$ \\
& & & & $H^{0.725} m_{T}^{0.425} 0.007184$ \\
Frontal area of rider, $A_{F r}\left(\mathrm{~m}^{2}\right)$ & 0.59 & 0.51 & 0.49 & Olds et al. (1995); $A_{F r}=0.3176 A_{S}-$ \\
& & & & 0.1478 \\
Frontal area of bicycle, $A_{F b}\left(\mathrm{~m}^{2}\right)$ & 0.12 & 0.12 & 0.12 & Olds et al. (1995) \\
Frontal area inflation factor, $F$ & 1.2 & 1.1 & 1.1 & Assumed; loose clothing, upright position, \\
& & & & panniers, and equipment \\
Total frontal area, $A_{F}\left(\mathrm{~m}^{2}\right)$ & 0.85 & 0.69 & 0.67 & $A_{F}=F\left(A_{F r}+A_{F b}\right)$ \\
$C_{D}$ & 1.1 & 1.0 & 1.0 & Wilson $(2004)$ \\
$\rho\left(\mathrm{kg} / \mathrm{m}^{3}\right)$ & 1.23 & 1.23 & 1.23 & Assumed; sea level, $15^{\circ} \mathrm{C}$ \\
$C_{D}^{\prime}$ & 0.6 & 0.4 & 0.4 & $C_{D}^{\prime}=\frac{1}{2} \rho C_{D} A_{F}$ \\
$C_{R}$ & 0.004 & 0.004 & 0.004 & Wilson $(2004)$ \\
Maximum workload $(\mathrm{W})$ & 300 & 250 & 200 & Ergometer testing \\
\hline
\end{tabular}

Table 41 shows workload parameters applied for the three study subjects, including measured values and estimates informed by the literature. All three subjects had 700c "commuter" style (semi-slick) tires, 25-28mm. Subjects A and B rode touring bicycles, while subject $\mathrm{C}$ rode a more upright city bicycle. All three subjects rode with rear panniers, though subject A also had a large trunk box for holding sample bags and air sampling equipment mounted in a front basket. These additions would increase both the frontal area and drag coefficient for subject A. All three subjects rode in "touring" or "upright" positions. The values in the following table for the unmeasured parameters are estimates from several sources in the literature, especially Olds et al. (1995) and Wilson (2004). 
Workload estimates $\left(\dot{W}_{M}\right)$ were made for each subject using Equations 3 and 4 with on-road speed and grade data and the parameters in Table $41 . \dot{W}_{M}$ was constrained to the maximum workload from ergometer testing (see Table 41). Workload was also calculated in units of MET. A MET is a standardized unit of metabolic energy expenditure that is normalized to body mass and resting metabolic rate. Resting activities are at a MET of 1. "Standard MET" values are calculated with respect to a resting metabolic rate of $3.5 \mathrm{~mL} \mathrm{O}_{2}$ per minute, per kg body mass. The American College of Sports Medicine (ACSM) equation ${ }^{5}$ for oxygen consumption during bicycling (in $\mathrm{mL} \mathrm{O} 2$ per $\mathrm{kg}$ per min) is:

$$
\dot{V}_{O_{2}}=10.8 \frac{\dot{W}_{M}}{m_{r}}+7
$$

with $\dot{W}_{M}$ in W and $m_{r}$ (body mass) in $\mathrm{kg}$ (Lang et al. 1992). Standard MET can then be calculated as

$$
M E T=\frac{\dot{V}_{O_{2}}}{3.5}=3.09 \frac{\dot{W}_{M}}{m_{r}}+2
$$

\section{ON-ROAD VENTILATION AND WORKLOAD RESULTS}

Summary statistics for physiology and workload data are shown in Table 42 using five-second aggregated data. Mean ventilation rate of $22.4 \mathrm{lpm}$ is in good agreement with past literature on bicyclist inhalation of air pollution (see Literature Review, Chapter 2 Table 2). The average sampling conditions were $17 \mathrm{kph}$ travel speed (without stops), 19

\footnotetext{
${ }^{5}$ http://certification.acsm.org/metabolic-calcs
} 
${ }^{\circ} \mathrm{C}, 75 \%$ relative humidity, and $1.8 \mathrm{mps}$ wind speed. The average travel speed, heart rate, and ventilation rate are all toward the low end of past research on bicyclists.

Table 42. Summary statistics for physiology and workload data (five-second aggregation)

\begin{tabular}{|c|c|c|c|c|c|c|c|c|}
\hline & Units & Min & $\begin{array}{l}l^{\text {st }} \\
\text { Quartile }\end{array}$ & Median & Mean & $\begin{array}{l}3^{\text {rd }} \\
\text { Quartile }\end{array}$ & $\operatorname{Max}$ & $\bar{N}$ \\
\hline $\overrightarrow{H R}$ & $\min ^{-1}$ & 20.4 & 68.5 & 80.7 & 83.6 & 95.9 & 200 & 39,508 \\
\hline$f_{b}$ & $\min ^{-1}$ & 2.2 & 16.1 & 22.0 & 21.9 & 27.9 & 50.6 & 39,508 \\
\hline$B_{A}$ & $\mathrm{mV}$ & 24.0 & 61.1 & 84.9 & 91.5 & 115.6 & 280.0 & 38,675 \\
\hline$V_{T}$ & $\mathrm{~mL}$ & 0.3 & 599.8 & 889.2 & 1001.7 & 1274.8 & 7238.3 & 32,471 \\
\hline$\dot{V}_{E}$ & $1 \mathrm{~min}^{-1}$ & 0.0 & 10.3 & 18.0 & 22.4 & 29.7 & 165.6 & 32,471 \\
\hline$\dot{W}_{M}$ & & & & & & & & \\
\hline Pooled & W & 0.0 & 0.0 & 114.4 & 126.3 & 234.8 & 300.0 & 21,963 \\
\hline Subject A & W & 0.0 & 0.0 & 125.7 & 135.4 & 264.5 & 300.0 & 16,950 \\
\hline Subject B & W & 0.0 & 0.0 & 72.7 & 100.6 & 206.6 & 250.0 & 2,555 \\
\hline Subject C & W & 0.0 & 0.0 & 73.8 & 89.8 & 200.0 & 200.0 & 2,458 \\
\hline MET & & & & & & & & \\
\hline Pooled & MET & 2.0 & 2.0 & 6.5 & 7.0 & 11.2 & 13.6 & 21,963 \\
\hline Subject A & MET & 2.0 & 2.0 & 6.8 & 7.2 & 12.2 & 13.6 & 16,950 \\
\hline Subject B & MET & 2.0 & 2.0 & 5.2 & 6.4 & 11.1 & 13.0 & 2,555 \\
\hline Subject C & MET & 2.0 & 2.0 & 5.0 & 5.7 & 10.2 & 10.2 & 2,458 \\
\hline
\end{tabular}

The calculated MET values agree well with published research. The Compendium of Physical Activity lists 16 different types of bicycling as activities with assumed static energy expenditures ranging from 3.5 MET for "leisure" bicycling at $5.5 \mathrm{mph}$ to $16 \mathrm{MET}$ for competitive mountain bicycle racing (Ainsworth et al. 2011a, 2011b). "General" bicycling is at a MET of 7.5 and bicycling "to/from work, self selected pace" is at a MET of 6.8 in the Compendium. Other research has reported typical non-racing bicyclist MET of 5-7 (Whitt 1971, Bernmark et al. 2006, de Geus et al. 2007).

\subsection{Ventilation and heart rate}

Figure 32 shows the lagged covariance between ventilation and heart rate using 1second data. The covariance peaks at around 20 seconds, indicating that heart rate 
changes lead ventilation changes by around 20 seconds. This lag is relevant to consider for research designs that use on-road measured $H R$ to predict ventilation rates.

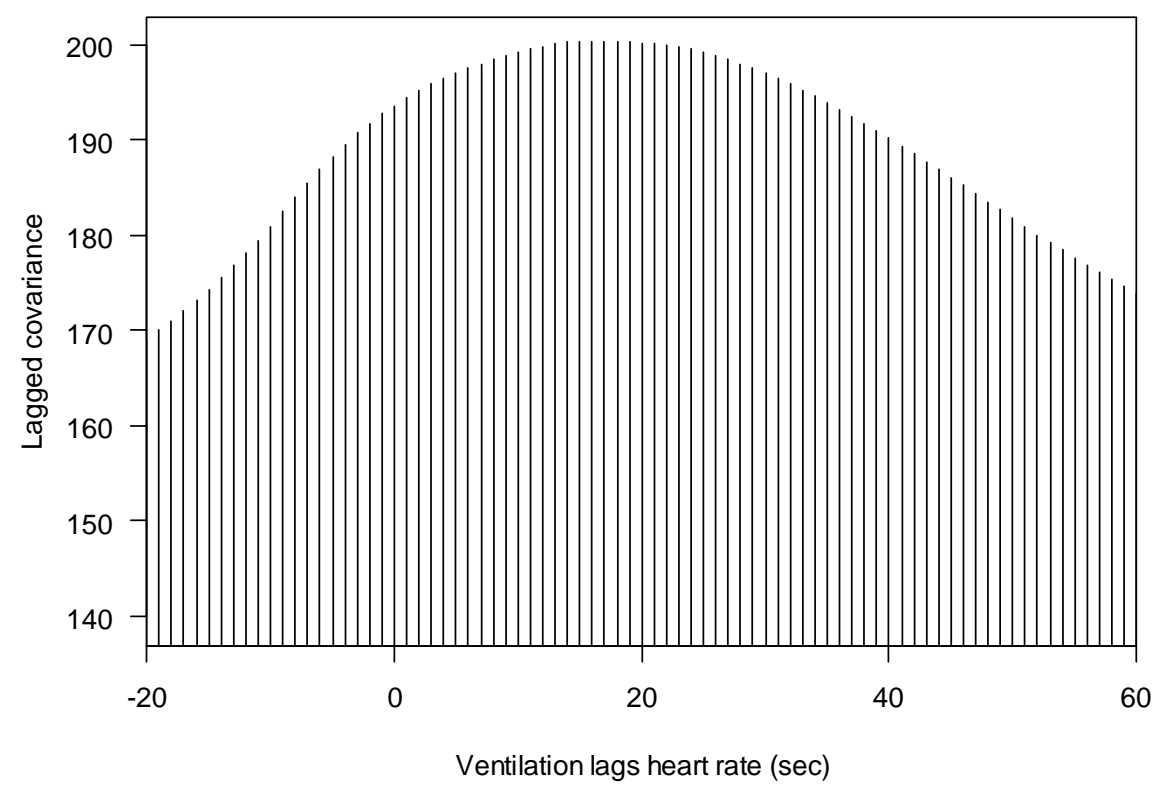

Figure 32. Lagged covariance between ventilation and heart rate

The relationship between ventilation and heart rate was modeled as

$$
\ln \left(\dot{V}_{E}\right)_{i}=\alpha+\beta \cdot H R_{i-4}
$$

using five-second data, where $H R_{i-4}$ is heart rate lagged by four periods (4 lags $=20$ seconds) and $\alpha$ and $\beta$ are fit parameters. Pooled and subject-segmented OLS models were estimated with Newey-West HAC (heteroscedasticity and autocorrelation consistent) robust standard error estimates. The estimated model results by subject and pooled are shown in Table 43. All coefficients are significant at $p<0.01$. Due to serial correlation, using un-lagged heart rate $\left(H R_{i}\right)$ as the independent variable generates similar models but with higher standard errors. 
Table 43. Model parameters relating ventilation to heart rate

\begin{tabular}{l|llll}
\hline & Subject $A$ & Subject $B$ & Subject $C$ & Pooled \\
\hline$\alpha$ & 0.406 & 0.159 & 1.487 & 0.782 \\
$\beta$ & 0.0298 & 0.0271 & 0.0156 & 0.0244 \\
$N$ & 23,127 & 5,053 & 4,291 & 32,471 \\
$R^{2}$ & 0.371 & 0.239 & 0.151 & 0.290 \\
\hline
\end{tabular}

The estimated coefficients are well in line with the literature, which suggests central value population slopes of $0.016-0.023$ for bicyclists, heterogeneous to individuals (Colucci 1982, Samet et al. 1993, Bernmark et al. 2006, Zuurbier et al. 2009). Mermier et al. (1993) report slopes ranging from 0.016 to 0.029 for 15 healthy men who performed maximum exercise tests on ergometers. Thus, the ventilation-heart rate models provide validation support for the BioHarness-based estimation of on-road $\dot{V}_{E}$.

\subsection{Workload Analysis}

The application of the power equations to calculate workload allows the power demands on the bicyclists to be broken down by terms. The net energy attributable to each power term was:

- Kinetic energy $(K E)$ flux: $0 \mathrm{~kW}$,

- Potential energy $(P E)$ flux: $-155 \mathrm{~kW}$ (net elevation loss),

- Aerodynamic drag loss: $1,792 \mathrm{~kW}$, and

- Rolling resistance loss: $403 \mathrm{~kW}$.

Cumulative wattage by power equation term was also calculated for observations with complete power data (some observations were missing grade data, so the $P E$ term was $N A$ ). Of the 39,508 five-second periods in the data set, 21,963 had complete power data, with total energy expenditure of the riders of 3,908 $\mathrm{kW}$. This energy (plus the input of 
$155 \mathrm{~kW}$ of $P E$ ) was dissipated as $43.5 \%$ aerodynamic drag, $9.7 \%$ rolling resistance, and $46.8 \%$ braking.

The bicyclists were performing pedaling work $\left(\dot{W}_{N}>0\right)$ for $14,978(68 \%)$ of the complete observations (20.8 hours). Isolating those periods when the riders were pedaling, the individual sums of energy for the other terms of the power equation were $54.5 \%$ kinetic energy, $2.2 \%$ potential energy, $35.7 \%$ aerodynamic drag, and $7.7 \%$ rolling resistance. In other words, when pedaling, $43 \%$ of the energy input was immediately dissipated as drag and rolling losses (marinating speed) and the other 57\% went to useable, recoverable energy (primarily as speed, but also as elevation).

\subsection{Ventilation and workload}

Lagged covariance between $\dot{W}_{M}$ and $H R$ and between $\dot{W}_{M}$ and $\dot{V}_{E}$ were calculated using five-second aggregated data (a five-second moving average was used to estimate grades) and are plotted in Figure 33. Covariance between $\dot{W}_{M}$ and $H R$ peaks at one lag (5 seconds), and covariance between $\dot{W}_{M}$ and $\dot{V}_{E}$ peaks at six lags (30 seconds). Thus, the physiological response to increased workload is fast in heart rate and slower in ventilation. Again, this is relevant for study designs where ventilation is not measured directly but estimated from heart rate or workload. 

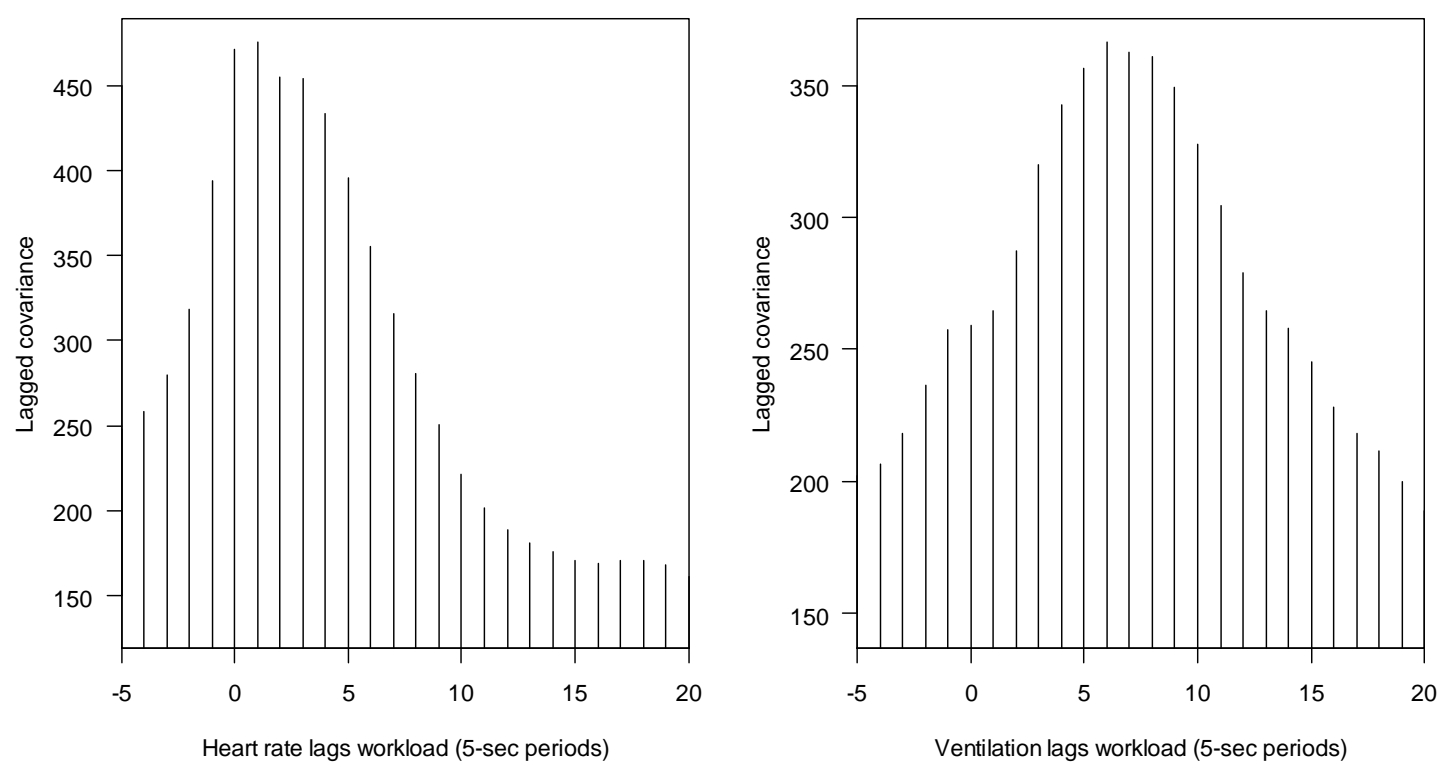

Figure 33. Lagged covariance between and heart rate and workload (left) and between ventilation and workload (right)

An unconstrained distributed lag model of ventilation on workload was specified out to 30 lags (2.5 min):

$$
\ln \left(\dot{V}_{E}\right)_{t}=\alpha+\sum_{i=0}^{30} \beta_{i} \dot{W}_{M, t-i}+\varepsilon_{t}
$$

with $\dot{V}_{E}$ in lpm, $\dot{W}_{M}$ in W, and $\varepsilon_{t}$ an i.i.d. error term. Longer lags were explored but found to be not significant. The model was estimated separately for each subject, with Newey-West HAC robust standard error estimates. The cumulative effect of $\dot{W}_{M}$ on $\dot{V}_{E}$ is represented by

$$
\beta_{T}=\sum_{i=0}^{30} \beta_{i}
$$


Estimated subject-specific and pooled model results are shown in Table 44, and full model coefficients and p-values are shown in Appendix F, Table S.12. The left plot in Figure 34 shows the marginal impact of $\dot{W}_{M}$ on $\dot{V}_{E}$ as $\beta_{i} \cdot 100 \%$ (versus lag in seconds, 5i). The right plot in Figure 34 shows the cumulative lagged impact of $\dot{W}_{M}$ on $\dot{V}_{E}$, calculated at lag $L$ as $\frac{\sum_{i=0}^{L} \beta_{i}}{\beta_{T}} \cdot 100 \%$.

Table 44 . Distributed lag models of on-road ventilation as a function of workload

\begin{tabular}{|c|c|c|c|c|}
\hline & $\bar{A}$ & $B$ & $C$ & Pooled \\
\hline$\alpha$ & 2.185 & 2.674 & 2.318 & 2.348 \\
\hline$\beta_{T}$ & 0.00744 & 0.00417 & 0.00761 & 0.00645 \\
\hline $\begin{array}{l}\text { Number of significant lags } \\
\qquad(p<0.05)\end{array}$ & 28 & 10 & 11 & 26 \\
\hline$N$ & 13,044 & 2,248 & 2,156 & 17,448 \\
\hline Adjusted $\mathrm{R}^{2}$ & 0.154 & 0.024 & 0.111 & 0.140 \\
\hline F-statistic & 77.36 & 2.76 & 9.72 & 92.36 \\
\hline
\end{tabular}

The plots in Figure 34 show that the majority of the effect of workload on ventilation is realized within the first minute. Mean and median lags for each model are shown in Table 45. The mean lag (the time period at which half of the effect of $\dot{W}_{M}$ on $\dot{V}_{E}$ is achieved) is computed $\frac{\sum_{i=0}^{30} i * \beta_{i}}{\beta_{T}}$. The median lag is the lag at which $\frac{\sum_{i=0}^{L} \beta_{i}}{\beta_{T}} \approx 0.5$. The lag values compare well with previous studies that found around 50\% adaptation of ventilation to exercise after the first minute, with some inter-subject variability (Edwards et al. 1972, O'Connor et al. 2000). Systematic differences in the speed of the ventilatory response to workload by age are not expected, although exercise training can affect response speed (McArdle et al. 2010). 

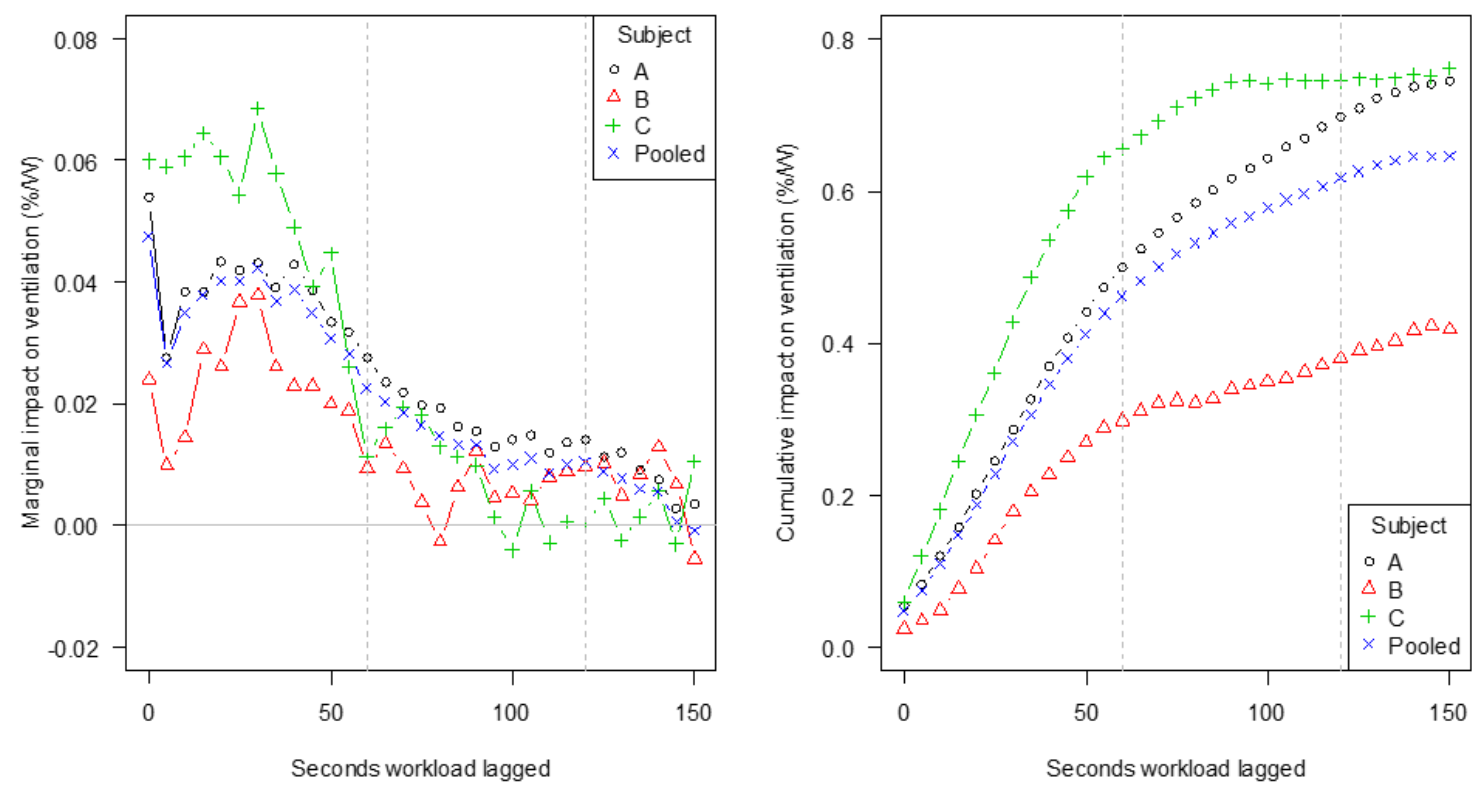

Figure 34 . Marginal and cumulative impacts of workload on ventilation

Table 45 . Mean and median lags for the effect of workload on ventilation

\begin{tabular}{l|llll}
\hline & $A$ & $B$ & $C$ & Pooled \\
\hline Mean lag & 10.2 & 10.2 & 6.8 & 9.4 \\
Mean lag (min) & 0.85 & 0.85 & 0.56 & 0.78 \\
Median lag & 10 & 9 & 7 & 9 \\
Median lag (min) & 0.83 & 0.75 & 0.58 & 0.75 \\
\hline
\end{tabular}

Figure 35 illustrates the sensitivity of the $\dot{V}_{E} \sim \dot{W}_{M}$ relationship to the energy equation parameters $C_{D}^{\prime}$ and $C_{R}$. The 3 plots in Figure 35 show modeled $\beta_{T}$ as shadings over a wide range of values for $C_{D}^{\prime}$ and $C_{R}$, for each subject. Note the different color scales in each figure, centered near the $\beta_{T}$ estimate in Table 44 . The selected ranges for $C_{D}^{\prime}$ and $C_{R}$ are based on the literature used in Table 41 (Martin et al. 1998, Wilson 2004). The $\dot{V}_{E} \sim \dot{W}_{M}$ relationship is more sensitive to $C_{D}^{\prime}$ than $C_{R}$. Higher values of these power equation parameters increase estimates of on-road $\dot{W}_{M}$ and so reduce $\beta_{T}$. Modeled $\beta_{T}$ is within 0.001 of the initial estimate over a wide range of parameter values. 


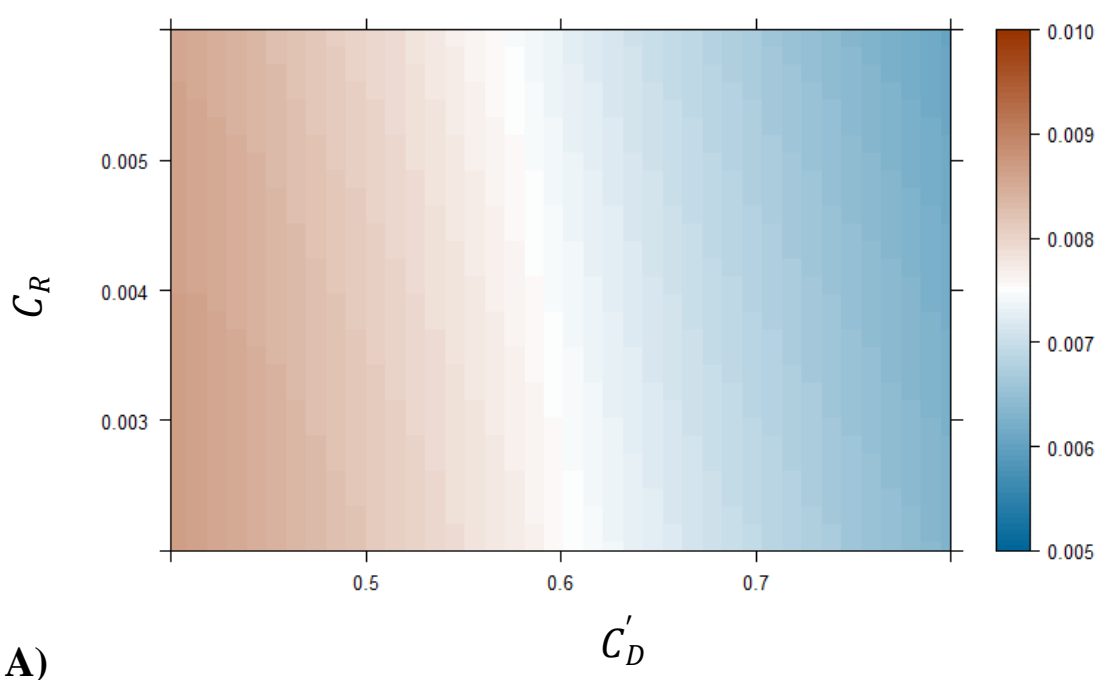

Subject A)

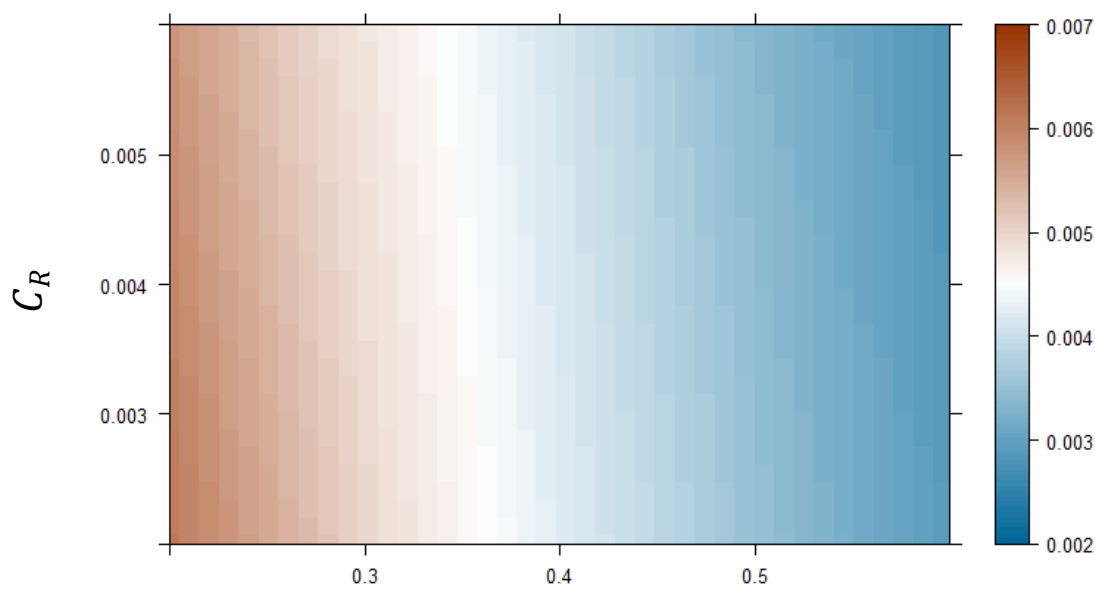

Subject B)

$C_{D}^{\prime}$

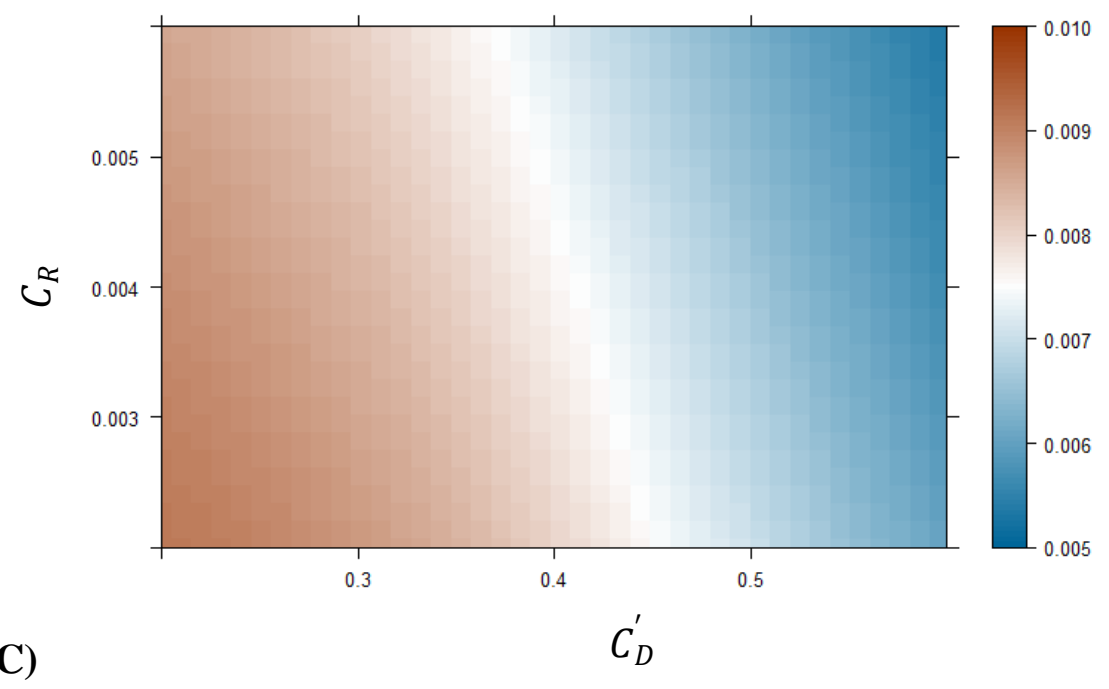

Subject C)

Figure 35. Sensitivity of modeled $\beta_{T}$ to power equation parameters $C_{D}^{\prime}$ and $C_{R}$ 
Unique startup effects were tested by segmenting the pooled $\dot{V}_{E} \sim \dot{W}_{M}$ model by the StartupEnRoute variable (a dummy variable for the first ten seconds of riding after a stop; see Exposure Modeling Chapter 5). The intercept $(\alpha)$ estimate for the StartupEnRoute segment is significantly higher than the other segment (2.659 vs. 2.6321) at $p<0.05$ based on Newey-West robust standard errors. But the combined slope coefficients $\left(\beta_{i}\right)$ are not significantly different between the two segments at $p<0.05$, based on an F-test with $F=1.012$ and 31 degrees of freedom. In other words, the ventilatory response to workload is the same whether the workload fluctuates due to a startup activity or due to the general dynamics encountered during bicycling.

Separate ventilatory effects of upper body control during unloaded $(0 \mathrm{~W})$ bicycling were tested by adding a dummy variable for the stopped condition and estimating the distributed lag model on the subset of 5-second observations with $\dot{W}_{M}=$ 0 :

$$
\ln \left(\dot{V}_{E}\right)_{t}=\alpha+\sum_{i=1}^{30} \beta_{i} \dot{W}_{M, t-i}+\gamma \text { Stopped }_{t}+\varepsilon_{t}
$$

The zero-lag of workload was excluded because it did not vary $\left(\dot{W}_{M, t}=0\right)$. The model was estimated with Newey-West robust standard errors, $N=5,356$, and adjusted $R^{2}=$ 0.082. Estimated coefficients compare well with the full model: $\alpha=2.420$ and $\beta_{T}=$ 0.0050 , with 12 significant lags (out to $60 \mathrm{sec}$ ) on $\beta_{i}$. The added coefficient estimate is $\gamma=-0.054$, not significant at $p<0.05$. The negative coefficient sign suggests that when not pedaling, ventilation is slightly lower when stopped versus riding, likely due to 
energy demands of upper body control. But the lack of statistical significance for $\gamma$ shows that workload over the preceding minute is still the primary determinant of ventilation, even when not pedaling.

\subsubsection{Effect of time aggregation interval}

The same $\dot{V}_{E} \sim \dot{W}_{M}$ relationship was modeled with aggregations up to $60 \mathrm{sec}$ to test for aggregation effects. A summary of model results for the pooled model with lags out to $2.5 \mathrm{~min}$ is shown in Table 46 . Note that the cumulative lag effect $\beta_{T}$ only ranges from 0.00642 to 0.00686 across all the aggregations. The distributive characteristics (mean lag, number of significant lags) are similar across aggregation interval as well. The results of the aggregation test show robustness of the estimated 5-second model.

Table 46. Summary of modeled $\dot{V}_{E} \sim \dot{W}_{M}$ relationship using different aggregation intervals

\begin{tabular}{c|ccccc}
\hline $\begin{array}{c}\text { Aggregation } \\
(\text { sec })\end{array}$ & $\alpha$ & $\beta_{T}$ & $\begin{array}{c}\text { Highest significant lag } \\
\text { (in sec) } \text { at } p<0.05\end{array}$ & $R^{2}$ & $\begin{array}{c}\text { Mean lag } \\
(\text { sec })\end{array}$ \\
\hline 5 & 2.348 & 0.00645 & 130 & 0.140 & 47 \\
10 & 2.362 & 0.00642 & 130 & 0.148 & 46 \\
20 & 2.378 & 0.00643 & 120 & 0.163 & 45 \\
30 & 2.372 & 0.00658 & 120 & 0.177 & 45 \\
40 & 2.393 & 0.00647 & 120 & 0.179 & 42 \\
50 & 2.353 & 0.00686 & 100 & 0.195 & 45 \\
60 & 2.391 & 0.00658 & 120 & 0.188 & 41 \\
\hline
\end{tabular}

\subsubsection{Comparison with theory}

The $\beta_{T}$ values in Table 44 are consistent with expectations from physiology.

Oxygen demand $\left(\dot{V}_{O_{2}}\right)$ increases with workload ${ }^{6}$ at around $10-12 \mathrm{~mL} \mathrm{O}_{2} / \mathrm{min}$ per W

${ }^{6}$ Zoladz et al. (1995) found that $\dot{V}_{O_{2}}$ increases non-linearly at workloads over $250 \mathrm{~W}$ 
(Zoladz et al. 1995, Swain 2000, Olds 2001, Weisman 2003, Glass et al. 2007, Gimenes et al. 2011). This slope reflects a unit conversion of $1 \mathrm{~W}=2.86 \mathrm{ml} \mathrm{O}_{2} / \mathrm{min}$ and a human mechanical cycling efficiency ${ }^{7}$ of $~ 25 \%$ (Moseley et al. 2004, Wilson 2004, Faria et al. 2005a).

The relationship between $\dot{V}_{E}$ and $\dot{V}_{O_{2}}$ has been modeled as both linear and exponential, with better fits over a wide range of $\dot{V}_{O_{2}}$ using exponential forms. The exponential form, $\ln \dot{V}_{E} \sim \dot{V}_{O_{2}}$, has been estimated with a slope of around 1.2 (Baba et al. 1996, Hollenberg and Tager 2000, Van Laethem et al. 2005) ${ }^{8}$. In linear form, the ventilatory equivalent for oxygen $\left(\dot{V}_{E} / \dot{V}_{O_{2}}\right)$ during moderate exercise is around 20-30 (Newstead 1987, Layton 1993, Lucía et al. 1999). Assuming a linear ventilatory equivalent of 25 (McArdle et al. 2010), at ventilation rates of 20-50 lpm during exercise the semi-elasticity of $\dot{V}_{E}$ to $\dot{V}_{O_{2}}$ (i.e. the slope of $\ln \dot{V}_{E} \sim \dot{V}_{O_{2}}$ ) would be expected to be around 0.5-1.3.

The slope of $\ln \dot{V}_{E} \sim \dot{V}_{O_{2}}$ can be converted to $\ln \dot{V}_{E} \sim \dot{W}_{M}$ using the factor 0.01 $\left(\mathrm{LO}_{2} / \mathrm{min} / \mathrm{W}\right)$, resulting in expected $\ln \dot{V}_{E} \sim \dot{W}_{M}$ slopes of roughly $0.005-0.013$. Thus, the modeled values of $\beta_{T}$ in Table 44 and the sensitivity ranges in Figure 35 are in line with expected ventilation response to workload. The theoretical values are based on steadystate relationships and ergometer testing protocols used physiology studies. Low-ranged

\footnotetext{
${ }^{7}$ the amount of energy derived from atmospheric oxygen that is translated to external work

${ }^{8} \mathrm{~A}$ common model uses the oxygen uptake efficiency slope (OUES), which is defined by $\dot{V}_{O_{2}}=O U E S \cdot \log _{10} \dot{V}_{E}+C$. OUES can be converted to a $\ln \dot{V}_{E} \sim \dot{V}_{O_{2}}$ slope coefficient by calculating $\frac{\ln 10}{\text { OUES }}$. Typical OUES values are around 1.8-2, increasing with cardiac fitness.

${ }^{9}$ typically lower at rest (Sin et al. 2010)
} 
values of the $\ln \dot{V}_{E} \sim \dot{W}_{M}$ slope in our study could be attributed to a muted ventilatory response to dynamic workload.

\subsubsection{Comparison with ergometer testing}

The $\ln \dot{V}_{E} \sim \dot{W}_{M}$ relationship was estimated for the same subjects using ergometer test data. A model was specified $\ln \left(\dot{V}_{E}\right)=\gamma+\lambda \dot{W}_{M}$ for each subject, with $\dot{V}_{E}$ in lpm, $\dot{W}_{M}$ in $\mathrm{W}$, and parameters $\gamma$ and $\lambda$. Subject-specific and pooled models were estimated using OLS with Newey-West HAC standard errors for data aggregated at each workload level from the ergometer test. Model estimation results are shown in Table 47. All coefficients were significant at $p<0.01$.

Table 47. Model parameters relating ventilation to workload from ergometer testing

\begin{tabular}{c|rrrr}
\hline & Subject A & Subject B & Subject $C$ & Pooled \\
\hline$\gamma$ & 2.512 & 2.550 & 1.815 & 2.328 \\
$\lambda$ & 0.00628 & 0.00561 & 0.01197 & 0.00728 \\
$\mathrm{R}^{2}$ & 0.60 & 0.72 & 0.71 & 0.65 \\
\hline
\end{tabular}

The parameter estimates in Table 47 are also in range of expectation from theory, and compare reasonably well with the slope parameters from on-road data shown in Table 44. The pooled model is nearly the same. In both the on-road and ergometer models, Subject B has higher baseline ventilation, but less ventilatory response to workload than the other subjects. Subject $\mathrm{C}$ has the highest ventilatory response to workload. Subjects B and C both showed stronger ventilatory responses to workload in ergometer testing than on-road, while the opposite occurred for subject A. Differences between ergometer and on-road testing could be due to static vs. dynamic workloads and/or errors in assumed bicycle power equation parameters (Figure 35). 


\subsubsection{Comparison with a linear model}

As a comparison with log-linear model presented above, a linear distributed lag model of ventilation on workload was specified out to 30 lags as:

$$
\dot{V}_{E_{t}}=\alpha+\sum_{i=0}^{30} \beta_{i} \dot{W}_{M, t-i}+\varepsilon_{t}
$$

with $\dot{V}_{E}$ in lpm, $\dot{W}_{M}$ in $\mathrm{W}$, and $\varepsilon_{t}$ an i.i.d. error term. The model was estimated separately for each subject and pooled, with Newey-West HAC robust standard error estimates. Estimated subject-specific and pooled model results are shown in Table 48. Overall model fits are similar to Table 44. The left plot in Figure 36 shows the marginal impact of $\dot{W}_{M}$ on $\dot{V}_{E}$ as $\beta_{i} \cdot 100$ (versus lag in seconds, 5i). The right plot in Figure 36 shows the cumulative lagged impact of $\dot{W}_{M}$ on $\dot{V}_{E}$, calculated at lag $L$ as $\frac{\sum_{i=0}^{L} \beta_{i}}{\beta_{T}} \cdot 100$.

Table 48 . Distributed lag models of on-road ventilation as a linear function of workload

\begin{tabular}{|c|c|c|c|c|}
\hline & $A$ & $B$ & $C$ & Pooled \\
\hline$\alpha$ & 2.000 & 16.534 & 8.057 & 4.759 \\
\hline$\beta_{T}$ & 0.210 & 0.084 & 0.166 & 0.192 \\
\hline $\begin{array}{l}\text { Number of significant lags } \\
\quad(p<0.05)\end{array}$ & 27 & 10 & 15 & 27 \\
\hline Mean lag (min) & 0.88 & 0.63 & 0.64 & 0.85 \\
\hline$N$ & 13,044 & 2,248 & 2,156 & 17,448 \\
\hline Adjusted $\mathrm{R}^{2}$ & 0.170 & 0.037 & 0.121 & 0.179 \\
\hline F-statistic & 87.45 & 3.79 & 10.59 & 123.7 \\
\hline
\end{tabular}



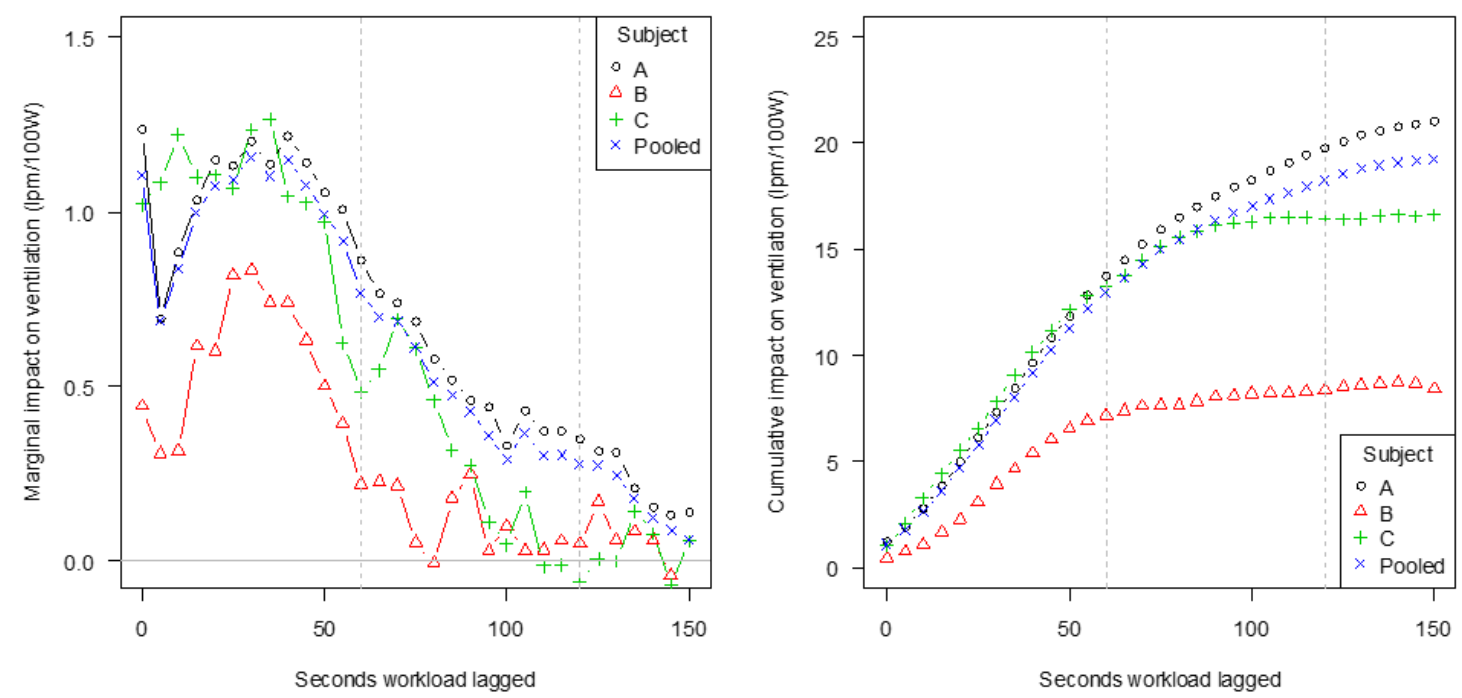

\section{Figure 36 . Marginal and cumulative impacts of workload on ventilation in the linear model}

The mean lags in Table 48 and the plots in Figure 36 show good agreement for the distribution of the lagged effect with the previous, log-linear model. Hence, the delayed response of ventilation to workload is similar for the two specifications. A comparison of estimated coefficients among subjects is also similar to the log-linear model: subjects $\mathrm{A}$ and $\mathrm{C}$ have similar response while subject $\mathrm{B}$ has a more muted ventilatory response to workload. Figure 37 presents a visual comparison of the predicted ventilation at steady-state workloads from 0 to $250 \mathrm{~W}$ from the log-linear and linear models for subjects A and B (the two subjects with the greatest difference between slope estimates in Table 48). The difference between the specifications ranges up to $3 \mathrm{lpm}$ for subject B and up to $7 \mathrm{lpm}$ for subject $\mathrm{A}$. The theoretical limitation of the linear model is manifest for subject $\mathrm{A}$, with a predicted $0 \mathrm{~W}$ ventilation rate of $2 \mathrm{lpm}$, well below a normal resting ventilation rate. 


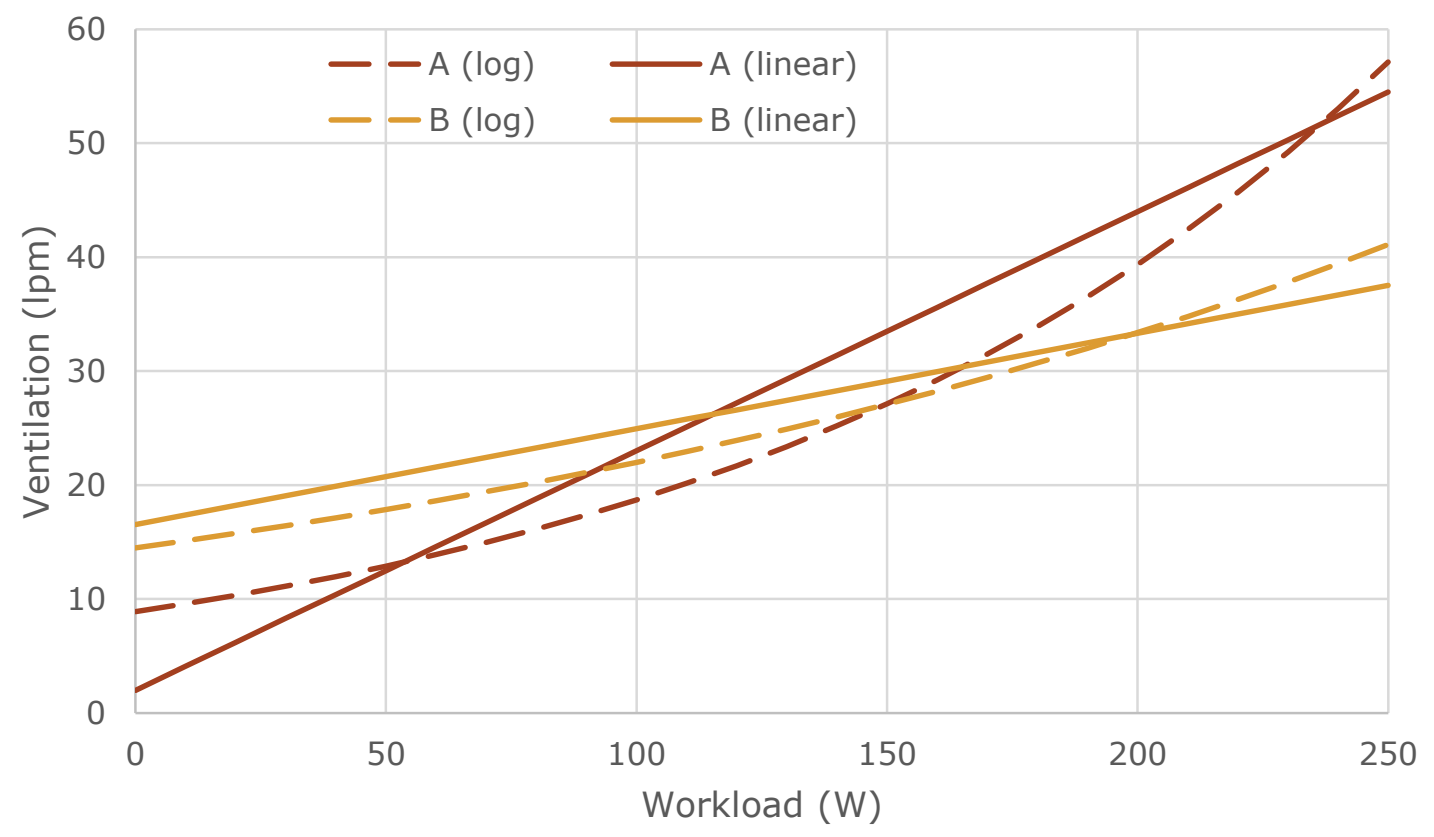

Figure 37. Comparison of steady-state predictions from log-linear and linear specifications of the ventilation-workload relationship

\section{POLLUTANT INHALATION RATE ESTIMATES}

In this section, on-road ventilation is combined with measured on-road exposure concentrations to generate estimates of on-road inhalation rates. Recalling that the inhalation rate (in mass per unit time) is $I^{t}=C \cdot \dot{V}_{E}$, the question arises as to the importance of knowing each of $C$ and $\dot{V}_{E}$ for estimation of intake rates. As noted in the Literature Review, Chapter 2, all but a few previous studies have assumed a fixed ventilation rate for bicyclists and measured concentration variability. Figure 35 shows coefficients of variability (standard deviation divided by the mean) in five-second aggregated on-road data for $\dot{V}_{E}$ and exposure concentrations of BTEX compounds, CO, $\mathrm{PM}_{2.5}$, and $\mathrm{CO}_{2}$, separated by mixed-traffic and off-street facilities. Figure 35 shows that for mixed-traffic facilities, BTEX and CO concentration variability is higher than 
ventilation variability, which is similar to $\mathrm{PM}_{2.5}$ variability. The opposite is true for offstreet facilities. $\mathrm{CO}_{2}$ and $H R$ variability are low at both locations. The data in Figure 35 suggest that for some facilities and pollutants, ventilation is as important a determinant of inhalation rate variability as concentrations are.

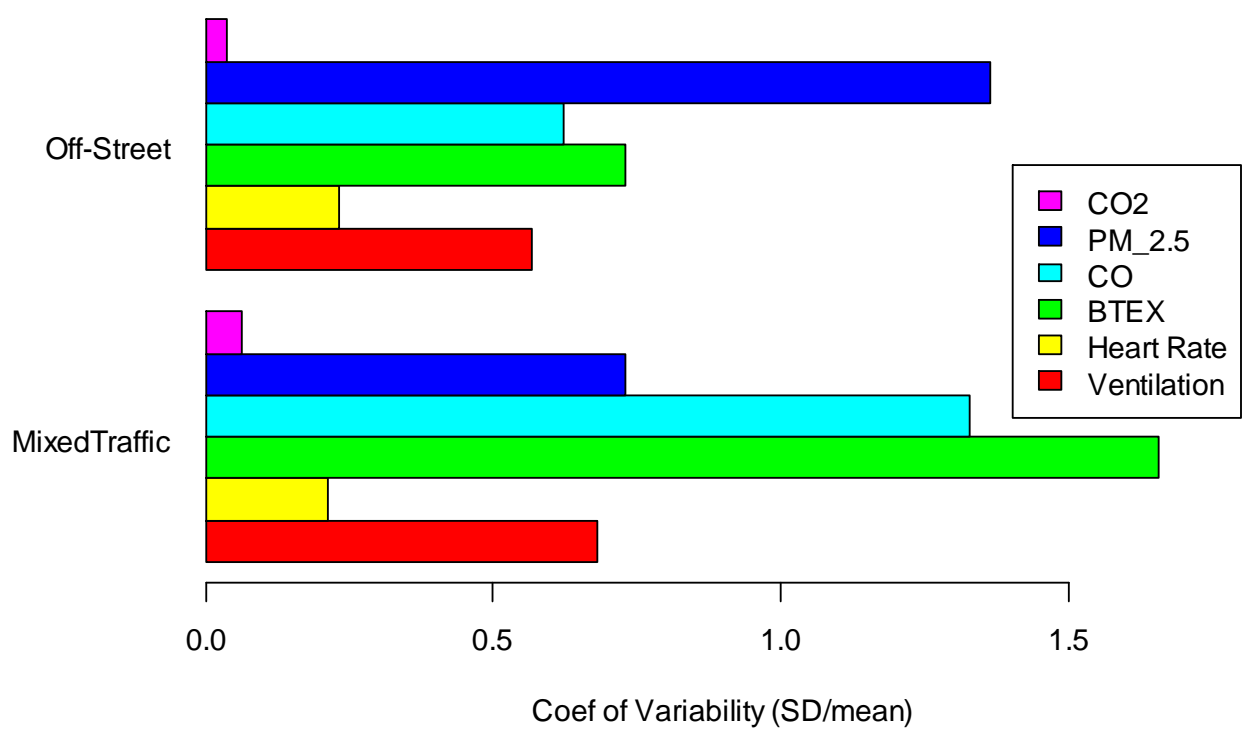

Figure 38. Coefficients of variability for 5 -second concentration and ventilation data by location

Calculated inhalation rates at five-second aggregation are summarized in Table 49. With the combined variation in concentration and exposure, the inhalation rate estimates are widely disperse. The coefficients of variability are 1.6, 1.8, and 1.4 for BTEX, $\mathrm{CO}$ and $\mathrm{PM}_{2.5}$, respectively. The mean inhalation rates in Table 49 were compared with inhalation rates based a fixed mean ventilation rate per subject. Ignoring ventilation variability in this way, mean inhalation rates are 5\% higher for BTEX compounds, $12 \%$ lower for $\mathrm{CO}$, and $8 \%$ higher for $\mathrm{PM}_{2.5}$. These inhalation rate errors are in the opposite directions of concentration correlations with ventilation. 
Table 49. Summary of inhalation rates using 5-second concentration and ventilation data

\begin{tabular}{l|rrrrrr}
\hline & Minimum & 1st Quartile & Median & Mean & 3rd Quartile & Maximum \\
\hline BTEX $(\mu \mathrm{g} / \mathrm{min})$ & 0.00 & 0.07 & 0.13 & 0.21 & 0.25 & 20.63 \\
$\mathrm{CO}(\mu \mathrm{g} / \mathrm{min})$ & 0.00 & 0.00 & 4.57 & 12.43 & 15.83 & 612.40 \\
$\mathrm{PM}_{2.5}(1,000$ & & & & & & \\
$\mathrm{pt} / \mathrm{min})$ & 0.00 & 1.43 & 2.56 & 3.45 & 4.31 & 368.10 \\
\hline
\end{tabular}

\section{CONCLUSIONS}

This chapter demonstrates that physiology monitoring straps provide an unobtrusive way to measure ventilation rates for bicyclists. Ventilation rate measurements were validated by heart rate vs. ventilation rate relationships. Future work should further validate this method by direct comparison with portable facemask systems. Besides comfort for the bicyclists and lower costs, physiology monitoring straps enable concurrent measurements of ventilation rates and pollutant uptake doses for bicyclists something which has not yet been done. In this study on-road ventilation lagged heart rate by 20 seconds. This lag is important to consider for study designs using heart rate monitors to estimate dynamic on-road ventilation rates.

Average ventilation rate for bicyclists was $22 \mathrm{lpm}$ and average workload was 126 W (MET of 7.0), in agreement with past studies of commuting bicyclists. Measured onroad ventilatory response to dynamic workload was $0.4-0.8 \%$ per $\mathrm{W}$, slightly lower than from ergometer testing for the same subjects (which was 0.6-1.2 \%/W) and at the low end of expected values from physiology literature. The ventilation vs. workload relationships were moderately sensitive to the assumed drag coefficient parameters. This quantification 
of the ventilatory response to dynamic workload allows more direct investigation of relationships between on-road physical exertion and pollutant inhalation.

The mean lag of on-road ventilation with respect to dynamic workload was 0.8 min. Thus, ventilatory responses are not coincident with locations of workload changes, but spread out over 1-2 minutes. Assuming bicycling speeds around $15 \mathrm{kph}$, a lag of 0.8 min is equivalent to a spatial difference of $200 \mathrm{~m}$ (2-3 Portland blocks). This spatial lag in the ventilatory response is a potentially important consideration for pollutant inhalation "hot spots". For example, exposure concentrations are expected to be elevated near intersections; workloads, too, are high during an acceleration from a stop at an intersection - but the ventilatory response is spread out over several blocks. Conversely, when bicyclists are stopped at an intersection with a workload of $0 \mathrm{~W}$, they are breathing with the residual influence of the past 2 minutes of exertion.

In this study $47 \%$ of on-road energy loss was due to braking and $44 \%$ due to aerodynamic drag. A random sample bicycle travel data set would be needed to estimate a more representative distribution of power demands for urban bicycling. Future work will explore the influence of travel attributes on workload and ventilation in more detail, including the effects of stops, grades, and travel speeds. This chapter is an important step toward quantifying the impact travel characteristics on bicyclists' pollutant inhalation risks. Observed variability in ventilation was similar to concurrent observed variability in exposure concentrations, which indicates the importance of including dynamic ventilation in analysis of pollutant inhalation risks for bicyclists. 


\section{Chapter 7: Bicyclist uptake of VOC}

\section{INTRODUCTION}

Modeling studies of toxicant uptake by travelers have shown that exposure concentration can be a poor surrogate for biological uptake or internal dose, due to varying respiratory physiology (McNabola et al. 2008, Nyhan et al. 2014). A persistent difficulty in quantifying the health risks of toxicant exposure during travel is quantifying the relationship between ambient concentrations and internal dose - particularly for conditions of physically active individuals and dynamic ambient concentrations. Exposure biomarkers are indicators of the internal dose in biological media that can be used to estimate health risks of toxicant exposure before the health effects are manifest (Amorim and de L. Cardeal 2007). Two studies measured traffic-related exposure biomarkers for bicyclists. Bergamaschi et al. (1999) found significant increases of benzene, toluene, and xylenes in blood and urine after riding in urban areas, but not after riding in rural areas. Nwokoro et al. (2012) concluded that inhaled doses of black carbon particulate matter in London were higher for bicyclists than non-bicyclists based on induced sputum samples. Internal dose as affected by the type of path within an urban transportation network has not been studied.

Breath analysis has emerged as a useful exposure biomarker because exhaled air can be sampled less invasively and more frequently than other biological media such as blood and urine (Costello et al. 2014). The principle of breath biomarkers is that toxicant concentrations in sampled breath air are proportional to their blood concentrations (Amorim and de L. Cardeal 2007). Blood is the first and most dynamic body 
“compartment" for internal dose of inhaled toxicants (Wallace et al. 1997). End-tidal exhaled air is representative of alveolar air that is in equilibrium with the blood in accordance with the blood/air partition coefficient for blood-soluble compounds (Heinrich-Ramm et al. 2000) ${ }^{1}$.

There are challenges of using breath analysis as an exposure biomarker, beyond the required high-sensitivity analytical techniques. Hundreds of compounds are endogenously produced and exhaled in "healthy" human breath (Costello et al. 2014), complicating the use of breath biomarkers of dose for those compounds. When measuring environmental exposures of exogenous compounds in an urban setting, another issue is the lack of a true clean reference location. Urban and suburban environments have background ambient concentrations (Pankow et al. 2003) which will be present even in “clean" reference breaths (Phillips et al. 1999). Additionally, the relationship between breath concentrations and fluctuating ambient concentrations and is still not well known (Amorim and de L. Cardeal 2007).

Breath biomarkers of dose have primarily been applied to occupational or extended environmental exposure settings (Amorim and de L. Cardeal 2007). This paper describes the first known application of breath analysis to study the uptake of volatile organic compounds (VOCs) by travelers. The objectives of this work were to 1) obtain on-road measurements of VOCs in ambient air and in the exhaled breath of urban

\footnotetext{
${ }^{1}$ It should be recognized that the blood/breath concentration ratio can also be affected by the ventilationperfusion ratio and airway gas exchange (King et al. 2011). The ventilation-perfusion ratio is important for low blood soluble inert gases, while airway gas exchange is more important for highly soluble gases.
} 
bicyclists and 2) examine the utility of breath biomarkers to observe the effects of urban path type on internal dose in a mobile setting.

Breath biomarkers are particularly attractive to study internal dose of VOC from transportation microenvironments because of short exposure duration and heterogeneous ambient concentrations. Motor vehicles emit numerous VOC in exhaust and transportation microenvironments often contain high concentrations of traffic-related VOC (Fujita et al. 2011, Tsai et al. 2012). Blood concentrations of aromatic VOC equilibrate quickly with ambient air (Wallace et al. 1997), and breath biomarkers can be collected at a resolution which would be impracticable for blood or urine sampling.

\section{MODELING APPROACH}

The preceding chapters analyzed and discussed exposure to and inhalation of traffic-related VOC. In this chapter, uptake of VOC is investigated. Concentrations of aromatic hydrocarbons in breath samples are used as indicators of VOC uptake into the bloodstream. As discussed in the Literature Review, Chapter 2, bicyclist uptake of air pollution has only been measured, even indirectly, in two studies. One study compared indicators of BTEX uptake in urban and rural bicyclists (Bergamaschi et al. 1999) and another compared lung-deposited black carbon particles for bicyclists and transit riders in London (Nwokoro et al. 2012). Several other studies have modeled uptake, but quantification of the impacts of travel conditions on uptake is still severely lacking.

The influence of travel conditions on pollution uptake is illustrated in Figure 39. First in this chapter, significant associations between changes in breath and ambient concentrations are established, to show that uptake is indicated in the breath samples. 
Second, breath concentrations are modeled as a function of exposure conditions and the immediate factors in Figure 39, to quantify the uptake proportion. Then breath concentrations are modeled using roadway and travel variables as explanatory variables, in an attempt to capture the longer connections between travel conditions and uptake (through exposure concentrations). The objectives of this last step are to 1) compare the influence of travel conditions on blood concentrations with the influence of exposure and 2) quantify relationships between travel variables and blood concentrations.

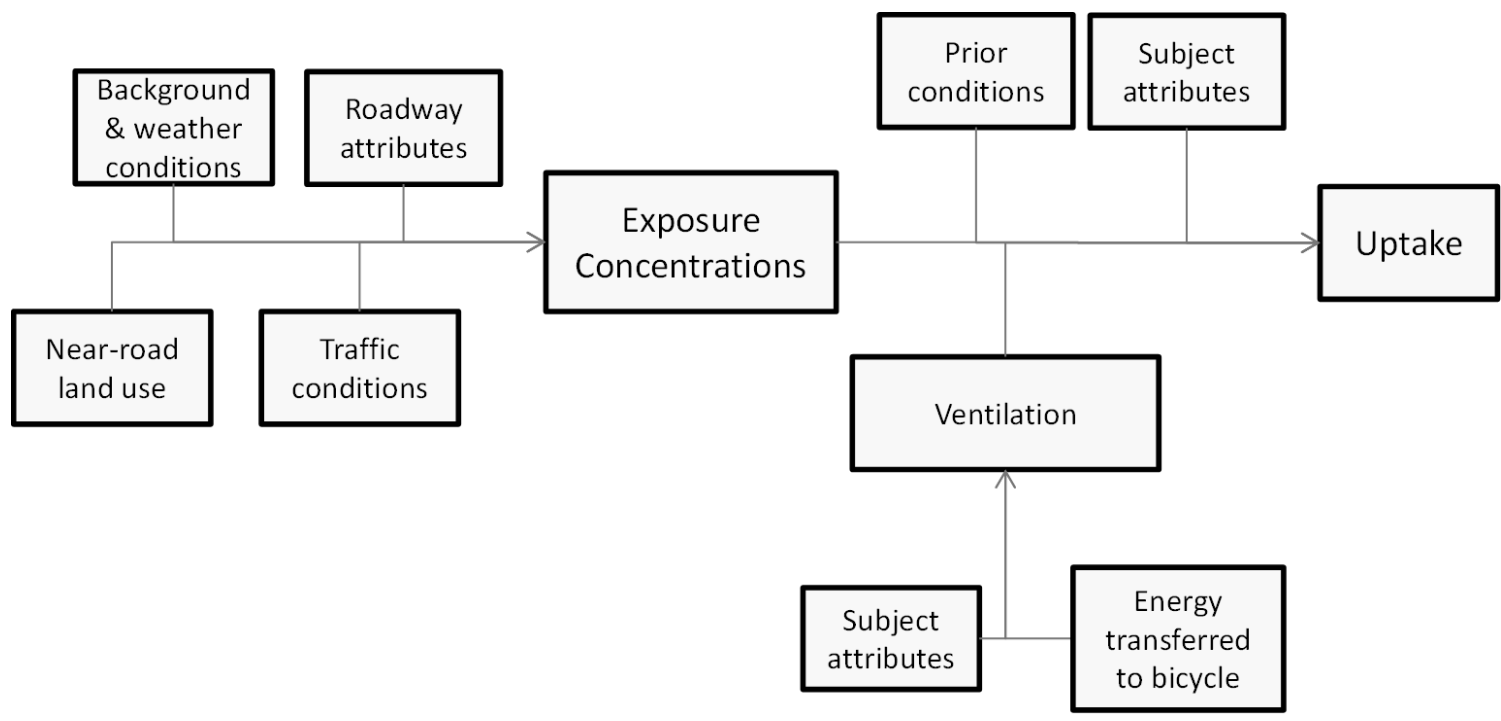

Figure 39. Conceptual diagram of the influence of travel conditions on pollution uptake

The literature on traveler uptake of traffic-related air pollution suggests the potential explanatory variables in Table 50 . Table 50 is primarily a concatenation of the potential explanatory variables for exposure and ventilation. 
Table 50. Potential explanatory variables for modeling uptake

\begin{tabular}{|c|c|c|c|c|}
\hline Influence & Category & Example variables & $\begin{array}{l}\text { Expected size } \\
\text { of influence }\end{array}$ & $\begin{array}{l}\text { Availability } \\
\text { of data }\end{array}$ \\
\hline Subject & Subject & $\begin{array}{l}\text { Metabolic clearance rate, blood } \\
\text { volume }\end{array}$ & Med & Low \\
\hline $\begin{array}{l}\text { Prior } \\
\text { conditions }\end{array}$ & Prior conditions & Initial blood/breath concentration & Med-High & High \\
\hline Ventilation & Physiology & Age, sex, fitness, aerobic capacity, etc. & Med & Med-High \\
\hline Ventilation & $\begin{array}{l}\text { Bicycle } \\
\text { attributes }\end{array}$ & Drivetrain efficiency & Low & Low \\
\hline Ventilation & $\begin{array}{l}\text { Bicycle } \\
\text { attributes }\end{array}$ & Tire condition, size and pressure & Med & High \\
\hline Ventilation & $\begin{array}{l}\text { Bicycle } \\
\text { attributes }\end{array}$ & Mass of bicycle and rider & High & High \\
\hline Ventilation & $\begin{array}{l}\text { Bicycle } \\
\text { attributes }\end{array}$ & Frontal area and drag coefficient & High & Low \\
\hline Ventilation & Travel attributes & Pedaling cadence & Low-Med & Low \\
\hline Ventilation & Travel attributes & Upper body control & Low & Low \\
\hline Ventilation & Travel attributes & Speed, acceleration & High & High \\
\hline Ventilation & Travel attributes & $\begin{array}{l}\text { Ground-level wind speed and } \\
\text { direction }\end{array}$ & Med & Med \\
\hline Ventilation & Travel attributes & Temperature, humidity & Low & High \\
\hline Ventilation & Travel attributes & Braking & High & Low \\
\hline Ventilation & $\begin{array}{l}\text { Roadway } \\
\text { attributes }\end{array}$ & Grade & High & Med-High \\
\hline Ventilation & $\begin{array}{l}\text { Roadway } \\
\text { attributes }\end{array}$ & Surface & Med & Low \\
\hline Exposure & Traffic & $\begin{array}{l}\text { Passing vehicles, hourly traffic counts, } \\
\text { ADT, facility type as proxy }\end{array}$ & High & $\begin{array}{l}\text { Low to } \\
\text { High }\end{array}$ \\
\hline Exposure & Traffic & Classification of vehicle volume data & High & Low-Med \\
\hline Exposure & Traffic & Fuel composition and characteristics & Low-Med & Low-Med \\
\hline Exposure & Traffic & $\begin{array}{l}\text { Speeds, queues, accelerations, idling, } \\
\text { etc. }\end{array}$ & Low-Med & Med \\
\hline Exposure & Weather & Temperature & Med & High \\
\hline Exposure & Weather & Relative humidity & Low & High \\
\hline Exposure & Weather & Wind speed \& variability & High & High \\
\hline Exposure & Weather & Mixing layer height & Low-Med & Low-Med \\
\hline Exposure & Land use & \# and types of activities & Med-High & Low \\
\hline Exposure & Land use & Building/wall height, set-back & Med & Low \\
\hline Exposure & Land use & $\begin{array}{l}\text { Number of trees/plants/shrubs, size, } \\
\text { location, foliage density, type }\end{array}$ & Low & Low \\
\hline Exposure & Land use & Crossing or parallel major road & Med & Med \\
\hline Exposure & Geography & $\begin{array}{l}\text { Roadway cuts, bridges, land berms, } \\
\text { hills, etc. }\end{array}$ & Med & Low \\
\hline Exposure & Geography & $\begin{array}{l}\text { \# of lanes, lanes widths, location of } \\
\text { bicyclists }\end{array}$ & Low-Med & Med \\
\hline Exposure & Geography & $\%$ grade & Med & Med \\
\hline Exposure & Background & Measured ambient concentration & Med & Med \\
\hline
\end{tabular}




\section{BREATH BIOMARKERS OF VOC EXPOSURE}

\subsection{Breath/Ambient Concentration Ratios}

For each compound, on-road breath and ambient concentrations were compared in order to identify exogenous compounds. Ordinary least squares was used to estimate the equation $C_{\mathrm{breath}, i}=\beta \cdot C_{\mathrm{ambient}, i}+\varepsilon_{i}$, where $C_{\mathrm{breath}, i}$ and $C_{\mathrm{ambient}, i}$ are the end-segment breath and in-segment ambient concentrations on segment $i, \beta$ is an estimated parameter, and $\varepsilon_{i}$ is an error term. Estimated $\beta$ values for 26 compounds are given in Table 51. All $\beta>0$ at $p<0.05$ except for methyl methacrylate $(p=0.055)$. Table 51 also gives the results of two-tailed t-tests with the null hypothesis $\left(H_{o}\right)$ that $\beta=1$, rejected at $p<0.05$ (53 degrees of freedom). The $\beta$ parameters represent breath/ambient concentration ratios, and can be interpreted as follows (similar to the alveolar gradients in Phillips et al. (1999)):

- $\beta<1$ : an exogenous compound absorbed into blood through breath,

- $\beta \approx 1$ : a compound with a breath/ambient balance (due to negligible metabolism/excretion), and

- $\quad \beta>1$ 1: a compound cleared from the blood through breath (either endogenous or previously absorbed). 
Table 51. On-road breath/ambient concentration ratios

\begin{tabular}{|c|c|c|c|}
\hline Compound & $\beta$ & $\begin{array}{l}\text { Std. } \\
\text { Error }\end{array}$ & $\begin{array}{c}\text { t-test with } \\
\mathrm{H}_{\mathrm{o}}: \beta=1 \\
\text { (reject at } \mathrm{p}<0.05 \text { ) }\end{array}$ \\
\hline \multicolumn{4}{|l|}{ halocarbons } \\
\hline trichlorofluoromethane (CFC11) & 0.914 & 0.029 & Reject: $\beta$ lower \\
\hline methylene chloride & 1.058 & 0.251 & Accept $H_{o}$ \\
\hline 1,1,2,-trichloro-1,2,2-trifluoroethane (CFC113) & 0.886 & 0.014 & Reject: $\beta$ lower \\
\hline chloroform & 1.074 & 0.053 & Accept $H_{o}$ \\
\hline carbon tetrachloride & 0.763 & 0.010 & Reject: $\beta$ lower \\
\hline tetrachloroethene (PCE) & 0.955 & 0.102 & Accept $H_{o}$ \\
\hline \multicolumn{4}{|l|}{ esters } \\
\hline methyl acetate & 37.385 & 3.870 & Reject: $\beta$ higher \\
\hline methyl methacrylate & 0.584 & 0.298 & Accept $H_{o}$ \\
\hline \multicolumn{4}{|l|}{$\underline{\text { sulfide }}$} \\
\hline carbon disulfide & 8.443 & 2.055 & Reject: $\beta$ higher \\
\hline \multicolumn{4}{|l|}{ ketones } \\
\hline 2-butanone (methyl ethyl ketone) & 1.920 & 0.144 & Reject: $\beta$ higher \\
\hline acetone & 64.895 & 6.535 & Reject: $\beta$ higher \\
\hline 4-methyl-2-pentanone (MIBK) & 0.924 & 0.048 & Accept $H_{o}$ \\
\hline 2-hexanone (MBK) & 1.021 & 0.090 & Accept $H_{o}$ \\
\hline \multicolumn{4}{|l|}{ aromatics } \\
\hline benzene & 0.450 & 0.039 & Reject: $\beta$ lower \\
\hline toluene & 0.303 & 0.016 & Reject: $\beta$ lower \\
\hline ethylbenzene & 0.197 & 0.011 & Reject: $\beta$ lower \\
\hline$m+p$-xylene & 0.169 & 0.009 & Reject: $\beta$ lower \\
\hline ethenylbenzene (styrene) & 0.028 & 0.004 & Reject: $\beta$ lower \\
\hline$o$-xylene & 0.167 & 0.010 & Reject: $\beta$ lower \\
\hline$n$-propylbenzene & 0.377 & 0.028 & Reject: $\beta$ lower \\
\hline 1,3,5-trimethylbenzene & 0.199 & 0.014 & Reject: $\beta$ lower \\
\hline 2-ethyltoluene & 0.181 & 0.013 & Reject: $\beta$ lower \\
\hline 1,2,4-trimethylbenzene & 0.147 & 0.010 & Reject: $\beta$ lower \\
\hline 1-isopropyl-4-methylbenzene & 2.808 & 0.285 & Reject: $\beta$ higher \\
\hline 1,2,3-trimethylbenzene & 0.211 & 0.015 & Reject: $\beta$ lower \\
\hline naphthalene & 0.625 & 0.069 & Reject: $\beta$ lower \\
\hline
\end{tabular}

Breath/ambient concentration ratios for benzene and toluene that are similar to

Table 51 have been reported in several studies (Carlsson 1982, Perbellini et al. 1988,

Brugnone et al. 1989, Egeghy et al. 2002). Wallace et al. $(1993,1997)$ report lower

equilibrium breath/ambient concentration ratios for aromatic hydrocarbons, but in a

similar ordering among compounds (benzene $>$ toluene $>$ ethylbenzene $\sim$ xylenes). 
According to Wallace et al. (1993), higher equilibrium breath/ambient concentration ratios are expected with

- lower blood-air partition coefficient $\left(P_{b: a}\right)$,

- lower metabolic rate $(K)$, or

- higher alveolar ventilation rate $\left(\dot{V}_{\text {alv }}\right)$.

Physical activity tends to increase ventilation $\dot{V}_{a l v}$, decrease metabolic rate $K$ (Astrand 1985, Nadeau et al. 2006), and raise body temperature - which can reduce $P_{b: a}$ (Anderson et al. 2003). All of these effects would tend to increase equilibrium breath/ambient concentration ratios with exercise.

Mean heart rates in our data were 86,106 , and $75 \mathrm{~min}^{-1}$ for subjects $\mathrm{A}, \mathrm{B}$, and $\mathrm{C}$, respectively (significantly different at $\mathrm{p}<0.05$ between $\mathrm{B}$ and $\mathrm{A}$ and between $\mathrm{B}$ and $\mathrm{C}$ based on paired t-tests). Isolating the subject with the most data (A), on-road breath/ambient concentration ratios were positively correlated with heart rate, significant for 5 of the tested aromatic hydrocarbons at $\mathrm{p}<0.05$ with correlation coefficients of 0.34 0.41. Similarly, Carlsson (1982) reports breath/ambient concentration ratios that increase with exertion and heart rate. Hence, greater uptake of aromatic hydrocarbons is expected for travelers with higher exertion levels.

On the other hand, both $K$ and $P_{b: a}$ have been shown to increase at lower concentrations for traffic-related VOC (Beliveau and Krishnan 2000, Kim et al. 2006), which would lead to lower breath/ambient ratios in lower-concentration environments. Supporting the hypothesis that lower concentrations lead to higher breath/ambient concentration ratios, a similar OLS regression to Table 51 was estimated with a term for 
squared ambient concentration as $C_{\mathrm{breath}, i}=\beta_{1} C_{\mathrm{ambient}, i}+\beta_{2} C_{\mathrm{ambient}, i}^{2}+\varepsilon_{i}$. The squared term coefficient $\beta_{2}$ is negative for all of the BTEX aromatic compounds, significant at $p<0.05$

Another consideration is that exercise tends to increase ventilation-perfusion ratios (West 2012), which can decrease exhaled alveolar air concentrations with respect to blood concentrations for low blood soluble gases (King et al. 2011) ${ }^{2}$. Hence, in addition to the real influence of physical activity on internal dose, continuously sampled breath biomarkers could underestimate blood concentrations if sampled during exercise. Breath samples in this study were collected from a slow expiration after riding had stopped. The effect of the ventilation-perfusion ratio in this context is negligible because alveolar air in the sampled breath had ample time to equilibrate with blood concentrations.

The 6 halocarbons in Table 51 have stable breath/ambient ratios near to 1, indicating little metabolic clearance. In agreement with Table 51, methyl acetate and ketones such as acetone, 2-hexanone, 2-butanone were previously found to be higher in exhaled breath than ambient air, most likely due to biological sources (King et al. 2010, Filipiak et al. 2012). The aromatic compounds with the highest breath/ambient ratios in Table 51 are 1-isopropyl-4-methylbenzene and naphthalene, which is consistent with results of Phillips et al. (1999).

\footnotetext{
${ }^{2}$ Consider the classic Farhi equation, $\frac{C_{\text {alveolar }}}{C_{\text {blood }}}=\frac{1}{P_{b: a}+\frac{V_{A}}{Q_{C}}}$, where $\frac{V_{A}}{Q_{C}}$ is the ventilation-perfusion ratio.
} 


\subsection{Changes in Breath and Ambient Concentrations}

Concurrent changes in breath and ambient concentrations are compared by estimating slope coefficients $\gamma$ for each compound: $\Delta C_{\text {breath }, i}=\gamma \cdot \Delta C_{\mathrm{ambient}, i}+\varepsilon_{i}$, where $\Delta C_{\text {breath, } i}$ is the differenced breath sample concentrations after and before segment $i, \Delta C_{\mathrm{ambient}, i}$ is the differenced ambient concentrations during segment $i$ and from the previous segment $i-1$ (or pre-ride location), and $\varepsilon_{i}$ is an error term. Table 52 gives slope coefficient $(\gamma)$ estimates and their p-values for 12 aromatic hydrocarbons that exhibit exogenous characteristics in the sample data $(\beta<1$ in Table 51). Table 52 also gives Pearson correlation coefficients $(\rho)$ between $\Delta C_{\mathrm{breath}, i}$ and $\Delta C_{\mathrm{ambient}, i}$. Changes in breath concentrations are significantly associated with changes in ambient concentrations for 7 of the 12 compounds at $p<0.05$, with slopes ranging from 0.02 to 0.16 . The correlation coefficients for these 7 compounds range from 0.24 to 0.75 .

Table 52. Relationship between changes in breath concentrations and changes in ambient concentrations $(N=62)$

\begin{tabular}{lccc}
\hline Compound & $\gamma$ & $\mathrm{p}$-value & correlation coefficient, $\rho$ \\
\hline benzene & 0.159 & 0.000 & 0.599 \\
toluene & 0.113 & 0.000 & 0.490 \\
ethylbenzene & 0.049 & 0.012 & 0.307 \\
$m+p$-xylene & 0.046 & 0.014 & 0.300 \\
ethenylbenzene (styrene) & 0.017 & 0.000 & 0.751 \\
$o$-xylene & 0.031 & 0.082 & 0.213 \\
$n$-propylbenzene & 0.033 & 0.244 & 0.145 \\
1,3,5-trimethylbenzene & 0.036 & 0.035 & 0.259 \\
2-ethyltoluene & 0.026 & 0.137 & 0.176 \\
1,2,4-trimethylbenzene & 0.028 & 0.047 & 0.244 \\
1,2,3-trimethylbenzene & 0.039 & 0.074 & 0.223 \\
naphthalene & 0.005 & 0.952 & 0.007 \\
\hline
\end{tabular}


In comparison with the slope coefficient of 0.16 for benzene in Table 52, Egeghy et al. (2002) estimate breath elasticity to exposure of 0.596 , which can be converted to a slope coefficient of 0.20 using their reported non-smoker breath and exposure mean concentrations (40.3 and $119 \mu \mathrm{g} \mathrm{m}^{-3}$, respectively). The uptake results compare favorably despite past breath sampling involving orders of magnitude higher exposure concentrations and longer exposure times.

\subsection{Discussion of Breath Biomarkers}

Breath analysis reveals at least four monoaromatic hydrocarbons feasible for exposure biomarkers in transportation microenvironments (benzene, ethylbenzene, $m+p$ xylene, and 1,3,5-trimethylbenzene). These compounds exhibited the common characteristics (at a significance level of $p<0.05$ ) of:

1. exogeneity, indicated by breath concentrations significantly lower than ambient concentrations (Table 51),

2. breath concentrations changed significantly with changes in ambient concentrations (Table 52), and

3. on-road ambient and breath concentrations significantly higher than the respective concentrations at the park location (Data Overview Chapter 4, Table 6).

Four other aromatics were also feasible exposure biomarkers at a significance level of $p<0.10$ (toluene, $o$-xylene, 1,2,4-trimethylbenzene, 1,2,3-trimethylbenzene).

Many other VOCs are present in motor vehicle exhaust and are likely taken up by travelers, but were not viable breath biomarkers. Possible reasons for exclusion from the set of breath biomarkers include: 
1. compounds that are primarily endogenous (i.e. breath > ambient concentrations),

2. breath and ambient concentration changes that are not significantly correlated, possibly due to interference from endogenous production or sampled breath that misrepresents blood concentrations,

3. background breath concentrations that are too high to allow detection of a significant concentration difference after travel, or

4. concentrations that are unquantified due to a lack of calibration gas standards or compounds co-eluting with water.

Unfortunately, most of these challenges in the application of breath biomarkers are inherent to the method.

High water content in exhaled breath is a known impediment to accurate quantification of compounds that are highly water-soluble (hydrophilic) or that co-elute with water. More water-soluble VOCs such as formaldehyde or methanol also interact with the mucosal lining of the respiratory tract, complicating interpretation of exhaled breath as representative of alveolar air and blood concentrations (Astrand 1975, Medinsky and Bond 2001, King et al. 2012). BTEX and other aromatics have the advantage as breath biomarkers that partitioning into blood is much stronger than partitioning into saline water. In contrast, alcohols, acetates, and ketones have similar affinity in saline water and blood (Meulenberg and Vijverberg 2000).

The issue of relatively high background concentrations is expected to be broadly applicable. Although transportation microenvironments often have high concentrations, the concentrations are highly dynamic and typical exposure durations are short. Thus, the 
internal dose signal from a trip or trip segment is not large with respect to the background condition of someone living in an urban area. In a highly polluted city both on-road and background concentrations would be high and breath biomarkers would likely still be small compared to the baseline body burden of VOC. A higher fraction of non-traffic (e.g. industrial) BTEX sources would reduce the relative importance of roadway facility type on exposure and increase the influence of surrounding land use.

Smaller roadway effects on exposure to alkanes and aldehydes can be expected than the effects on exposure to aromatics presented here. Aromatics are concentrated near roadways (Beckerman et al. 2008, Karner et al. 2010), whereas Alkanes tend to be more disperse due to non-roadway sources (O'Donoghue and Broderick 2007). Trafficrelated aldehydes such as acetaldehyde and acrolein have large secondary components from oxidation of primary VOC emissions and so are also more disperse (Clements et al. 2009). Note that acetaldehyde was poorly correlated with benzene in ambient air in our sample data (see Data Overview, Chapter 4 Table S.2).

Despite these challenges, breath biomarkers of certain monoaromatics show good potential for quantifying the differences in internal dose from travel options within an urban area. Breath biomarkers can be used at the facility level, a resolution which is too fine for the application of exposure biomarkers from other biological media such as blood and urine. But when applying breath biomarkers for active travelers, it is important to consider several ways in which physical activity affects biological concentrations of VOC: 
1. Inhalation/intake doses increase dramatically (by 2-5 times) due to increases in ventilation.

2. Uptake/internal doses increase slightly (by less than the increase in inhalation) due to a higher blood/air ratio at equilibrium.

3. If sampled continuously, alveolar concentrations (breath biomarkers) can decrease with respect to blood concentrations for low blood soluble compounds due to a higher overall ventilation-perfusion ratio (i.e. dilution of the expiratory mass flow).

\section{BREATH CONCENTRATIONS AS A FUNCTION OF EXPOSURE}

The measured segment-level explanatory variables tested in this analysis are shown in Table 53. Correlations among the measured segment-level explanatory variables and toluene breath concentrations are shown in Figure 40.

Table 53. Measured explanatory variables tested in uptake models

\begin{tabular}{lll}
\hline Explanatory element & Variable & Units \\
\hline Concentration & Measured VOC concentration & $\mathrm{ng} / \mathrm{l}$ \\
Concentration variability & $\begin{array}{c}\text { Measured TVOC coefficient of variation } \\
\text { (standard deviation/mean) }\end{array}$ & $\mathrm{NA}$ \\
Ventilation & Ventilation rate & \\
Ventilation & Heart rate & $\mathrm{lpm}$ \\
Ventilation & Breathing rate & $\mathrm{min}^{-1}$ \\
Subject physiology & Dummy variable & $\mathrm{min}^{-1}$ \\
Initial breath and exposure & Pre-segment breath and exposure & $\mathrm{A}, \mathrm{B}, \mathrm{C}$ \\
concentration & concentrations & $\mathrm{ng} / 1$ \\
Weather & Temperature & \\
Weather & Relative Humidity & ${ }^{\circ} \mathrm{C}$ \\
Duration & Riding time on segment & $\%$ \\
\hline
\end{tabular}




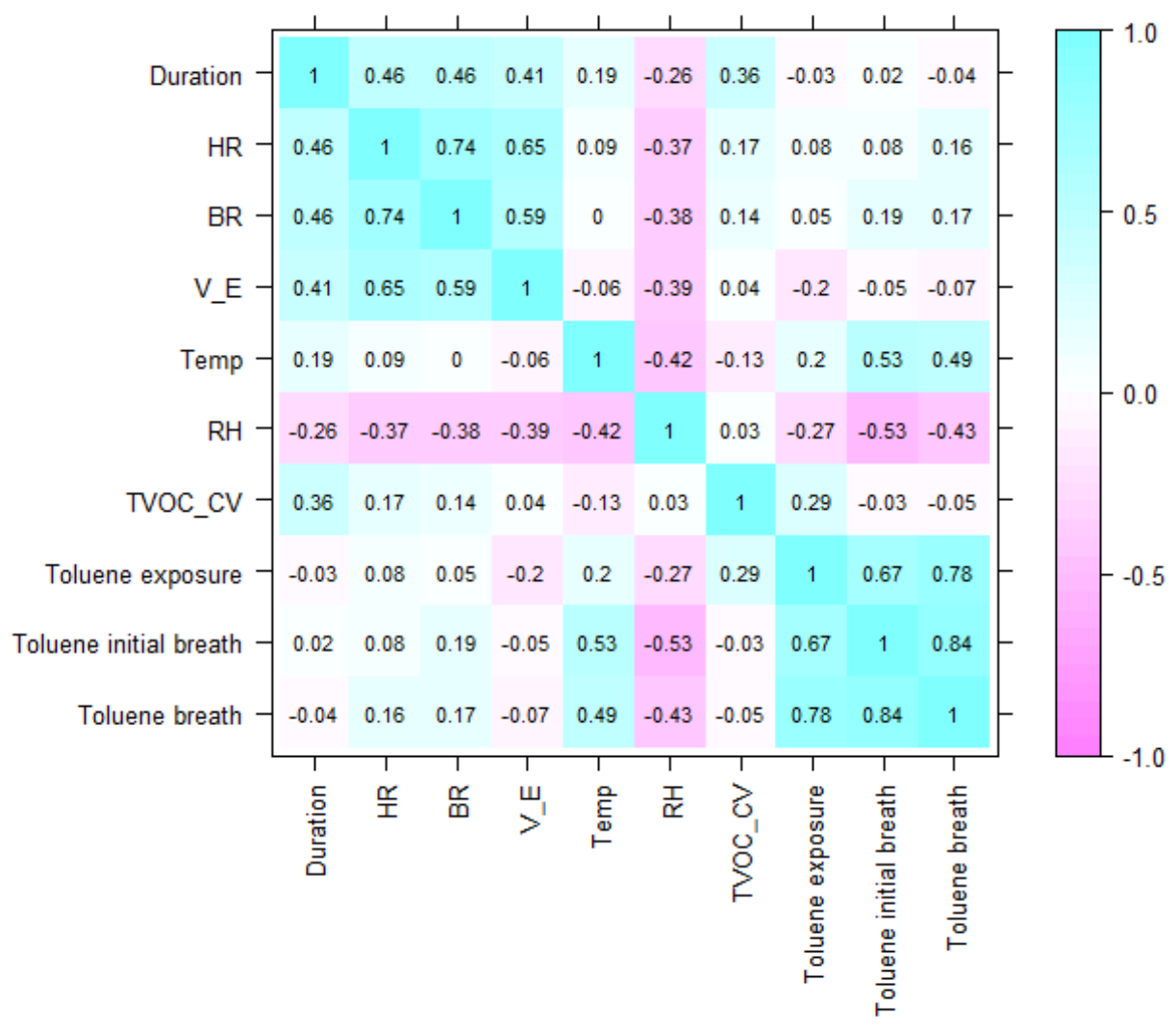

Figure 40. Correlations among segment-aggregated exposure and uptake variables

A segment-level model of breath VOC concentrations was estimated using seemingly unrelated regression (SUR) with a separate equation for each of 10 selected aromatic hydrocarbon compounds (see Data Overview, Chapter 4 for a discussion of compound selection). The measured explanatory variables in Table 24 were tested by stepwise addition to the model. A preferred model was selected based on theoretical basis, statistical significance, model fit, and judgment. The preferred model was specified:

$$
\ln \left(C_{i}^{b r}\right)=\beta_{0}+\beta_{1} \ln \left(C_{i}^{e x}\right)+\beta_{2} \ln \left(C_{i-1}^{b r}\right)+\beta_{3} \ln \left(T V O C_{i}^{C V}\right)+\beta_{4} \ln \left(\dot{V}_{E, i}\right)+\varepsilon_{i}
$$


where $\varepsilon_{i}$ is an error term that is i.i.d. within an equation, but correlates across equations for the same observation $i$. The other variables are described in Table 54. Figure 41 illustrates the breath and exposure concentration variables on a time graph.

Table 54. Variable definitions for VOC uptake model; $i$ is the observation index

\begin{tabular}{l|ll}
\hline Variable & Units & Description \\
\hline$C_{i}^{b r}$ & $\mathrm{ng} / \mathrm{L}$ & Breath concentration after segment $i$ \\
$C_{i}^{e x}$ & $\mathrm{ng} / \mathrm{L}$ & Exposure concentration on segment $i$ \\
$C_{i-1}^{b r}$ & $\mathrm{ng} / \mathrm{L}$ & Breath concentration preceding segment $i$ \\
VVOC $_{i}^{C V}$ & None & $\begin{array}{l}\text { Coefficient of variability (standard deviation divided by the } \\
\text { mean) for 1-Hz TVOC concentration data on segment } i\end{array}$ \\
$\dot{V}_{E, i}$ & $\mathrm{lpm}$ & Mean ventilation rate on segment $i$ \\
\hline
\end{tabular}

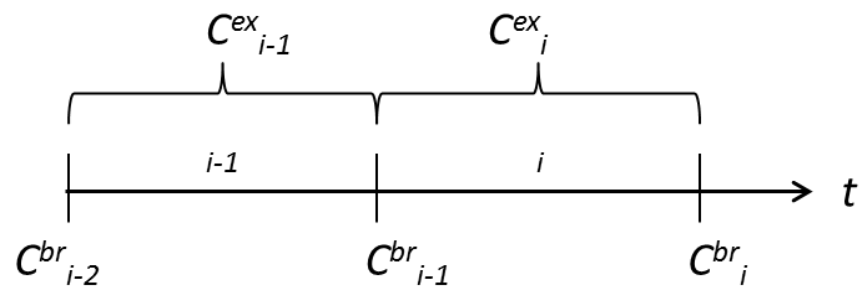

Figure 41. Time graph illustrating segment variable notation

Linear restrictions were tested in which similar $\beta_{j}$ coefficients were constrained to be equal across equations (compounds). A restricted SUR model with equal $\beta_{1}, \beta_{2}$ and $\beta_{4}$ for all compounds except benzene and $n$-propylbenzene was tested against the unrestricted model and was not rejected at $p<0.05$, with an F statistic of 1.505 on 21 degrees of freedom $(p=0.0695)$. The restricted model was estimated with $N=610$ and 581 degrees of freedom $(D F)$ for the entire system. The overall OLS $\mathrm{R}^{2}$ was 0.56 and McElroy SUR-specific $\mathrm{R}^{2}$ was 0.46 . Individual equation statistics are shown in Table 55. 
Table 55. Fit characteristics for the SUR system of 10 equations

\begin{tabular}{llrrrrrrr}
\hline & $N$ & $D F$ & $S S R$ & MSE & RMSE & $R^{2}$ & Adjusted $R^{2}$ \\
\hline 1 & benzene & 61 & 56 & 6.863 & 0.123 & 0.350 & 0.658 & 0.633 \\
2 & toluene & 61 & 56 & 5.011 & 0.089 & 0.299 & 0.655 & 0.630 \\
3 & ethylbenzene & 61 & 56 & 3.752 & 0.067 & 0.259 & 0.619 & 0.592 \\
4 & m,p-xylene & 61 & 56 & 4.022 & 0.072 & 0.268 & 0.603 & 0.574 \\
5 & $o$-xylene & 61 & 56 & 4.089 & 0.073 & 0.270 & 0.575 & 0.545 \\
6 & $n$-propylbenzene & 61 & 56 & 2.440 & 0.044 & 0.209 & 0.677 & 0.653 \\
7 & 1,3,5-trimethylbenzene & 61 & 56 & 4.963 & 0.089 & 0.298 & 0.430 & 0.389 \\
8 & 2-ethyltoluene & 61 & 56 & 6.695 & 0.120 & 0.346 & 0.375 & 0.330 \\
9 & 1,2,4-trimethylbenzene & 61 & 56 & 4.602 & 0.082 & 0.287 & 0.438 & 0.398 \\
10 & 1,2,3-trimethylbenzene & 61 & 56 & 5.807 & 0.104 & 0.322 & 0.420 & 0.379 \\
\hline
\end{tabular}

The estimated restricted SUR model coefficients are shown in Table 56.

Coefficients significant at $p<0.05$ are highlighted by bold text. The estimated $\beta_{1}$ coefficients indicate an elasticity of breath to exposure concentrations of $0.44-0.46$ for all compounds except $n$-propylbenzene, which also had the lowest correlation between breath and exposure concentration changes among these compounds in Table 52. In other words, a certain percent increase in BTEX exposure concentrations leads to about half as large of a percent increase in breath concentrations. The significance of the $\beta_{1}$ coefficients further support the finding from Section 3 that the breath sampling method is sufficiently sensitive to measure uptake differences on segments of a ride with varying exposure concentrations (urban microenvironment variability).

The $\beta_{3}$ coefficients reveal a significant negative effect of concentration variability on uptake for all compounds. This influence could be due to lower overall uptake rates with higher variability, or to concentrated exposure at mid-ride locations with some clearance occurring by the end of the segment. Ventilation has a significant positive influence on breath concentrations for the eight pooled compounds/ In the unrestricted 
form of the model, breath concentration elasticity to exposure concentration $\left(\beta_{1}\right)$ is 0.40 0.47 for all compounds except $n$-propylbenzene, and the ventilation coefficients for all compounds range from 0.04 to 0.21 .

Table 56. Estimated uptake model coefficients

\begin{tabular}{l|rrrrr}
\hline Coefficients & \multicolumn{1}{|c|}{ Intercept } & Exposure & Initial Breath & \multicolumn{1}{c}{ TVOC } & \multicolumn{1}{c}{$\dot{V}_{E}$} \\
\hline benzene & -0.528 & $\mathbf{0 . 4 5 9}$ & $\mathbf{0 . 4 4 6}$ & $\mathbf{- 0 . 2 2 3}$ & 0.074 \\
toluene & $\mathbf{- 0 . 8 8 8}$ & $\mathbf{0 . 4 3 9}$ & $\mathbf{0 . 3 3 4}$ & -0.123 & $\mathbf{0 . 1 6 7}$ \\
ethylbenzene & $\mathbf{- 1 . 5 0 6}$ & $\mathbf{0 . 4 3 9}$ & $\mathbf{0 . 3 3 4}$ & $\mathbf{- 0 . 1 7 9}$ & $\mathbf{0 . 1 6 7}$ \\
m,p-xylene & $\mathbf{- 1 . 3 1 3}$ & $\mathbf{0 . 4 3 9}$ & $\mathbf{0 . 3 3 4}$ & $\mathbf{- 0 . 1 6 1}$ & $\mathbf{0 . 1 6 7}$ \\
-xylene & $\mathbf{- 1 . 5 4 1}$ & $\mathbf{0 . 4 3 9}$ & $\mathbf{0 . 3 3 4}$ & $\mathbf{- 0 . 1 9 4}$ & $\mathbf{0 . 1 6 7}$ \\
$n$-propylbenzene & $\mathbf{- 0 . 7 5 9}$ & $\mathbf{0 . 2 0 0}$ & $\mathbf{0 . 6 3 9}$ & $\mathbf{- 0 . 1 2 3}$ & 0.075 \\
1,3,5-trimethylbenzene & $\mathbf{- 1 . 6 9 9}$ & $\mathbf{0 . 4 3 9}$ & $\mathbf{0 . 3 3 4}$ & $\mathbf{- 0 . 2 5 1}$ & $\mathbf{0 . 1 6 7}$ \\
2-ethyltoluene & $\mathbf{- 1 . 7 8 6}$ & $\mathbf{0 . 4 3 9}$ & $\mathbf{0 . 3 3 4}$ & $\mathbf{- 0 . 3 1 2}$ & $\mathbf{0 . 1 6 7}$ \\
1,2,4-trimethylbenzene & $\mathbf{- 1 . 6 1 8}$ & $\mathbf{0 . 4 3 9}$ & $\mathbf{0 . 3 3 4}$ & $\mathbf{- 0 . 3 0 6}$ & $\mathbf{0 . 1 6 7}$ \\
1,2,3-trimethylbenzene & $\mathbf{- 1 . 7 0 9}$ & $\mathbf{0 . 4 3 9}$ & $\mathbf{0 . 3 3 4}$ & $\mathbf{- 0 . 2 6 0}$ & $\mathbf{0 . 1 6 7}$ \\
\hline
\end{tabular}

Table 57 shows the changes in SSR with the individual removal of explanatory variables form the unrestricted form of the model. The strongest explanatory variable is initial breath concentrations, followed by exposure concentrations. Ventilation has only a small role in explaining breath concentrations.

Table 57. Changes in SUR model system SSR with individual removal of explanatory variables $(\triangle D F=10$ for each $)$

\begin{tabular}{l|rr}
\hline & \multicolumn{1}{|c}{ SSR } & Change in SSR \\
\hline- & 47.4 & - \\
$C_{t}^{e x}$ & 59.9 & 12.5 \\
$C_{t-1}^{b r}$ & 99.9 & 52.5 \\
$T V O C_{t}^{C V}$ & 53.2 & 5.8 \\
$\dot{V}_{E, i}$ & 49.0 & 1.6 \\
\hline
\end{tabular}


The correlation of residuals among equations is shown in Figure 42. The high correlations support the use of a SUR specification, which is more efficient than individual OLS under cross-correlated errors.

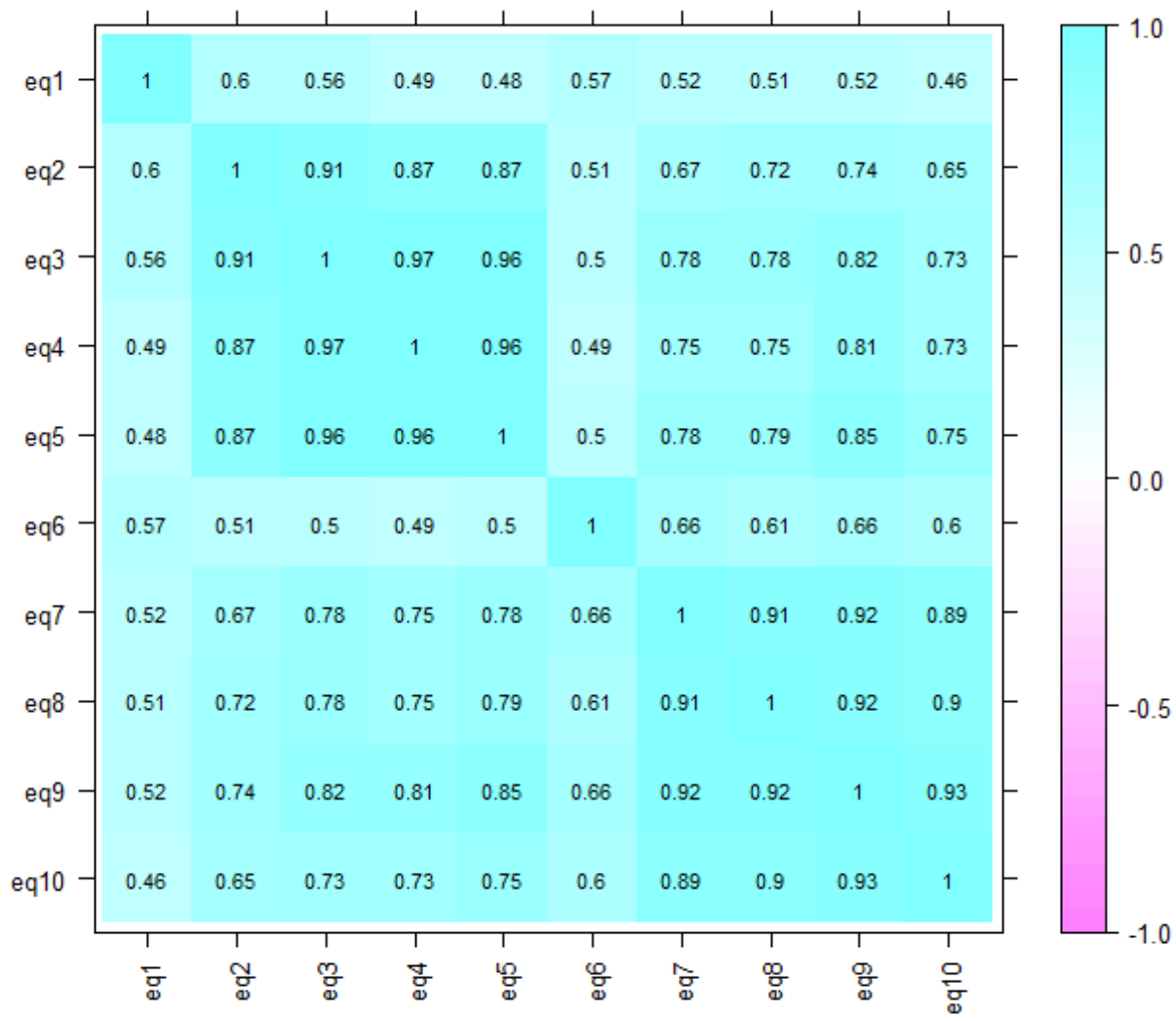

Figure 42. Correlation coefficients of residuals among 10 SUR model equations

Serial correlation in the residuals was checked by regressing $\varepsilon_{i}$ on $\varepsilon_{i-1}$ for each equation using OLS. Significant serial correlation of the residuals was not found: $\mathrm{p}$ values for the lagged residual term were over 0.05 for all 10 equations $\left(R^{2}\right.$ ranged from $<0.01$ to 0.07$)$. Endogeneity in the lagged dependent variable concentration term $\left(\beta_{2}\right)$ was checked by regressing $\varepsilon_{i}$ on $\ln \left(C_{i-1}^{b r}\right)$ for each equation using OLS. Significant 
endogeneity was not found: p-values for the background concentration term were over 0.05 for all 10 equations $\left(R^{2}\right.$ ranged from $<0.01$ to 0.04$)$.

Heteroscedasticity by facility type was checked by regressing $\varepsilon_{i}^{2}$ on RoadType ${ }_{i}$ for each equation. RoadType ${ }_{i}$ is a seven-level factor variable describing the predominant facility type for segment $i$, with the levels Park, I-205 Path, Springwater Path, Local Roads, Minor Arterials, Major Arterials, and Mixed Roadway Types. Significant heteroscedasticity by facility was found for $o$-xylene only: p-values for F-tests on the RoadType factor variable $(D F=6)$ were over 0.05 for all 9 other equations, and $p=$ 0.05 for $o$-xylene.

An alternative specification with $C_{i-1}^{e x}$ replacing $C_{i-1}^{b r}$ in the model (pre-segment exposure instead of breath conditions) has a poorer overall model fit of 0.44 for the OLS $\mathrm{R}^{2}\left(0.29\right.$ for McElroy's $\left.\mathrm{R}^{2}\right)$. The $C_{i-1}^{e x}$ term coefficients are significant at $p<0.05$ for compound 2 through 5 , with coefficients of $0.127-0.146$. Also, in this specification the $C_{i}^{e x}$ term coefficients (breath concentration elasticity to exposure) increase to $0.51-0.67$ for all compounds except $n$-propylbenzene.

In order to test for subject-specific uptake (i.e. elasticity of breath to ambient concentrations), a subject-segmented $\beta_{1}$ coefficient was estimated with the specification:

$$
\begin{gathered}
\ln \left(C_{i}^{b r}\right)=\beta_{0}+\beta_{1} \ln \left(C_{i}^{e x}\right) \times \text { Subject }+\beta_{2} \ln \left(C_{i-1}^{b r}\right)+\beta_{3} \ln \left(T V O C_{i}^{C V}\right)+ \\
\beta_{4} \ln \left(\dot{V}_{E, i}\right)+\varepsilon_{i}
\end{gathered}
$$

The unrestricted pooled model is not rejected by the subject-segmented model based on a likelihood ratio test with a $\chi^{2}$ test statistic of 3.68 on 20 degrees of freedom. Individual 
compounds (equations) were also tested with the restriction that the subject-specific $\beta_{1}$ estimates were equal. Only for 1,2,4-trimethylbenzene are the subject differences in $\beta_{1}$ significant at $p<0.05\left(\chi^{2}=7.03\right.$ on $\left.2 D F\right)$. Breath elasticity to exposure concentrations is consistent among the three subjects of this study. Minimal subject-specific effects on uptake agrees with Egeghy et al. (2002), who find that "under conditions of rather low benzene exposure...physiological and metabolic difference among subjects had relatively little influence upon benzene uptake."

\section{BREATH CONCENTRATIONS AS A FUNCTION OF TRAVEL CONDITION}

Models in the previous section showed that on-road breath concentrations are a function of exposure and ventilation conditions. In this section, breath concentrations are modeled as a function of roadway and travel variables, mediated by exposure and ventilation (as illustrated in Figure 39). Two approaches of modeling these indirect effects were employed and the results compared: multi-stage least squares and path analysis. Concentrations of BTEX compounds were summed to create a single dependent variable. Summary data for the variables used in the uptake model are shown in Table 58. 
Table 58. Segment-level summary data for uptake model explanatory variables

\begin{tabular}{|c|c|c|c|c|c|c|}
\hline & Minimum & $\begin{array}{l}1^{s t} \\
\text { Quartile }\end{array}$ & Median & Mean & $\begin{array}{l}3^{\text {rd }} \\
\text { Quartile }\end{array}$ & Maximum \\
\hline Breath BTEX concentration (ng/l) & 0.86 & 1.93 & 2.65 & 3.13 & 4.03 & 7.52 \\
\hline Exposure BTEX concentration (ng/l) & 1.82 & 5.49 & 7.90 & 9.36 & 11.54 & 41.33 \\
\hline $\begin{array}{l}\text { Exposure concentration variability - } \\
\text { TVOC concentration coefficient } \\
\text { of variability }\end{array}$ & 0.19 & 0.56 & 0.93 & 1.07 & 1.33 & 2.96 \\
\hline Ventilation (lpm) & 8 & 14 & 20 & 22 & 25 & 68 \\
\hline Workload (W) & 0 & 2 & 134 & 108 & 155 & 227 \\
\hline Temperature (C) & 11 & 17 & 19 & 19 & 20 & 25 \\
\hline Wind Speed (mps) & 0.4 & 1.0 & 1.6 & 1.7 & 2.4 & 3.6 \\
\hline ADT (vehicles/day) & 0 & 0 & 1,045 & 5,773 & 5,045 & 32,000 \\
\hline Cumulative Elevation Gain (m) & 0 & 21 & 45 & 44 & 62 & 140 \\
\hline Average Speed (kph) & 0 & 3 & 14 & 11 & 16 & 20 \\
\hline $\begin{array}{l}\text { Mass of bicycle + rider }(\mathrm{kg}) \\
\text { Springwater Path dummy } \\
\text { I-205 Path dummy }\end{array}$ & \multicolumn{6}{|c|}{$\begin{array}{c}91(17 \%), 97(15 \%), \text { or } 105(68 \%) \\
3 \% \text { True } \\
8 \% \text { True }\end{array}$} \\
\hline
\end{tabular}

\subsection{Multi-stage least squares}

Multi-stage least squares (MSLS) was used to assess how roadway, travel, and weather variables influence breath concentrations through exposure and respiration variables. In MSLS, endogenous variables are first estimated using exogenous regressors, then the fitted endogenous variable values are used as regressors for the dependent variable. A common use of MSLS is the instrumented variable technique to address endogeneity in econometrics.

Specification of the MSLS equations was guided by theory and exploratory OLS regressions. The third-stage model was specified

$$
\ln \left(C_{i}^{b r}\right)=\beta_{0}+\beta_{1} \ln \left({\widehat{C_{i}^{e x}}}^{b}+\beta_{2} \ln \left(\widehat{T V O C_{i}^{C V}}\right)+\beta_{3} \ln \left(\widehat{V_{E, i}}\right)+\varepsilon_{i}\right.
$$


Three second-stage regressions were used to estimate fitted values for the right hand side variables in Equation 1:

$$
\begin{aligned}
& \ln \left(C_{i}^{\text {ex }}\right)=\alpha_{0}+\alpha_{1} \text { ADT }_{i}+\alpha_{2} \text { Temp }_{i}+\alpha_{3} \text { WindSpeed }_{i}+\alpha_{4} \text { Springwater }_{i}+ \\
& \alpha_{5} \text { I205Path }_{i}+\varepsilon_{i} \\
& \ln \left(\text { TVOC }_{i}^{C V}\right)=\gamma_{0}+\gamma_{1} \text { ADT }_{i}+\gamma_{2} \text { Temp }_{i}+\gamma_{3} \text { WindSpeed }_{i}+ \\
& \gamma_{4} \text { Springwater }_{i}+\gamma_{5} \text { I205Path }_{i}+\varepsilon_{i} \\
& \ln \left(\dot{V}_{E, i}\right)=\delta_{0}+\delta_{1}{\widehat{\dot{W}_{M, i}}}_{\text {SP }_{i}}
\end{aligned}
$$

The first-stage regression included a single equation of workload, the fitted value of which were used in the second-stage regression of ventilation:

$$
\dot{W}_{M, i}=\zeta_{0}+\zeta_{1} \text { Elev }_{i}+\zeta_{2} \text { Speed }_{i}+\zeta_{3} \text { Mass }_{i}+\varepsilon_{i}
$$

All equations were estimated by OLS with HAC-robust standard errors. Table 59 shows the estimated coefficients and explained variance (change in sum of squares $\Delta \mathrm{SS}$ divided by total sum of squares SST) associated with independent variables for each regression equation. 
Table 59. Multi-stage least squares model of breath concentration

\begin{tabular}{|c|c|c|c|c|c|}
\hline Regression & Independent variable & Estimate & $\begin{array}{c}H A C \\
\text { standard } \\
\text { error }\end{array}$ & $p$-value & $\begin{array}{c}\text { Explained } \\
\text { variance } \\
(\triangle S S / S S T)\end{array}$ \\
\hline \multirow{4}{*}{$\begin{array}{l}C^{b r}(\mathrm{ng} / \mathrm{l}) \\
\left(\text { Adj. } R^{2}=0.35\right)\end{array}$} & (Intercept) & -1.265 & 0.490 & 0.01 & \\
\hline & $C^{e x}(\mathrm{ng} / \mathrm{l})$ & 0.691 & 0.131 & $<0.01$ & $28 \%$ \\
\hline & $T V O C^{C V}$ & -0.487 & 0.168 & $<0.01$ & $8 \%$ \\
\hline & $V_{E}(\mathrm{lpm})$ & 0.261 & 0.171 & 0.13 & $2 \%$ \\
\hline \multirow{6}{*}{$\begin{array}{l}C^{e x}(\mathrm{ng} / \mathrm{l}) \\
\left(\text { Adj. } R^{2}=0.51\right)\end{array}$} & (Intercept) & 1.006 & 0.453 & 0.03 & \\
\hline & Wind (mps) & -0.287 & 0.065 & $<0.01$ & $19 \%$ \\
\hline & Temp (C) & 0.073 & 0.023 & $<0.01$ & $7 \%$ \\
\hline & $A D T(1,000 \mathrm{veh} /$ day $)$ & 0.029 & 0.005 & $<0.01$ & $16 \%$ \\
\hline & Springwater & 1.184 & 0.290 & $<0.01$ & $11 \%$ \\
\hline & I205 path & 0.026 & 0.177 & 0.88 & $1 \%$ \\
\hline \multirow{6}{*}{$\begin{array}{l}\text { TVOC } C^{C V} \\
\left(\text { Adj. } R^{2}=0.22\right)\end{array}$} & (Intercept) & 1.420 & 0.585 & 0.02 & \\
\hline & Wind (mps) & -0.163 & 0.083 & 0.05 & $3 \%$ \\
\hline & Temp (C) & -0.071 & 0.029 & 0.02 & $7 \%$ \\
\hline & $A D T$ (1,000 veh/day) & 0.023 & 0.006 & $<0.01$ & $13 \%$ \\
\hline & Springwater & -0.001 & 0.374 & 0.99 & $0 \%$ \\
\hline & I205 path & -0.565 & 0.229 & 0.02 & $5 \%$ \\
\hline \multirow{2}{*}{$\begin{array}{l}\dot{V}_{E} \quad(\mathrm{lpm}) \\
\left(\text { Adj. } R^{2}=0.46\right)\end{array}$} & (Intercept) & 2.496 & 0.071 & $<0.001$ & \\
\hline & $\dot{W}_{M}(\mathrm{~W})$ & 0.00429 & 0.00054 & $<0.001$ & $47 \%$ \\
\hline \multirow{4}{*}{$\begin{array}{l}\dot{W}_{M}(\mathrm{~W}) \\
\left(\operatorname{Adj} . R^{2}=0.94\right)\end{array}$} & (Intercept) & -89.2 & 40.1 & 0.029 & \\
\hline & Elev (m) & 0.293 & 0.094 & 0.003 & $47 \%$ \\
\hline & Speed (kph) & 9.48 & 0.42 & $<0.001$ & $44 \%$ \\
\hline & Mass (kg) & 0.799 & 0.397 & 0.048 & $2 \%$ \\
\hline
\end{tabular}

In the first stage, cumulative elevation gain, average speed, and rider mass all increased average on-road workload. The high $R^{2}$ is expected because $\dot{W}_{M}$ is a calculated value. Fitted workload significantly predicted segment-average ventilation, with a coefficient at the low end of values reported in Chapter 6 on ventilation from highresolution models. ADT was a major determinant of on-road exposure and exposure variability. A similar MSLS model using a natural log transformation of $A D T$ in all regressions has slightly poorer overall breath concentration fit (adjusted $R^{2}=0.34$ ), but 
better fit for exposure and exposure variaibility second-stage regressions (adjusted $R^{2}$ of 0.61 and 0.38 , respectively).

About half of the explained exposure variance was due to traffic variables and the other half was due to weather variables. The estimated exposure coefficients agree with the segment-level model presented in Chapter 5 on Exposure Concentrations. The breath model coefficients are larger in magnitude than the coefficients from the model in Section 4. Coefficient differences between the models could be due to the exclusion of a pre-segment condition variable or the use of fitted (not measured) explanatory variables.

Table 60 shows a reference model of breath concentrations, estimated using measured instead of fitted explanatory variables. Although the overall explained variance is higher than the model in Table 59, the improvement is modest (adjusted $R^{2}$ increases from 0.35 to 0.45 ). The last column shows that the additional explained variance is due to the exposure concentration variable. Ventilation has small explanatory power and is not significant at $p<0.05$ in either model.

Table 60. Reference model of breath concentrations

\begin{tabular}{l|lrrrr}
\hline Regression & $\begin{array}{l}\text { Independent } \\
\text { variable }\end{array}$ & Estimate & $\begin{array}{c}\text { HAC } \\
\text { standard } \\
\text { error }\end{array}$ & $\begin{array}{l}\text {-value } \\
\text { Explained } \\
\text { variance } \\
\text { (USS/SST) }\end{array}$ \\
\hline$C^{b r}(\mathrm{ng} / \mathrm{l})$ & $($ Intercept) & -0.682 & 0.330 & 0.04 & \\
$\left(\right.$ Adj. $\left.R^{2}=0.45\right)$ & $C^{\text {ex }}(\mathrm{ng} / \mathrm{l})$ & 0.618 & 0.083 & $<0.01$ & $40 \%$ \\
& TVOC & -0.234 & 0.080 & $<0.01$ & $6 \%$ \\
& $\dot{V}_{E}(\mathrm{lpm})$ & 0.123 & 0.103 & 0.24 & $1 \%$ \\
\hline
\end{tabular}




\subsection{Path model}

Path analysis was used as a second approach to assess how roadway, travel, and weather variables influence breath concentrations through exposure and respiration variables. Path analysis (a form of structural equation modeling without latent variables) allows simultaneous estimation of the relationships between multiple endogenous variables. General practice holds that at least 5-10 observation are needed for each free parameter in path analysis. This study included 72 complete observations ${ }^{3}$, meaning that at most 14 free parameters could be estimated ${ }^{4}$.

Figure 43 illustrates the estimated path model. The path model structure followed the MSLS specification above, with explanatory variables selected based on largest explained variance in Table 59. The blue boxes in Figure 43 are endogenous variables. Standardized path coefficients are included along the links, with coefficients in red text not significant at $p<0.05$. The model was estimated by maximum likelihood, with robust standard errors and mean- and variance-adjusted test statistics (using the 'lavaan' package in R). All variables are as described in the previous section, including natural log transformations for all endogenous variables.

\footnotetext{
${ }^{3}$ Two observations were missing ventilation data.

${ }^{4}$ Observed mean and variance were used for exogenous variables. Each endogenous variable has a free intercept in addition to each free path coefficient.
} 


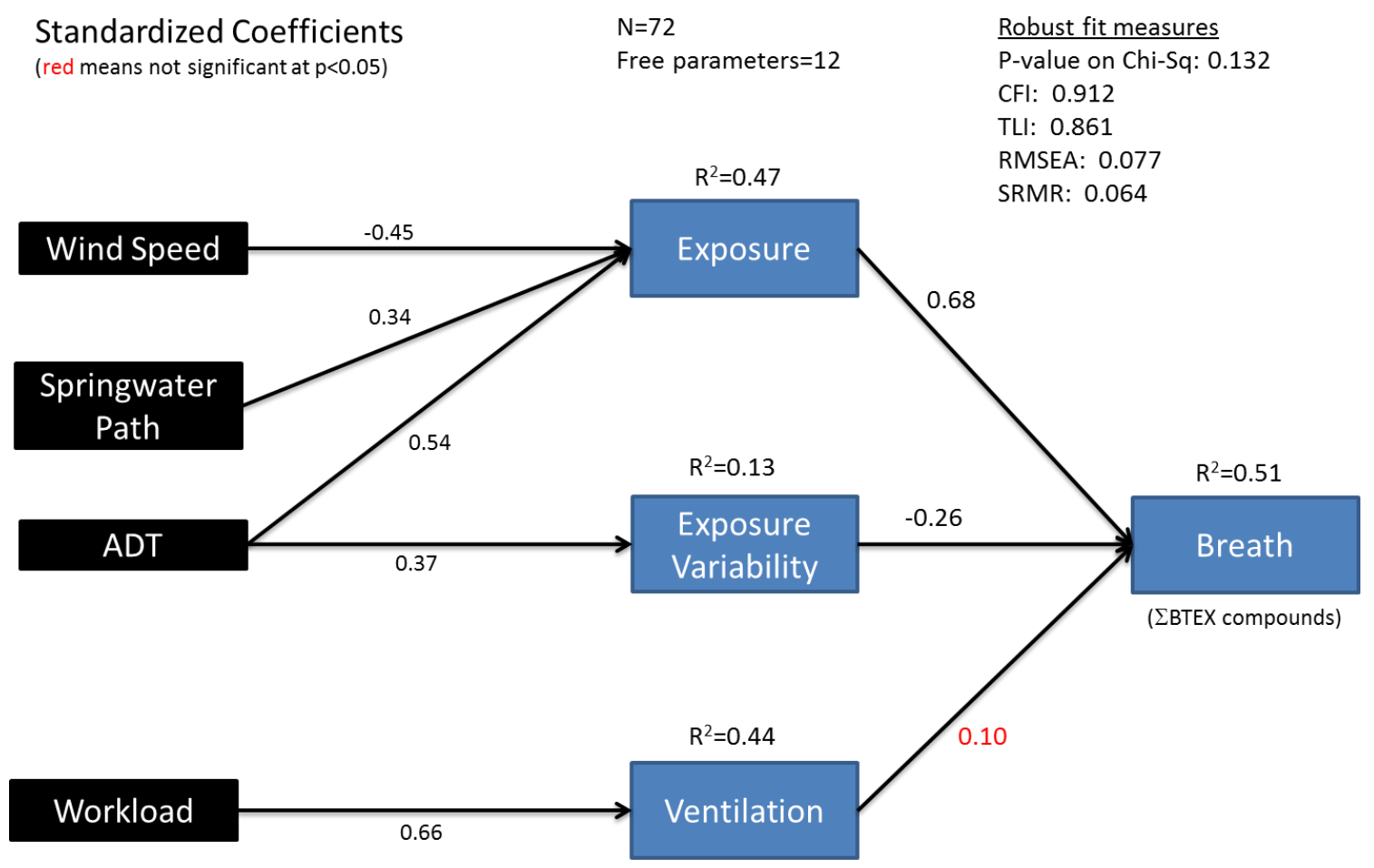

Figure 43. Path model of breath concentrations

Figure 43 includes robust goodness of fit indicators, which are marginally acceptable $^{5}$. The ventilation effect on breath concentrations is not significant, in agreement with the MSLS model. The mid-stage endogenous variables have poorer fits $\left(R^{2}\right)$ in the path model than in the MSLS model because fewer explanatory variables are included. The breath concentration fit $\left(R^{2}\right)$ in the path model is better than in the MSLS model because full information in the endogenous variables is used (as opposed to fitted values).

Path effects are calculated by multiplying standardized path coefficients. The path effect of workload on breath concentrations is 0.07 (not significant at $p<0.05$ ). The

\footnotetext{
${ }^{5}$ Marginal fits are around 0.9 for CTI and TLI (higher is better), 0.1 for RMSEA (lower is better), and 0.05 for the chi-squared p-value (higher is better).
} 
path effect of ADT on breath concentrations is 0.27 , including both exposure and exposure variability paths $(p<0.01)$. The non-standardized regression coefficients were essentially the same as those in Table 59 .

\section{CONCLUSIONS}

This analysis revealed several aromatic hydrocarbons that can serve as breath biomarkers of VOC exposure for travelers and showed that breath analysis is a useful tool to examine VOC uptake in different urban microenvironments. End-tidal breath sampling was sufficiently sensitive to measure differences within a moderately-sized sample in a relatively low-concentration city. The breath analysis results compare favorably despite past breath analysis involving orders of magnitude higher exposure concentrations and longer exposure times.

Segment-level uptake/breath concentration models in this chapter show that onroad exposure is a significant determinant of breath concentrations for bicyclists. Breath elasticity to exposure concentrations was 0.4 to 0.5 for BTEX compounds, consistent among subjects. Higher concentration variability led to lower end-segment breath concentrations, though it is unclear if this is due to lower uptake rates or clearance toward the end of the ride.

Roadway, travel, and weather variables explained $\sim 1 / 3^{\text {rd }}$ of the variance in BTEX breath concentrations. Including measured exposure concentrations explained another $\sim 10 \%$ of breath concentration variance. Roadway and weather variables each explained $\sim 1 / 4^{\text {th }}$ of the variance in BTEX exposure concentrations. ADT is an important variable for both exposure concentrations and exposure concentration variability. 
Ventilation had only a small influence on uptake. This finding is not surprising because VOC uptake is not expected to be proportional to VOC intake (Astrand 1985). Breath and blood concentrations approach an equilibrium ratio with ambient air. The equilibrium blood and breath concentration is expected to increase with alveolar ventilation (Wallace et al. 1993), but by less than the increase in $V_{E}$ and inhalation rate (Carlsson 1982) ${ }^{6}$. This finding is good news for active travelers, who have much higher pollutant inhalation rates than travelers in motor vehicles (see Literature Review, Chapter 2). The limited effect of ventilation on VOC uptake should temper alarm about the findings from studies that report extremely high VOC inhalation doses for bicyclists (such as Do et al. (2014)). Although differences in the uptake of particulates would be equal to or greater than the inhalation rate differences, differences in the uptake of VOC during travel will be smaller.

\footnotetext{
${ }^{6}$ The limiting effect of equilibrium conditions on uptake of VOC is reflected in the findings of McNabola et al. (2007). In their study, a faster bicyclist had lower total benzene uptake over a trip than a slower bicyclist (duration was more important than inhalation). This effect disappeared at high exposure concentrations, when equilibrium body concentrations were less likely to be reached and increased ventilation and inhalation could still increase uptake rates.
} 


\section{Chapter 8: Applications \& Implications}

\section{INTRODUCTION}

The preceding chapters presented models that reveal new quantitative information about the connections between travel/roadway characteristics and exposure, inhalation, and uptake of pollutants by bicyclists. Those chapters contain substantial contributions to our understanding of on-road pollution uptake, but the findings might not be readily applicable by practitioners (not, in TRB parlance, "practice ready"). The objective of this chapter is to translate the modeling results into more practical, actionable information for transportation professionals such as engineers and planners.

The next section (2) summarizes the relationships between pollutant inhalation doses and travel and roadway variables, based on findings of the previous chapters in this dissertation. The following three sections (3-5) quantify the expected impacts on inhalation doses of hills (grades), cruising speed, and a stop/start event during a ride. Section 6 explores trade-offs of route and exertion level choices, such as when total doses are reduced by detouring to a low-volume facility. Section 7 describes the comparative effects of ventilation on uptake of gas and particulate air pollutants. Lastly, Section 8 provides sketch-level guidance to improve understanding of the expected impacts of bikeway designs on air pollution risks for bicyclists.

\section{INHALATION DOSE EFFECTS OF TRAVEL AND ROADWAY VARIABLES}

The objective of this section is to pull together the key equations, parameters, and model coefficients from the preceding chapters that allow estimation of roadway and 
travel effects on bicyclist inhalation doses. While not "sketch-level", the information in this section enables relatively simple estimation of inhalation doses for applications such as network analysis and scenario planning.

Recall that intake per unit time is the product of the exposure concentration and the ventilation rate: $I^{t}=C \dot{V}_{E}$. The intake effect of an arbitrary variable $x$ on $I^{t}$ is differentiated

$$
\frac{\partial I^{t}}{\partial x}=\frac{\partial}{\partial x}\left(C \cdot \dot{V}_{E}\right)=\dot{V}_{E} \frac{\partial C}{\partial x}+C \frac{\partial V_{E}}{\partial x}
$$

The intake rate per unit distance, which includes the effects of exposure duration, is calculated $I^{d}=C \frac{\dot{V}_{E}}{v_{b}}$. Ventilation per unit distance is calculated ${ }^{1} \frac{\dot{V}_{E}}{v_{b}}$. The intake effect of an arbitrary variable $x$ on $I^{d}$ is differentiated

$$
\frac{\partial I^{d}}{\partial x}=\frac{\partial}{\partial x}\left(C \frac{\dot{V}_{E}}{v_{b}}\right)=\frac{\dot{V}_{E}}{v_{b}} \frac{\partial C}{\partial x}+\frac{C}{v_{b}} \frac{\partial \dot{V}_{E}}{\partial x}-\frac{C \dot{V}_{E}}{v_{b}^{2}} \frac{\partial v_{b}}{\partial x} .
$$

Note that

$$
\frac{\partial I^{d}}{\partial x}=\frac{1}{v_{b}} \frac{\partial I^{t}}{\partial x}-\frac{I^{t}}{v_{b}^{2}} \frac{\partial v_{b}}{\partial x}
$$

implying that the sensitivity of the two are proportional (by $1 / v_{b}$ ) if $x$ is independent of speed $\left(\frac{\partial v_{b}}{\partial x}=0\right)$ and the sensitivity of $I^{d}$ is reduced with $\frac{\partial v_{b}}{\partial x}$.

\footnotetext{
${ }^{1}$ To compensate for units, ventilation in $1 / \mathrm{km}$ with $\dot{V}_{E}$ in $1 \mathrm{pm}$ and $v_{b}$ in $\mathrm{kph}$ is calculated $60 \frac{\dot{V}_{E}}{v_{b}}$.
} 
As an illustration, consider increased bicyclists workload $\dot{W}_{M}$ as the variable $x$. We can safely assume $\frac{\partial C}{\partial \dot{W}_{M}}=0$ and $\frac{\partial \dot{V}_{E}}{\partial \dot{W}_{M}}>0$, and hence the inhalation rate per time response is $\frac{\partial I^{t}}{\partial \dot{W}_{M}}=C \frac{\partial \dot{V}_{E}}{\partial \dot{W}_{M}}$. If speed is maintained and the change in $\dot{W}_{M}$ is in response to grade, then $\frac{\partial v_{b}}{\partial \dot{W}_{M}}=0$ and the inhalation rate per distance response is $\frac{\partial I^{d}}{\partial \dot{W}_{M}}=\frac{C}{v_{b}} \frac{\partial \dot{V}_{E}}{\partial \dot{W}_{M}}$. If, on the other hand, speed is increased by the additional workload, the inhalation rate per distance is dampened as $\frac{\partial I^{d}}{\partial \dot{W}_{M}}=\frac{C}{v_{b}} \frac{\partial \dot{V}_{E}}{\partial \dot{W}_{M}}-\frac{C \dot{V}_{E}}{v_{b}^{2}} \frac{\partial v_{b}}{\partial \dot{W}_{M}}$.

Table 61 presents a summary of roadway and travel variables studied in the preceding chapters and their expected impacts on exposure and inhalation. For a variable $x$ the exposure concentration response is $\frac{\partial \mathrm{C}}{\partial \mathrm{x}}$ and the ventilation response is $\frac{\partial \dot{V}_{E}}{\partial \mathrm{x}}$. Several of the variables in Table 61 are explored in more detail in the following sections. The impacts of travel variables on BTEX exposure concentration $\left(\frac{\partial C}{\partial x}\right)$ are based on the fivesecond and segment-level model results presented in Exposure Modeling, Chapter 5. The impacts of travel variables on ventilation $\left(\frac{\partial \dot{V}_{E}}{\partial x}\right)$ are based on the model results presented in Chapter 6 on ventilation and Chapter 7 on uptake. Recall that the ventilation response is based on the ventilatory response to workload

$$
\ln \dot{V}_{E}=a+b * \dot{W}_{M}
$$

and the travel determinants of bicyclist workload

$$
\dot{W}_{M}=\frac{m_{T}}{2} \frac{\Delta v_{b}^{2}}{\Delta t}+v_{b} m_{T} g \mathrm{G}+C_{D}^{\prime} v_{b}^{3}+v_{b} C_{R} m_{T} g
$$


from Chapter 6 on ventilation. Hence,

$$
\frac{\partial \dot{V}_{E}}{\partial x}=\dot{V}_{E} b \frac{\partial \dot{W}_{M}}{\partial x}
$$

Table 61. Summary of model parameter impacts on exposure and ventilation

\begin{tabular}{|c|c|c|}
\hline Variable & $\begin{array}{c}\text { Impact on }(B T E X) \\
\text { exposure } \\
\frac{\partial C}{\partial x}\end{array}$ & $\begin{array}{l}\text { Impact on ventilation } \\
\qquad \frac{\partial \dot{V}_{E}}{\partial x}\end{array}$ \\
\hline Off-street facility (vs. Park) & $\begin{array}{l}60 \%,+ \text { up to } 300 \% \text { in a } \\
\text { highly industrial area }\end{array}$ & \\
\hline $\begin{array}{l}\text { Mixed-traffic facility (vs. } \\
\text { Park) }\end{array}$ & $\begin{array}{c}40 \% \\
+1-3 \% \text { per } 1,000 \mathrm{ADT}\end{array}$ & \\
\hline Stop-and-go riding & $\begin{array}{c}+20-30 \% \text { (decreasing } \\
\text { with facility ADT) }\end{array}$ & \\
\hline Workload & & $0.6 \%$ per $\mathrm{W}$ \\
\hline $\begin{array}{l}\text { High-resolution workload } \\
\text { effects: }\end{array}$ & & \\
\hline Grade $^{1}$ & & $\begin{array}{c}28 \% \text { per } 1 \% \\
\text { (increasing at } 2 \% \cdot v_{b} \text { per } \\
1 \% \text { ) }\end{array}$ \\
\hline $\begin{array}{l}\text { Rolling resistance } \\
\text { coefficient }{ }^{1}\left(C_{R}\right)\end{array}$ & & $\begin{array}{c}2.8 \% \text { per } 0.001 \\
\text { (increasing at } 0.2 \% \cdot v_{b} \text { per } \\
0.001 \text { ) }\end{array}$ \\
\hline Drag coefficient $\left(C_{D}^{\prime}\right)^{1}$ & & $\begin{array}{c}2.7 \% \text { per } 0.1 \\
\text { (increasing at } 0.001 \% \cdot v_{b}^{3} \\
\text { per } 0.1 \text { ) }\end{array}$ \\
\hline \multicolumn{3}{|l|}{$\begin{array}{l}\text { Segment-level workload } \\
\text { effects: }\end{array}$} \\
\hline Speed & & $4 \%$ per $\mathrm{kph}$ \\
\hline $\begin{array}{l}\text { Cumulative elevation } \\
\text { gain }\end{array}$ & & $0.1 \%$ per $\mathrm{m}$ \\
\hline Mass (bicycle + rider) & & $0.3 \%$ per $\mathrm{kg}$ \\
\hline
\end{tabular}


As discussed in Chapter 5 on exposure modeling, ADT effects on exposure concentrations can be represented as log-linear, log-log, or log-quadratic. The linear representation of the ADT variable in the exposure model with a $2 \%$ per 1,000 ADT effect enables us to compare the expected concentrations of two mixed-traffic facilities as

$$
\frac{C_{1}}{C_{2}}=e^{\left(\frac{\Delta A D T}{50,000}\right)}
$$

For example, in this study local road ADT averaged $\sim 1,500$ ADT while major arterial ADT averaged $\sim 30,500$. Hence, the concentration difference is expected to be $\frac{C_{1}}{C_{2}}=$ $e^{\left(\frac{29,000}{50,000}\right)}=e^{0.58}=1.79$, or about $80 \%$ higher on the major arterial (this agrees with the Data Overview in Chapter 4). The quadratic representation of the ADT variable in the exposure model with coefficients from the high-resolution model in Chapter 5 enables us to compare the expected concentrations of two mixed-traffic facilities as

$$
\frac{C_{1}}{C_{2}}=e^{\left(\frac{\Delta A D T}{30,303}-\frac{\Delta\left(A D T^{2}\right)}{2.5 \times 10^{9}}\right)}
$$

In this case, the expected concentration difference between 1,500 and 30,500 ADT facilities would be:

$$
\frac{C_{1}}{C_{2}}=e^{\left(\frac{29000}{30303}-\frac{9.28 \times 10^{8}}{2.5 \times 10^{9}}\right)}=e^{(0.586)}=1.80
$$

almost exactly the same as the linear approach. 
Figure 44 illustrates components of steady-state workload $\left(\dot{W}_{M}\right)$ at various speeds assuming $C_{D}^{\prime}=0.4, C_{R}=0.004, m_{T}=100 \mathrm{~kg}, g=9.81 \mathrm{~m} / \mathrm{s}^{2}$, and a $1 \%$ grade. The demands of overcoming drag losses increase most dramatically with speed, but even a small $1 \%$ grade is important for determining workload. Up to around $14 \mathrm{kph}$, a $1 \%$ grade more than doubles the workload at a given speed. Higher grades would increase the role of slope (the size of the blue band in Figure 44) proportionally - i.e. a $2 \%$ grade would lead to a grade component of workload twice as large. The horizontal width of the blue band in Figure 44 indicates the speed reduction that is needed to offset the workload of a $1 \%$ grade. For example, a bicyclists on level ground at $20 \mathrm{kph}$ could maintain constant workload by reducing speed to about $17 \mathrm{kph}$ when encountering a $1 \%$ grade. The power required to accelerate is proportional to the mass, acceleration, and speed $\left(m_{T} \frac{\Delta v_{b}}{\Delta t} v_{b}\right)$. Assuming an acceleration rate of $1 \mathrm{mps} / \mathrm{s}$ leads to acceleration workload of $280 \mathrm{~W}$ at 10 kph, increasing proportionally with speed. In the context of the values illustrated in Figure 44, acceleration events will generally dominate the other components of workload. 


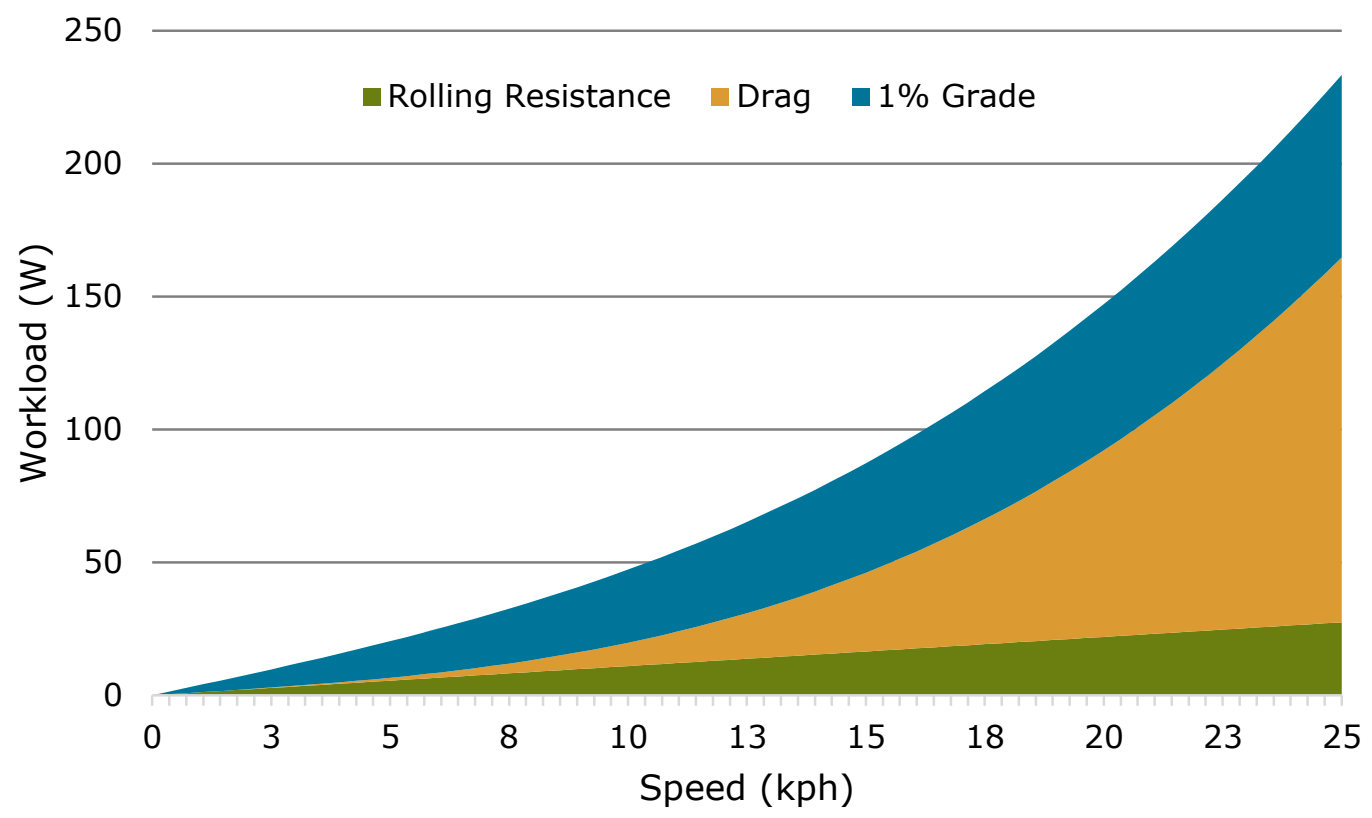

Figure 44. Components of steady-state workload

\section{EFFECT OF GRADE ON INTAKE}

The main effect of grade on intake is through ventilation rate, $\frac{\partial \dot{V}_{E}}{\partial \mathrm{G}}$. Although grade is known to affect vehicle emissions rates per mile, the aggregate effect was not significant in exposure modeling in Chapter 5 on exposure. Therefore, grade effects on inhalation rates are assessed as $\frac{\partial I^{t}}{\partial G}=C \frac{\partial \dot{V}_{E}}{\partial G}$. The effect of sustained positive slopes on workload can be assessed using the assumption $\frac{\partial v_{b}}{\partial G}=0$, i.e. speed is maintained ${ }^{2}$. Then,

$$
\frac{\partial \dot{W}_{M}}{\partial G}=v_{b} m_{T} g
$$

and

${ }^{2}$ An alternative assumption, $\frac{\partial \dot{W}_{M}}{\partial G}=0$, would meant that workload is constant and speed decreases with hills. 


$$
\frac{\partial \dot{V}_{E}}{\partial G}=\dot{V}_{E} b\left(v_{b} m_{T} g\right)
$$

As a semi-elasticity, ventilation increases by $0.01 b v_{b} m_{T} g$ with each $1 \%$ grade increase. This semi-elasticity is linear with respect to speed. For a representative calculation, assuming

- $b=0.00645$

- $v_{b}=4 \mathrm{~m} / \mathrm{s}(14 \mathrm{kph}, 9 \mathrm{mph})$

- $\quad m_{T}=100 \mathrm{~kg}$

- $g=9.81 \mathrm{~m} / \mathrm{s}^{2}$

then the differentials determining intake are calculated

$$
\begin{gathered}
\frac{\partial \dot{W}_{M}}{\partial G}=0.01(4)(100)(9.81)=39 \mathrm{~W} \text { per } 1 \% \text { grade }, \text { and } \\
\frac{\partial \dot{V}_{E}}{\partial G} \frac{1}{\dot{V}_{E}}=0.00645(39)=25 \% \text { per } 1 \% \text { grade. }
\end{gathered}
$$

Figure 45 shows the ventilation sensitivity to grade at steady speeds of 3 and 5 mps (11 and $18 \mathrm{kph})$ using the assumptions:

- $\quad a=2.348$

- $\quad b=0.00645$

- $C_{D}^{\prime}=0.4$

- $C_{R}=0.004$

- $m_{T}=100 \mathrm{~kg}$

- $g=9.81 \mathrm{~m} / \mathrm{s}^{2}$ 
The effect of grade depends strongly on the speed maintained on the upslope. Since $\frac{\partial \dot{W}_{M}}{\partial G}$ is linear with respect to speed, the nonlinearity in the curves in Figure 45 are due to the exponential form of the $V_{E} \sim \dot{W}_{M}$ relationship. At high speeds, even a slight down grade requires some elevated ventilation because the rider must pedal to overcome losses. The $2 \%$ grade ventilation reflects the $0 \mathrm{~W}$ ventilation parameter $a$. Note that the high end of the upper line occurs at a very high workload $(315 \mathrm{~W})$.

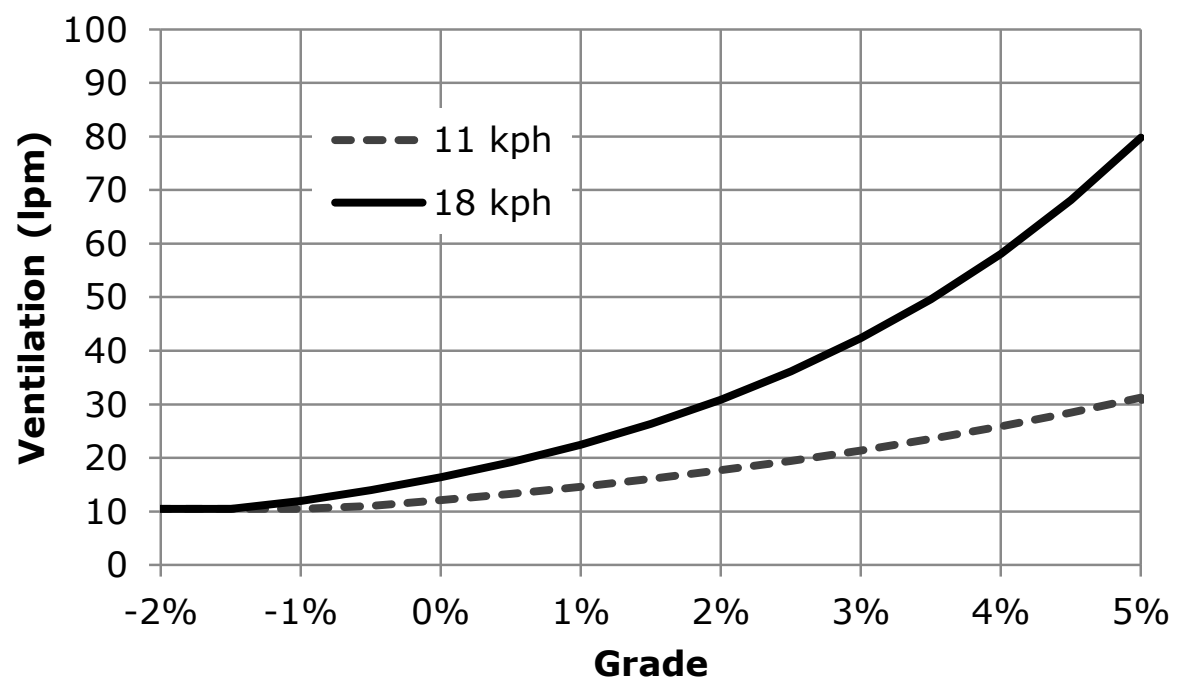

Figure 45. Effect of extended grades on ventilation per unit time at different speeds

In reality, that the effect of grade is likely compensated by a reduction in speed ${ }^{3}$. Ventilation per unit distance $\left(\dot{V}_{E} / v_{b}\right)$ incorporates the time trade-off of bicycling at a lower speed to compensate for positive grades. Maintaining the assumption $\frac{\partial v_{b}}{\partial G}=0$, the response of ventilation per unit distance to grade is calculated

\footnotetext{
${ }^{3}$ This is both intuitive and reflected in the on-road data, which reveals a negative correlation between grade and speed.
} 


$$
\frac{\partial\left(\dot{V}_{E} / v_{b}\right)}{\partial G}=\dot{V}_{E} b m_{T} g
$$

Interestingly, as a semi-elasticity,

$$
\frac{\partial\left(\dot{V}_{E} / v_{b}\right)}{\partial G} \frac{1}{\left(\dot{V}_{E} / v_{b}\right)}=v_{b} b m_{T} g
$$

which is the same semi-elasticity as ventilation per unit time, $\frac{\partial \dot{V}_{E}}{\partial G} \frac{1}{\dot{V}_{E}}$.

Ventilation per unit distance $(1 / \mathrm{km})$ is shown in Figure 46, using the same parameter assumptions as in Figure 45. Comparing to Figure 45, the compensating effect of speed is seen as an upward shift of the low-speed curve with respect to the high-speed curve. The result is less of a ventilation penalty for riding at high speed at a high grade, due to shorter duration. Assuming a compensating effect of grade on speed, the outcome would be beneficial from a ventilation/intake perspective because as the grade increased the bicyclist would slow and shift toward the lower-speed and lower-ventilation curve. Optimal speeds at varying grades are explored in the next section. 


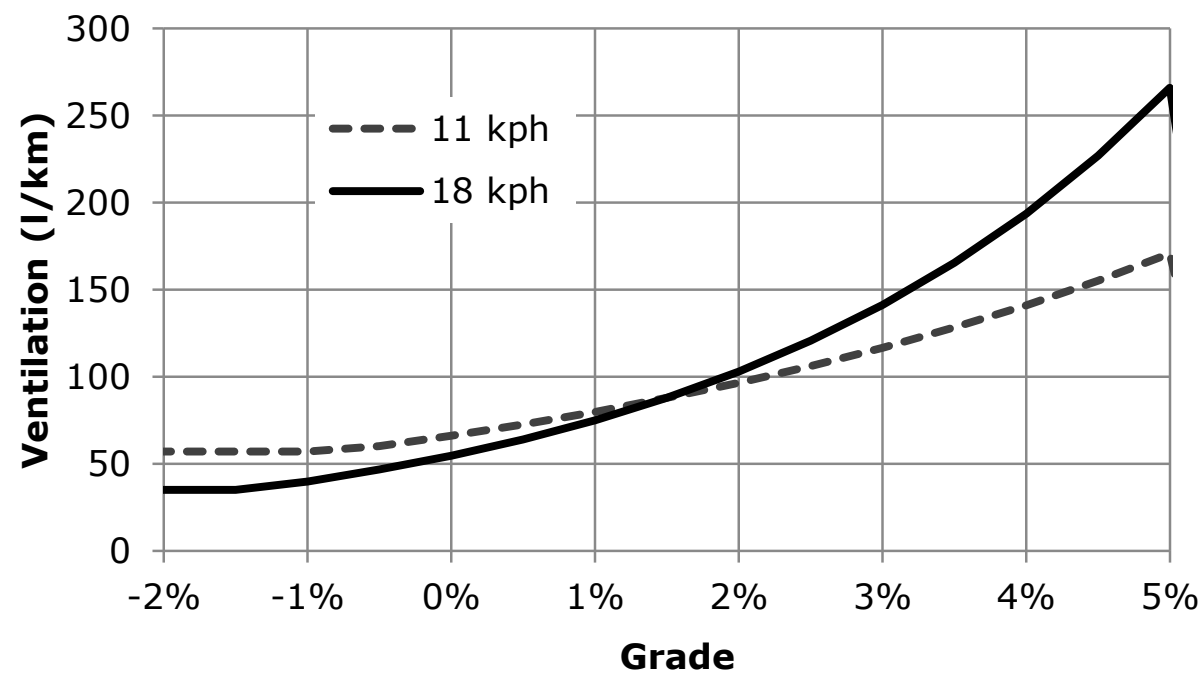

Figure 46. Effect of extended grades on ventilation per unit distance at different speeds

\section{EFFECT OF SPEED ON INTAKE}

The main effect of speed on intake is through ventilation rate, $\frac{\partial \dot{V}_{E}}{\partial \mathrm{G}}$. Speed effects on inhalation rates are assessed as $\frac{\partial I^{t}}{\partial G}=C \frac{\partial \dot{V}_{E}}{\partial G}$. The steady-state workload response to speed (i.e. excluding acceleration activity, $\frac{\Delta K E}{\Delta t}=0$ ) is:

$$
\frac{\partial \dot{W}_{M}}{\partial v_{b}}=m_{T} g \mathrm{G}+3 C_{D}^{\prime} v_{b}^{2}+C_{R} m_{T} g
$$

and the ventilatory response to speed is:

$$
\frac{\partial \dot{V}_{E}}{\partial v_{b}}=\dot{V}_{E} b\left(m_{T} g \mathrm{G}+3 C_{D}^{\prime} v_{b}^{2}+C_{R} m_{T} g\right) .
$$


As a semi-elasticity, ventilation increases by $0.3 b\left(m_{T} g \mathrm{G}+3 C_{D}^{\prime} v_{b}^{2}+C_{R} m_{T} g\right)$ with each kph speed increase ${ }^{4}$. This semi-elasticity is linear with respect to speed. For a representative calculation, assuming

- $b=0.00645$

- $v_{b}=4 \mathrm{~m} / \mathrm{s}(14 \mathrm{kph}, 9 \mathrm{mph})$

- $m_{T}=100 \mathrm{~kg}$

- $g=9.81 \mathrm{~m} / \mathrm{s}^{2}$

- $G=0$

- $C_{D}^{\prime}=0.4$

- $C_{R}=0.004$

then the differentials determining intake are calculated

$$
\begin{gathered}
\frac{\partial \dot{W}_{M}}{\partial v_{b}}=3(0.4)(4)^{2}+(0.004)(100)(9.81)=23 \mathrm{~W} \text { per mps }(6 \mathrm{~W} \text { per kph }), \text { and } \\
\frac{\partial \dot{V}_{E}}{\partial v_{b}} \frac{1}{\dot{V}_{E}}=0.00645(23)=15 \% \text { per mps }(4 \% \text { per } \mathrm{kph})
\end{gathered}
$$

Note that $4 \%$ ventilation per kph is exactly the value in Table 61 , which was based on segment-level model coefficients from the multi-stage least squares uptake model presented in Chapter 7 on uptake.

${ }^{4}$ The coefficient of 0.3 represents the unit conversion from mps to $\mathrm{kph}$. 
We can compare the steady-state workload response to speed with an acceleration event by using $\dot{W}_{M}=\frac{m_{T}}{2} \frac{\Delta v_{b}^{2}}{\Delta t}$ and assuming an acceleration rate of $\frac{\Delta v_{b}}{\Delta t}=1 \mathrm{mps} / \mathrm{s}$ in addition to the previous assumptions:

$$
\dot{W}_{M}=\frac{100}{2} \frac{\left(v_{b}+0.5\right)^{2}-\left(v_{b}-0.5\right)^{2}}{1}=100 v_{b}
$$

Thus, the acceleration workload (at a rate of $1 \mathrm{mps} / \mathrm{s}$ ) increases proportionally by $100 \mathrm{~W}$ for each additional mps (3.6 kph) of speed gained. The acceleration effect on workload will likely dominate the steady-state difference due to speed; but note that the effect only occurs during the acceleration even itself, which at $1 \mathrm{mps} / \mathrm{s}$ would last $4 \mathrm{~s}$ to reach the assumed cruising speed.

Figure 47 shows the ventilation sensitivity to speed at grades of $0 \%$ and $2 \%$ using the same assumptions as in Figure 45. Non-linearity in the ventilatory response to speed is due both to the third-order relationship between workload and speed and the exponential relationship between ventilation and workload. 


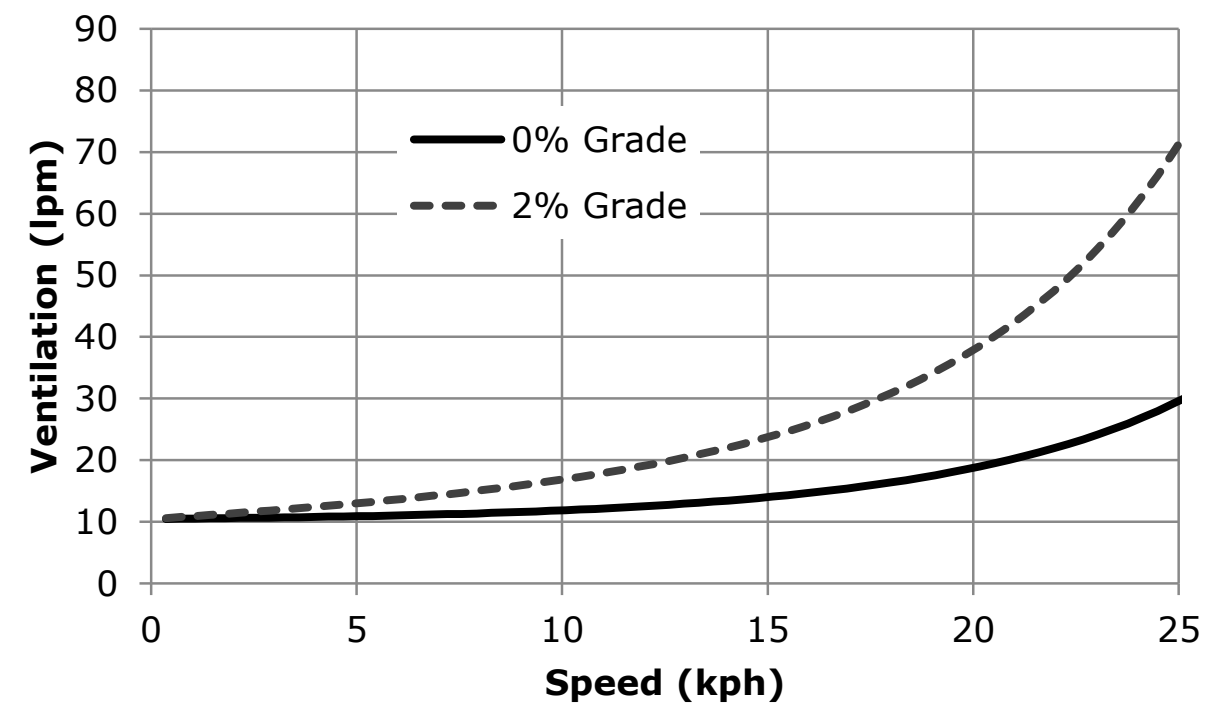

Figure 47. Effect of steady speed on ventilation per unit time at different grades

Again, perhaps of greater interest is the intake per unit distance $I^{d}$, which requires the differential of ventilation per unit distance $\left(\frac{\dot{V}_{E}}{v_{b}}\right)$ with respect to speed:

$$
\frac{\partial\left(\dot{V}_{E} / v_{b}\right)}{\partial v_{b}}=\frac{\frac{\partial \dot{V}_{E}}{\partial v_{b}} v_{b}-\dot{V}_{E}}{v_{b}^{2}}=\frac{\dot{V}_{E}}{v_{b}^{2}}\left[v_{b} b\left(m_{T} g \mathrm{G}+3 C_{D}^{\prime} v_{b}^{2}+C_{R} m_{T} g\right)-1\right],
$$

which as a semi-elasticity is

$$
\frac{\partial\left(\dot{V}_{E} / v_{b}\right)}{\partial v_{b}} \frac{1}{\left(\dot{V}_{E} / v_{b}\right)}=b\left(m_{T} g \mathrm{G}+3 C_{D}^{\prime} v_{b}^{2}+C_{R} m_{T} g\right)-\frac{1}{v_{b}},
$$

(not equivalent to $\frac{\partial \dot{V}_{E}}{\partial v_{b}} \frac{1}{\dot{V}_{E}}$ ).

Ventilation per unit distance $(1 / \mathrm{km})$ is shown in Figure 48, using the same parameter assumptions as in Figure 47. There is a clear non-linear relationship, with a minimum within a realistic range of bicycling speed. Ventilation per distance is 
asymptotic at low speeds as duration increases, and increases nonlinearly at high speeds as the effects of aerodynamic drag increase dramatically.

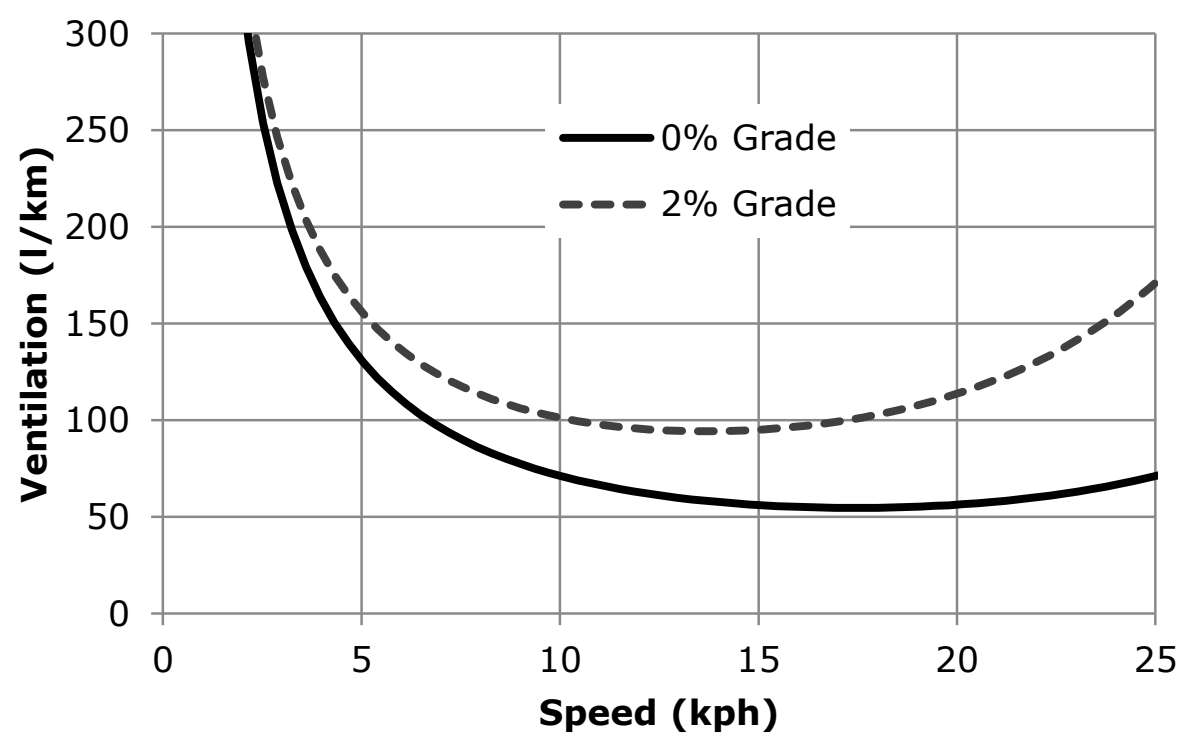

Figure 48. Effect of steady speed on ventilation per unit distance at different grades

The minimum-ventilation (per distance) speed can be calculated, occurring at $\frac{\partial\left(\dot{V}_{E} / v_{b}\right)}{\partial v_{b}}=0$, or

$$
v_{b} b\left(m_{T} g \mathrm{G}+3 C_{D}^{\prime} v_{b}^{2}+C_{R} m_{T} g\right)=1
$$

Rearranging to a cubic polynomial,

$$
\begin{gathered}
\left(3 b C_{D}^{\prime}\right) v_{b}^{3}+\left(b m_{T} g\left(\mathrm{G}+C_{R}\right)\right) v_{b}-1=0 \\
v_{b}^{3}+\left(\frac{m_{T} g\left(\mathrm{G}+C_{R}\right)}{3 C_{D}^{\prime}}\right) v_{b}-\frac{1}{3 b C_{D}^{\prime}}=0
\end{gathered}
$$


Using an example of the preceding parameter value assumptions (including $G=0$ ), the minimum-ventilation speed is $v_{b}^{3}+3.27 v_{b}-129=0$, which has a solution at $4.8 \mathrm{mps}$ (17.4 kph).

For the general $G$ but using the other parameter value assumptions (for $m_{T}, g, C_{D}^{\prime}, C_{R}$, and $\left.b\right)$

$$
\begin{gathered}
v_{b}^{3}+\left(\frac{981(G+0.004)}{3(0.4)}\right) v_{b}-\frac{1}{3(0.00645)(0.4)}=0 \\
v_{b}^{3}+(3.27+817.5 G) v_{b}-129=0 .
\end{gathered}
$$

Figure 49 shows the (real) solutions ${ }^{5}$ of Equation 3 (minimum-ventilation speed) over a range of grades. The minimum-ventilation speed declines with grade, as also seen in Figure 48. Interestingly, the minimum-ventilation speed is near realistic urban bicycling speeds. The average on-road speed (without stops) in this study was $17.2 \mathrm{kph}$ (see Data Overview, Chapter 4) - almost exactly the minimum-ventilation speed at a grade of 0. This could be due to a natural inclination of utilitarian bicyclists to minimize the total energy expenditure per unit distance traveled, given the relationship between energy expenditure, $\dot{V}_{O_{2}}$ and $\dot{V}_{E}$. However, the selection of urban bicyclist speeds is a topic needing further study. Also, note that the minimum-ventilation speed is also somewhat sensitive to the other input parameters besides grade:

- For a $b$ range of $0.004-0.008$, the minimum-ventilation speed at $G=0$ ranges from 16-21 kph.

\footnotetext{
${ }^{5}$ Calculated using Cardano's formula.
} 
- For a $C_{D}^{\prime}$ range of 0.2-0.6, the minimum-ventilation speed at $G=0$ ranges from $15-22 \mathrm{kph}$.

- For a $C_{R}$ range of $0.002-0.006$, the minimum-ventilation speed at $G=0$ ranges from $17-18 \mathrm{kph}$.

- For a $m_{T}$ range of $80-120 \mathrm{~kg}$, the minimum-ventilation speed at $G=0$ ranges from $17-18 \mathrm{kph}^{6}$

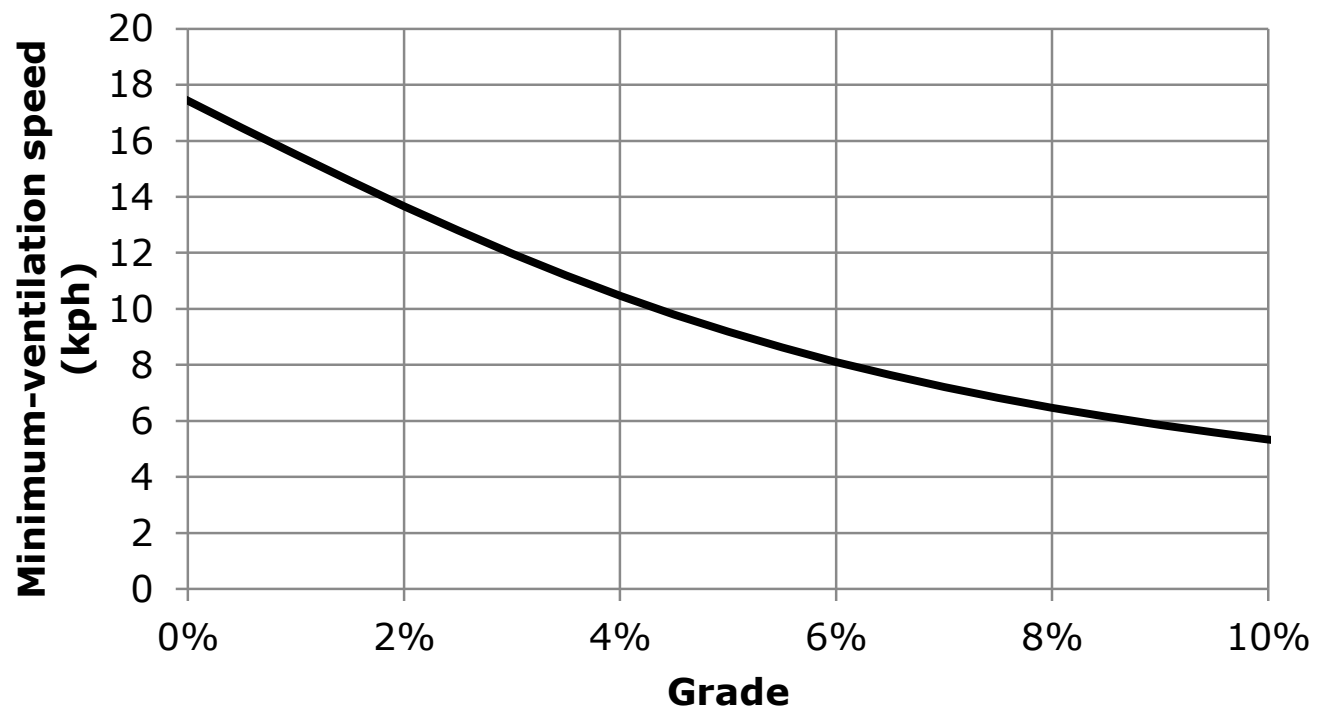

Figure 49. Speed for minimum total ventilation per unit distance at increasing grades

Assuming the ventilation parameters $a=2.348$ and $b=0.00645$, Figure 50

shows the ventilation envelope at grades of $0-10 \%$. The ventilation envelope is the steady-state ventilation assuming a rider adopts the minimum-ventilation speeds shown in Figure 49. Figure 50 shows that a rider's ability to offset steeper grades with a

\footnotetext{
${ }^{6}$ Mass $m_{T}$ is a slightly more important factor at higher grades. At $G=2 \%$, the minimum-ventilation speed ranges $13-15 \mathrm{kph}$ for a mass range of $80-120 \mathrm{~kg}$.
} 
compensatory reduction in speed increases with grade. In other words, as grades increase to over about $8 \%$, a rider can almost maintain ventilation by reducing speed to a point that the workload and ventilation rates are unaffected by grade. In Figure 50, workload levels out at $155 \mathrm{~W}$ at $8 \%+$ grade, where ventilation levels out at $28 \mathrm{lpm}$.

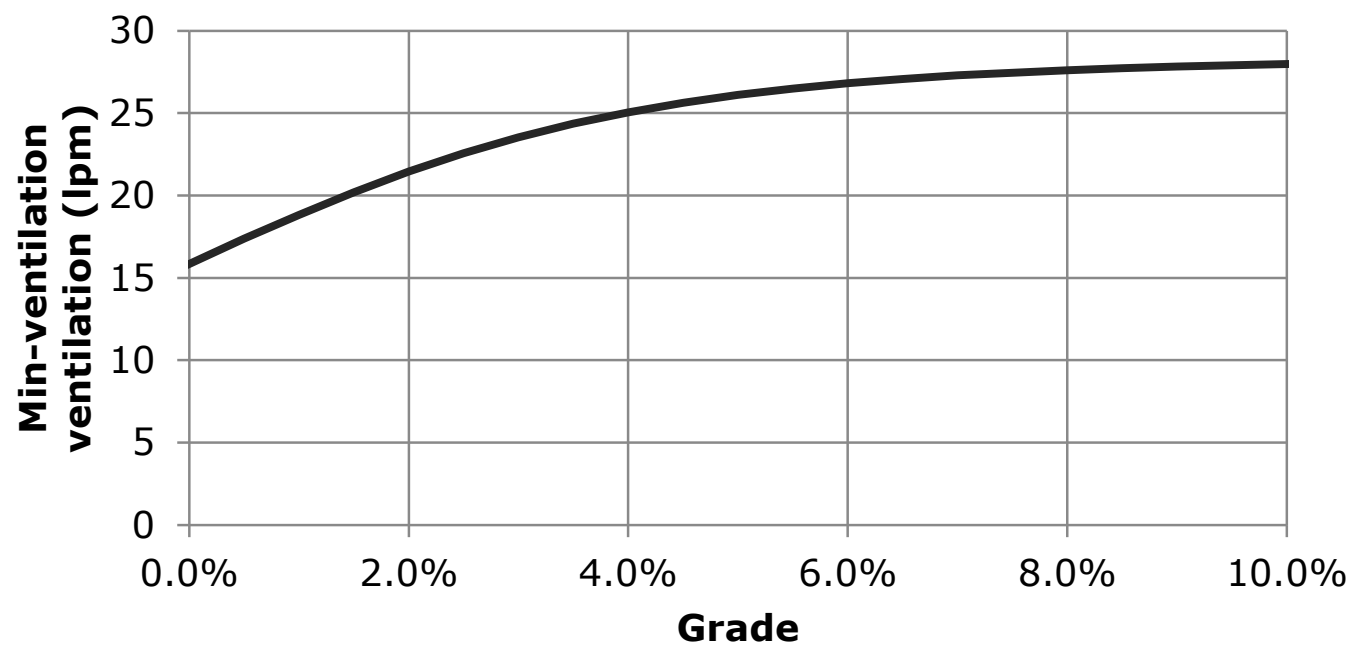

\section{Figure 50. Ventilation envelope: ventilation at the minimum-ventilation speeds shown in Figure 49}

It should be noted that the ventilation vs. speed findings are contrary to the only known paper on this topic. McNabola et al. (2007) used a human respiratory tract model to determine that bicycling and walking at higher speeds reduced uptake of VOC, without an inflection point. The difference in findings is partially attributable ${ }^{7}$ to the ventilation-

\footnotetext{
${ }^{7}$ Another difference between the analysis in this section and McNabola et al. is that McNabola et al. modeled absorption (uptake), not inhalation. At low exposure concentrations, total absorption of benzene over a fixed-length trip decreased with travel speed. The stated lung model input parameters (Table 2 of their paper) are inconsistent with their ventilation vs. speed function, so it is unknown whether inhalation dose per trip increased or decreased with speed. A divergence of intake and uptake doses for VOC is consistent with the findings in Chapter 7 , where ventilation rate is a minor determinant of breath concentrations. However, McNabola et al. state that the same results were found for $\mathrm{PM}_{2.5}$ deposition, which would be inconsistent with particulate lung deposition theory.
} 
speed relationship they used, which was $\dot{V}_{E}=3.55 v_{b}-5.85$ with $\dot{V}_{E}$ in lpm and $v_{b}$ in mph. By modeling the $\dot{V}_{E} \sim v_{b}$ relationship as linear, $\dot{V}_{E} / v_{b}$ is an inverse function of speed, monotonically increasing ${ }^{8}$. Their ventilation equation was based on bicycle ergometer testing, and the linear form could be due to neglect of aerodynamic drag effects (which do not exist on an ergometer). Also, the speeds compared by McNabola et al. were 8 and $19 \mathrm{kph}$, which at $0 \%$ grade would be below the speeds at which aerodynamic drag can dramatically increase ventilation rate per unit distance (Figure 47). Lastly, recall from Chapter 6 on ventilation that the $\dot{V}_{E} \sim \dot{W}_{M}$ relationship can also be modeled as linear, in which case $\frac{\partial \dot{V}_{E}}{\partial \dot{W}_{M}}$ is a constant slope parameter $\gamma$, estimated in Chapter 6 to be around $\gamma=0.2$. Using this linear form, the ventilatory response to speed is:

$$
\frac{\partial \dot{V}_{E}}{\partial v_{b}}=\frac{\partial \dot{V}_{E}}{\partial \dot{W}_{M}} \frac{\partial \dot{W}_{M}}{\partial v_{b}}=\gamma\left(m_{T} g \mathrm{G}+3 C_{D}^{\prime} v_{b}^{2}+C_{R} m_{T} g\right)
$$

and the ventilatory response per unit distance is:

$$
\frac{\partial\left(\dot{V}_{E} / v_{b}\right)}{\partial v_{b}}=\frac{\frac{\partial \dot{V}_{E}}{\partial v_{b}} v_{b}-\dot{V}_{E}}{v_{b}^{2}}=\frac{1}{v_{b}^{2}}\left[v_{b} \gamma\left(m_{T} g \mathrm{G}+3 C_{D}^{\prime} v_{b}^{2}+C_{R} m_{T} g\right)-\dot{V}_{E}\right]
$$

The minimum-ventilation speed occurs at $\frac{\partial\left(\dot{V}_{E} / v_{b}\right)}{\partial v_{b}}=0$, or $\dot{V}_{E}=v_{b} \gamma\left(m_{T} g \mathrm{G}+3 C_{D}^{\prime} v_{b}^{2}+\right.$ $\left.C_{R} m_{T} g\right)$. Substituting $\delta+\gamma \dot{W}_{M}$ for $\dot{V}_{E}$ and rearranging,

$8 \frac{\dot{V}_{E}}{v_{b}}=3.55-5.85 \frac{1}{v_{b}}$, which asymptotically approaches $3.55(\mathrm{lpm} / \mathrm{mph})$ from below 


$$
2 \gamma C_{D}^{\prime} v_{b}^{3}-\delta=0
$$

where $\delta$ is the intercept of the $\dot{V}_{E} \sim \dot{W}_{M}$ equation and $\gamma$ is the slope. Substituting $C_{D}^{\prime}=$ $0.4, \gamma=0.2$ and $\delta=5$, the minimum-ventilation speed is at $v_{b}^{3}=31.25$, or $3 \mathrm{mps}$ (11kph). Substituting individual $\gamma$ and $\delta$ parameters from Chapter 6 , the minimumventilation speed ranges from 8,23 , and $14 \mathrm{kph}$ for subjects $\mathrm{A}, \mathrm{B}$, and $\mathrm{C}$, respectively. These speeds are within a reasonable range of bicyclist speeds and further support the finding (contrary to McNabola et al. (2007)) that there is a speed bicyclists can travel which will minimize their pollutant inhalation over a trip.

\section{EFFECT OF STOPS ON INTAKE}

A stop and acceleration at an arbitrary point on the network might only affect ventilation, but exposure modeling showed that higher concentrations are associated with stop and start-up periods while bicycling (Table 61 and Chapter 5). Hence, the intake

effect of a stop should incorporate both $\frac{\partial \dot{V}_{E}}{\partial x}$ and $\frac{\partial C}{\partial x}$.

\subsection{Ventilation effect of an acceleration from stop}

Consider a bicyclist with a cruising speed of $v_{b}$ and workload of $\dot{W}_{M}$ on level ground. In order to put acceleration effort into context, let us assume that the power of acceleration from a stop is at a factor $k \geq 1$ with respect to the cruising workload. An acceleration event from stop was modeled using Equation 1 for $\dot{W}_{M}$ and assuming $k$ along with the other parameters $\left(C_{D}^{\prime}=0.4, C_{R}=0.004, m_{T}=100 \mathrm{~kg}\right.$, and $g=9.81$ 
$\mathrm{m} / \mathrm{s}^{2}$ ). Ventilation effects were modeled with $\ln \dot{V}_{E}=2.348+0.00645 \dot{W}_{M}$, as in the previous sections.

For a target speed of $4 \mathrm{mps}(14.4 \mathrm{kph})$, the cruising workload on level ground is $41 \mathrm{~W}$. Assuming a $k$ value of 2 , the acceleration power is $83 \mathrm{~W}$ and cruising speed is reached in 14 seconds and $39 \mathrm{~m}$. Subtracting the cruising time and energy which would have been required to traverse an equivalent distance, the penalty of acceleration is 4 extra seconds and 717 excess $\mathbf{J}$ of energy. The excess energy is the kinetic energy input $\left(\frac{1}{2} m_{t} v_{b}^{2}=800 \mathrm{~J}\right)$, minus the energy saved in losses by traversing the distance at lower speed $(83 \mathrm{~J})$.

Translating this into ventilation, the cruising workload leads to ventilation of 13.7 lpm, whereas acceleration ventilation is at $17.8 \mathrm{lpm}$. The excess ventilation is 1.91 , again calculated as the ventilation during acceleration minus the ventilation which would have occurred cruising the equivalent distance. To put this volume into travel terms, the excess ventilation is equivalent to cruising ventilation of 8.3 seconds or 33 meters. In other words, the ventilation (or intake) cost of the acceleration is equivalent to $8 \mathrm{~s}$ or $33 \mathrm{~m}$ of riding.

Varying the $k$ value from $2-6$, the equivalent penalty of ventilation/intake is $8-11$ sec and 33-43 m, while the excess travel time is 2-4 s. Similar to the effect of speed on ventilation per unit distance, there is an off-setting effect of harder accelerations, where the shorter duration is offset by higher ventilation, so even though the acceleration duration changes by a factor of 3 , the ventilation penalty is relatively stable. Figure 51 shows speed vs. time plots for accelerations from stop to cruising speed for $k=2,4$, and 
6 (with acceleration workloads of 83,165 , and $248 \mathrm{~W}$, respectively). The average acceleration for the first 3 seconds after starting is $0.72,1.02$, and $1.25 \mathrm{mps} / \mathrm{s}$ for $k=2$, 4 , and 6, respectively. These are in range of previously reported bicyclist accelerations of 0.5-1.5 mps/s (Pein 1997, AASHTO 2012, Figliozzi et al. 2013).

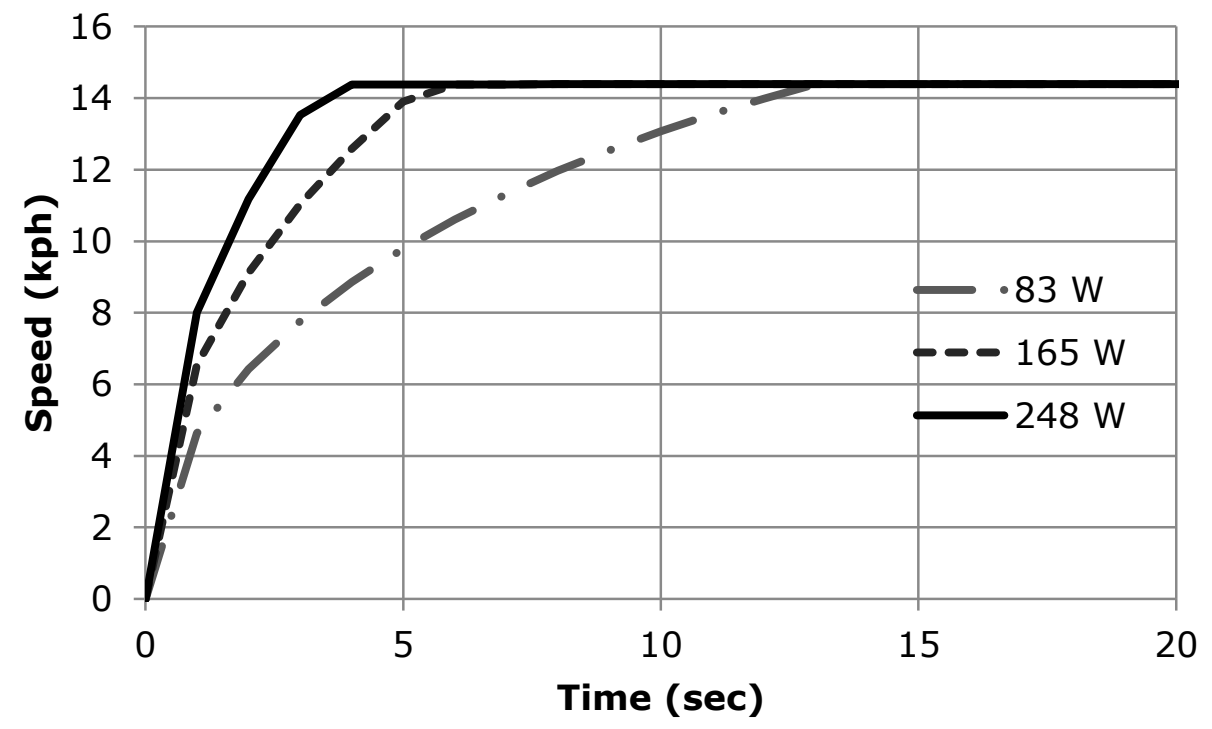

Figure 51. Acceleration curves for start-up workloads at factors of $k=2,4$, and 6 of cruising-speed workload

The target speed is another important factor; the startup penalty increases with cruising speed. A $50 \%$ higher target speed of $6 \mathrm{mps}(21.6 \mathrm{kph})$ leads to $15 \mathrm{~s}(89 \mathrm{~m})$ of equivalent excess ventilation using the same parameters as above $(k=2)$. The cruising $W_{M}$ for this target speed is $110 \mathrm{~W}$, excess ventilation 5.31 , and excess time 4 s. Ranging $k$ from 2 to 3 for this target speed leads to equivalent excess ventilation of $15-22 \mathrm{~s}$, with an acceleration workload of $330 \mathrm{~W}$ at $k=3$. 


\subsection{Ventilation effect of a deceleration to stop}

The effect of a deceleration to stop on ventilation was modeled using the same parameters and equations as the previous section, with an initial cruising speed of $4 \mathrm{mps}$ (14.4 kph). A broader range of braking power is considered, 1-10 times the cruising workload (i.e. $41-410 \mathrm{~W}$ ). The braking distance is $3-30 \mathrm{~m}$ and the braking time is $2-14 \mathrm{~s}$. To cover the braking distance, 1-6 seconds of excess time is needed (above the time required to traverse the equivalent distance at cruising speed).

The excess ventilation is the $(0 \mathrm{~W})$ ventilation during braking time, minus the ventilation required to traverse the equivalent distance at cruising speed and ventilation rate. The net value is $0.2-0.71$ excess ventilation, due to the excess duration dominating the effect of lower power output during braking. The excess ventilation is equivalent to 1$3 \mathrm{~s}$ or $4-13 \mathrm{~m}$ of cruising ventilation. The impact of a deceleration on total ventilation is positive but smaller than the impact of an acceleration.

At a higher cruising speed of $6 \mathrm{mps}(21.6 \mathrm{kph})$, the braking power is $110-1,100 \mathrm{~W}$. Braking distance is $3-39 \mathrm{~m}$ and braking time is 2-12 s. Excess time is 1-5 s, and excess ventilation is -0.2 to 0.1 l. At higher cruising speeds with greater workloads, the ventilation rate reduction of a deceleration completely offsets the excess duration.

\subsection{Combined effect of a stop/start on ventilation}

Figure 52 shows the net effect of a stop during riding (excluding stopped time) as the summed effects of the acceleration and cruise events modeled in the previous sections. Cruise speeds of 2-8 mps (7-29 kph) are included, with acceleration workload at twice the cruising workload $\left(k_{a}=2\right)$ and deceleration power at five times the cruising 
workload $\left(k_{d}=-5\right)$. The penalty of a stop increases non-linearly with cruising speed.

Higher cruising speeds lead to more of a ventilation penalty during acceleration and less of a penalty during deceleration. As a reference point, a Portland city block face is approximately $80 \mathrm{~m}$ long; stops/start events at cruising speeds over $20 \mathrm{kph}$ generate excess ventilation of more than a block. Excess ventilation for these cruising speeds is

\section{$1.4-27.81$.}

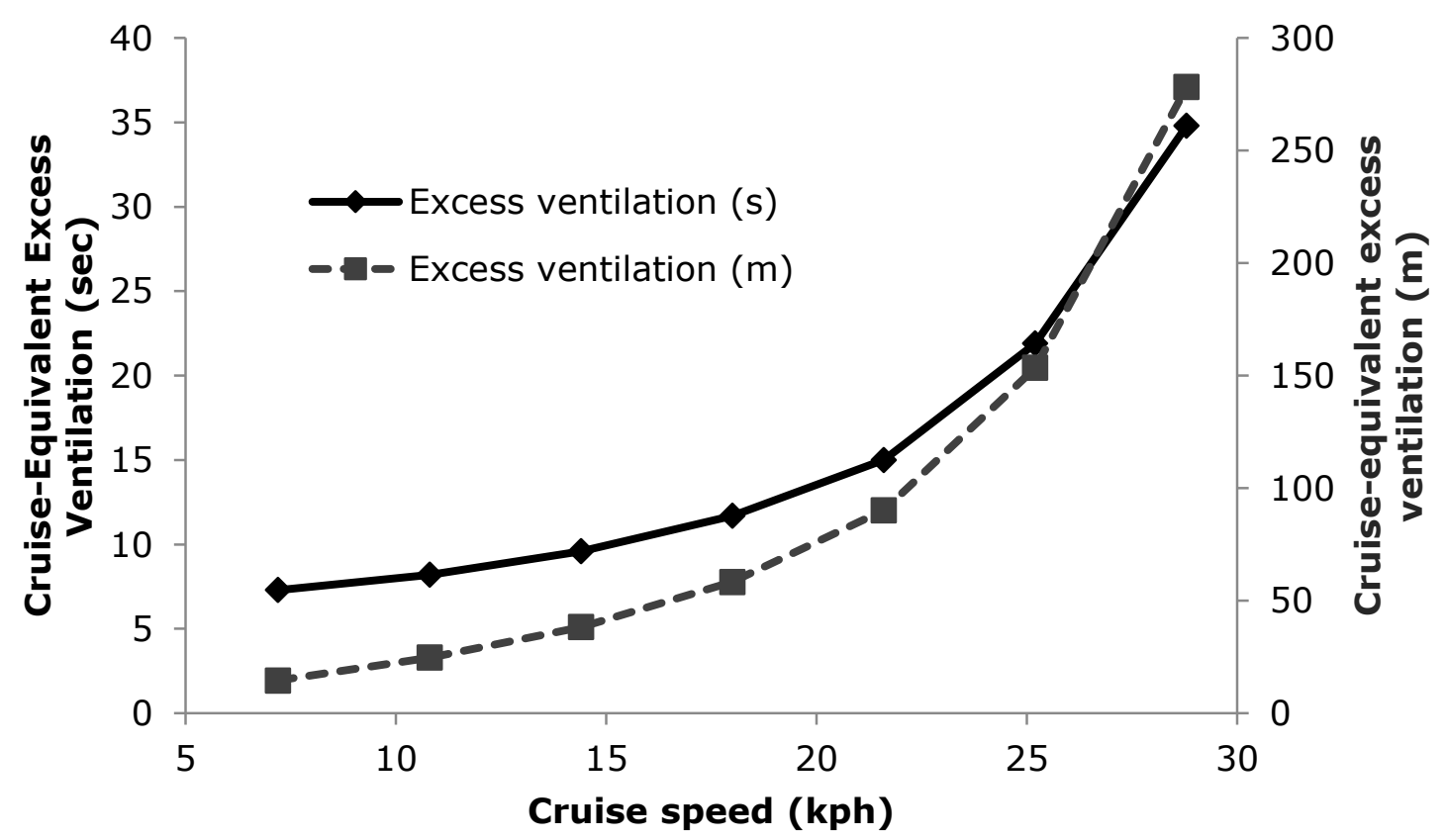

Figure 52. Cruise-equivalent excess ventilation associated with the deceleration and acceleration of a stop event at cruising speeds of $2-8 \mathrm{mps}(7-29 \mathrm{kph})$

Because the ventilation penalty of a stop event increases with cruise speed, the minimum-ventilation target speed for an urban route is lower than the minimumventilation steady-state speed presented in Figure 49. A network-based minimumventilation cruising speed for a trip would include the frequency of stops to determine the optimal trade-off between cruising ventilation and excess ventilation due to stops. 


\subsection{Exposure effect of stops}

The high-resolution exposure model in Chapter 5 suggests that concentrations are 20-30\% higher during stop-and-go riding. A startup exposure penalty of 20-30\% for 10 seconds is equivalent to $2-3$ seconds of excess exposure. At $4 \mathrm{mps}(14.4 \mathrm{kph})$ cruising speed, a stop event generates a cruise-equivalent ventilation penalty of $10 \mathrm{~s}$ (Figure 52). Thus, for an instantaneous stop event the main effect on intake is through ventilation (10 $\mathrm{s}$ excess ventilation vs. 2-3 s excess exposure). For a sustained stop event, the excess exposure effect will be similar to the ventilation effect (10 s of total excess exposure) for a stop duration of about $25 \mathrm{~s}$. For longer stops the exposure effect is expected to dominate, and for shorter stops the ventilation effect is expected to dominate.

\section{TRADE-OFFS FOR INTAKE AND UPTAKE}

\subsection{Choice of two facilities}

Consider two parallel facilities with an ADT differential of $\triangle A D T$. Assuming $2 \%$ higher exposure concentrations per 1,000 ADT (Table 61), the concentration ratio between the facilities is $\frac{C_{1}}{C_{2}}=e^{\left(\frac{\Delta A D T}{50,000}\right)}$ (Equation 2). The inhalation dose of each unit distance on the high-volume facility is equivalent to the inhalation dose on a distance of $e^{\left(\frac{\triangle A D T}{50,000}\right)}$ on the low-volume facility (i.e. $1 \mathrm{~km}_{\text {high }} \equiv e^{\left(\frac{\triangle A D T}{50,000}\right)} \mathrm{km}_{\text {low }}$ ). For a minor arterial with 20,000 ADT and a parallel local street of 1,000 ADT,

$$
1 \mathrm{~km}_{\text {MinorArterial }} \equiv 1.46 \mathrm{~km}_{\text {Local }} \text {. }
$$


These relative inhalation doses by facility can be compared with traveler preferences based on published research. According to Broach et al. (2012), commuting bicyclists will trade off $12 \%$ additional distance on a bicycle boulevard (typically a lowvolume local road) versus a road with a bicycle lane (often an arterial or collector), $53 \%$ additional distance on a bicycle boulevard versus a 10,000-20,000 ADT roadway (typically a minor arterial) with no bicycle facilities, and $814 \%$ additional distance on a bicycle boulevard versus a 30,000 ADT arterial with no bicycle facilities. The same trade-offs, respectively, were $22 \%, 43 \%$, and $776 \%$ for non-commuters.

Let this equivalent distance of preferences be represented $D_{e q}^{p}$. The equivalent distance of inhalation doses for mixed-traffic facilities is calculated $D_{e q}^{I}=e^{\left(\frac{\triangle A D T}{50,000}\right)}$. For each set of preferences, the ADT difference which elicits an equivalent facility trade-off as preferences is calculated $D_{e q}^{p}=D_{e q}^{I}$. In this case, bicyclists will naturally minimize their inhalation doses by acting in accordance with route preferences. If $D_{e q}^{p}>D_{e q}^{I}$, bicyclist preferences for low-volume, low-exposure routes are stronger than the exposure differences, and bicyclists might increase inhalation doses by increasing exposure duration unnecessarily. If $D_{e q}^{p}<D_{e q}^{I}$, bicyclist preferences for low-volume, low-exposure routes are weaker than the exposure differences, and bicyclists might increase inhalation doses by traveling on high-exposure facilities when lower-exposure facilities are available. Note that this analysis does not assume that travelers are trying to minimize their inhalation doses - it simply compares revealed behavior preferences (motivated by numerous factors, including comfort, perceived safety, and possibly avoiding motor vehicle exhaust) with behavior that would minimize inhalation doses. In addition, 
bicyclist routing decisions are influenced by attributes of the route other than traffic volume (e.g. grade, pavement quality, land use, lighting); these attributes are not included in this analysis.

Comparison of $D_{e q}^{p}$ and $D_{e q}^{I}$ for three facility types are as follows:

- Bicyclist preference for bicycle boulevards versus roads with bicycle lanes (12$22 \%)$ is equivalent to VOC inhalation dose effects $\left(D_{e q}^{p}=D_{e q}^{I}\right)$ for ADT differences of 6,000-10,000 ADT. This preference would align with VOC inhalation risks only for bicycle lanes on lower-volume roads such as collectors (e.g. SW Terwillger Dr., SE $7^{\text {th }}$ Ave). For bicycle lanes on higher-volume roads (arterials), $D_{e q}^{p}<D_{e q}^{I}$ and bicyclists are less willing to detour than would be optimal in order to minimize inhalation doses.

- Bicyclist preference for bicycle boulevards versus minor arterials $(10,000-20,000$ ADT) without bicycle lanes (43-53\%) is equivalent to VOC inhalation dose effects $\left(D_{e q}^{p}=D_{e q}^{I}\right)$ for ADT differences of 18,000-21,000 ADT. Thus, the preference to avoid minor arterials without a bicycle lane is similar to or slightly higher than what would be necessary to minimize VOC inhalation dose: $D_{e q}^{p} \geq$ $D_{e q}^{I}$.

- Bicyclist preference for bicycle boulevards versus major arterials (30,000 ADT) with no bicycle lanes (776-814\%) is equivalent to VOC inhalation dose effects $\left(D_{e q}^{p}=D_{e q}^{I}\right)$ for ADT differences of 109,000-111,000 ADT. This preference to avoid major roadways is much greater than the VOC inhalation risks differences: $D_{e q}^{p}>D_{e q}^{I}$. Bicyclists will tend to avoid these facilities more than would be 
optimal from an inhalation dose perspective (i.e. reducing their exposure concentrations but increasing total inhalation due to longer travel distance and time).

This comparison of bicycle route choice data with exposure differences shows that bicyclists will avoid arterials without bicycle infrastructure in such a way as to reduce exposure concentrations, possibly to the point of increasing trip VOC inhalation dose by increasing duration. However, bicyclist preference for bicycle boulevards over arterials with bicycle lanes is likely weaker than what would be optimal from a VOC inhalation dose perspective (i.e. $D_{e q}^{p}<D_{e q}^{I}$ ). The inequality is especially likely for roads with bicycle lanes and $A D T>10,000$. In choosing between these facilities, bicyclists are unlikely to be willing to detour as far to the lower-volume road as would be optimal from an inhalation dose perspective.

The policy implication is that providing bicycle lanes on roads with $A D T>$ 10,000 will most likely increase VOC inhalation doses for bicyclists with a route choice set that includes the new facility and low-volume alternatives. One counter-argument is that for bicyclists already using the arterial facility (due to a lack of low-volume options in the route choice set or unique personal preferences), adding a bicycle lane increases safety and comfort without affecting inhalation dose. In addition, these trade-offs are only applicable when bicyclists must detour to use low-traffic roadways: excepting facilities with near-road stationary sources, bicyclists prefer low-exposure routes. Providing a good network of low-volume roadways and off-street paths ensures that bicyclists can choose 
low-exposure routes with minimal trade-offs of additional distance. As with other complex topics in transportation policy, good decision-making requires understanding and analysis of induced demand.

\subsection{Detour to a parallel, low-volume facility}

Detouring to a parallel low-volume facility is justified from an inhalation

perspective if the additional distance is $<\left(e^{\left(\frac{\triangle A D T}{50,000}\right)}-1\right)$ of the high-volume route.

Consider a street grid where the high-volume route is $x$ blocks long. A detour to a facility $y$ blocks away is justified if

$$
\frac{2 y}{x}<e^{\left(\frac{\Delta A D T}{50,000}\right)}-1
$$

For a minor arterial with 20,000 ADT and a parallel local street of 1,000 ADT, a detour of 1 block is justified by

$$
\begin{gathered}
\frac{2(1)}{x}<e^{\left(\frac{19,000}{50,000}\right)}-1=0.46 \\
4.3<x
\end{gathered}
$$

a length of 4.3 blocks. For a distance of $1 \mathrm{~km}$ on the minor arterial, a detour of $230 \mathrm{~m} \mathrm{(3}$ blocks of $80 \mathrm{~m}$ ) would be justified. In the extreme case of $\triangle A D T=40,000$, a 1-block detour is justified by a route length of just 1.6 blocks and $1 \mathrm{~km}$ on the major road would warrant detouring to a low-volume facility $613 \mathrm{~m}$ away ( 8 blocks of $80 \mathrm{~m}$ ). These results suggest that in most cases detouring to a parallel low-volume facility, if available, would be justified from an inhalation dose perspective. 


\subsection{Exercise location and inhalation dose}

If engaging in physical activity for exercise, the inhalation dose for on-road exercise can be compared with inhalation dose at a reference park location. From Table 61 , assume concentrations are $40 \%+2 \%$ per 1,000 ADT higher on-road than at a clean park. If the ventilation is the same for either type of exercise, inhalation doses are higher by $1.4 e^{\left(\frac{A D T}{50,000}\right)}$ on-road. Thus 1 minute of on-road exercise leads the same inhalation dose estimate as $1.4 e^{\left(\frac{A D T}{50,000}\right)}$ min of exercise at the park. For a minor arterial with 20,000 ADT, 1 min on-road is equivalent to $2.1 \mathrm{~min}$ at the park for inhalation doses.

\section{UPTAKE OF GASES AND PARTICULATES}

Motor vehicle exhaust contains gas and particulate toxicants. Inhalation of both increases with ventilation and workload, but uptake follows different mechanism. For gases such as BTEX compounds, blood/air equilibrium can be reached over the course of a trip. In this case, increased ventilation has only a minor impact on gas uptake and exposure duration and concentration are more important determinant s of uptake. Astrand (1985) provides an excellent discussion of the limited uptake of VOC during exercise. For particulate matter (PM), on the other hand, the lungs have a nearly unlimited ability to take up more pollutants, and so increased inhalation always exacerbates uptake. Even more, the deposition fraction of particulates (fraction of inhaled particles that are retained in the lungs) is expected to increase with exercise (Daigle et al. 2003) ${ }^{9}$.

\footnotetext{
${ }^{9}$ UFP deposition fractions increased from 0.6 to 0.8 at ventilations of 12 to $38 \mathrm{lpm}$.
} 
In this and previous research, bicyclists' ventilation has been shown to be about 25 times higher than that of non-active travelers (i.e. in motor vehicles). Thus, considering only physical activity differences, inhalation doses of all pollutants are 2-5 times higher and uptake of PM is at least 2-5 times higher for bicyclists. Chapter 7 on uptake suggested an elasticity of breath concentrations to ventilation of around $0.17(0.07-0.26)$ for aromatic hydrocarbons. Thus, 2-5 times higher ventilation would lead to 1.2-1.7 times higher internal doses of VOC. An empirical study reported 1.9 times higher breath concentrations and 2.2 times higher venous blood concentrations with 3.0 times higher ventilation (Carlsson 1982). Alternatively, by the 1-compartment model presented in Wallace et al. (1993) and (1997), expired breath concentrations at blood/ambient air equilibrium would be 1.6 to 3.4 times higher with $2-5$ times higher ventilation ${ }^{10}$. Note that limited uptake of VOC depends on exposure concentrations low enough to reach a blood/air equilibrium condition during the exposure period.

Given the lack of quantitative dose-response data for individual traffic-related pollutants, the optimal trade-offs for gas and particulate toxicant uptake cannot be calculated. But qualitative differences are known. Duration is more important for VOC uptake, while ventilation is more important for particulate uptake. Minimum-uptake

\footnotetext{
${ }^{10}$ In Wallace et al. (1993) and (1997), breath/ambient air concentration ratios $(f)$ at blood/ambient air equilibrium was modeled as $f=\frac{1}{1+\frac{K P}{0.7 V_{E}}}$, where $K$ is metabolic clearance rate and $P$ is the blood/air partition coefficient. Assuming $K P=20$ to 60 (Wallace et al. (1993) report $f$ of 0.1-0.3 for aromatics and $\dot{V}_{E}$ around $10 \mathrm{lpm}$ ), we can use $\frac{f_{2}}{f_{1}}=\frac{0.7+\frac{K P}{V_{E_{1}}}}{0.7+\frac{K P}{V_{E_{2}}}}$ to calculate the effect on $f$ of a ventilation change from $V_{E_{1}}=11 \mathrm{lpm}$ to $V_{E_{2}}=22$ to $55 \mathrm{lpm}$. For $K P$ values of 20,40 , and $60, \frac{f_{2}}{f_{1}}=1.6$ to $2.4,1.7$ to 3.0, and 1.8 to 3.4 , respectively.
} 
speed would be lower than minimum-ventilation speed for particulates and higher for VOC. Grades are more of a concern for PM uptake than VOC uptake. In general the relative air pollution risks for active travelers (with respect to travelers in motor vehicles) are greater for PM than VOC.

\section{SKETCH-LEVEL TABLE FOR DESIGN GUIDANCE}

The last section in this chapter presents summary guidance for transportation professionals to compare the expected pollution impacts of different bicycle facilities. The information in this section draws from the preceding sections of this chapter as well as previous chapters of the dissertation. As stated in the Introduction Chapter 1, this information was missing from the design guidance in Portland 2030 Bicycle Master Plan. First, Table 62 presents a list of basic principles about bicyclist pollution risks that would be useful for practitioners to understand. Table 63 presents summary information about the effects of different bicycle facilities on air pollution risks for bicyclists. The information in both tables was distilled from literature and the findings of this dissertation. 
Table 62. Principles about bicyclist pollution risks for transportation professionals

Principles

1. Exposure

a. Motor vehicle exhaust contains many different toxicants with varying properties, distributions, and health effects. The pollutants most concentrated around roadways are $\mathrm{VOC}, \mathrm{CO}, \mathrm{BC}$, and UFP.

b. Traffic levels are major determinants of exposure concentrations, but adjacent land use can also be important (i.e. off-street paths are not always lowexposure).

c. Physical separation of bicycles from traffic, even on the street scale, has measurable benefits for exposure levels.

2. Inhalation

a. On-road ventilation varies greatly with speed, grade, and acceleration. Avoid accelerations and positive grades in high-concentration locations

b. Breathing response to workload is not immediate, but spread out over 1-2 minutes. Therefore, locations of high exertion are not necessarily locations with high ventilation.

3. Uptake

a. Uptake of particulates is highly sensitive to ventilation.

b. Uptake of gases such as VOC is more sensitive to duration than ventilation. 
Table 63. Bikeway Design Considerations for Air Pollution Risks

\begin{tabular}{|c|c|}
\hline Facility & Air Pollution Considerations \\
\hline Bike lane & $\begin{array}{l}\text { - Bike lanes on high-volume streets lead to high exposure } \\
\text { concentrations; each 10,000 ADT is associated with } \sim 20 \% \\
\text { higher BTEX exposure concentrations } \\
\text { - Provides some lateral separation, with concentration benefits } \\
\text { versus in-lane riding } \\
\text { - Dedicated right-of-way can reduce exposure duration during } \\
\text { motor vehicle congestion (exposure concentrations are 20-30\% } \\
\text { higher during stop-and-go riding) }\end{array}$ \\
\hline $\begin{array}{l}\text { Bike boulevard/ } \\
\text { Neighborhood } \\
\text { greenway }\end{array}$ & $\begin{array}{l}\text { - Low exposure concentrations due to low ADT (only 40\% } \\
\text { higher BTEX exposure than background) } \\
\text { - Additional exposure concentration benefits from traffic } \\
\text { calming/volume reductions } \\
\text { - Fewer stops leads to lower inhalation doses (e.g. turning stop } \\
\text { signs) }\end{array}$ \\
\hline Cycle track & 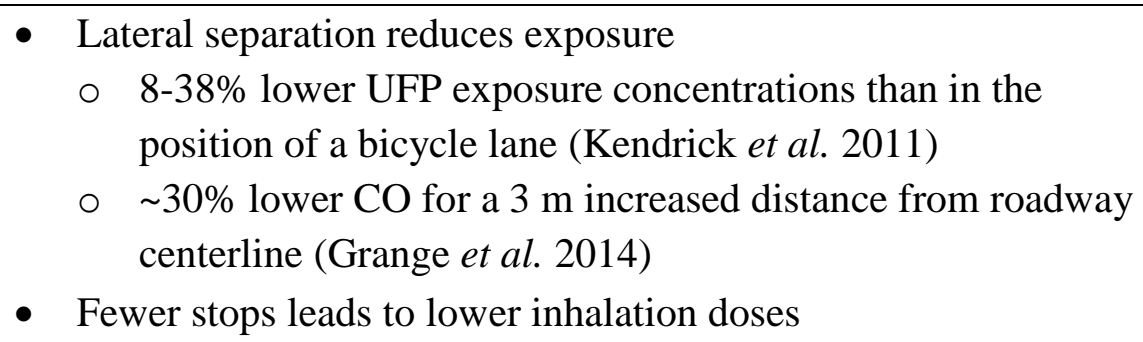 \\
\hline Off-street path & 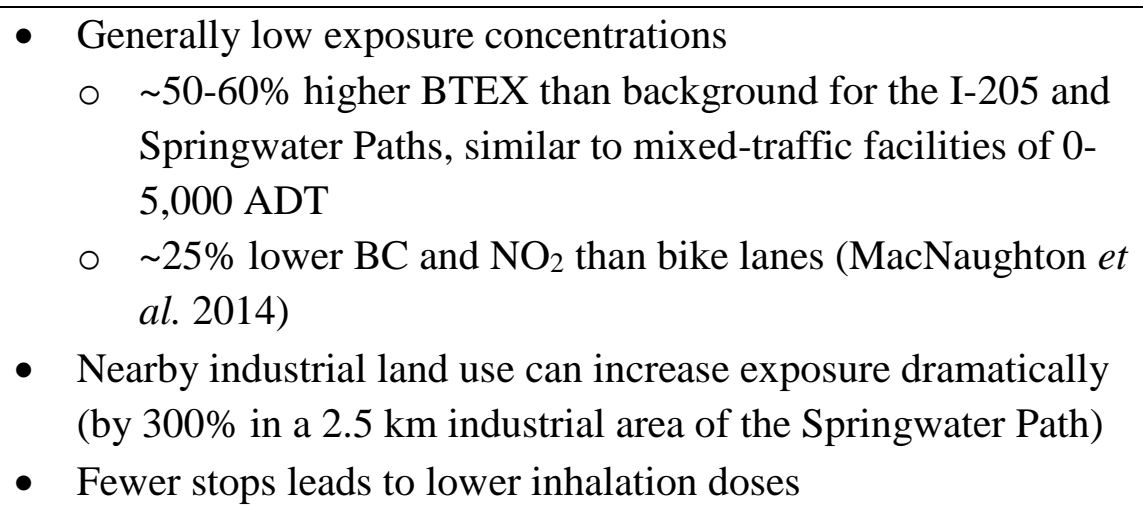 \\
\hline
\end{tabular}




\section{Chapter 9: Conclusions}

\section{RESEARCH QUESTIONS}

This dissertation concludes by revisiting the research questions stated in the introduction.

\section{Q1. How do urban bicyclists' intake and uptake of traffic-related air pollution vary with roadway and travel characteristics?}

The exposure, ventilation, and uptake models presented and analyzed in Chapters 5-8 show that roadway and travel variables are important determinants of VOC intake and uptake. Weather and traffic variables explained an approximately equal amount of variance in exposure concentrations for BTEX compounds. BTEX concentrations approximately doubled on high-volume versus low-volume mixed-traffic facilities. Offroad facilities had both very high and very low exposure concentrations; high on-path exposure was coincident with near-path industrial land use. At higher resolution, BTEX concentrations were $20-30 \%$ higher during stop-and-go riding.

BTEX breath concentrations were strongly associated with exposure concentrations, with an elasticity of 0.4-0.5 (consistent among subjects). Ventilation was a minor factor for breath concentrations, indicative of the fact that VOC uptake is not proportional to intake, but depended on the breath/ambient equilibrium condition. Ventilation is important for uptake of particulate matter, however, and on-road variability of PM exposure concentrations and ventilation were similar. On-road ventilation increased by $0.4-0.8 \%$ with each additional watt of bicyclist workload, lagged by about 1 
minute. Changes in kinetic energy (speed) and aerodynamic drag were the main drivers of on-road energy expenditure.

\section{Q2. To what extent can transportation-related strategies reduce bicyclists' pollution uptake?}

Application of the developed models showed that route and speed choices can have large impacts on exposure concentrations and inhalation doses. Selecting travel routes along low-volume facilities can dramatically decrease exposure to and uptake of VOC. Total inhalation dose is reduced for a trip length of just a few blocks by taking a detour from a mid-sized mixed traffic roadway to a parallel local street one block away. Although off-street facilities can have the lowest concentrations, nearby industrial land uses can lead to very high VOC concentrations. Choice of travel speed also has a large influence on inhalation doses. Estimated minimum-ventilation speed is around $17 \mathrm{kph}$ (11 $\mathrm{mph}$ ), decreasing with grade. Avoiding a stop event reduces inhalation dose by $\sim 15 \mathrm{~s}$ of exposure, not counting stopped time.

Reduction in exposure concentrations through spatial and temporal separation of bicyclists from motor vehicle traffic can be achieved with separated bicycle facilities, low-volume routes, and off-peak travel. These are potential "win-win" strategies because bicyclists already prefer low-traffic routes and bicycle-specific facilities (Dill 2009, Broach et al. 2012, Kang and Fricker 2013). In a survey of Australian commuters, few active travelers changed routes because of air pollution concerns, though most were 
already on low-traffic routes (Badland and Duncan 2009) ${ }^{1}$. Comparison of exposure differences by facility with the parameters of a bicycle route choice model showed that bicyclist preferences for low-volume streets over bicycle lanes on arterials is likely weaker than what would be optimal from an inhalation dose perspective (Applications, Chapter 8).

\section{SUMMARY OF FINDINGS AND UNIQUE CONTRIBUTIONS}

The following list summarizes the main findings of each chapter of this dissertation.

1) Literature review

a) Existing literature focuses on modal comparisons and lacks analysis of intramodal covariates for exposure and uptake.

b) Exposure differences on high-traffic vs. low-traffic routes vary with pollutant, from $0 \%$ for $\mathrm{PM}_{10}$ to $100 \%$ for $\mathrm{VOC}$.

c) On-road ventilation is rarely studied with exposure; typically bicyclist ventilation rates are 2-5 times higher than those of motorists.

d) Uptake doses and health outcomes for bicyclists are poorly understood.

2) Data overview

a) On-road ambient concentrations of aromatic hydrocarbons were highly correlated among compounds.

\footnotetext{
${ }^{1}$ Air pollution exposure during commuting was seen as a health risk by $45 \%$ of respondents, with no significant differences by mode. Air pollution was only seen as a barrier to walking and biking for $13 \%$ of respondents (much smaller than the results for infrastructure barriers).
} 
b) Ambient concentrations of BTEX compounds were 50-120\% higher on major arterials than local roads; breath concentrations were $10-60 \%$ higher.

c) Ambient concentrations on off-street paths were very high in locations coincident with near-path industrial land use, and low elsewhere.

d) Significant concentration reductions were measured for minor, one-block detours to parallel low-volume facilities.

3) Exposure concentrations

a) BTEX and CO exposure concentrations increased 1.4-3.5\% per 1,000 ADT.

b) BTEX exposure during a ride increased by 19-33\% in stop-and-go riding conditions (during a stop, start from a stop, and low-speed riding).

c) BTEX exposure concentrations increased with temperature and decreased with wind speed; on-road exposure had an elasticity to background concentrations of 0.7 .

4) Ventilation and workload

a) On-road ventilation measurement using a chest strap was validated by ventilation $\sim$ heart rate relationships: $\ln \dot{V}_{E} \sim H R$ slopes of 0.02 .

b) The on-road ventilation response to workload was a $0.4-0.8 \%$ increase in $\dot{V}_{E}$ per W (lower than ergometer testing for the same subjects).

c) Ventilation lagged workload with a mean lag of $0.8 \mathrm{~min}$.

d) Average workload was $126 \mathrm{~W}$; average MET was 7.0.

e) Of on-road energy losses, $47 \%$ was due to braking and $44 \%$ was due to aerodynamic drag. 
5) Uptake and breath concentrations

a) Four to eight monoaromatic hydrocarbons are feasible exposure biomarkers in transportation microenvironments.

b) Breath/ambient concentration ratios for BTEX compounds were 0.2-0.5.

c) Breath concentrations were significantly associated with exposure; breath elasticity to exposure concentrations for BTEX compounds was 0.4-0.5, consistent among subjects.

d) Roadway, travel, and weather variables explained about $1 / 3^{\text {rd }}$ of the variance in BTEX breath concentrations.

e) Breath concentrations were lower with higher concentration variability on a segment.

f) Ventilation had only a minor influence on breath concentrations.

6) Applications and implications

a) The minimum-ventilation speed is around $17 \mathrm{kph}$ at $0 \%$ grade, decreasing by about $2 \mathrm{kph}$ per $1 \%$ higher grade.

b) The inhalation dose effect of a stop on a route increases nonlinearly with cruising speed.

c) Detouring to a parallel, low-volume route will usually reduce total trip inhalation dose, despite longer exposure duration.

d) The preferences of bicyclists to use bicycle boulevards rather than arterials with bicycle lanes is weaker than would be optimal from an inhalation dose perspective. 
e) Uptake of particulate matter is more sensitive to speed, grade, and other determinants of workload than uptake of VOC (which is less affected by ventilation).

In addition to the findings above, this dissertation is notable for several unique contributions. The reported ambient concentrations are the first VOC exposure measurements for bicyclists in the U.S., and the first quantification of VOC exposure by facility type. This research is the first application of breath sampling to measure VOC uptake by travelers of any mode, with higher exposure variability and shorter time scales than previous breath biomarker studies. The breath analysis is the first use of uptake indicators of any pollutant to look at roadway-level covariates. The ventilation analysis is the first to investigate on-road determinants of ventilation rates for bicyclists, and the first to use a non-invasive method of measuring breath (chest strap physiology monitor) that does not obstruct uptake doses for subjects.

Important new quantifications coming from this research include the on-road ventilation $\sim$ workload relationship for bicyclists, a simplified, two-parameter model of on-road workload, the exposure concentration response to ADT, and the elasticity of breath concentrations to exposure concentrations of VOC. Important new findings include the lagged workload-> heart rate -> ventilation relationship and the limited role of ventilation rate in uptake of VOC.

\section{TRANSFERABILITY OF FINDINGS}

Some findings of the research presented in this dissertation are context-specific, while others are more broadly applicable. Where possible, results have been compared 
with empirical and theoretical values in the literature to provide outside validation. As discussed in Chapter 6, the energy expenditure, ventilation, and physiology of bicyclists in this study are consistent with past research on utilitarian, amateur bicyclists. Findings related to these attributes are expected to transfer well to most populations, although trained athletes, children, and adults with respiratory problems will likely have different physiology characteristics and/or energy expenditure patterns (McArdle et al. 2010).

As discussed in Chapter 2, exposure concentrations are highly context-specific. The measured exposure concentrations in this study agree well with recently-reported near-road concentrations in the U.S., Canada, and Western Europe (see Chapter 4), but these concentrations will likely only be relevant for cities in developed countries with similar vehicle fleets. Extrapolation of exposure concentrations to other U.S. and Canadian cities is reasonable for perhaps a decade, and might also be possible to cities in other OECD countries and longer time scales. But developing-world cities will likely have vastly different exposure concentrations, as will Portland in 40 years.

The relative contribution of traffic and facility type to on-road exposure can vary by location and pollutant. A higher fraction of non-traffic (e.g. industrial) pollution sources in a city will reduce the relative importance of roadway facility type on exposure and increase the influence of surrounding land use, background concentrations, and possibly weather. In much larger cities, background concentrations are likely to be higher, but traffic volumes on arterials are likely higher as well. Thus, relative exposure on "high-traffic" and "low-traffic" routes might be similar, although the absolute concentrations change. In terms of different VOCs, smaller roadway effects on exposure 
to alkanes and aldehydes can be expected than the effects on exposure to aromatics explored in this dissertation (alkanes and aldehydes tend to be more disperse). CO and UFP are expected to be highly concentrated around roadways, whereas larger PM is more disperse (see Chapter 5).

The uptake relationships explored in Chapter 7 are expected to be broadly applicable. Breath/ambient air concentration ratios and breath elasticity to exposure was consistent among participants in this study, as well as with past research (despite past breath sampling involving orders of magnitude higher exposure concentrations and longer exposure times). Thus, we expect the models developed here to estimate VOC uptake as a function of exposure and ventilation to apply to active travelers in any city. Breath biomarkers are also expected to be useful for studying BTEX uptake in a wide variety of contexts. Portland is a relatively low-concentration city, and yet breath biomarkers were shown to indicate internal dose. In cities with higher on-road exposure, the uptake signal/noise ratio in breath samples will be even higher, and so less statistical uncertainty would be expected. Unfortunately, the issues that make breath biomarkers unsuitable for measuring uptake of certain compounds (endogenous production, high water solubility, co-elution with water, high background concentrations) will also likely apply in other cities.

\section{BROADER HEALTH EFFECTS OF BICYCLING}

This dissertation focused on the health risk of bicycling caused by traffic-related air pollution. In order to offer some context for that risk, this section provides a 
comparison with two other known health impacts of bicycling: crashes and physical activity.

Utilitarian bicycle travel can help people meet weekly physical activity goals, with large potential public health benefits (Dill 2009, Oja et al. 2011). However, the state of knowledge about active transportation's health effects through increased physical activity is still limited (Wanner et al. 2012). Much like intake doses, the health benefits of physical activity are affected by both the intensity and duration of the exercise event. Schnohr et al. (2012) found that cycling intensity is more important than duration for reducing coronary heart disease mortality.

Crash risks, like pollution risks, can be mitigated by intelligent infrastructure and facility design (Reynolds et al. 2009, Teschke, Harris, et al. 2012, Winters et al. 2013). In fact, the same principle of separation from motor vehicles that can reduce pollution exposure concentrations on certain facility types (cycle tracks, for example), could also reduce crash risks for the same reason (Lusk et al. 2011, Winters et al. 2013).

Several health impact studies have attempted to assess the cumulative net health benefits of increases in bicycling from changes in physical activity, air pollution uptake, and crashes, both for the travelers making the switch to bicycling and for society at large. Teschke et al. (2012) provides a review of five recent net health benefit studies that assess all three factors (Woodcock et al. 2009, de Hartog et al. 2010, Rojas-Rueda et al. 2011, Grabow et al. 2012, Rabl and de Nazelle 2012). Teschke et al. conclude that while there is good evidence for the physical and mental health benefits of physical activity, the pollution and safety effects are less clear. Bicycling can have higher injury and fatality 
risks per-trip and per-mile, but that effect could be offset by a "safety-in-numbers" effect which would reduce crash rates. While increases in pollution inhalation are expected due to greater ventilation, general emissions levels could decline and route choice is a powerful intervening factor.

The five studies of net health effects discussed in Teschke et al. (1 from North America and 4 from Europe) all conclude that the physical activity benefits of bicycling far outweigh the safety and pollution risks (by factors of 9 to 96). However, there are still many methodological challenges and largely neglected factors (such as climate change and congestion). Teschke et al. also point out that the health benefits could be achievable while mitigating the risks, such as with more separated bicycle infrastructure. The observations of Teschke et al. are largely supported by de Nazelle et al. (2011). A more recent study of bicycle-promotion policies found similarly dramatic net benefits of an increase in commuter bicycling (Macmillan et al. 2014). It is also worth noting that both Rojas-Rueda et al. (2012) and Rabl and de Nazelle (2012) predict health benefits for society at large due to reduced urban air pollution concentrations following a mode shift toward bicycling - despite greater health risks from air pollution exposure for the bicyclists. But the claim of improved air quality needs more justification that the increased bicycle usage will be replacing motor vehicle use (Teschke, Reynolds, et al. 2012).

Int Panis (2011) submitted a commentary on the health impact analysis by de Hartog et al. (2010) (with a response by de Hartog) that points out some of the methodological challenges to estimating the net health effects of bicycling. Of particular 
relevance to this dissertation, Int Panis points out that intake is sensitive to the assumed bicycling speed (which is not well established for commuters), that epidemiologicallyderived dose-response functions are imperfectly matched with inhalation estimates for short-duration high-intensity exposures, and that estimated pollution uptake effects could be tempered by opportunities for route selection and by the possibility that bicyclists are a less-susceptible population.

Finally, it can be noted that obesity is trending up, while air pollutant concentrations are trending down. The net effect being that the health benefits of bicycling (through physical activity) are becoming more valuable, while the health risks of bicycling (through pollution uptake) are becoming less dangerous. One potentially complicating factor is interactions between obesity levels and susceptibility to health effects from air toxics (Dong et al. 2013). In sum, air pollution risks for bicyclists are a health concern, but not one that should discourage the use of bicycles for transportation and exercise.

\section{LIMITATIONS}

This section summarizes the main limitations of the research in this dissertation. Several types of secondary data which could have improved models of exposure were not readily available, including the fraction of ADT that is heavy vehicles (trucks and buses) for each link in the network, real-time traffic data on each link in the network (as opposed to static traffic data and real-time data from a single corridor), and near-road land use (including explicit data on point and area sources of air pollutants). 
Other data were estimated or roughly quantified, and some uncertainty is likely due to error in these values. Aerodynamic drag and rolling resistance coefficients for the bicyclists (which are difficult to measure) were assumed from the literature, with sensitivity analysis presented in Chapter 6. Road grade data were calculated from LIDAR-based digital elevation maps which provided poor estimates near elevated roadway structures. Grades were filtered for unrealistic values and smoothed with a moving average, but a GIS inventory of true roadway grades would likely have improved the workload estimates and ventilation models. Workload in this research was estimated from well-validated physical models, but directly-measured workload might also have improved the ventilation models. Lastly, the link ADT data were based on interpolation from traffic counts that could have been up to 13 years old. Although a validity check showed good agreement with more recent counts (see Chapter 3), the ADT data might not have been a good indicator of traffic volumes during data collection.

Some assumptions also should be noted as limitations. Street-level wind was ignored, and so varying aerodynamic drag (an important determinant of workload) was based on speed only. Internal doses were not directly measured (i.e. through blood draws), and so the methodology relies on the science of breath analysis to support the assertion that exhaled breath concentrations are a good proxy for blood concentrations (though the use of breath biomarkers is also supported by measured relationships with exposure).

Lastly, we recall some limitations on the scope of the research. The research went as far along the emissions-health pathway as uptake (see Chapter 1). Health effects 
biomarkers were not measured and health outcomes were not modeled. Land-use regression was also beyond the scope of study: exposure was modeled primarily using roadway, traffic, and weather variables. The natural laboratory of Portland presented some limitations on the range of facilities which could be studied; for example, the largest arterial facility had around 40,000 ADT. Lastly, in order to prioritize environmental and travel covariates, only three healthy adult subjects participated in the research, which limited the range of physiological characteristics among the participants.

\section{FUTURE RESEARCH}

These conclusions conclude with some prime topics for future research. This is one of only three studies that have measured bicyclist pollution uptake. Clearly, more measurements of pollution uptake in various settings would improve understanding of on-road pollution risks. This study has shown that breath analysis is a feasible method of studying travelers' uptake of VOC. Sampling of induced sputum (as in Nwokoro et al. (2012)) could be used to measure differences in bicyclist uptake of BC at the facility level. A study including both induced sputum and breath samples could prove the divergence of PM and VOC uptake doses with physical exertion.

In order to apply the findings of this research to the broader bicycling population, more information is needed about the physical and physiological characteristics of urban bicyclists. Data on mass, $C_{R}$, and $C_{D}^{\prime}$ parameters could be collected with intercept surveys and simplified on-road testing methods such as described by Candau et al. (1999). Although several bicycle route choice models have been developed in recent years, little information is available about speed and acceleration choices of urban bicyclists - 
especially speed choices tied to personal, route, and trip characteristics. There was some evidence of speed dependence on ADT in the study data, which should be studied in a more representative data set because it would lead to positive correlation between workload/ventilation and exposure. Another unknown relationship is the speed adjustment to grade by utilitarian bicyclists.

More ubiquitous pollution exposure data would help inform bicyclist route choice decisions and bicycle network planning. High-precision exposure measurements are expensive, but new low-cost technologies provide low-precision alternatives which could be combined with high-precision measurements to created detailed urban on-road pollution maps ${ }^{2}$. Finally, in order to compare pollution exposure risks among toxicants and with other health effects such as crashes and physical activity, quantitative doseresponse relationships are needed that pertain to commuting exposures. Biomarker studies have found some acute impacts of pollution exposure during commuting, and long-term epidemiology studies have quantified the expected health outcomes of changes in annual average $\mathrm{PM}_{2.5}$ and $\mathrm{PM}_{10}$ concentrations, but researchers' current ability to translate daily commuting dose estimates into health outcomes (e.g. mortality, mobility) is severely limited.

\footnotetext{
${ }^{2}$ The Portland ACE/SPEC is one effort to use new technology to "crowd-source" pollution exposure data (Bigazzi 2013) - see www.alexbigazzi/Spec/.
} 


\section{References}

AASHTO, 2012. Guide for the Development of Bicycle Facilities. 4th ed. Washington, D.C.: American Assoication of State Highway and Transportation Officials.

Adams, H.S., Nieuwenhuijsen, M.J., and Colvile, R.N., 2001. Determinants of fine particle (PM2. 5) personal exposure levels in transport microenvironments, London, UK. Atmospheric Environment, 35 (27), 4557-4566.

Adams, H.S., Nieuwenhuijsen, M.J., Colvile, R.N., McMullen, M.A.S., and Khandelwal, P., 2001. Fine particle (PM2. 5) personal exposure levels in transport microenvironments, London, UK. Science of the Total Environment, The, 279 (13), 29-44.

Adams, H.S., Nieuwenhuijsen, M.J., Colvile, R.N., Older, M.J., and Kendall, M., 2002. Assessment of road users' elemental carbon personal exposure levels, London, UK. Atmospheric Environment, 36 (34), 5335-5342.

Adams, W.C., 1993. Measurement of breathing rate and volume in routinely performed daily activities. U.S. Environmental Protection Agency.

Ainsworth, B.E., Haskell, W.L., Herrmann, S.D., Meckes, N., Bassett, D.R., TudorLocke, C., Greer, J.L., Vezina, J., Whitt-Glover, M.C., and Leon, A.S., 2011a. The Compendium of Physical Activities Tracking Guide [online]. Healthy Lifestyles Research Center, College of Nursing \& Health Innovation, Arizona State University. Available from:

https://sites.google.com/site/compendiumofphysicalactivities/home [Accessed 11 Jun 2013].

Ainsworth, B.E., Haskell, W.L., Herrmann, S.D., Meckes, N., Bassett, D.R., TudorLocke, C., Greer, J.L., Vezina, J., Whitt-Glover, M.C., and Leon, A.S., 2011 b. 2011 compendium of physical activities: a second update of codes and MET values. Medicine and Science in Sports and Exercise, 43 (8), 1575-1581.

Amorim, L.C.A. and de L. Cardeal, Z., 2007. Breath air analysis and its use as a biomarker in biological monitoring of occupational and environmental exposure to chemical agents. Journal of Chromatography B, 853 (1-2), 1-9.

Andersen L, S.P., 2000. ALl-cause mortality associated with physical activity during leisure time, work, sports, and cycling to work. Archives of Internal Medicine, 160 (11), 1621-1628.

Anderson, J.C., Babb, A.L., and Hlastala, M.P., 2003. Modeling Soluble Gas Exchange in the Airways and Alveoli. Annals of Biomedical Engineering, 31 (11), 14021422.

Andreae, M.O. and Gelencsér, A., 2006. Black carbon or brown carbon? The nature of light-absorbing carbonaceous aerosols. Atmos. Chem. Phys., 6 (10), 3131-3148. 
Andrews, D.W., 1991. Heteroskedasticity and autocorrelation consistent covariance matrix estimation. Econometrica: Journal of the Econometric Society, 817-858.

Andrews, D.W. and Monahan, J.C., 1992. An improved heteroskedasticity and autocorrelation consistent covariance matrix estimator. Econometrica: Journal of the Econometric Society, 953-966.

Astrand, I., 1975. Uptake of solvents in the blood and tissues of man. A review. Scand $j$ work environ health, 1 (4), 199-218.

Astrand, I., 1985. Uptake of Solvents from the Lungs. British Journal of Industrial Medicine, 42 (4), 217-218.

Astrand, I., Engstrom, J., and Ovrum, P., 1978. Exposure to xylene and ethylbenzene: I. Uptake, distribution and elimination in man. Stand J Work Environ Health, 4, 185-194.

Atabi, F., Moattar, F., Mansouri, N., Alesheikh, A.A., and Mirzahosseini, S.A.H., 2013. Assessment of variations in benzene concentration produced from vehicles and gas stations in Tehran using GIS. International Journal of Environmental Science and Technology, 10 (2), 283-294.

Atkinson, R., 2000. Atmospheric chemistry of VOCs and NOx. Atmospheric Environment, 34 (12-14), 2063-2101.

Baba, R., Nagashima, M., Goto, M., Nagano, Y., Yokota, M., Tauchi, N., and Nishibata, K., 1996. Oxygen uptake efficiency slope: A new index of cardiorespiratory functional reserve derived from the relation between oxygen uptake and minute ventilation during incremental exercise. Journal of the American College of Cardiology, 28 (6), 1567-1572.

Badland, H.M. and Duncan, M.J., 2009. Perceptions of air pollution during the workrelated commute by adults in Queensland, Australia. Atmospheric Environment, 43 (36), 5791-5795.

Batterman, S.A., Peng, C.-Y., and Braun, J., 2002. Levels and composition of volatile organic compounds on commuting routes in Detroit, Michigan. Atmospheric Environment, 36 (39-40), 6015-6030.

Bean, T., Carslaw, N., Ashmore, M., Gillah, A., and Parkinson, C., 2011. How does exposure to nitrogen dioxide compare between on-road and off-road cycle routes? Journal of Environmental Monitoring, 13 (4), 1039.

Beckerman, B., Jerrett, M., Brook, J.R., Verma, D.K., Arain, M.A., and Finkelstein, M.M., 2008. Correlation of nitrogen dioxide with other traffic pollutants near a major expressway. Atmospheric Environment, 42 (2), 275-290.

Beliveau, M. and Krishnan, K., 2000. Concentration Dependency of Rat Blood:air Partition Coefficients of Some Volatile Organic Chemicals. Journal of Toxicology and Environmental Health, Part A, 60 (6), 377-389. 
Bell, M., 2012. Assessment of the health impacts of particulate matter characteristics. Boston, MA: Health Effects Institute, Research Report No. 161.

Bergamaschi, E., Brustolin, A., De Palma, G., Manini, P., Mozzoni, P., Andreoli, R., Cavazzini, S., and Mutti, A., 1999. Biomarkers of dose and susceptibility in cyclists exposed to monoaromatic hydrocarbons. Toxicology Letters, 108 (2-3), 241-247.

Berghmans, P., Bleux, N., Int Panis, L., Mishra, V.K., Torfs, R., and Van Poppel, M., 2009. Exposure assessment of a cyclist to PM10 and ultrafine particles. Science of The Total Environment, 407 (4), 1286-1298.

Bernmark, E., Wiktorin, C., Svartengren, M., Lewné, M., and Åberg, S., 2006. Bicycle messengers: energy expenditure and exposure to air pollution. Ergonomics, 49 (14), 1486-1495.

Bevan, M.A.J., Proctor, C.J., Baker-Rogers, J., and Warren, N.D., 1991. Exposure to carbon monoxide, respirable suspended particulates and volatile organic compounds while commuting by bicycle. Environmental Science \& Technology, 25 (4), 788-791.

Bigazzi, A., Van Lint, J.W.C., Klunder, G., Stelwagen, U., and Ligterink, N., 2010. Traffic data for local emissions monitoring at a signalized intersection. In: Intelligent Transportation Systems (ITSC), 2010 13th International IEEE Conference on. Presented at the Intelligent Transportation Systems (ITSC), 2010 13th International IEEE Conference on, 210-215.

Bigazzi, A.Y., 2013. The Portland ACE Documentation: a Portable, Low-cost, and Networked Device for Assessing Cyclists' Exposure.

Bigazzi, A.Y. and Figliozzi, M.A., 2014. Review of Urban Bicyclists' Intake and Uptake of Traffic-Related Air Pollution. Transport Reviews, 34 (2), 221-245.

Boogaard, H., Borgman, F., Kamminga, J., and Hoek, G., 2009. Exposure to ultrafine and fine particles and noise during cycling and driving in 11 Dutch cities. Atmospheric Environment, 43 (27), 4234-4242.

Boots, A.W., van Berkel, J.J.B.N., Dallinga, J.W., Smolinska, A., Wouters, E.F., and van Schooten, F.J., 2012. The versatile use of exhaled volatile organic compounds in human health and disease. Journal of Breath Research, 6 (2), 027108.

Bos, I., Jacobs, L., Nawrot, T.S., de Geus, B., Torfs, R., Int Panis, L., Degraeuwe, B., and Meeusen, R., 2011. No exercise-induced increase in serum BDNF after cycling near a major traffic road. Neuroscience Letters, 500 (2), 129-132.

Broach, J., Dill, J., and Gliebe, J., 2012. Where do cyclists ride? A route choice model developed with revealed preference GPS data. Transportation Research Part A: Policy and Practice, 46 (10), 1730-1740.

Brook, R.D., Rajagopalan, S., Pope, C.A., Brook, J.R., Bhatnagar, A., Diez-Roux, A.V., Holguin, F., Hong, Y., Luepker, R.V., Mittleman, M.A., Peters, A., Siscovick, D., 
Smith, S.C., Whitsel, L., and Kaufman, J.D., 2010. Particulate Matter Air Pollution and Cardiovascular Disease An Update to the Scientific Statement From the American Heart Association. Circulation, 121 (21), 2331-2378.

Brown, S.G., Frankel, A., and Hafner, H.R., 2007. Source apportionment of VOCs in the Los Angeles area using positive matrix factorization. Atmospheric Environment, 41 (2), 227-237.

Brugge, D., Durant, J., and Rioux, C., 2007. Near-highway pollutants in motor vehicle exhaust: A review of epidemiologic evidence of cardiac and pulmonary health risks. Environmental Health, 6, 23-34.

Brugnone, F., Perbellini, L., Faccini, G.B., Pasini, F., Maranelli, G., Romeo, L., Gobbi, M., and Zedde, A., 1989. Breath and blood levels of benzene, toluene, cumene and styrene in non-occupational exposure. International Archives of Occupational and Environmental Health, 61 (5), 303-311.

Burnett, R.T., Cakmak, S., Raizenne, M.E., Stieb, D., Vincent, R., Krewski, D., Brook, J.R., Philips, O., and Ozkaynak, H., 1998. The Association between Ambient Carbon Monoxide Levels and Daily Mortality in Toronto, Canada. Journal of the Air \& Waste Management Association, 48 (8), 689-700.

Candau, R.B., Grappe, F., Menard, M., Barbier, B., Millet, G.Y., Hoffman, M.D., Belli, A.R., and Rouillon, J.D., 1999. Simplified deceleration method for assessment of resistive forces in cycling. Medicine \& Science in Sports \& Exercise, 31 (10), 1441.

Carlsson, A., 1982. Exposure to toluene: uptake, distribution and elimination in man. Scandinavian journal of work, environment \& health, 8 (1), 43.

Carslaw, D.C. and Beevers, S.D., 2005. Estimations of road vehicle primary NO2 exhaust emission fractions using monitoring data in London. Atmospheric Environment, 39 (1), 167-177.

Chalupa, D.C., Morrow, P.E., Oberdorster, G., Utell, M.J., and Frampton, M.W., 2004. Ultrafine particle deposition in subjects with asthma. Environmental Health Perspectives, 112 (8), 879-882.

Chan, L.Y., Hung, W.T., and Qin, Y., 1994. Vehicular emission exposure of bicycle commuters in the urban area of Guangzhou, South China (PRC). Environment International, 20 (2), 169-177.

Chertok, M., Voukelatos, A., Sheppeard, V., and Rissel, C., 2004. Comparison of air pollution exposure for five commuting modes in Sydney - car, train, bus, bicycle and walking. Health Promotion Journal of Australia, 15 (1), 63-67.

Chien, Y.-C., 2007. Variations in amounts and potential sources of volatile organic chemicals in new cars. Science of the total environment, 382 (2), 228-239.

Cho, S.-H., Tong, H., McGee, J.K., Baldauf, R.W., Krantz, Q.T., and Gilmour, M.I., 2009. Comparative toxicity of size-fractionated airborne particulate matter 
collected at different distances from an urban highway. Environmental health perspectives, 117 (11), 1682-1689.

City of Portland, 2010. Portland Bicycle Plan for 2030. Portland, Oregon: Bureau of Transportation.

City of Portland and Multnomah County, 2009. Climate Action Plan 2009. Portland, Oregon: Bureau of Planning and Sustainability.

Clements, A.L., Jia, Y., Denbleyker, A., McDonald-Buller, E., Fraser, M.P., Allen, D.T., Collins, D.R., Michel, E., Pudota, J., Sullivan, D., and Zhu, Y., 2009. Air pollutant concentrations near three Texas roadways, part II: Chemical characterization and transformation of pollutants. Atmospheric Environment, 43 (30), 4523-4534.

Clifford, M.J., Clarke, R., and Riffat, S.B., 1997. Local aspects of vehicular pollution. Atmospheric Environment, 31 (2), 271-276.

Cole-Hunter, T., Morawska, L., Stewart, I., Hadaway, M., Jayaratne, R., and Solomon, C., 2013. Utility of an alternative bicycle commute route of lower proximity to motorised traffic in decreasing exposure to ultra-fine particles, respiratory symptoms and airway inflammation -- a structured exposure experiment. Environmental Health, 12 (1).

Cole-Hunter, T., Morawska, L., Stewart, I., Jayaratne, R., and Solomon, C., 2012. Inhaled particle counts on bicycle commute routes of low and high proximity to motorised traffic. Atmospheric Environment, 61.

Colucci, A.V., 1982. Comparison of the dose/effect relationship between N02 and other pollutants. In: Air Pollution by Nitrogen Oxides. Amsterdam: Elsevier Scientific Publishing, 427-440.

Costello, B. de L., Amann, A., Al-Kateb, H., Flynn, C., Filipiak, W., Khalid, T., Osborne, D., and Ratcliffe, N.M., 2014. A review of the volatiles from the healthy human body. Journal of Breath Research, 8 (1), 014001.

CROW, 2007. Design manual for bicycle traffic. The Netherlands.

Csanády, G.A. and Filser, J.G., 2001. The relevance of physical activity for the kinetics of inhaled gaseous substances. Archives of Toxicology, 74 (11), 663-672.

Daigle, C.C., Chalupa, D.C., Gibb, F.R., Morrow, P.E., Oberdörster, G., Utell, M.J., and Frampton, M.W., 2003. Ultrafine particle deposition in humans during rest and exercise. Inhalation Toxicology, 15 (6), 539-552.

deCastro, B.R., Wang, L., Mihalic, J.N., Breysse, P.N., Geyh, A.S., and Buckley, T.J., 2008. The Longitudinal Dependence of Black Carbon Concentration on Traffic Volume in an Urban Environment. Journal of the Air \& Waste Management Association, 58 (7), 928-939. 
Dekoninck, L., Botteldooren, D., and Int Panis, L., 2013. An instantaneous spatiotemporal model to predict a bicyclist's Black Carbon exposure based on mobile noise measurements. Atmospheric Environment, 79, 623-631.

Department for Transport, 2013. Briefing on the Government's ambition for cycling. London, UK: Department for Transport.

Dill, J., 2009. Bicycling for Transportation and Health: The Role of Infrastructure. Journal of Public Health Policy, 30, S95-S110.

Dill, J. and Carr, T., 2003. Bicycle Commuting and Facilities in Major U.S. Cities: If You Build Them, Commuters Will Use Them. Transportation Research Record: Journal of the Transportation Research Board, 1828 (-1), 116-123.

Dirks, K.N., Sharma, P., Salmond, J.A., and Costello, S.B., 2012. Personal Exposure to Air Pollution for Various Modes of Transport in Auckland, New Zealand. Open Atmospheric Science Journal, 6 (1), 84-92.

Do, D.H., Van Langenhove, H., Chigbo, S.I., Amare, A.N., Demeestere, K., and Walgraeve, C., 2014. Exposure to volatile organic compounds: Comparison among different transportation modes. Atmospheric Environment, 94, 53-62.

Dong, G.H., Qian, Z., Liu, M.-M., Wang, D., Ren, W.-H., Fu, Q., Wang, J., Simckes, M., Ferguson, T.F., and Trevathan, E., 2013. Obesity enhanced respiratory health effects of ambient air pollution in Chinese children: the Seven Northeastern Cities study. International Journal of Obesity, 37 (1), 94-100.

Dons, E., Int Panis, L., Van Poppel, M., Theunis, J., and Wets, G., 2012. Personal exposure to Black Carbon in transport microenvironments. Atmospheric Environment, 55, 392-398.

Dons, E., Temmerman, P., Van Poppel, M., Bellemans, T., Wets, G., and Int Panis, L., 2013. Street characteristics and traffic factors determining road users' exposure to black carbon. Science of The Total Environment, 447, 72-79.

Edwards, R.H., Denison, D.M., Jones, G., Davies, C.M., and Campbell, E.M., 1972. Changes in mixed venous gas tensions at start of exercise in man. J. appl. Physiol, 32 (2), 165-169.

Egeghy, P.P., Hauf-Cabalo, L., Gibson, R., and Rappaport, S.M., 2003. Benzene and naphthalene in air and breath as indicators of exposure to jet fuel. Occupational and Environmental Medicine, 60 (12), 969-976.

Egeghy, P.P., Nylander-French, L., Gwin, K.K., Hertz-Picciotto, I., and Rappaport, S.M., 2002. Self-collected Breath Sampling for Monitoring Low-level Benzene Exposures among Automobile Mechanics. Annals of Occupational Hygiene, 46 (5), 489-500.

Elen, B., Peters, J., Poppel, M., Bleux, N., Theunis, J., Reggente, M., and Standaert, A., 2013. The Aeroflex: A Bicycle for Mobile Air Quality Measurements. Sensors, 13 (1), 221-240. 
El-Fadel, M. and Abi-Esber, L., 2009. In-vehicle Exposure to Carbon Monoxide Emissions from Vehicular Exhaust: A Critical Review. Critical Reviews in Environmental Science and Technology, 39 (8), 585-621.

Fajardo, O.A. and Rojas, N.Y., 2012. Particulate matter exposure of bicycle path users in a high-altitude city. Atmospheric Environment, 46 (0), 675-679.

Farhi, L.E., 1967. Elimination of inert gas by the lung. Respiration Physiology, 3 (1), 111.

Faria, E.W., Parker, D.L., and Faria, I.E., 2005a. The science of cycling: physiology and training-part 1. Sports Medicine, 35 (4), 285-312.

Faria, E.W., Parker, D.L., and Faria, I.E., 2005b. The science of cycling: factors affecting performance-part 2. Sports Medicine, 35 (4), 313-337.

Farrar, D., Dingle, P., and Tan, R., 2001. Exposure to Nitrogen Dioxide in Buses, Taxis, and Bicycles in Perth, Western Australia. Bulletin of Environmental Contamination and Toxicology, 66 (4), 433-438.

Figliozzi, M., Wheeler, N., and Monsere, C.M., 2013. Methodology for estimating bicyclist acceleration and speed distributions at intersections. Transportation Research Record: Journal of the Transportation Research Board, 2387 (1), 6675.

Filipiak, W., Ruzsanyi, V., Mochalski, P., Filipiak, A., Bajtarevic, A., Ager, C., Denz, H., Hilbe, W., Jamnig, H., Hackl, M., Dzien, A., and Amann, A., 2012. Dependence of exhaled breath composition on exogenous factors, smoking habits and exposure to air pollutants. Journal of Breath Research, 6 (3), 036008.

Filley, G.F., MacIntosh, D.J., and Wright, G.W., 1954. Carbon Monoxide Uptake and Pulmonary Diffusing Capacity in Subjects at Rest and During Exercise. Journal of Clinical Investigation, 33 (4), 530-539.

Forastiere, F. and Agabiti, N., 2013. Assessing the link between air pollution and heart failure. The Lancet.

Fruin, S.A., Westerdahl, D., Sax, T., Sioutas, C., and Fine, P.M., 2008. Measurements and predictors of on-road ultrafine particle concentrations and associated pollutants in Los Angeles. Atmospheric Environment, 42 (2), 207-219.

Fujita, E.M., Campbell, D.E., Zielinska, B., Arnott, W.P., and Chow, J.C., 2011. Concentrations of air toxics in motor vehicle-dominated environments. Research report (Health Effects Institute), (156), 3-77.

Gee, I.L. and Raper, D.W., 1999. Commuter exposure to respirable particles inside buses and by bicycle. Science of The Total Environment, 235 (1-3), 403-405.

Gertler, A.W., Fujita, E.M., Pierson, W.R., and Wittorff, D.N., 1996. Apportionment of NMHC tailpipe vs non-tailpipe emissions in the Fort McHenry and Tuscarora mountain tunnels. Atmospheric Environment, 30 (12), 2297-2305. 
De Geus, B., de Smet, S., Nijs, J., and Meeusen, R., 2007. Determining the intensity and energy expenditure during commuter cycling. British Journal of Sports Medicine, 41 (1), 8-12.

Gimenes, A.C., Neder, J.A., Dal Corso, S., Nogueira, C.R., Nápolis, L., Mello, M.T., Bulle, A.S., and Nery, L.E., 2011. Relationship between work rate and oxygen uptake in mitochondrial myopathy during ramp-incremental exercise. Brazilian Journal of Medical and Biological Research, 44 (4), 354-360.

Glass, S., Dwyer, G.B., and American College of Sports Medicine, 2007. ACSM's Metabolic Calculations Handbook. Lippincott Williams \& Wilkins.

González-Haro, C., Ballarini, P.A.G., Soria, M., Drobnic, F., and Escanero, J.F., 2007. Comparison of nine theoretical models for estimating the mechanical power output in cycling. British Journal of Sports Medicine, 41 (8), 506-509.

Gordon, M., Staebler, R.M., Liggio, J., Li, S.-M., Wentzell, J., Lu, G., Lee, P., and Brook, J.R., 2012. Measured and modeled variation in pollutant concentration near roadways. Atmospheric Environment, 57 (0), 138-145.

Gotschi, T., 2011. Costs and benefits of bicycling investments in Portland, Oregon. Journal of Physical Activity and Health, 8 (1), S49-S58.

Grabow, M.L., Spak, S.N., Holloway, T., Stone, B., Mednick, A.C., and Patz, J.A., 2012. Air Quality and Exercise-Related Health Benefits from Reduced Car Travel in the Midwestern United States. Environmental Health Perspectives, 120 (1), 68-76.

Grange, S.K., Dirks, K.N., Costello, S.B., and Salmond, J.A., 2014. Cycleways and footpaths: What separation is needed for equivalent air pollution dose between travel modes? Transportation Research Part D: Transport and Environment, 32, 111-119.

Gulliver, J. and Briggs, D.J., 2004. Personal exposure to particulate air pollution in transport microenvironments. Atmospheric Environment, 38 (1), 1-8.

Gunatilaka, A., Skvortsov, A., and Gailis, R., 2014. A review of toxicity models for realistic atmospheric applications. Atmospheric Environment, 84, 230-243.

Hall, J.V., Brajer, V., and Lurmann, F.W., 2008. Measuring the gains from improved air quality in the San Joaquin Valley. Journal of Environmental Management, 88 (4), 1003-1015.

Hamer, M. and Chida, Y., 2008. Active commuting and cardiovascular risk: A metaanalytic review. Preventive Medicine, 46 (1), 9-13.

De Hartog, J.J., Boogaard, H., Nijland, H., and Hoek, G., 2010. Do the Health Benefits of Cycling Outweigh the Risks? Environmental Health Perspectives, 118 (8), 11091116.

Hatzopoulou, M., Weichenthal, S., Barreau, G., Goldberg, M., Farrell, W., Crouse, D., and Ross, N., 2013. A web-based route planning tool to reduce cyclists' exposures 
to traffic pollution: A case study in Montreal, Canada. Environmental Research, $123,58-61$.

Hatzopoulou, M., Weichenthal, S., Dugum, H., Pickett, G., Miranda-Moreno, L., Kulka, R., Andersen, R., and Goldberg, M., 2013. The impact of traffic volume, composition, and road geometry on personal air pollution exposures among cyclists in Montreal, Canada. Journal of Exposure Science and Environmental Epidemiology, 23 (1), 46-51.

Health Effects Institute, 2010. Traffic-Related Air Pollution: A Critical Review of the Literature on Emissions, Exposure, and Health Effects. Boston, MA: Health Effects Institute, Special Report No. Special Report 17.

Heinrich-Ramm, R., Jakubowski, M., Heinzow, B., Christensen, J.M., Olsen, E., and Hertel, O., 2000. Biological monitoring for exposure to volatile organic compounds (VOCs) (IUPAC Recommendations 2000). Pure and Applied Chemistry, 72 (3), 385-436.

Hertel, O., Hvidberg, M., Ketzel, M., Storm, L., and Stausgaard, L., 2008. A proper choice of route significantly reduces air pollution exposure -- A study on bicycle and bus trips in urban streets. Science of The Total Environment, 389 (1), 58-70.

Hill, L.B. and Gooch, J., 2010. A Multi-City Investigation of Exposure to Diesel Exhaust in Multiple Commuting Modes. Boston, MA: Clean Air Task Force, CATF Special Report No. 2007-1.

Hoehner, C.M., Barlow, C.E., Allen, P., and Schootman, M., 2012. Commuting Distance, Cardiorespiratory Fitness, and Metabolic Risk. American Journal of Preventive Medicine, 42 (6), 571-578.

Hofmann, W., 2011. Modelling inhaled particle deposition in the human lung-A review. Journal of Aerosol Science, 42 (10), 693-724.

Hollenberg, M. and Tager, I.B., 2000. Oxygen uptake efficiency slope: an index of exercise performance and cardiopulmonary reserve requiring only submaximal exercise. Journal of the American College of Cardiology, 36 (1), 194-201.

Hong, E.-S. and Bae, C.-H., 2012. Exposure of Bicyclists to Air Pollution in Seattle, Washington Hybrid. Transportation Research Record: Journal of the Transportation Research Board, 2270 (-1), 59-66.

Huang, J., Deng, F., Wu, S., and Guo, X., 2012. Comparisons of personal exposure to PM2.5 and $\mathrm{CO}$ by different commuting modes in Beijing, China. Science of The Total Environment, 425, 52-59.

International Commission on Radiological Protection Task Group, 1994. Human respiratory tract model for radiological protection. Annals of the ICRP, 24 (1-3), $1-480$.

Int Panis, L., 2011. Cycling: Health Benefits and Risks. Environmental Health Perspectives, 119 (3), A114. 
Int Panis, L., de Geus, B., Vandenbulcke, G., Willems, H., Degraeuwe, B., Bleux, N., Mishra, V., Thomas, I., and Meeusen, R., 2010. Exposure to particulate matter in traffic: A comparison of cyclists and car passengers. Atmospheric Environment, 44 (19), 2263-2270.

Jacobs, L., Nawrot, T., de Geus, B., Meeusen, R., Degraeuwe, B., Bernard, A., Sughis, M., Nemery, B., and Int Panis, L., 2010. Subclinical responses in healthy cyclists briefly exposed to traffic-related air pollution: an intervention study. Environmental Health, 9 (1), 64.

Jan van Garderen, K. and Shah, C., 2002. Exact interpretation of dummy variables in semilogarithmic equations. Econometrics Journal, 5 (1), 149-159.

Jarjour, S., Jerrett, M., Westerdahl, D., Nazelle, A. de, Hanning, C., Daly, L., Lipsitt, J., and Balmes, J., 2013. Cyclist route choice, traffic-related air pollution, and lung function: a scripted exposure study. Environmental Health, 12.

Johnson, T., 2002. A Guide to Selected Algorithms, Distributions, and Databases Used in Exposure Models Developed by The Office Of Air Quality Planning and Standards. Research Triangle Park, NC: U.S. Environmental Protection Agency, Office of Research and Development, No. CR827033.

Kang, L. and Fricker, J.D., 2013. Bicyclist commuters' choice of on-street versus offstreet route segments. Transportation.

Kansal, A., 2009. Sources and reactivity of NMHCs and VOCs in the atmosphere: A review. Journal of Hazardous Materials, 166 (1), 17-26.

Karner, A.A., Eisinger, D.S., and Niemeier, D.A., 2010. Near-Roadway Air Quality: Synthesizing the Findings from Real-World Data. Environmental Science \& Technology, 44 (14), 5334-5344.

Kaur, S., Nieuwenhuijsen, M., and Colvile, R., 2005. Personal exposure of street canyon intersection users to PM2. 5, ultrafine particle counts and carbon monoxide in Central London, UK. Atmospheric Environment, 39 (20), 3629-3641.

Kaur, S. and Nieuwenhuijsen, M.J., 2009. Determinants of Personal Exposure to PM2.5, Ultrafine Particle Counts, and CO in a Transport Microenvironment. Environmental Science \& Technology, 43 (13), 4737-4743.

Kaur, S., Nieuwenhuijsen, M.J., and Colvile, R.N., 2007. Fine particulate matter and carbon monoxide exposure concentrations in urban street transport microenvironments. Atmospheric Environment, 41 (23), 4781-4810.

Kendrick, C., Moore, A., Haire, A., Bigazzi, A., Figliozzi, M.A., Monsere, C., and George, L., 2011. Impact of Bicycle Lane Characteristics on Exposure of Bicyclists to Traffic-Related Particulate Matter. Transportation Research Record: Journal of the Transportation Research Board, 2247, 24-32.

Kim, S., Vermeulen, R., Waidyanatha, S., Johnson, B.A., Lan, Q., Smith, M.T., Zhang, L., Li, G., Shen, M., Yin, S., Rothman, N., and Rappaport, S.M., 2006. Modeling 
Human Metabolism of Benzene Following Occupational and Environmental Exposures. Cancer Epidemiology Biomarkers \& Prevention, 15 (11), 2246-2252.

Kingham, S., Longley, I., Salmond, J., Pattinson, W., and Shrestha, K., 2013. Variations in exposure to traffic pollution while travelling by different modes in a low density, less congested city. Environmental Pollution, 181, 211-218.

Kingham, S., Meaton, J., Sheard, A., and Lawrenson, O., 1998. Assessment of exposure to traffic-related fumes during the journey to work. Transportation Research Part D: Transport and Environment, 3 (4), 271-274.

King, J., Mochalski, P., Kupferthaler, A., Unterkofler, K., Koc, H., Filipiak, W., Teschl, S., Hinterhuber, H., and Amann, A., 2010. Dynamic profiles of volatile organic compounds in exhaled breath as determined by a coupled PTR-MS/GC-MS study. Physiological measurement, 31 (9), 1169-1184.

King, J., Unterkofler, K., Teschl, G., Teschl, S., Koc, H., Hinterhuber, H., and Amann, A., 2011. A mathematical model for breath gas analysis of volatile organic compounds with special emphasis on acetone. Journal of Mathematical Biology, 63 (5), 959-999.

King, J., Unterkofler, K., Teschl, G., Teschl, S., Mochalski, P., Koç, H., Hinterhuber, H., and Amann, A., 2012. A modeling-based evaluation of isothermal rebreathing for breath gas analyses of highly soluble volatile organic compounds. Journal of Breath Research, 6 (1), 016005.

Kleiner, B.C. and Spengler, J.D., 1976. Carbon Monoxide Exposures of Boston Bicyclists. Journal of the Air Pollution Control Association, 26 (2), 147-149.

Knibbs, L.D., Cole-Hunter, T., and Morawska, L., 2011. A review of commuter exposure to ultrafine particles and its health effects. Atmospheric Environment, 45 (16), 2611-2622.

Krzyzanowski, M. and Cohen, A., 2008. Update of WHO air quality guidelines. Air Quality, Atmosphere \& Health, 1 (1), 7-13.

Kumagai, S. and Matsunaga, I., 2000. A Lung Model Describing Uptake of Organic Solvents and Roles of Mucosal Blood Flow and Metabolism in the Bronchioles. Inhalation Toxicology, 12 (6), 491-510.

Van Laethem, C., Bartunek, J., Goethals, M., Nellens, P., Andries, E., and Vanderheyden, M., 2005. Oxygen uptake efficiency slope, a new submaximal parameter in evaluating exercise capacity in chronic heart failure patients. American Heart Journal, 149 (1), 175-180.

Lang, P.B., Latin, R.W., Berg, K.E., and Mellion, M.B., 1992. The accuracy of the ACSM cycle ergometry equation. Medicine and Science in Sports and Exercise, 24 (2), 272-276.

Layton, D.W., 1993. Metabolically consistent breathing rates for use in dose assessments. Health physics, 64 (1), 23-36. 
Li, T.-T., Bai, Y.-H., Liu, Z.-R., Liu, J.-F., Zhang, G.-S., and Li, J.-L., 2006. Air quality in passenger cars of the ground railway transit system in Beijing, China. Science of The Total Environment, 367 (1), 89-95.

Löndahl, J., Massling, A., Pagels, J., Swietlicki, E., Vaclavik, E., and Loft, S., 2007.

Size-Resolved Respiratory-Tract Deposition of Fine and Ultrafine Hydrophobic and Hygroscopic Aerosol Particles During Rest and Exercise. Inhalation Toxicology, 19 (2), 109-116.

Lucía, A., Carvajal, A., Calderón, F.J., Alfonso, A., and Chicharro, J.L., 1999. Breathing pattern in highly competitive cyclists during incremental exercise. European Journal of Applied Physiology and Occupational Physiology, 79 (6), 512-521.

Lusk, A.C., Furth, P.G., Morency, P., Miranda-Moreno, L.F., Willett, W.C., and Dennerlein, J.T., 2011. Risk of injury for bicycling on cycle tracks versus in the street. Injury prevention, 17 (2), 131-135.

Macmillan, A., Connor, J., Witten, K., Kearns, R., Rees, D., and Woodward, A., 2014. The Societal Costs and Benefits of Commuter Bicycling: Simulating the Effects of Specific Policies Using System Dynamics Modeling. Environmental Health Perspectives.

MacNaughton, P., Melly, S., Vallarino, J., Adamkiewicz, G., and Spengler, J.D., 2014. Impact of bicycle route type on exposure to traffic-related air pollution. Science of The Total Environment, 490, 37-43.

Martin, J.C., Milliken, D.L., Cobb, J.E., McFadden, K.L., and Coggan, A.R., 1998. Validation of a mathematical model for road cycling power. Journal of Applied Biomechanics, 14, 276-291.

McArdle, W.D., Katch, F.I., and Katch, V.L., 2010. Exercise Physiology: Nutrition, Energy, and Human Performance. Lippincott Williams \& Wilkins.

McCole, S.D., Claney, K., Conte, J.C., Anderson, R., and Hagberg, J.M., 1990. Energy expenditure during bicycling. Journal of Applied Physiology, 68 (2), 748-753.

McCreanor, J., Cullinan, P., Nieuwenhuijsen, M.J., Stewart-Evans, J., Malliarou, E., Jarup, L., Harrington, R., Svartengren, M., Han, I.-K., Ohman-Strickland, P., Chung, K.F., and Zhang, J., 2007. Respiratory Effects of Exposure to Diesel Traffic in Persons with Asthma. New England Journal of Medicine, 357 (23), 2348-2358.

McNabola, A., Broderick, B.M., and Gill, L.W., 2007. Optimal cycling and walking speed for minimum absorption of traffic emissions in the lungs. Journal of environmental science and health. Part A, Toxic/hazardous substances \& environmental engineering, 42 (13), 1999-2007.

McNabola, A., Broderick, B.M., and Gill, L.W., 2008. Relative exposure to fine particulate matter and VOCs between transport microenvironments in Dublin: Personal exposure and uptake. Atmospheric Environment, 42 (26), 6496-6512. 
McNabola, A., Broderick, B.M., and Gill, L.W., 2009a. The impacts of inter-vehicle spacing on in-vehicle air pollution concentrations in idling urban traffic conditions. Transportation Research Part D: Transport and Environment, 14 (8), 567-575.

McNabola, A., Broderick, B.M., and Gill, L.W., 2009b. A principal components analysis of the factors effecting personal exposure to air pollution in urban commuters in Dublin, Ireland. Journal of Environmental Science and Health, Part A:

Toxic/Hazardous Substances and Environmental Engineering, 44 (12), 12191226.

Medinsky, M.A. and Bond, J.A., 2001. Sites and mechanisms for uptake of gases and vapors in the respiratory tract. Toxicology, 160 (1-3), 165-172.

Mermier, C.M., Samet, J.M., Lambert, W.E., and Chick, T.W., 1993. Evaluation of the Relationship between Heart Rate and Ventilation for Epidemiologic Studies. Archives of Environmental Health: An International Journal, 48 (4), 263-269.

Meulenberg, C.J.W. and Vijverberg, H.P.M., 2000. Empirical Relations Predicting Human and Rat Tissue:Air Partition Coefficients of Volatile Organic Compounds. Toxicology and Applied Pharmacology, 165 (3), 206-216.

Michaels, R.A. and Kleinman, M.T., 2000. Incidence and apparent health significance of brief airborne particle excursions. Aerosol Science and Technology, 32 (2), 93105.

Miller, L., Xu, X., Grgicak-Mannion, A., Brook, J., and Wheeler, A., 2012. Multi-season, multi-year concentrations and correlations amongst the BTEX group of VOCs in an urbanized industrial city. Atmospheric Environment, 61, 305-315.

Morawska, L., Ristovski, Z., Jayaratne, E.R., Keogh, D.U., and Ling, X., 2008. Ambient nano and ultrafine particles from motor vehicle emissions: Characteristics, ambient processing and implications on human exposure. Atmospheric Environment, 42 (35), 8113-8138.

Moseley, L., Achten, J., Martin, J.C., and Jeukendrup, A.E., 2004. No Differences in Cycling Efficiency Between World-Class and Recreational Cyclists. International Journal of Sports Medicine, 25 (5), 374-379.

Nadeau, V., Truchon, G., Brochu, M., and Tardif, R., 2006. Effect of physical exertion on the biological monitoring of exposure of various solvents following exposure by inhalation in human volunteers: I. Toluene. Journal of occupational and environmental hygiene, 3 (9), 481-489.

Nankervis, M., 1999. The effect of weather and climate on bicycle commuting. Transportation Research Part A: Policy and Practice, 33 (6), 417-431.

Nawrot, T.S., Perez, L., Künzli, N., Munters, E., and Nemery, B., 2011. Public health importance of triggers of myocardial infarction: a comparative risk assessment. The Lancet, 377 (9767), 732-740. 
Nawrot, T.S., Vos, R., Jacobs, L., Verleden, S.E., Wauters, S., Mertens, V., Dooms, C., Hoet, P.H., Raemdonck, D.E.V., Faes, C., Dupont, L.J., Nemery, B., Verleden, G.M., and Vanaudenaerde, B.M., 2011. The impact of traffic air pollution on bronchiolitis obliterans syndrome and mortality after lung transplantation. Thorax, 66 (9), 748-754.

De Nazelle, A., Fruin, S., Westerdahl, D., Martinez, D., Ripoll, A., Kubesch, N., and Nieuwenhuijsen, M., 2012. A travel mode comparison of commuters' exposures to air pollutants in Barcelona. Atmospheric Environment, 59 (0), 151-159.

De Nazelle, A., Nieuwenhuijsen, M.J., Antó, J.M., Brauer, M., Briggs, D., BraunFahrlander, C., Cavill, N., Cooper, A.R., Desqueyroux, H., Fruin, S., and others, 2011. Improving health through policies that promote active travel: a review of evidence to support integrated health impact assessment. Environment international.

De Nazelle, A., Rodríguez, D.A., and Crawford-Brown, D., 2009. The built environment and health: Impacts of pedestrian-friendly designs on air pollution exposure. Science of The Total Environment, 407 (8), 2525-2535.

Newstead, C.G., 1987. The relationship between ventilation and oxygen consumption in man is the same during both moderate exercise and shivering. The Journal of Physiology, 383, 455-459.

Nwokoro, C., Ewin, C., Harrison, C., Ibrahim, M., Dundas, I., Dickson, I., Mushtaq, N., and Grigg, J., 2012. Cycling to work in London and inhaled dose of black carbon. European Respiratory Journal, 40 (5), 1091-1097.

Nyhan, M., McNabola, A., and Misstear, B., 2014. Comparison of particulate matter dose and acute heart rate variability response in cyclists, pedestrians, bus and train passengers. Science of The Total Environment, 468-469, 821-831.

O’Connor, S., McLoughlin, P., Gallagher, C.G., and Harty, H.R., 2000. Ventilatory response to incremental and constant-workload exercise in the presence of a thoracic restriction. Journal of Applied Physiology, 89 (6), 2179-2186.

O’Donoghue, R.T. and Broderick, B.M., 2007. Spatial variation of roadside C2-C6 hydrocarbon concentrations during low wind speeds: A note. Transportation Research Part D: Transport and Environment, 12 (8), 589-595.

O’Donoghue, R.T., Gill, L.W., McKevitt, R.J., and Broderick, B., 2007. Exposure to hydrocarbon concentrations while commuting or exercising in Dublin. Environment international, 33 (1), 1-8.

Oja, P., Titze, S., Bauman, A., de Geus, B., Krenn, P., Reger-Nash, B., and Kohlberger, T., 2011. Health benefits of cycling: a systematic review. Scandinavian Journal of Medicine \& Science in Sports, 21 (4), 496-509.

Olds, T.S., 2001. Modelling Human Locomotion: Applications to Cycling. Sports Medicine, 31 (7), 497-509. 
Olds, T.S., Norton, K.I., and Craig, N.P., 1993. Mathematical model of cycling performance. Journal of Applied Physiology, 75 (2), 730-737.

Olds, T.S., Norton, K.I., Lowe, E.L., Olive, S., Reay, F., and Ly, S., 1995. Modeling road-cycling performance. Journal of Applied Physiology, 78 (4), 1596-1611.

Oregon Department of Environmental Quality, 2011. Benzene in Oregon's Air. Fact Sheet.

Oregon Department of Environmental Quality, 2012. Fact Sheet: Portland Air Toxics Solutions Report and Recommendations.

Ott, W., Steinemann, A.C., and Wallace, L.A., 2007. Exposure Analysis. Boca Raton, Florida, USA: CRC Press.

Pankow, J.F., Luo, W., Bender, D.A., Isabelle, L.M., Hollingsworth, J.S., Chen, C., Asher, W.E., and Zogorski, J.S., 2003. Concentrations and co-occurrence correlations of 88 volatile organic compounds (VOCs) in the ambient air of 13 semi-rural to urban locations in the United States. Atmospheric Environment, 37 (36), 5023-5046.

Pankow, J.F., Luo, W., Isabelle, L.M., Bender, D.A., and Baker, R.J., 1998.

Determination of a wide range of volatile organic compounds in ambient air using multisorbent adsorption/thermal desorption and gas chromatography/mass spectrometry. Analytical chemistry, 70 (24), 5213-5221.

Pankow, J.F., Luo, W., Melnychenko, A.N., Barsanti, K.C., Isabelle, L.M., Chen, C., Guenther, A.B., and Rosenstiel, T.N., 2011. Volatilizable biogenic organic compounds (VBOCs) with two dimensional gas chromatography-time of flight mass spectrometry (GC $\times$ GC-TOFMS): sampling methods, VBOC complexity, and chromatographic retention data. Atmos. Meas. Tech. Discuss., 4 (3), 36473684.

Pankow, J.F., Luo, W., Tavakoli, A.D., Chen, C., and Isabelle, L.M., 2004. Delivery levels and behavior of 1, 3-butadiene, acrylonitrile, benzene, and other toxic volatile organic compounds in mainstream tobacco smoke from two brands of commercial cigarettes. Chemical research in toxicology, 17 (6), 805-813.

Pein, W., 1997. Bicyclist Performance on a Multiuse Trail. Transportation Research Record: Journal of the Transportation Research Board, 1578 (-1), 127-131.

Perbellini, L., Faccini, G.B., Pasini, F., Cazzoli, F., Pistoia, S., Rosellini, R., Valsecchi, M., and Brugnone, F., 1988. Environmental and occupational exposure to benzene by analysis of breath and blood. British Journal of Industrial Medicine, 45 (5), 345-352.

Peters, A., Von Klot, S., Heier, M., Trentinaglia, I., Hörmann, A., Wichmann, H.E., and Löwel, H., 2004. Exposure to traffic and the onset of myocardial infarction. New England Journal of Medicine, 351 (17), 1721-1730. 
Peters, A., Klot, S. von, Mittleman, M.A., Meisinger, C., Hörmann, A., Kuch, B., and Wichmann, H.E., 2013. Triggering of acute myocardial infarction by different means of transportation. European Journal of Preventive Cardiology, 20 (5), $750-758$.

Pezzagno, G., Imbriani, M., Ghittori, S., and Capodaglio, E., 1988. Urinary concentration, environmental concentration, and respiratory uptake of some solvents: effect of the work load. American Industrial Hygiene Association journal, 49 (11), 546-552.

Phillips, M., Herrera, J., Krishnan, S., Zain, M., Greenberg, J., and Cataneo, R.N., 1999. Variation in volatile organic compounds in the breath of normal humans. Journal of Chromatography B: Biomedical Sciences and Applications, 729 (1-2), 75-88.

Piechocki-Minguy, A., Plaisance, H., Schadkowski, C., Sagnier, I., Saison, J.Y., Galloo, J.C., and Guillermo, R., 2006. A case study of personal exposure to nitrogen dioxide using a new high sensitive diffusive sampler. Science of The Total Environment, 366 (1), 55-64.

Plaut, P.O., 2005. Non-motorized commuting in the US. Transportation Research Part D: Transport and Environment, 10 (5), 347-356.

Pope, C.A.I. and Dockery, D.W., 2006. Health effects of fine particulate air pollution: lines that connect. Journal of the Air \& Waste Management Association, 56 (6), 709-742.

Di Prampero, P.E., Cortili, G., Mognoni, P., and Saibene, F., 1979. Equation of motion of a cyclist. Journal of Applied Physiology, 47 (1), 201-206.

Pucher, J., Buehler, R., and Seinen, M., 2011. Bicycling renaissance in North America? An update and re-appraisal of cycling trends and policies. Transportation Research Part A: Policy and Practice, 45 (6), 451-475.

Pucher, J., Dill, J., and Handy, S., 2010. Infrastructure, programs, and policies to increase bicycling: An international review. Preventive Medicine, 50, Supplement, S106S125.

Pucher, J.R. and Buehler, R., 2012. City Cycling. Cambridge, MA, USA: MIT Press.

Quiros, D.C., Lee, E.S., Wang, R., and Zhu, Y., 2013. Ultrafine particle exposures while walking, cycling, and driving along an urban residential roadway. Atmospheric Environment, 73, 185-194.

Rabl, A. and de Nazelle, A., 2012. Benefits of shift from car to active transport. Transport Policy, 19 (1), 121-131.

Ragettli, M.S., Corradi, E., Braun-Fahrländer, C., Schindler, C., de Nazelle, A., Jerrett, M., Ducret-Stich, R.E., Künzli, N., and Phuleria, H.C., 2013. Commuter exposure to ultrafine particles in different urban locations, transportation modes and routes. Atmospheric Environment, 77, 376-384. 
Ragland, D.R., Grembek, O., Orrick, P., and Felschundneff, G., 2013. Roadway and Infrastructure Design and Its Relation to Pedestrian and Bicyclist Safety: Basic Principles, Applications, and Benefits. Presented at the 92nd Annual Meeting of the Transportation Research Board, Washington, D.C.

Rank, J., Folke, J., and Homann Jespersen, P., 2001. Differences in cyclists and car drivers exposure to air pollution from traffic in the city of Copenhagen. Science of the Total Environment, The, 279 (1-3), 131-136.

Reynolds, C.C., Harris, M.A., Teschke, K., Cripton, P.A., and Winters, M., 2009. The impact of transportation infrastructure on bicycling injuries and crashes: a review of the literature. Environmental Health, 8 (1), 47-65.

Reynolds, C.C.O., Winters, M., Ries, F., and Gouge, B., 2010. Active transportation in urban areas: exploring health benefits and risks. National Collaborating Centre for Environmental Health.

Rojas-Rueda, D., de Nazelle, A., Tainio, M., and Nieuwenhuijsen, M.J., 2011. The health risks and benefits of cycling in urban environments compared with car use: health impact assessment study. BMJ, 343 (aug04 2), d4521-d4521.

Rojas-Rueda, D., de Nazelle, A., Teixidó, O., and Nieuwenhuijsen, M.J., 2012. Replacing car trips by increasing bike and public transport in the greater Barcelona metropolitan area: A health impact assessment study. Environment International, 49, 100-109.

Rosenbaum, A., Carr, E., and Cohen, J., 2004. Air Dispersion Modeling Component of the Portland Air Toxics Assessment (PATA). U.S. EPA.

Samet, J.M., 2007. Traffic, Air Pollution, and Health. Inhalation Toxicology, 19 (12), 1021-1027.

Samet, J.M., Lambert, W.E., James, D.S., Mermier, C.M., and Chick, T.W., 1993. Assessment of Heart Rate As a Predictor of Ventilation. Health Effects Institute, Investigator's Report No. 59.

Samoli, E., Aga, E., Touloumi, G., Nisiotis, K., Forsberg, B., Lefranc, A., Pekkanen, J., Wojtyniak, B., Schindler, C., Niciu, E., Brunstein, R., Fikfak, M.D., Schwartz, J., and Katsouyanni, K., 2006. Short-term effects of nitrogen dioxide on mortality: an analysis within the APHEA project. European Respiratory Journal, 27 (6), 1129-1138.

Von Schneidemesser, E., Monks, P.S., and Plass-Duelmer, C., 2010. Global comparison of VOC and CO observations in urban areas. Atmospheric Environment, 44 (39), 5053-5064.

Schnohr, P., Marott, J.L., Jensen, J.S., and Jensen, G.B., 2012. Intensity versus duration of cycling, impact on all-cause and coronary heart disease mortality: the Copenhagen City Heart Study. European Journal of Preventive Cardiology, 19 (1), 73-80. 
Seinfeld, J.H. and Pandis, S.N., 2012. Atmospheric Chemistry and Physics: From Air Pollution to Climate Change. John Wiley \& Sons.

Shah, A.S., Langrish, J.P., Nair, H., McAllister, D.A., Hunter, A.L., Donaldson, K., Newby, D.E., and Mills, N.L., 2012. Global association of air pollution and heart failure: a systematic review and meta-analysis. The Lancet, 382 (9897), 10391048.

Sharker, M.H. and Karimi, H.A., 2013. Computing least air pollution exposure routes. International Journal of Geographical Information Science, 28 (2), 343-362.

Sin, P.Y.W., Webber, M.R., Galletly, D.C., Ainslie, P.N., Brown, S.J., Willie, C.K., Sasse, A., Larsen, P.D., and Tzeng, Y.-C., 2010. Interactions between heart rate variability and pulmonary gas exchange efficiency in humans. Experimental Physiology, 95 (7), 788-797.

Sitzmann, B., Kendall, M., Watt, J., and Williams, I., 1999. Characterisation of airborne particles in London by computer-controlled scanning electron microscopy. Science of The Total Environment, 241 (1-3), 63-73.

Steinle, S., Reis, S., and Sabel, C.E., 2013. Quantifying human exposure to air pollution-Moving from static monitoring to spatio-temporally resolved personal exposure assessment. Science of The Total Environment, 443, 184-193.

Strak, M., Boogaard, H., Meliefste, K., Oldenwening, M., Zuurbier, M., Brunekreef, B., and Hoek, G., 2010. Respiratory health effects of ultrafine and fine particle exposure in cyclists. Occupational and Environmental Medicine, 67 (2), 118-124.

Strauss, J., Miranda-Moreno, L., Crouse, D., Goldberg, M.S., Ross, N.A., and Hatzopoulou, M., 2012. Investigating the link between cyclist volumes and air pollution along bicycle facilities in a dense urban core. Transportation Research Part D: Transport and Environment, 17 (8), 619-625.

Swain, D.D.P., 2000. Energy Cost Calculations for Exercise Prescription. Sports Medicine, 30 (1), 17-22.

Teschke, K., Harris, M.A., Reynolds, C.C.O., Winters, M., Babul, S., Chipman, M., Cusimano, M.D., Brubacher, J.R., Hunte, G., Friedman, S.M., Monro, M., Shen, H., Vernich, L., and Cripton, P.A., 2012. Route Infrastructure and the Risk of Injuries to Bicyclists: A Case-Crossover Study. American Journal of Public Health, 102 (12), 2336-2343.

Teschke, K., Reynolds, C.C.O., Ries, F.J., Gouge, B., and Winters, M., 2012. Bicycling: Health risk or benefit? UBC Medical Journal, 3 (2).

Thai, A., McKendry, I., and Brauer, M., 2008. Particulate matter exposure along designated bicycle routes in Vancouver, British Columbia. Science of The Total Environment, 405 (1-3), 26-35. 
Tian, L., Hossain, S.R., Lin, H., Ho, K.F., Lee, S.C., and Yu, I.T.S., 2011. Increasing trend of primary $\mathrm{NO}(2)$ exhaust emission fraction in Hong Kong. Environmental geochemistry and health, 33 (6), 623-630.

Tiwary, A., Robins, A., Namdeo, A., and Bell, M., 2011. Air flow and concentration fields at urban road intersections for improved understanding of personal exposure. Environment International, 37 (5), 1005-1018.

Townsend, C.L. and Maynard, R.L., 2002. Effects on health of prolonged exposure to low concentrations of carbon monoxide. Occupational and Environmental Medicine, 59 (10), 708-711.

Tsai, J.-H., Chang, S.-Y., and Chiang, H.-L., 2012. Volatile organic compounds from the exhaust of light-duty diesel vehicles. Atmospheric Environment, 61 (0), 499-506.

U.S. Environmental Protection Agency, 2008. Integrated Science Assessment for Oxides of Nitrogen - Health Criteria. Final Report No. EPA-600-R-08-07.

U.S. Environmental Protection Agency, 2009. Metabolically Derived Human Ventilation Rates: A Revised Approach Based Upon Oxygen Consumption Rates. Washington, D.C.: U.S. Environmental Protection Agency, No. EPA/600/R06/129F.

U.S. Environmental Protection Agency, 2010. Integrated Science Assessment for Carbon Monoxide. Final Report No. EPA-600-R-09-019F.

U.S. Environmental Protection Agency, 2012. National Ambient Air Quality Standards (NAAQS) [online]. Air and Radiation. Available from: http://www.epa.gov/air/criteria.html [Accessed 6 Jun 2013].

U.S. Environmental Protection Agency, 2013a. Integrated Science Assessment for Ozone and Related Photochemical Oxidants. Final Report No. EPA-600-R-10-076F.

U.S. Environmental Protection Agency, 2013b. Carbon Monoxide - AirTrends [online]. Available from: http://www.epa.gov/airtrends/carbon.html\#conat [Accessed 22 Jan 2014].

U.S. Federal Highway Administration, 2009. Interim Guidance Update on Mobile Source Air Toxic Analysis in NEPA Documents.

Vallero, D., 2008. Fundamentals of Air Pollution. 4th ed. Burlington, MA: Elsevier Academic Press.

Vinzents, P.S., Møller, P., Sørensen, M., Knudsen, L.E., Hertel, O., Jensen, F.P., Schibye, B., and Loft, S., 2005. Personal Exposure to Ultrafine Particles and Oxidative DNA Damage. Environmental Health Perspectives, 113 (11), 1485-1490.

Waldman, M., Weiss, S., and Articola, W., 1977. A Study of the Health Effects of Bicycling in an Urban Atmosphere. Washington, D.C.: U.S. Department of Transportation.

Wallace, L.A., Nelson, W.C., Pellizzari, E.D., and Raymer, J.H., 1997. Uptake and decay of volatile organic compounds at environmental concentrations: application of a 
four-compartment model to a chamber study of five human subjects. Journal of exposure analysis and environmental epidemiology, 7 (2), 141-163.

Wallace, L.A., Pellizzari, E.D., and Gordon, S., 1993. A linear model relating breath concentrations to environmental exposures: application to a chamber study of four volunteers exposed to volatile organic chemicals. Journal of exposure analysis and environmental epidemiology, 3 (1), 75-102.

Wang, P. and Zhao, W., 2008. Assessment of ambient volatile organic compounds (VOCs) near major roads in urban Nanjing, China. Atmospheric Research, 89 (3), 289-297.

Wang, X., Sheng, G., Fu, J., Chan, C., Lee, S.-C., Chan, L.Y., and Wang, Z., 2002. Urban roadside aromatic hydrocarbons in three cities of the Pearl River Delta, People's Republic of China. Atmospheric Environment, 36 (33), 5141-5148.

Wang, Y., Hopke, P.K., Chalupa, D.C., and Utell, M.J., 2011. Long-term study of urban ultrafine particles and other pollutants. Atmospheric Environment, 45 (40), 7672 7680 .

Wanner, M., Götschi, T., Martin-Diener, E., Kahlmeier, S., and Martin, B.W., 2012. Active Transport, Physical Activity, and Body Weight in Adults: A Systematic Review. American Journal of Preventive Medicine, 42 (5), 493-502.

Wardman, M., Tight, M., and Page, M., 2007. Factors influencing the propensity to cycle to work. Transportation Research Part A: Policy and Practice, 41 (4), 339-350.

Watson, J.G., Chow, J.C., and Fujita, E.M., 2001. Review of volatile organic compound source apportionment by chemical mass balance. Atmospheric Environment, 35 (9), 1567-1584.

Weichenthal, S., Kulka, R., Bélisle, P., Joseph, L., Dubeau, A., Martin, C., Wang, D., and Dales, R., 2012. Personal exposure to specific volatile organic compounds and acute changes in lung function and heart rate variability among urban cyclists. Environmental Research, 118, 118-123.

Weichenthal, S., Kulka, R., Dubeau, A., Martin, C., Wang, D., and Dales, R., 2011. Traffic-related air pollution and acute changes in heart rate variability and respiratory function in urban cyclists. Environmental Health Perspectives, 119 (10), 1373-1378.

Weisman, I.M., 2003. Erratum ATS/ACCP statement on cardiopulmonary exercise testing. American journal of respiratory and critical care medicine, 167 (10), 1451-1452.

West, J.B., 2012. Respiratory Physiology: The Essentials. 9th ed. Baltimore, MD: Lippincott Williams \& Wilkins.

Whitt, F.R., 1971. A Note on the Estimation of the Energy Expenditure of Sporting Cyclists. Ergonomics, 14 (3), 419-424. 
Van Wijnen, J.H., Verhoeff, A.P., Jans, H.W.., and Bruggen, M., 1995. The exposure of cyclists, car drivers and pedestrians to traffic-related air pollutants. International archives of occupational and environmental health, 67 (3), 187-193.

Wilson, D.G., 2004. Bicycling science. 3rd ed. Cambridge, MA: MIT Press.

Winters, M., Harris, M.A., Reynolds, C.C.O., Cripton, P.A., Chipman, M., Cusimano, M.D., Brubacher, J., Friedman, S.M., Monro, M., and Vernich, L., 2013. Bicyclists' Injuries and the Cycling Environment: The Impact of Route Infrastructure. Presented at the 92nd Annual Meeting of the Transportation Research Board, Washington, D.C.

Woodcock, J., Edwards, P., Tonne, C., Armstrong, B.G., Ashiru, O., Banister, D., Beevers, S., Chalabi, Z., Chowdhury, Z., and Cohen, A., 2009. Public health benefits of strategies to reduce greenhouse-gas emissions: urban land transport. The Lancet, 374 (9705), 1930-1943.

World Health Organization, 1999. Carbon Monoxide (2nd Ed.). Geneva, Environmental Health Criteria No. 213.

Yu, Q., Lu, Y., Xiao, S., Shen, J., Li, X., Ma, W., and Chen, L., 2012. Commuters' exposure to PM1 by common travel modes in Shanghai. Atmospheric Environment, 59 (0), 39-46.

Zhao, L., Wang, X., He, Q., Wang, H., Sheng, G., Chan, L.Y., Fu, J., and Blake, D.R., 2004. Exposure to hazardous volatile organic compounds, $\mathrm{PM}<\mathrm{sub}>10</$ sub $>$ and $\mathrm{CO}$ while walking along streets in urban Guangzhou, China. Atmospheric Environment, 38 (36), 6177-6184.

Zoladz, J.A., Rademaker, A.C., and Sargeant, A.J., 1995. Non-linear relationship between $\mathrm{O} 2$ uptake and power output at high intensities of exercise in humans. The Journal of Physiology, 488 (Pt 1), 211-217.

Zuurbier, M., Hoek, G., Hazel, P., and Brunekreef, B., 2009. Minute ventilation of cyclists, car and bus passengers: an experimental study. Environmental Health, 8 (1), 48-57.

Zuurbier, M., Hoek, G., Oldenwening, M., Lenters, V., Meliefste, K., Van Den Hazel, P., and Brunekreef, B., 2010. Commuters' Exposure to Particulate Matter Air Pollution Is Affected by Mode of Transport, Fuel Type, and Route. Environmental Health Perspectives, 118 (6), 783-789.

Zuurbier, M., Hoek, G., Oldenwening, M., Meliefste, K., van den Hazel, P., and Brunekreef, B., 2011. Respiratory Effects of Commuters' Exposure to Air Pollution in Traffic. Epidemiology, 22 (2), 219-227.

Zuurbier, M., Hoek, G., Oldenwening, M., Meliefste, K., Krop, E., van den Hazel, P., and Brunekreef, B., 2011. In-Traffic Air Pollution Exposure and CC16, Blood Coagulation, and Inflammation Markers in Healthy Adults. Environmental Health Perspectives, 119 (10), 1384-1389. 


\section{APPENDIX A: TRAFFIC-RELATED AIR POLLUTANTS}

This appendix briefly introduces the main traffic-related air pollutants linked to health risks for road travelers. Most primary traffic-related air pollutants are combustion by-products emitted from the tailpipes of motor vehicles; other sources include evaporation, brake and tire wear, and resuspension of road dust. As vehicle engine exhaust becomes cleaner, brake and tire wear may be a growing portion of vehicle-related urban particulate matter. Secondary traffic-related air pollutants are formed through atmospheric physical and chemical processes, after the emission of primary pollutants. Detailed information on these pollutants is readily found in textbooks on air pollution such as Vallero (2008). Several important traffic-related air pollutants are excluded from this review because they have not been directly measured on-road in bicyclist exposure studies, including ground-level ozone $\left(\mathrm{O}_{3}\right)$ and sulfur oxides $\left(\mathrm{SO}_{\mathrm{x}}\right)$. This is particularly troublesome for $\mathrm{O}_{3}$, a secondary pollutant associated with numerous health effects including neurodegeneration, respiratory and cardiovascular morbidity, and mortality (Health Effects Institute 2010, U.S. Environmental Protection Agency 2013a).

Carbon monoxide $(\mathrm{CO})$ is emitted by vehicles as a result of incomplete combustion of hydrocarbon fuel. Transportation microenvironments tend to have elevated concentrations of CO (Kaur et al. 2007, El-Fadel and Abi-Esber 2009). Even at ambient levels CO has known negative health effects such as exacerbation of heart disease and neurological damage, with little to no evidence of safe threshold concentrations (Burnett et al. 1998, World Health Organization 1999, Townsend and Maynard 2002, Ott et al. 2007, U.S. Environmental Protection Agency 2010). 
Nitrogen oxides $\left(\mathrm{NO}_{\mathrm{x}}\right)$ are another major component (by mass) of motor vehicle primary pollution emissions. $\mathrm{NO}_{\mathrm{x}}$ is emitted in the forms of nitric oxide (NO) and nitrogen dioxide $\left(\mathrm{NO}_{2}\right)$; $\mathrm{NO}_{\mathrm{x}}$ composition changes through secondary reactions with ozone and other oxidants (Carslaw and Beevers 2005, Tian et al. 2011). Short-term $\mathrm{NO}_{2}$ exposure, even at ambient levels, has been associated with adverse respiratory effects and mortality rates (Samoli et al. 2006, U.S. Environmental Protection Agency 2008).

Volatile organic compounds (VOC) are commonly emitted through vehicle exhaust, engine evaporation, and refueling evaporation (Gertler et al. 1996, Brown et al. 2007). VOC is a broad category including many individual gas compounds such as hydrocarbons in fuel (octane, benzene), fuel additives (ethers such as MTBE), and combustion byproducts (acrolein, formaldehyde). Motor vehicles are a major source of gaseous hydrocarbons and other VOC in urban areas (Watson et al. 2001, Brown et al. 2007, Kansal 2009). The U.S. Federal Highway Administration (FHWA) and Environmental Protection Agency (EPA) have identified seven high-priority mobile source air toxics with "significant contributions" to cancer risk; six of these air toxics are VOC: acrolein, benzene, 1,3-butidiene, formaldehyde, naphthalene, and other polycyclic organic matter (U.S. Federal Highway Administration 2009).

Particulate Matter (PM) air pollution includes particles of varying size and composition, often composed of dissimilar molecules. Disproportionately large fractions of total daily exposure to PM occur during commuting (Fruin et al. 2008, Dons et al. 2012, Nwokoro et al. 2012, Ragettli et al. 2013). Particulate matter is often categorized by its size. The smallest size category commonly studied in the exposure literature is 
ultrafine particles (UFP): particles with aerodynamic diameters below $100 \mathrm{~nm}$. Larger particulate matter is designated $\mathrm{PM}_{\mathrm{x}}$, where $\mathrm{x}$ is the maximum aerodynamic diameter. Two important size categories are $\mathrm{PM}_{2.5}$ ("fine") and $\mathrm{PM}_{10}$ ("inhalable") - both of which are subject to ambient air quality standards due to their known negative health effects (Ott et al. 2007, U.S. Environmental Protection Agency 2012). $\mathrm{PM}_{\mathrm{x}}$ categories are reported as mass concentrations but UFP are typically reported as particle number concentrations (PNC). In contrast to the size categories, elemental carbon (EC) and black carbon (BC) are terms for soot particles generated as a combustion byproduct (Andreae and Gelencsér 2006).

The larger PM size categories have better-established monitoring data and more robust epidemiological evidence for health outcomes such as cardiopulmonary morbidity and mortality (Brook et al. 2010). $\mathrm{PM}_{2.5}$ is thought to have larger impacts on health than $\mathrm{PM}_{10}$ because of more toxic composition and deeper penetration in the lungs; $\mathrm{PM}_{2.5}$ appears to have no safe concentration threshold for exposure (Pope and Dockery 2006). Similarly, UFP have received increasing attention as a health risk because of their size (allowing deep lung penetration and entry to the bloodstream) and composition (high surface area and reactive compounds) (Knibbs et al. 2011). The larger particles have more biogenic sources and a smaller proportion of ambient concentrations are due to primary emissions from motor vehicles than for smaller PM. High UFP number concentrations are often found in transportation microenvironments (Knibbs et al. 2011), and the UFP size category dominates total PNC in near-road environments (Morawska et 
al. 2008). However, UFP emissions models, monitoring data, and epidemiological evidence are all still lacking when compared to larger PM size categories. 


\section{APPENDIX B: REPORTED BICYCLIST EXPOSURE CONCENTRATIONS}

The following Tables (S.1 through S.8) summarize all 42 on-road bicycle exposure monitoring studies, grouped by pollutant. In cases where the same original data set appears in more than one publication, a single citation is included in the tables.

The earliest studies measured $\mathrm{CO}$ exposure concentrations for bicyclists in U.S. cities (Kleiner and Spengler 1976, Waldman et al. 1977). The first multi-pollutant study measured CO, $\mathrm{PM}_{3.5}$, and VOC for bicyclists in the UK (Bevan et al. 1991). Since then the majority of on-bicycle pollution exposure studies have taken place in Europe, North America, Australia, and New Zealand, with a few recent exceptions from China (Huang et al. 2012, Yu et al. 2012). In addition to the on-bicycle data collections included in these tables, several other studies approximated bicyclists' exposure concentrations using stationary near-road (or near-path) measurements of $\mathrm{PM}_{10}$ (Fajardo and Rojas 2012), UFP (Kendrick et al. 2011), $\mathrm{NO}_{2}$ (Bean et al. 2011), and $\mathrm{CO}$ and $\mathrm{NO}_{\mathrm{x}}$ (Chan et al. 1994).

To provide context for the values in these tables, World Health Organization guidelines for annual mean $\mathrm{PM}_{2.5}, \mathrm{PM}_{10}$, and $\mathrm{NO}_{2}$ concentrations are 10,20 , and 40 $\mu \mathrm{g} / \mathrm{m}^{3}$, respectively (Krzyzanowski and Cohen 2008). A review of UFP measurements suggests an "urban background" concentration of 7,290 pt/cc (Morawska et al. 2008). Ambient monitoring in U.S. cities shows typical annual $2^{\text {nd }}$ maximum 8-hour average ambient CO concentrations of 1.5 ppm in 2012 (U.S. Environmental Protection Agency 2013b); annual average CO concentrations would be much lower (Wang et al. 2011). Pankow et al. (2003) measured ambient VOC levels in U.S. urban areas as 0.12-1.1 $\mu \mathrm{g} / \mathrm{m}^{3}$ for benzene, $0.39-2.7 \mu \mathrm{g} / \mathrm{m}^{3}$ for toluene, and $0.54-1.6 \mu \mathrm{g} / \mathrm{m}^{3}$ for xylenes. Although 
a multi-city background study for BC was not found, deCastro et al. (2008) estimate a representative urban background BC concentration of $0.9 \mu \mathrm{g} / \mathrm{m}^{3}$ for a U.S. city, while monitoring in a Belgian city measured median background $\mathrm{BC}$ concentrations around 1.5 $\mu \mathrm{g} / \mathrm{m}^{3}$ (Dekoninck et al. 2013). 


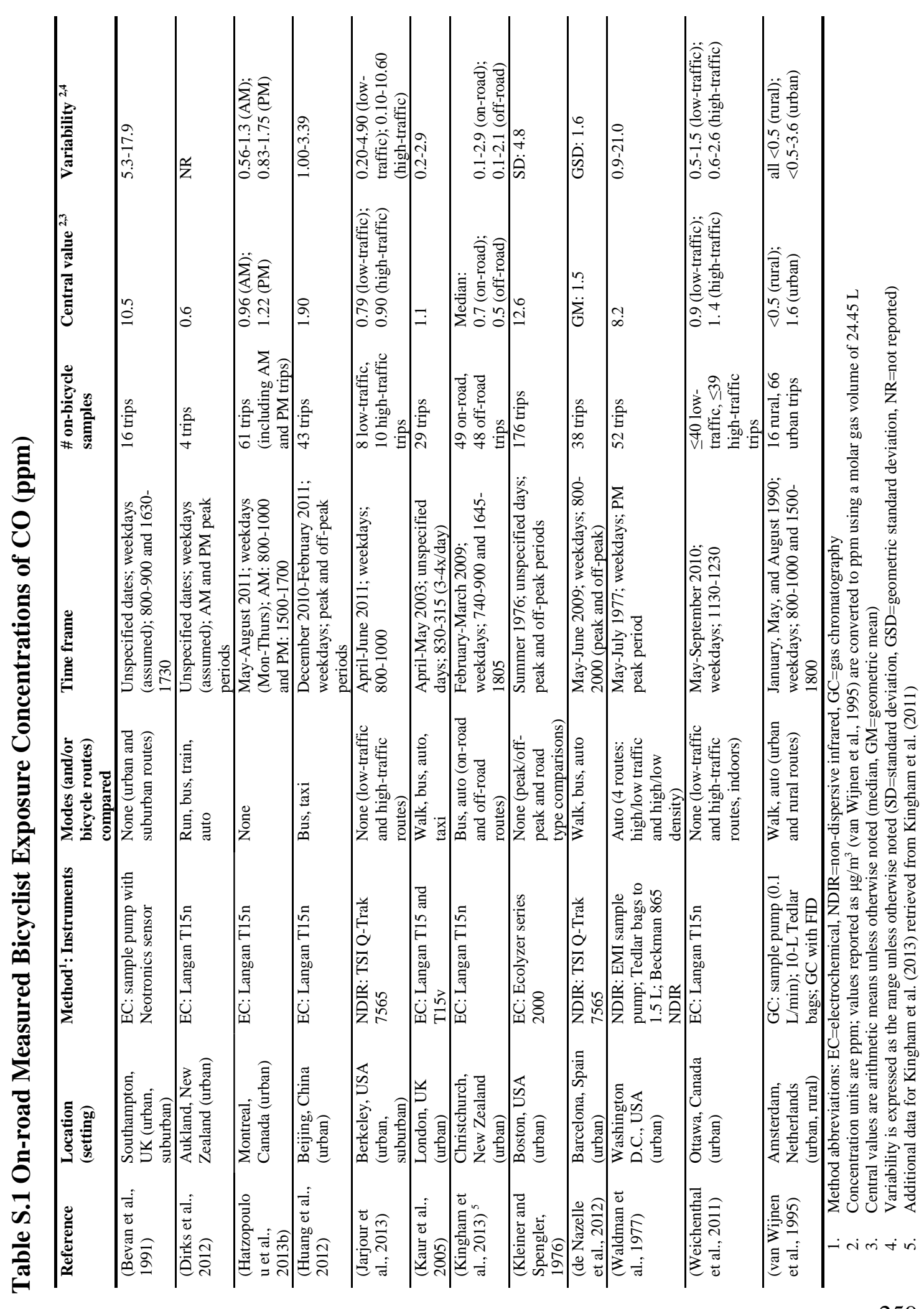




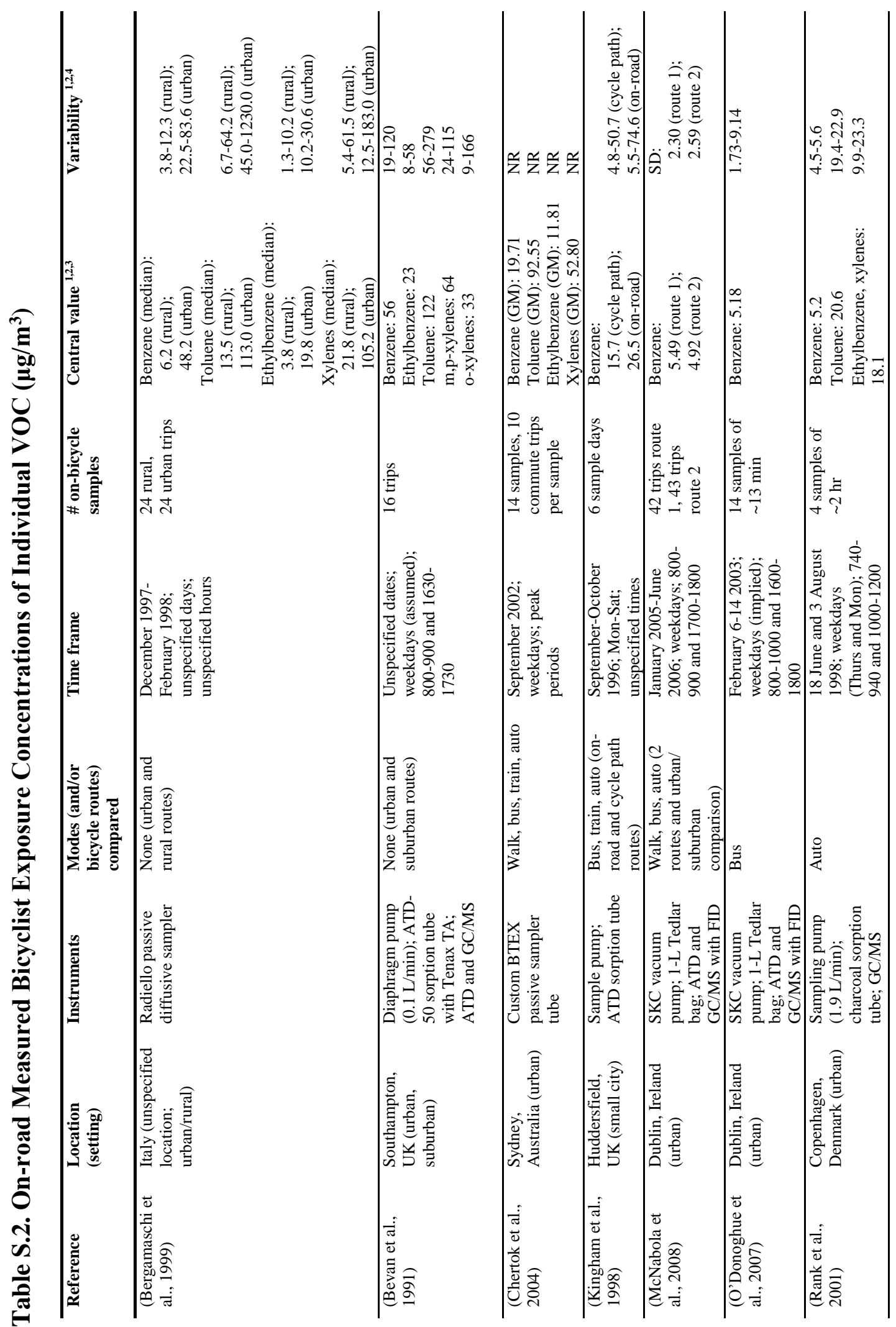




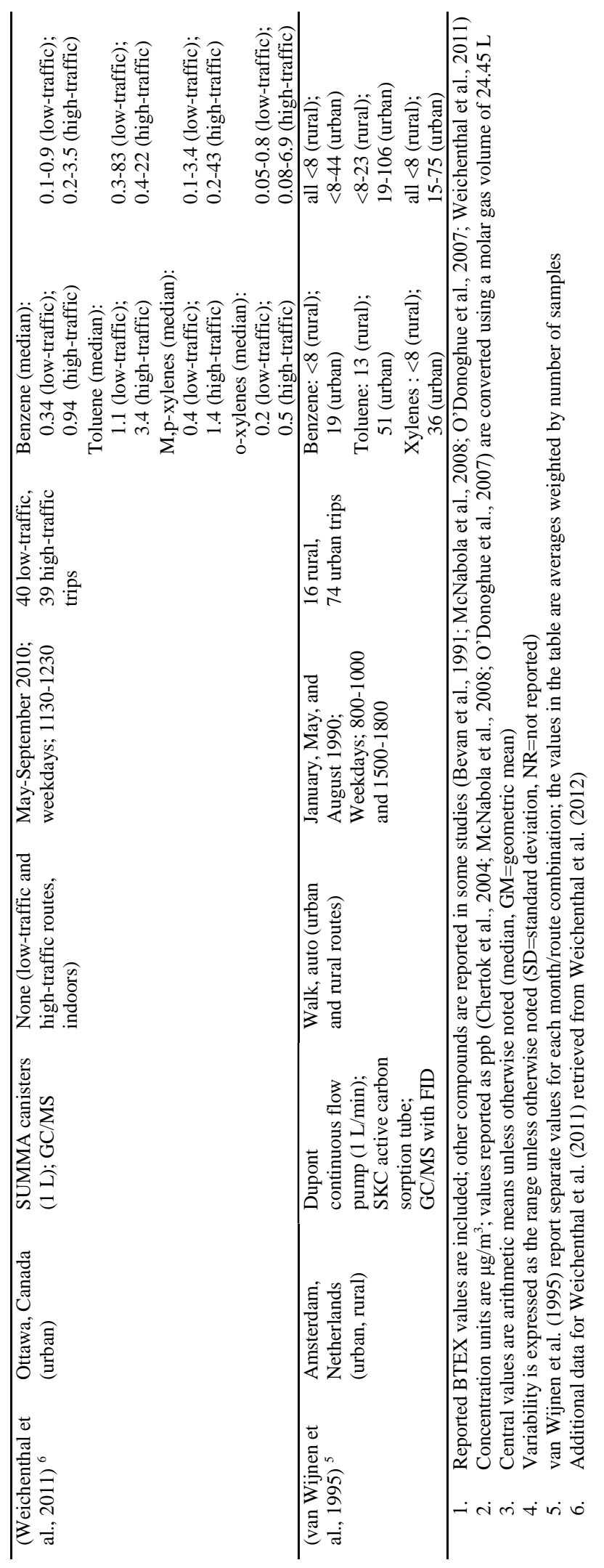




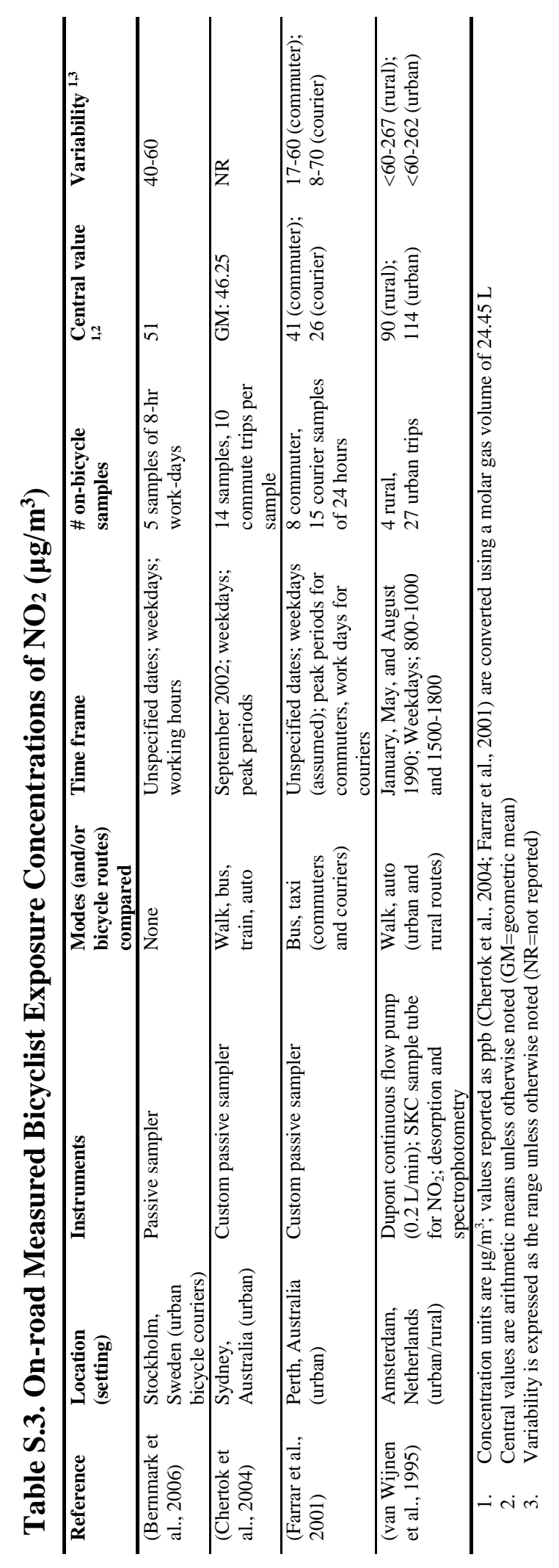




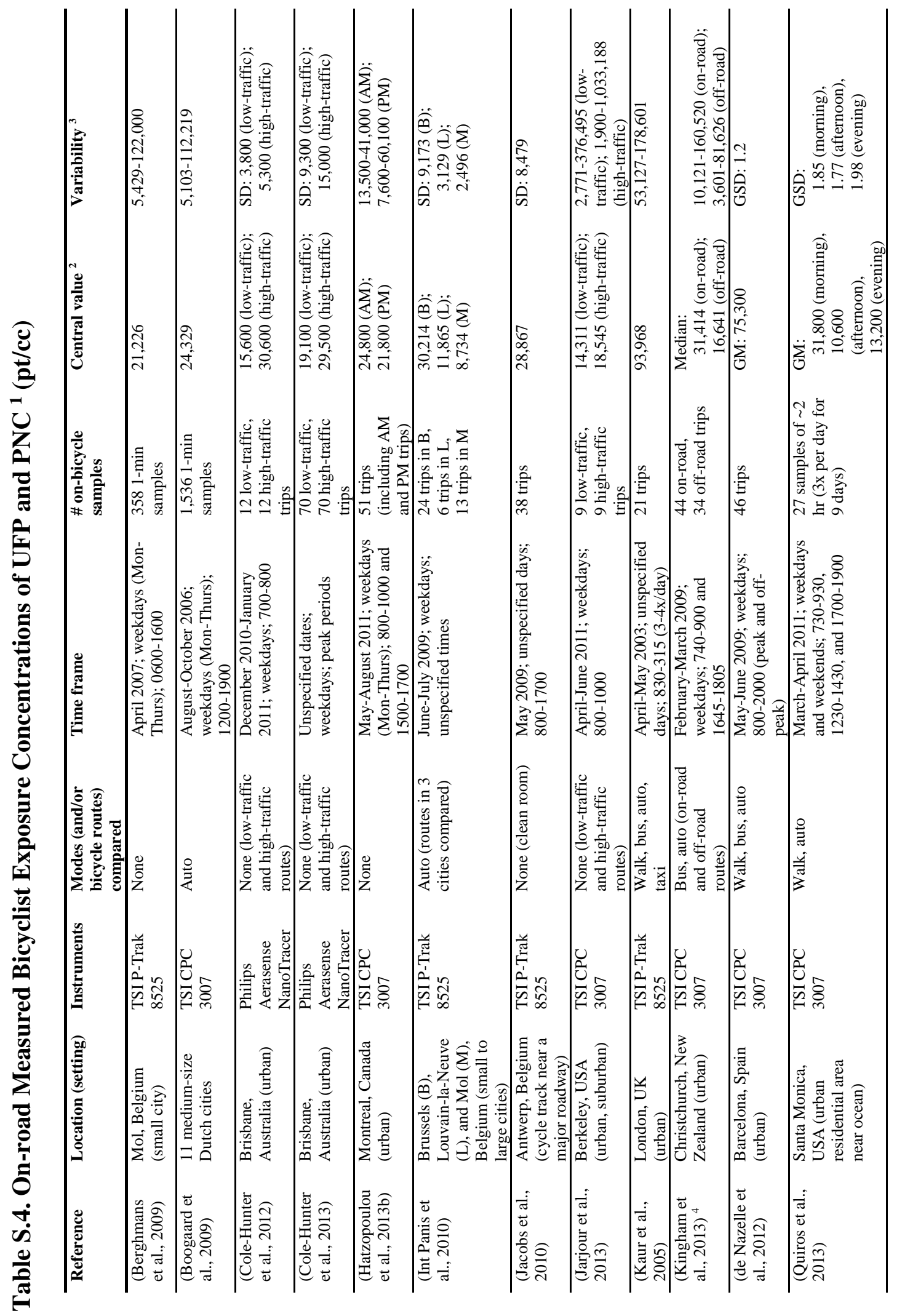




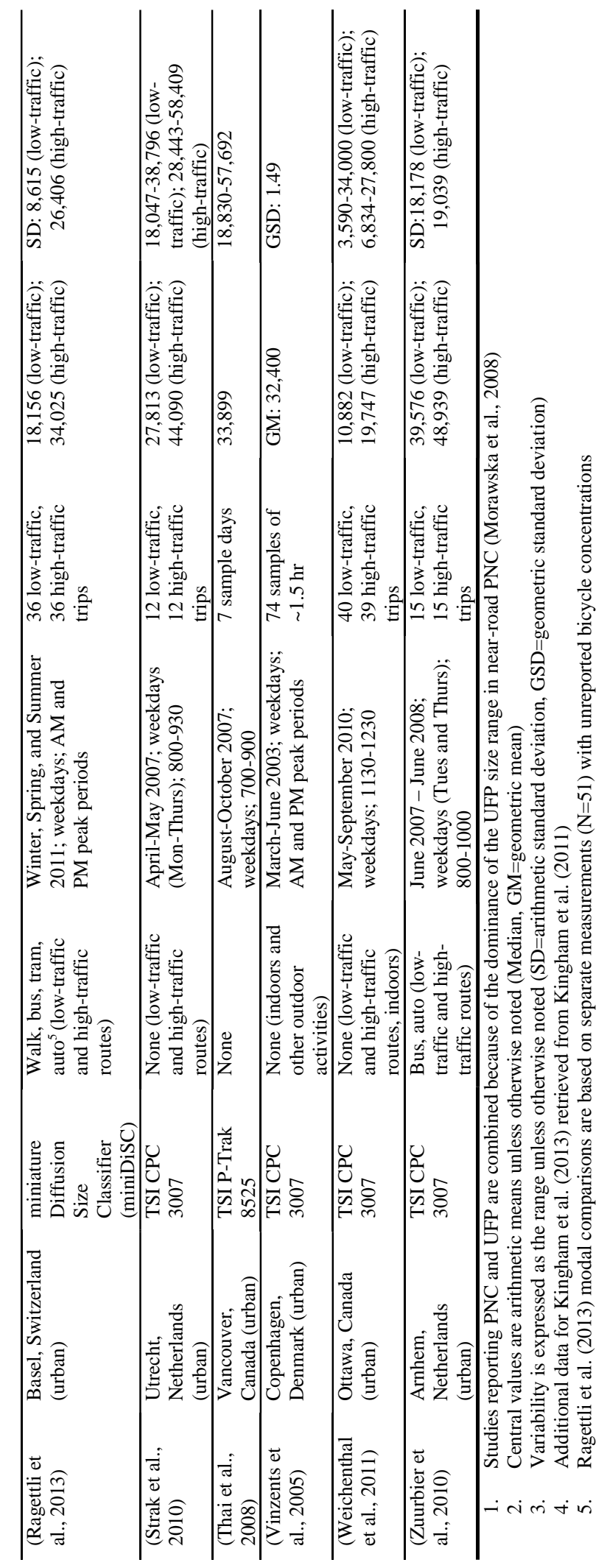




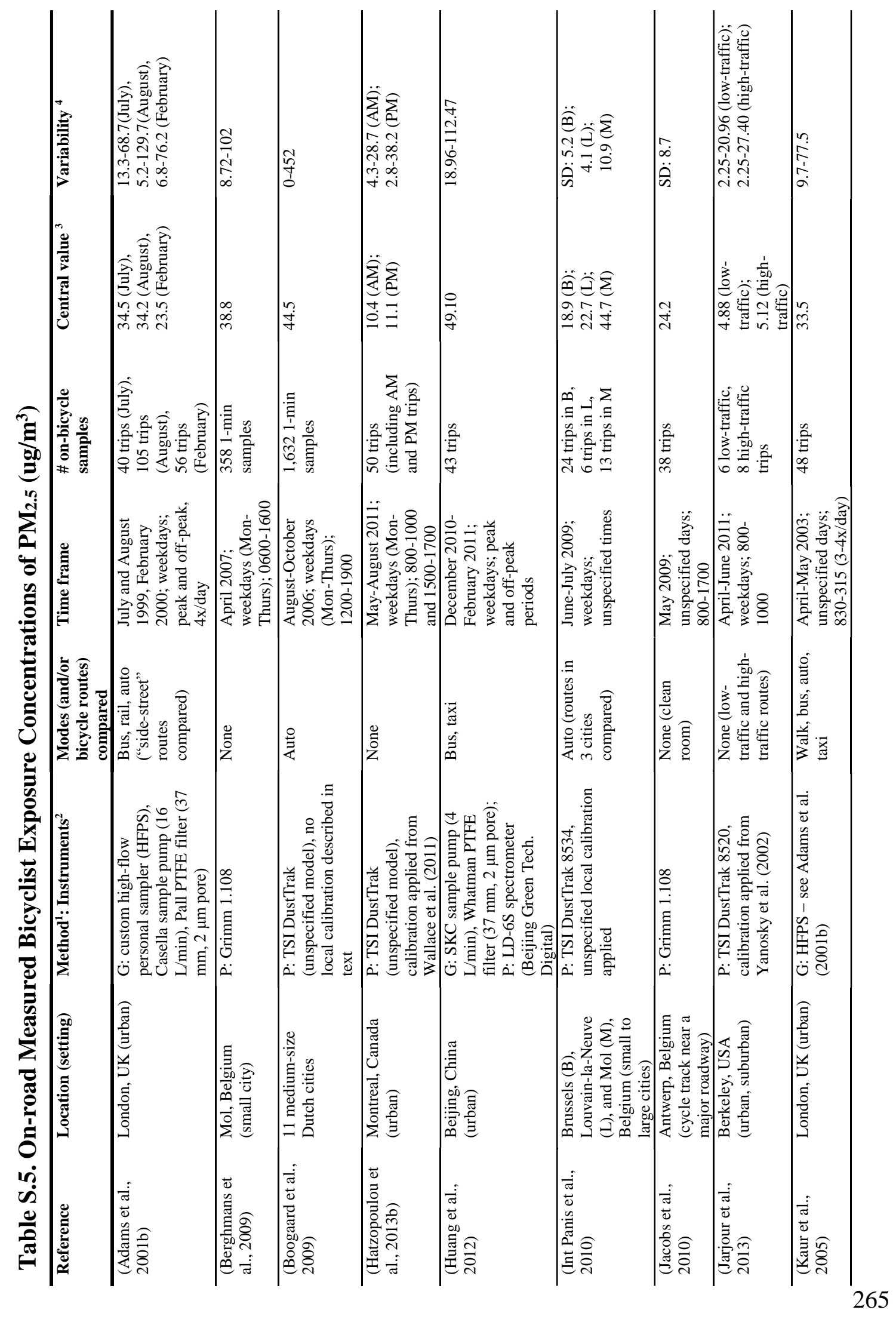




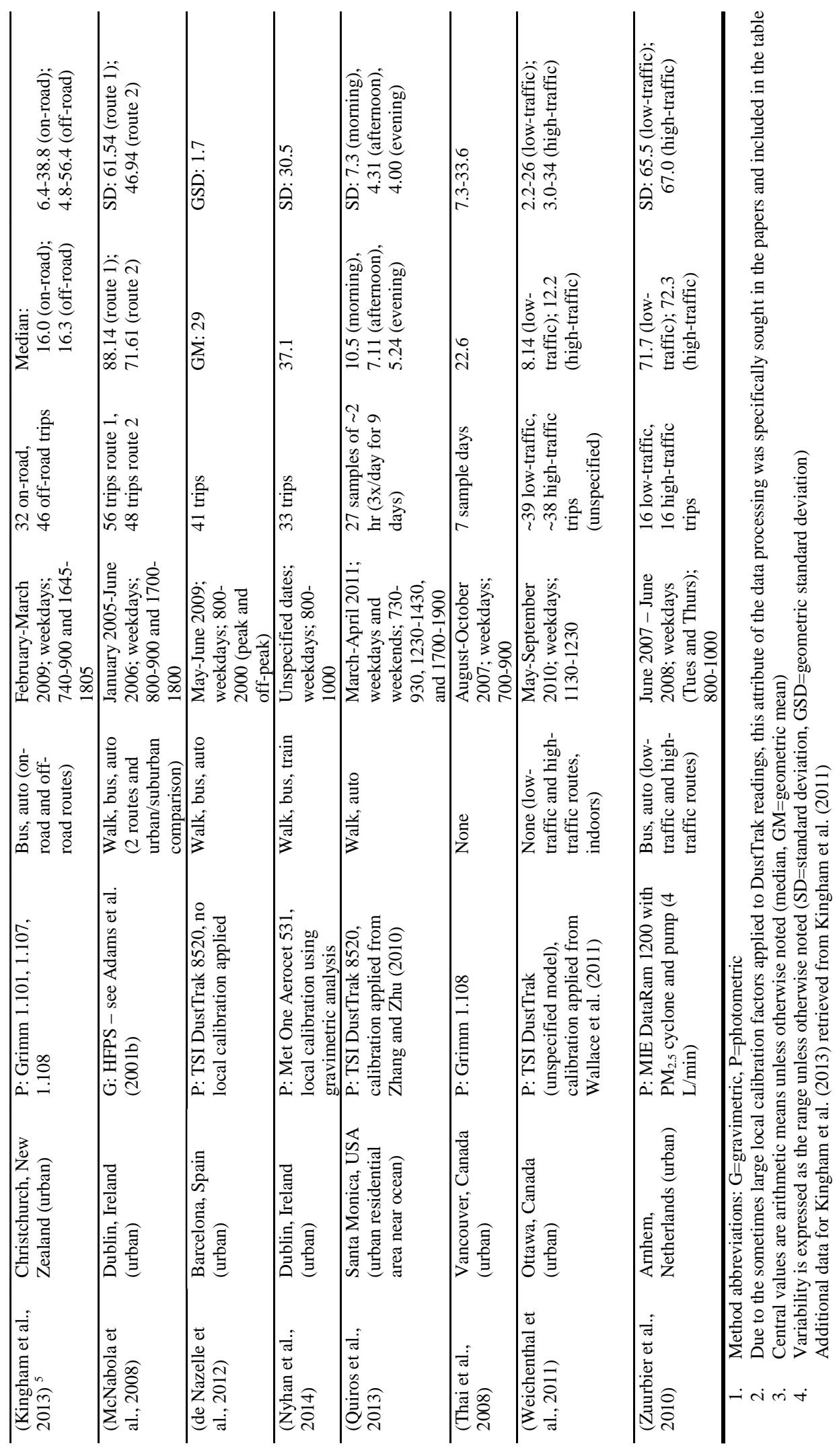




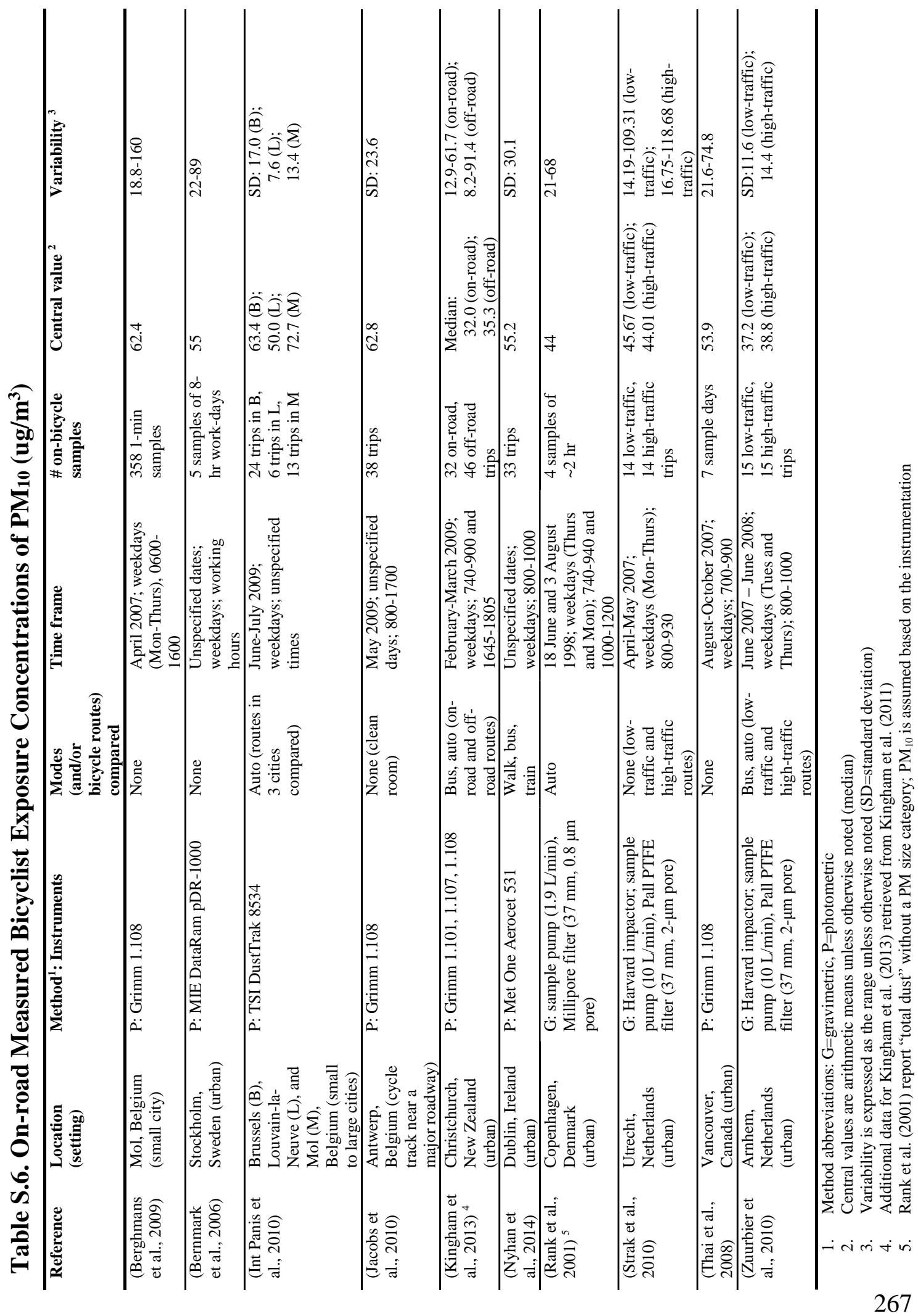




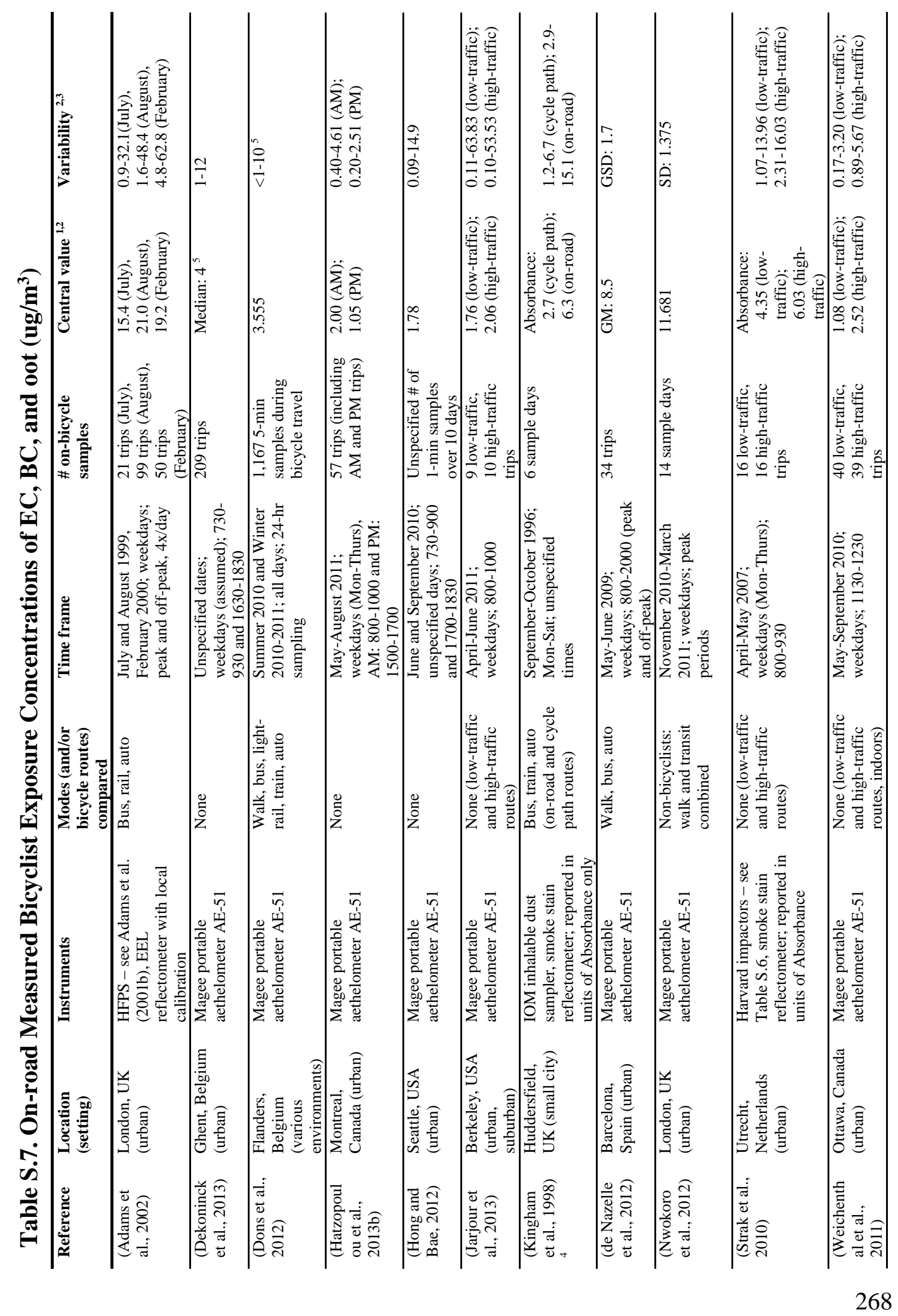




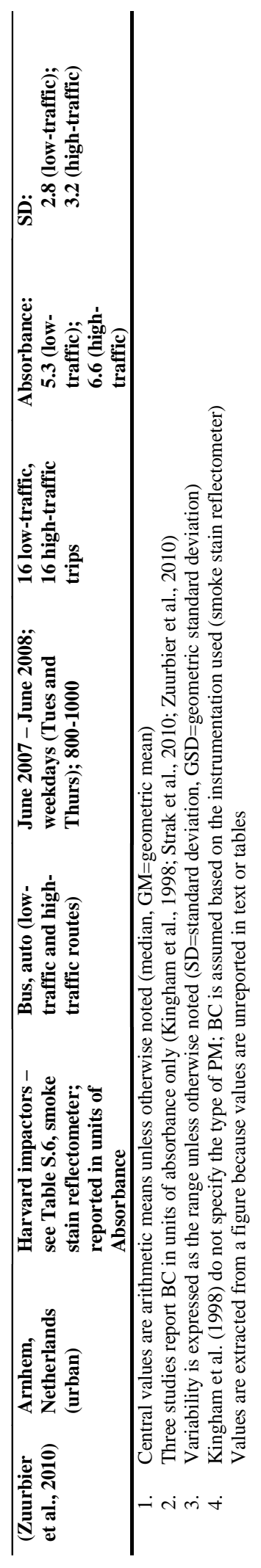




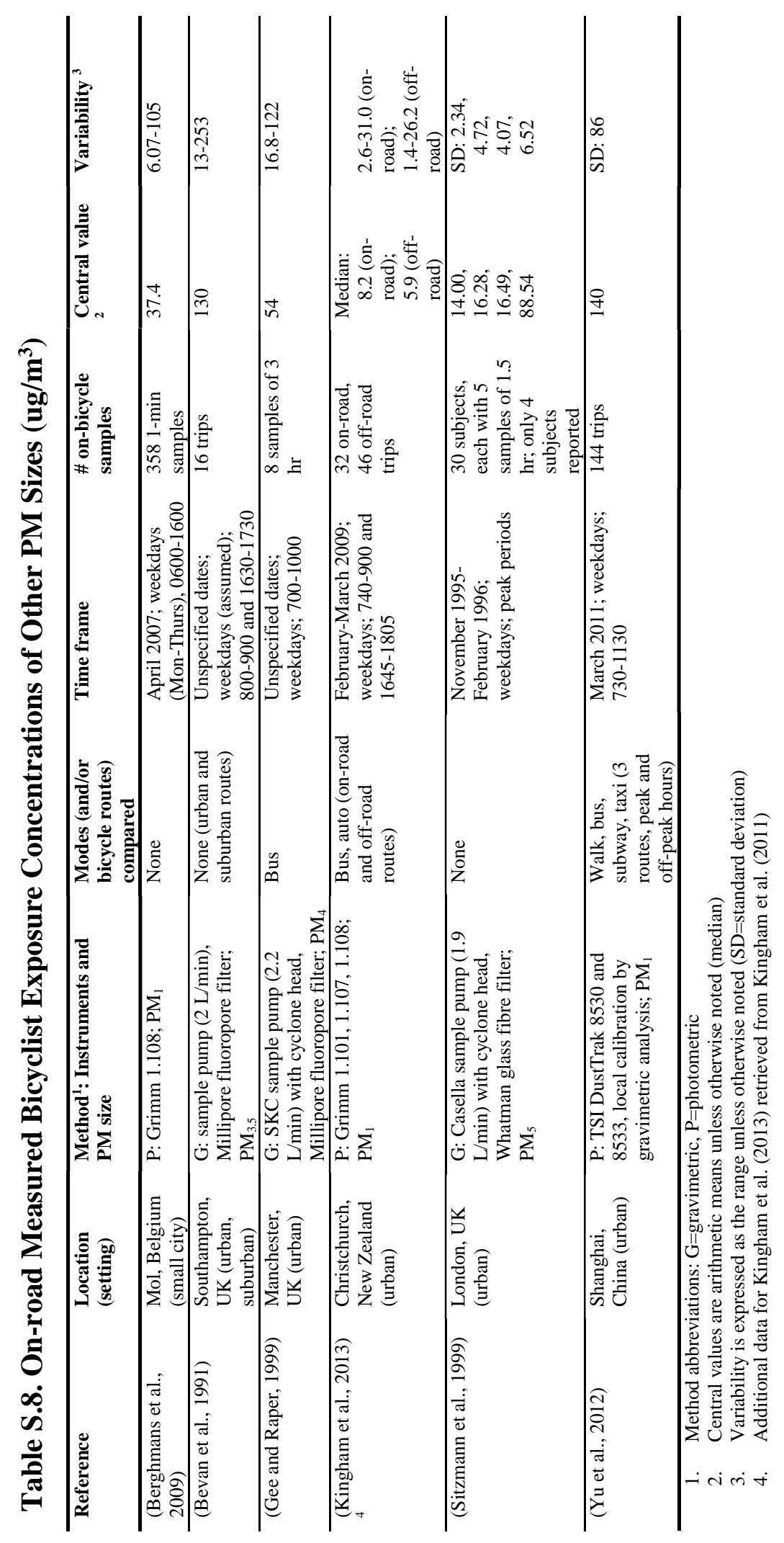




\section{APPENDIX C: REPORTED BICYCLIST RESPIRATION MEASUREMENTS}

Table 2 in the paper summarizes published traveling bicyclists' respiration parameters. Some of the studies in Table 2 measured respiration on-road, while others used bicycle ergometer laboratory testing; see Weisman (2003) for a discussion of physiology and exercise testing. Without measuring on-road workloads it is difficult to compare the conditions of the laboratory tests with on-road bicycling. McNabola et al. (2007) found a linear relationship between speed and $\dot{V}_{E}$ based on ergometer testing, while Adams (1993) found nonlinearly increasing ventilation with bicycling speed. The difference in results could be explained by the laboratory setting neglecting the strong effects of aerodynamic drag on increasing workload with bicycling speed (Faria et al. 2005b).

A third study methodology in Table 2 combines laboratory bicycle ergometer tests with on-road heart rate (HR) monitoring to estimate on-road respiration. This method relies on the strong intra-subject relationship between HR and (log-transformed) $\dot{V}_{E}$ for bicycling (Samet et al. 1993, Zuurbier et al. 2009) and is appealing because HR is easier to measure in situ than $\dot{V}_{E}$. Consistent with the ranges in Table 2, Mermier et al. (1993) observed average $\dot{V}_{E}$ of around 15 to $60 \mathrm{~L} / \mathrm{min}$ for laboratory bicycling exercise tests with HR from 80 to 140 beats per minute (bpm). Comparing the slope estimates for $\ln \left(\dot{V}_{E}\right)$ as a function of $\mathrm{HR}$ (in L/min and bpm) while bicycling, the results in Zuurbier et al. (2009) and Mermier et al. (1993) agree well, with group means in the range of 0.019 to 0.023 for healthy subjects (men, women, boys, and girls). Bernmark et al. (2006) do not report their estimated slopes, but an example figure shows a slope of 0.018 . 
Energy expenditure is a key factor for respiration and thus air pollution intake (Nadeau et al. 2006). Creating external work requires delivery of oxygen to body tissues, which in turn requires inhalation of oxygen. The volume rate of oxygen inhalation $\left(\dot{V}_{O_{2}}\right)$, which is closely related to $\dot{V}_{E}$, increases "nearly linearly" with external workload or power (Weisman 2003). For this reason, Vinzents et al. (2005) use a slightly different approach from the "estimated" method in Table 2 to model pollution intake, establishing individual HR-workload relationships using a bicycle ergometer and monitoring on-road HR to estimate workload during travel, which they assume is linearly proportional to $\dot{V}_{E}$. 


\section{APPENDIX D: ZERO-ADJUSTMENT FUNCTION CODE (R SCRIPT)}

Function which returns a convex, monotonically decreasing zero curve from the raw data:

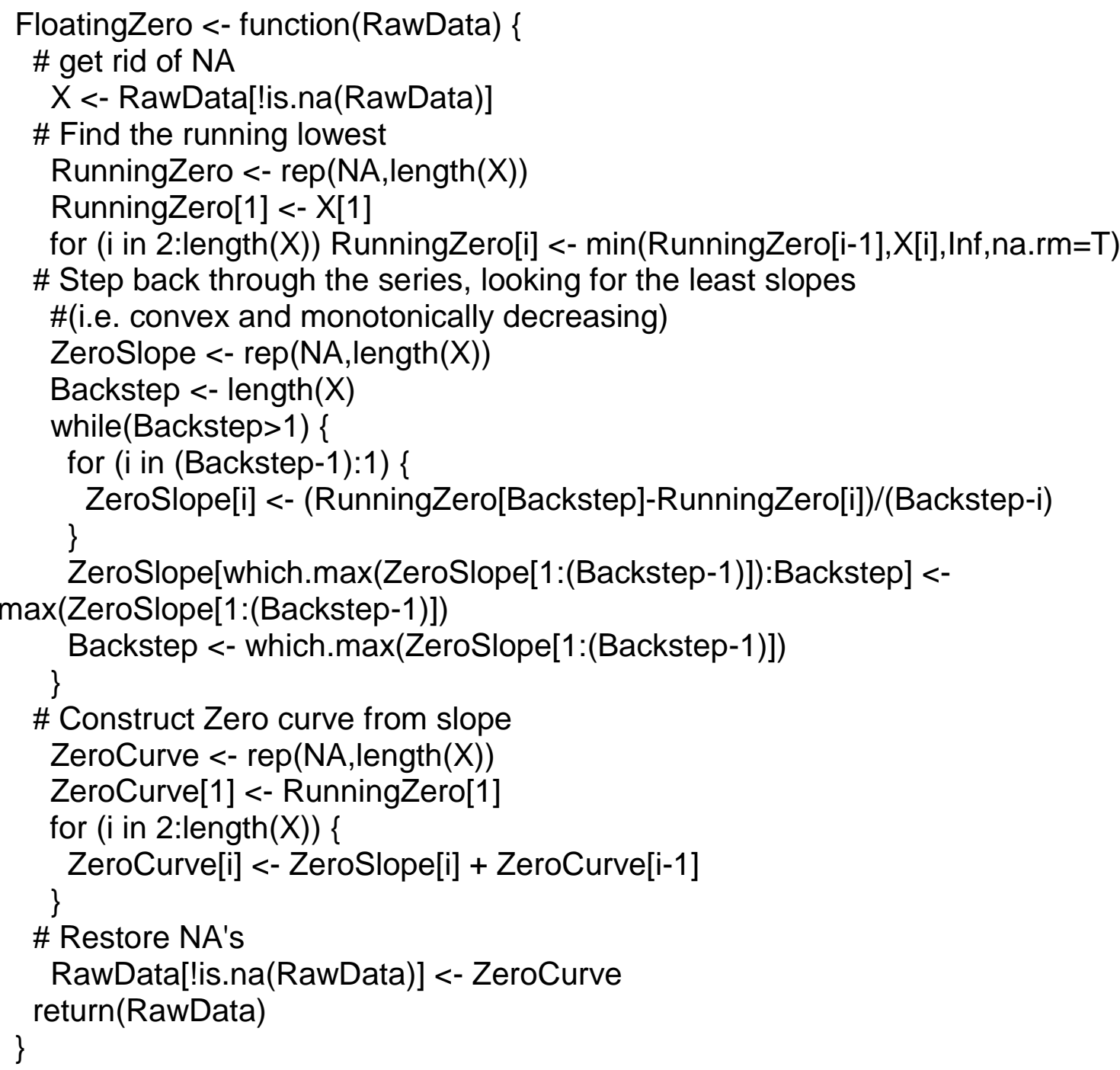

Function which applies the constructed zero curve:

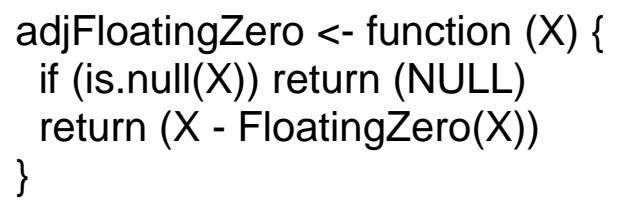




\section{APPENDIX E: SUPPLEMENTAL CONCENTRATION DATA}

Table S.9. Detection data from on-road samples for all 75 target compounds

\begin{tabular}{|c|c|c|}
\hline \multirow[b]{2}{*}{ Compound } & \multicolumn{2}{|c|}{ Detections (above limit of $0.05 \mathrm{ng} / \mathrm{l}$ ) } \\
\hline & Breath & Exposure Air \\
\hline trichlorofluoromethane (CFC11) & $100 \%$ & $100 \%$ \\
\hline acetone & $100 \%$ & $100 \%$ \\
\hline diethyl ether & $0 \%$ & $0 \%$ \\
\hline 1,1-dichloroethene & $0 \%$ & $0 \%$ \\
\hline tert-butyl alcohol & $0 \%$ & $0 \%$ \\
\hline methylene chloride & $98 \%$ & $100 \%$ \\
\hline methyl acetate & $100 \%$ & $86 \%$ \\
\hline 1,1,2,-trichloro-1,2,2-trifluoroethane (CFC113) & $100 \%$ & $100 \%$ \\
\hline carbon disulfide & $100 \%$ & $41 \%$ \\
\hline trans-1,2-dichloroethene & $0 \%$ & $0 \%$ \\
\hline methyl tert-butyl ether (MTBE) & $15 \%$ & $0 \%$ \\
\hline 1,1-dichloroethane & $0 \%$ & $0 \%$ \\
\hline 2-butanone (methyl ethyl ketone) & $100 \%$ & $100 \%$ \\
\hline diisopropyl ether (DIPE) & $0 \%$ & $0 \%$ \\
\hline methyl acrylonitrile & $0 \%$ & $0 \%$ \\
\hline cis-1,2-dichloroethene & $0 \%$ & $0 \%$ \\
\hline bromochloromethane & $0 \%$ & $0 \%$ \\
\hline chloroform & $100 \%$ & $100 \%$ \\
\hline 2,2-dichloropropane & $0 \%$ & $0 \%$ \\
\hline methyl acrylate & $0 \%$ & $0 \%$ \\
\hline ethyl tert-butyl ether (ETBE) & $0 \%$ & $0 \%$ \\
\hline tetrahydrofran & $0 \%$ & $0 \%$ \\
\hline tert-amyl alcohol & $0 \%$ & $0 \%$ \\
\hline 1,2-dichloroethane & $0 \%$ & $19 \%$ \\
\hline 1,1,1-trichloroethane & $2 \%$ & $5 \%$ \\
\hline 1,1-dichloropropene & $0 \%$ & $0 \%$ \\
\hline carbon tetrachloride & $100 \%$ & $100 \%$ \\
\hline benzene & $100 \%$ & $100 \%$ \\
\hline dibromomethane & $0 \%$ & $0 \%$ \\
\hline 1,2-dichloropropane & $0 \%$ & $0 \%$ \\
\hline trichloroethene (TCE) & $19 \%$ & $30 \%$ \\
\hline bromodichloromathane & $0 \%$ & $0 \%$ \\
\hline methyl methacrylate & $100 \%$ & $92 \%$ \\
\hline cis-1,3-dichloropropene & $8 \%$ & $0 \%$ \\
\hline 4-methyl-2-pentanone (MIBK) & $75 \%$ & $76 \%$ \\
\hline trans-1,3-dichloropropene & $0 \%$ & $0 \%$ \\
\hline 1,1,2-trichloroethane & $0 \%$ & $0 \%$ \\
\hline toluene & $100 \%$ & $100 \%$ \\
\hline 1,3-dichloropropane & $0 \%$ & $0 \%$ \\
\hline ethyl methacrylate & $2 \%$ & $0 \%$ \\
\hline 2-hexanone (MBK) & $72 \%$ & $62 \%$ \\
\hline dibromochloromethane & $0 \%$ & $0 \%$ \\
\hline 1,2-dibromoethane & $0 \%$ & $0 \%$ \\
\hline tetrachloroethene (PCE) & $100 \%$ & $100 \%$ \\
\hline 1,1,1,2-tetrachloroethane & $0 \%$ & $0 \%$ \\
\hline chlorobenzene & $0 \%$ & $0 \%$ \\
\hline ethylbenzene & $100 \%$ & $100 \%$ \\
\hline$m+p$-xylene & $100 \%$ & $100 \%$ \\
\hline bromoform & $0 \%$ & $0 \%$ \\
\hline ethenylbenzene (styrene) & $100 \%$ & $97 \%$ \\
\hline$o$-xylene & $100 \%$ & $100 \%$ \\
\hline
\end{tabular}


1,2,3-trichloropropane trans-1,4-dichloro-2-butene isopropylbenzene (cumene) $n$-propylbenzene

1,3,5-trimethylbenzene

2-ethyltoluene

tert-butylbenzene

1,2,4-trimethylbenzene

sec-butylbenzene

1,3-dichlorobenzene

1,4-dichlorobenzene

1-isopropyl-4-methylbenzene

1,2,3-trimethylbenzene

1,2-dichlorobenzene

$n$-butylbenzene

1,2-dibromo-3-chloropropane (DBCP)

hexachloroethane

1,2,4,5-tetramethylbenzene

1,2,3,5-tetramethylbenzene

1,2,3,4-tetramethylbenzene

1,2,4-trichlorobenzene

naphthalene

hexachlorobutadiene

1,2,3-trichlorobenzene

\begin{tabular}{rr}
$0 \%$ & $0 \%$ \\
$0 \%$ & $0 \%$ \\
$0 \%$ & $43 \%$ \\
$91 \%$ & $100 \%$ \\
$66 \%$ & $100 \%$ \\
$49 \%$ & $100 \%$ \\
$0 \%$ & $0 \%$ \\
$100 \%$ & $100 \%$ \\
$0 \%$ & $0 \%$ \\
$0 \%$ & $0 \%$ \\
$68 \%$ & $19 \%$ \\
$100 \%$ & $89 \%$ \\
$49 \%$ & $100 \%$ \\
$0 \%$ & $0 \%$ \\
$13 \%$ & $59 \%$ \\
$0 \%$ & $0 \%$ \\
$0 \%$ & $0 \%$ \\
$11 \%$ & $78 \%$ \\
$23 \%$ & $89 \%$ \\
$8 \%$ & $30 \%$ \\
$4 \%$ & $3 \%$ \\
$98 \%$ & $100 \%$ \\
$2 \%$ & $3 \%$ \\
$17 \%$ & $11 \%$ \\
\hline
\end{tabular}


Table S.10. Additional compounds identified in breath and exposure air but not quantified

\begin{tabular}{|c|c|c|c|c|c|c|}
\hline \multirow[b]{2}{*}{ Compound } & \multicolumn{3}{|c|}{ Breath Samples } & \multicolumn{3}{|c|}{ Exposure Samples } \\
\hline & $\begin{array}{l}\text { Detects } \\
\text { (peak } \\
\text { area } \\
\geq 1,000 \text { ) }\end{array}$ & $\begin{array}{c}\text { Peak area } \\
\text { correlation } \\
\text { with } \\
\text { benzene }\end{array}$ & $\begin{array}{l}\text { Peak area } \\
\text { normalized } \\
\text { to benzene } \\
(\text { mean })\end{array}$ & $\begin{array}{c}\text { Detects } \\
\text { (peak } \\
\text { area } \\
\geq 1,000 \text { ) }\end{array}$ & $\begin{array}{c}\text { Peak area } \\
\text { correlation } \\
\text { with } \\
\text { benzene }\end{array}$ & $\begin{array}{c}\text { Peak area } \\
\text { normalized } \\
\text { to benzene } \\
(\text { mean })\end{array}$ \\
\hline acetaldehyde & $100 \%$ & 0.52 & 1.04 & $100 \%$ & 0.12 & 0.57 \\
\hline ethanol & $100 \%$ & -0.03 & 3.22 & $100 \%$ & 0.37 & 0.21 \\
\hline 2-propanol & $100 \%$ & 0.15 & 4.16 & $100 \%$ & 0.70 & 0.47 \\
\hline isoprene & $100 \%$ & 0.47 & 141.99 & $100 \%$ & 0.43 & 0.15 \\
\hline dimethyl sulfide & $100 \%$ & 0.51 & 2.33 & $15 \%$ & -0.15 & 0.01 \\
\hline 1-propanol & $98 \%$ & 0.15 & 0.90 & $96 \%$ & 0.22 & 0.04 \\
\hline (methylselanyl)methane & $99 \%$ & 0.45 & 0.35 & $0 \%$ & NA & NA \\
\hline $\begin{array}{l}\text { 3-buten-2-ol, 2-methyl- } \\
\text { 1.3-dioxolane, 2- }\end{array}$ & $98 \%$ & 0.12 & 0.37 & $90 \%$ & 0.66 & 0.04 \\
\hline methyl- & $98 \%$ & 0.39 & 0.14 & $98 \%$ & 0.01 & 0.09 \\
\hline 1-butanol & $99 \%$ & 0.44 & 0.33 & $100 \%$ & 0.31 & 0.07 \\
\hline 2-pentanone & $100 \%$ & 0.55 & 2.31 & $100 \%$ & 0.87 & 0.12 \\
\hline $\begin{array}{l}\text { 3-(methylsulfanyl)-1- } \\
\text { propene }\end{array}$ & $100 \%$ & 0.62 & 9.69 & $4 \%$ & 0.06 & 0.00 \\
\hline $\begin{array}{l}1,4 \text {-dioxane } \\
1-\end{array}$ & $99 \%$ & 0.18 & 0.50 & $100 \%$ & 0.07 & 0.09 \\
\hline $\begin{array}{l}\text { (methylsulfanyl)propane } \\
\text { Z-1-( methylsulfanyl)-1- }\end{array}$ & $100 \%$ & 0.42 & 2.64 & $2 \%$ & -0.05 & 0.00 \\
\hline $\begin{array}{l}\text { propene } \\
\text { E-1-(methylsulfanyl)-1- }\end{array}$ & $98 \%$ & 0.48 & 0.77 & $0 \%$ & NA & NA \\
\hline $\begin{array}{l}\text { propene } \\
\text { 4-methyl-2,3- }\end{array}$ & $98 \%$ & 0.58 & 3.97 & $13 \%$ & 0.42 & 0.00 \\
\hline pentanedione & $99 \%$ & 0.45 & 0.70 & $100 \%$ & 0.38 & 0.33 \\
\hline 1H-pyrrole & $99 \%$ & 0.09 & 0.10 & $88 \%$ & 0.68 & 0.02 \\
\hline $\begin{array}{l}\text { 1,3-dioxane, 2-ethyl-4- } \\
\text { methyl- } \\
\text { formamide, } \mathrm{N}, \mathrm{N}-\end{array}$ & $100 \%$ & 0.42 & 0.15 & $96 \%$ & -0.03 & 0.08 \\
\hline dimethyl- & $98 \%$ & 0.33 & 0.26 & $23 \%$ & -0.06 & 0.01 \\
\hline 2,4-dimethylhexane & $88 \%$ & 0.74 & 0.30 & $100 \%$ & 0.96 & 0.15 \\
\hline hexanal & $99 \%$ & 0.51 & 0.20 & $100 \%$ & 0.34 & 0.11 \\
\hline nonane & $100 \%$ & 0.83 & 0.17 & $100 \%$ & 0.89 & 0.12 \\
\hline heptanal & $100 \%$ & 0.62 & 0.13 & $100 \%$ & 0.32 & 0.07 \\
\hline$\alpha$-pinene & $100 \%$ & 0.19 & 2.56 & $100 \%$ & 0.50 & 0.65 \\
\hline benzaldehyde & $100 \%$ & 0.77 & 1.15 & $100 \%$ & 0.93 & 0.94 \\
\hline sabinene & $100 \%$ & 0.37 & 0.47 & $96 \%$ & 0.61 & 0.08 \\
\hline$\beta$-pinene & $99 \%$ & 0.17 & 3.14 & $100 \%$ & 0.40 & 0.21 \\
\hline octanal & $100 \%$ & 0.52 & 0.23 & $98 \%$ & 0.78 & 0.15 \\
\hline isocyanatocyclohexane & $100 \%$ & 0.07 & 0.13 & $4 \%$ & 0.02 & 0.00 \\
\hline 1-hexanol, 2-ethyl- & $97 \%$ & 0.53 & 12.96 & $96 \%$ & 0.51 & 0.13 \\
\hline limonene & $100 \%$ & 0.09 & 8.39 & $100 \%$ & 0.61 & 0.11 \\
\hline eucalyptol & $100 \%$ & 0.13 & 0.31 & $88 \%$ & 0.61 & 0.05 \\
\hline$\gamma$-terpinene & $100 \%$ & 0.07 & 0.55 & $50 \%$ & 0.62 & 0.02 \\
\hline acetophenone & $100 \%$ & 0.71 & 0.95 & $100 \%$ & 0.45 & 0.31 \\
\hline $\begin{array}{l}\text { benzaldehyde, 4- } \\
\text { methyl- }\end{array}$ & $100 \%$ & 0.50 & 0.22 & $100 \%$ & 0.97 & 0.12 \\
\hline & & & & & & 276 \\
\hline
\end{tabular}




\begin{tabular}{lrrrrrr} 
nonanal & $100 \%$ & 0.67 & 1.09 & $100 \%$ & 0.13 & 0.54 \\
benzoic acid & $100 \%$ & 0.65 & 0.29 & $100 \%$ & 0.44 & 0.22 \\
dodecane & $100 \%$ & 0.60 & 1.02 & $100 \%$ & 0.81 & 0.10 \\
decanal & $99 \%$ & 0.55 & 1.04 & $100 \%$ & 0.03 & 0.66 \\
thiourea, tetramethyl- & $100 \%$ & 0.24 & 0.86 & $37 \%$ & 0.07 & 0.02 \\
$\begin{array}{l}\text { cyclohexane, } \\
\text { isothiocyanato- }\end{array}$ & $100 \%$ & 0.49 & 1.88 & $17 \%$ & 0.09 & 0.01 \\
benzothiazole & $100 \%$ & 0.62 & 1.94 & $100 \%$ & 0.67 & 0.18 \\
\hline
\end{tabular}

Table S.11. Exposure concentrations at the park reference location

\begin{tabular}{l|rrrr}
\hline & Minimum & Median & Mean & Maximum \\
\hline trichlorofluoromethane (CFC11) & 0.41 & 0.78 & 0.81 & 1.44 \\
acetone & 1.56 & 3.65 & 3.84 & 6.74 \\
methylene chloride & 0.26 & 0.64 & 0.67 & 1.25 \\
methyl acetate & 0.00 & 0.11 & 0.12 & 0.28 \\
1,1,2,-trichloro-1,2,2-trifluoroethane (CFC113) & 0.47 & 0.62 & 0.62 & 0.74 \\
carbon disulfide & 0.02 & 0.04 & 0.06 & 0.22 \\
2-butanone (methyl ethyl ketone) & 0.24 & 0.64 & 0.73 & 1.52 \\
chloroform & 0.06 & 0.14 & 0.36 & 2.93 \\
carbon tetrachloride & 0.35 & 0.52 & 0.51 & 0.65 \\
benzene & 0.30 & 0.61 & 0.65 & 1.23 \\
methyl methacrylate & 0.00 & 0.14 & 0.12 & 0.21 \\
4-methyl-2-pentanone (MIBK) & 0.00 & 0.08 & 0.12 & 0.65 \\
toluene & 0.53 & 1.70 & 2.34 & 6.91 \\
2-hexanone (MBK) & 0.00 & 0.04 & 0.04 & 0.08 \\
tetrachloroethene (PCE) & 0.03 & 0.16 & 0.21 & 0.48 \\
ethylbenzene & 0.10 & 0.42 & 0.43 & 0.97 \\
$m+p$-xylene & 0.35 & 1.53 & 1.61 & 3.56 \\
ethenylbenzene (styrene) & 0.05 & 0.08 & 0.17 & 1.17 \\
$o$-xylene & 0.12 & 0.56 & 0.59 & 1.32 \\
$n$-propylbenzene & 0.03 & 0.09 & 0.09 & 0.18 \\
1,3,5-trimethylbenzene & 0.04 & 0.10 & 0.11 & 0.19 \\
2-ethyltoluene & 0.03 & 0.08 & 0.10 & 0.20 \\
1,2,4-trimethylbenzene & 0.11 & 0.31 & 0.34 & 0.67 \\
1-isopropyl-4-methylbenzene & 0.05 & 0.15 & 0.16 & 0.25 \\
1,2,3-trimethylbenzene & 0.03 & 0.10 & 0.11 & 0.24 \\
naphthalene & 0.05 & 0.13 & 0.19 & 0.67 \\
\hline
\end{tabular}




\section{APPENDIX F: DISTRIBUTED LAG MODEL OF VENTILATION}

Table S.12. Estimated ventilation model coefficients and p-values (coefficients in bold are $p<0.05$ )

\begin{tabular}{|c|c|c|c|c|c|c|c|c|}
\hline & \multicolumn{2}{|c|}{ Subject A } & \multicolumn{2}{|c|}{ Subject B } & \multicolumn{2}{|c|}{ Subject C } & \multicolumn{2}{|c|}{ Pooled } \\
\hline & Estimate & p-val. & Estimate & p-val. & Estimate & p-val. & Estimate & p-val. \\
\hline (Intercept) & 2.185 & $<0.001$ & 2.674 & $<0.001$ & 2.318 & $<0.001$ & 2.348 & $<0.001$ \\
\hline$\beta_{0} \times 1,000$ & 0.539 & $<0.001$ & 0.239 & 0.049 & 0.600 & $<0.001$ & 0.475 & $<0.001$ \\
\hline$\beta_{1} \times 1,000$ & 0.277 & $<0.001$ & 0.098 & 0.330 & 0.590 & $<0.001$ & 0.268 & $<0.001$ \\
\hline$\beta_{2} \times 1,000$ & 0.383 & $<0.001$ & 0.144 & 0.155 & 0.605 & $<0.001$ & 0.348 & $<0.001$ \\
\hline$\beta_{3} \times 1,000$ & 0.385 & $<0.001$ & 0.288 & 0.003 & 0.647 & $<0.001$ & 0.378 & $<0.001$ \\
\hline$\beta_{4} \times 1,000$ & 0.435 & $<0.001$ & 0.260 & 0.013 & 0.606 & $<0.001$ & 0.402 & $<0.001$ \\
\hline$\beta_{5} \times 1,000$ & 0.419 & $<0.001$ & 0.368 & 0.001 & 0.543 & $<0.001$ & 0.402 & $<0.001$ \\
\hline$\beta_{6} \times 1,000$ & 0.431 & $<0.001$ & 0.379 & 0.001 & 0.685 & $<0.001$ & 0.422 & $<0.001$ \\
\hline$\beta_{7} \times 1,000$ & 0.390 & $<0.001$ & 0.260 & 0.043 & 0.579 & $<0.001$ & 0.369 & $<0.001$ \\
\hline$\beta_{8} \times 1,000$ & 0.428 & $<0.001$ & 0.229 & 0.064 & 0.491 & $<0.001$ & 0.388 & $<0.001$ \\
\hline$\beta_{9} \times 1,000$ & 0.387 & $<0.001$ & 0.229 & 0.037 & 0.394 & $<0.001$ & 0.349 & $<0.001$ \\
\hline$\beta_{10} \times 1,000$ & 0.334 & $<0.001$ & 0.198 & 0.049 & 0.447 & $<0.001$ & 0.308 & $<0.001$ \\
\hline$\beta_{11} \times 1,000$ & 0.317 & $<0.001$ & 0.189 & 0.157 & 0.262 & 0.010 & 0.281 & $<0.001$ \\
\hline$\beta_{12} \times 1,000$ & 0.277 & $<0.001$ & 0.094 & 0.467 & 0.112 & 0.306 & 0.224 & $<0.001$ \\
\hline$\beta_{13} \times 1,000$ & 0.234 & $<0.001$ & 0.135 & 0.300 & 0.160 & 0.201 & 0.203 & $<0.001$ \\
\hline$\beta_{14} \times 1,000$ & 0.218 & $<0.001$ & 0.094 & 0.395 & 0.195 & 0.105 & 0.185 & $<0.001$ \\
\hline$\beta_{15} \times 1,000$ & 0.199 & $<0.001$ & 0.037 & 0.759 & 0.182 & 0.154 & 0.164 & $<0.001$ \\
\hline$\beta_{16} \times 1,000$ & 0.193 & $<0.001$ & -0.028 & 0.790 & 0.129 & 0.315 & 0.146 & $<0.001$ \\
\hline$\beta_{17} \times 1,000$ & 0.162 & $<0.001$ & 0.062 & 0.625 & 0.112 & 0.430 & 0.133 & $<0.001$ \\
\hline$\beta_{18} \times 1,000$ & 0.156 & $<0.001$ & 0.122 & 0.347 & 0.098 & 0.412 & 0.133 & $<0.001$ \\
\hline$\beta_{19} \times 1,000$ & 0.129 & $<0.001$ & 0.046 & 0.706 & 0.013 & 0.917 & 0.092 & 0.004 \\
\hline$\beta_{20} \times 1,000$ & 0.142 & $<0.001$ & 0.053 & 0.646 & -0.041 & 0.745 & 0.100 & 0.002 \\
\hline$\beta_{21} \times 1,000$ & 0.147 & $<0.001$ & 0.042 & 0.746 & 0.056 & 0.668 & 0.111 & $<0.001$ \\
\hline$\beta_{22} \times 1,000$ & 0.120 & $<0.001$ & 0.080 & 0.536 & -0.028 & 0.843 & 0.085 & 0.005 \\
\hline$\beta_{23} \times 1,000$ & 0.136 & $<0.001$ & 0.089 & 0.497 & 0.007 & 0.957 & 0.100 & 0.002 \\
\hline$\beta_{24} \times 1,000$ & 0.142 & $<0.001$ & 0.095 & 0.414 & 0.002 & 0.990 & 0.105 & 0.001 \\
\hline$\beta_{25} \times 1,000$ & 0.113 & 0.002 & 0.101 & 0.348 & 0.043 & 0.738 & 0.087 & 0.006 \\
\hline$\beta_{26} \times 1,000$ & 0.119 & $<0.001$ & 0.049 & 0.600 & -0.025 & 0.862 & 0.078 & 0.008 \\
\hline$\beta_{27} \times 1,000$ & 0.092 & 0.009 & 0.083 & 0.432 & 0.015 & 0.909 & 0.061 & 0.051 \\
\hline$\beta_{28} \times 1,000$ & 0.075 & 0.044 & 0.129 & 0.249 & 0.056 & 0.636 & 0.055 & 0.096 \\
\hline$\beta_{29} \times 1,000$ & 0.029 & 0.380 & 0.068 & 0.497 & -0.031 & 0.807 & 0.006 & 0.836 \\
\hline$\beta_{30} \times 1,000$ & 0.036 & 0.463 & -0.055 & 0.675 & 0.106 & 0.517 & -0.008 & 0.855 \\
\hline
\end{tabular}

